\title{
Targeting Potassium Channel Trafficking In Cardiac Arrhythmia
}

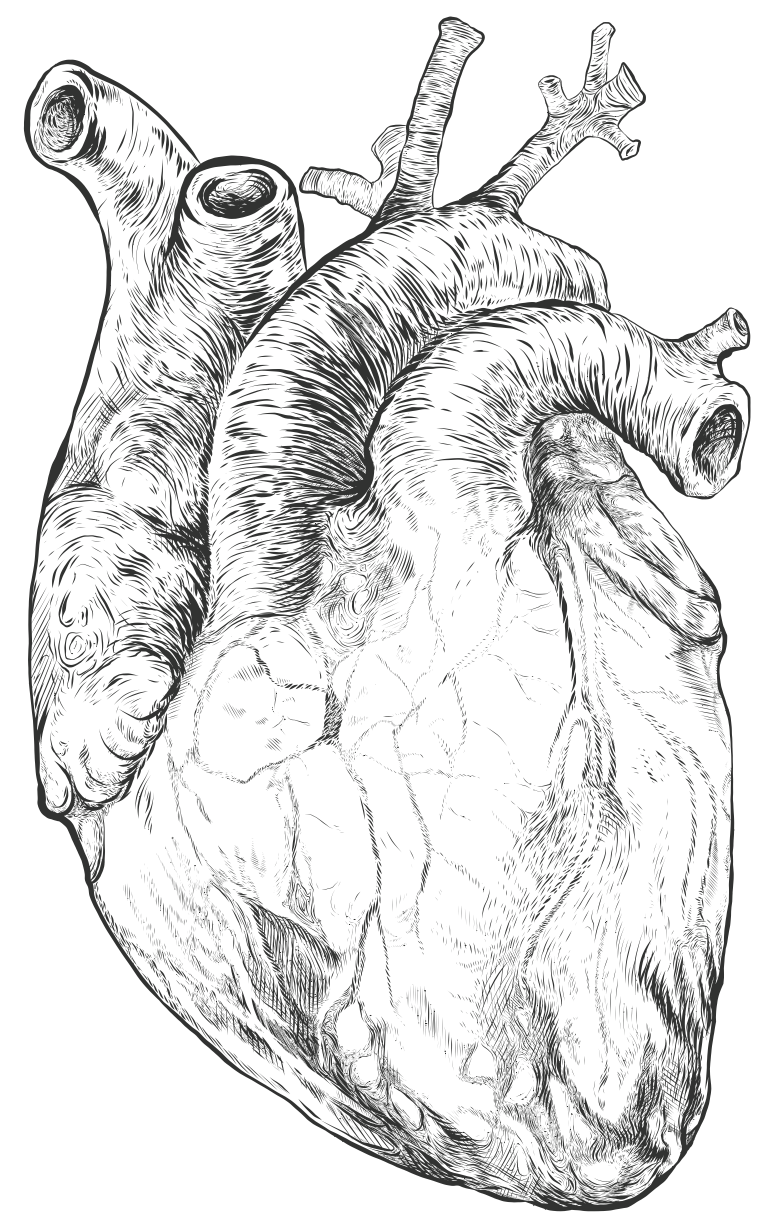

Muge Qile 
Targeting Potassium Channel Trafficking In Cardiac Arrhythmia Copyright@ 2020 Muge Qile

ISBN: $\quad$ 978-94-6416-050-5

Cover Design: Muge Qile

Layout: Muge Qile

Printed by: $\quad$ Ridderprint BV, the Netherlands 


\title{
Targeting Potassium Channel Trafficking in Cardiac Arrhythmia
}

\author{
Intracellulair transport van kalium ionkanalen als \\ aangrijpingspunt bij hartritmestoornissen
}

(met een samenvatting in het Nederlands)

\begin{abstract}
Proefschrift
ter verkrijging van de graad van doctor aan de Universiteit Utrecht op gezag van de rector magnificus, prof.dr. H.R.B.M. Kummeling, ingevolge het besluit van het college voor promoties in het openbaar te verdedigen op
\end{abstract} donderdag 3 september 2020 des middags te 12.45 uur

door

\section{Muge Qile}

geboren op 16 februari 1991

te Hulunbuir, China 
Promotor: $\quad$ Prof. dr. M.A. Vos

Copromotor: Dr. M.A.G. van der Heyden

Financial support by the China Scholarship Council (CSC) for supporting Muge Qile to finish this thesis is gratefully acknowledged. Part of the research described in this thesis was supported by Austrian Science Fund (FWF) Grant and The Netherlands Heart Foundation. 


\section{Contents}

$\begin{array}{llc}\text { Chapter } 1 & \text { Introduction } & 8\end{array}$

Chapter 2 Disease associated mutations in KIR proteins linked 20 to aberrant inward rectifier channel trafficking Biomolecules, 2019

Chapter 3 Applicability of current animal models for studying 48 cardiac potassium channel trafficking In preparation

Chapter 4 Identification of a PEST sequence in vertebrate 66 $\mathrm{K}_{\mathrm{IR}} 2.1$ that modifies rectification

Front Physiol, 2019

Chapter 5 LUF7244, an allosteric modulator/activator of 92 $\mathrm{K}_{\mathrm{v}} 11.1$ channels, counteracts dofetilide-induced torsades de pointes arrhythmia in the chronic atrioventricular block dog model

Br J Pharmacol, 2019

Chapter 6 LUF7244 plus dofetilide rescues aberrant $K_{v} 11.1$ trafficking and produces functional $\mathrm{I}_{\mathrm{Kv} 11.1}$

Mol Pharmacol, 2020

Chapter 7 Drug-likeness of linear pentamidine analogues and their impact on the hERG $\mathrm{K}^{+}$channel - correlation with structural features

RSC ADV, 2019

Chapter 8 General discussion

Appendix English summary

Nederlandse samenvatting

Acknowledgements

List of publications

Curriculum Vitae 


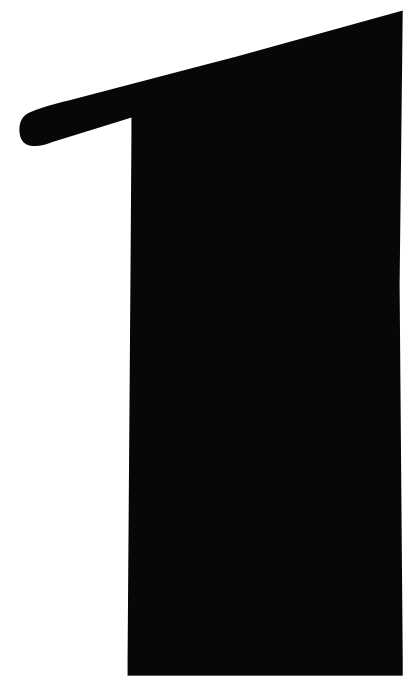


CHAPTER 1

\section{Introduction}




\section{INTRODUCTION}

Cardiovascular disease (CVD), as a major global health concern formally recognized by United Nations (WHO, 2011), is the largest contributor to global mortality (Global Health Estimates, 2016). Meanwhile, cardiac arrhythmias are considered as the major cause of health lost to CVD (Timmis et al., 2018). Either congenital or acquired arrhythmia is characterized by an abnormal rhythm of the heart's beat. The longer the symptoms remain, the poorer the cardiac function is. Compensating mechanisms will take place, resulting in structural changes, electrical alterations, and contractile adaptations. Unfortunately, these in principal helpful adaptations may however enforce the occurrence of cardiac arrhythmia as seen in atrial fibrillation (AF) (Wijffels et al., 1995). Many risk factors that associate with cardiac arrhythmia exist of which some are inherent to human nature, like age, race, sex, and genetic predisposition, while others are influenced by life style, like physical activity, diet and smoking (Khurshid et al., 2018), and finally iatrogenic risk factors, like drug use. Some of these risk factors are known to correlate with ion channel expression differences at the plasma membranes of cardiomyocytes. For example, many forms of congenital long QT syndrome result from point mutations present in an ion channel that affects proper expression (Anderson et al., 2014), whereas many drugs also impair normal channel expression in the heart (de Git et al., 2013).

To better understand the underlying pathological mechanism, we need to know how the electrical system of the heart works under physiological conditions. The cardiac action potential (AP) is generated by ionic influx/outflux through ion channels within the cardiac cell membrane which leads to changes in membrane voltage (Rudy, 2008). Due to complex interactions between various transmembrane ion channels, dynamic cellular ionic environment and different gating kinetics of each ionic channel, a spontaneous, rapid and highly regulated depolarization/repolarization cycle controlled by ionic currents is generated. The rate-dependent and synchronous property of the cardiac AP, resulting from the underlying fundamental cellular electrophysiology, determines cardiac systolic/diastolic function, and abnormalities could result in cardiac arrhythmia and even sudden cardiac death (Hoffman and Cranefield, 1960). 
The standard appearance of the normal ventricular AP consists of 5 phases outlined below (Figure 1):

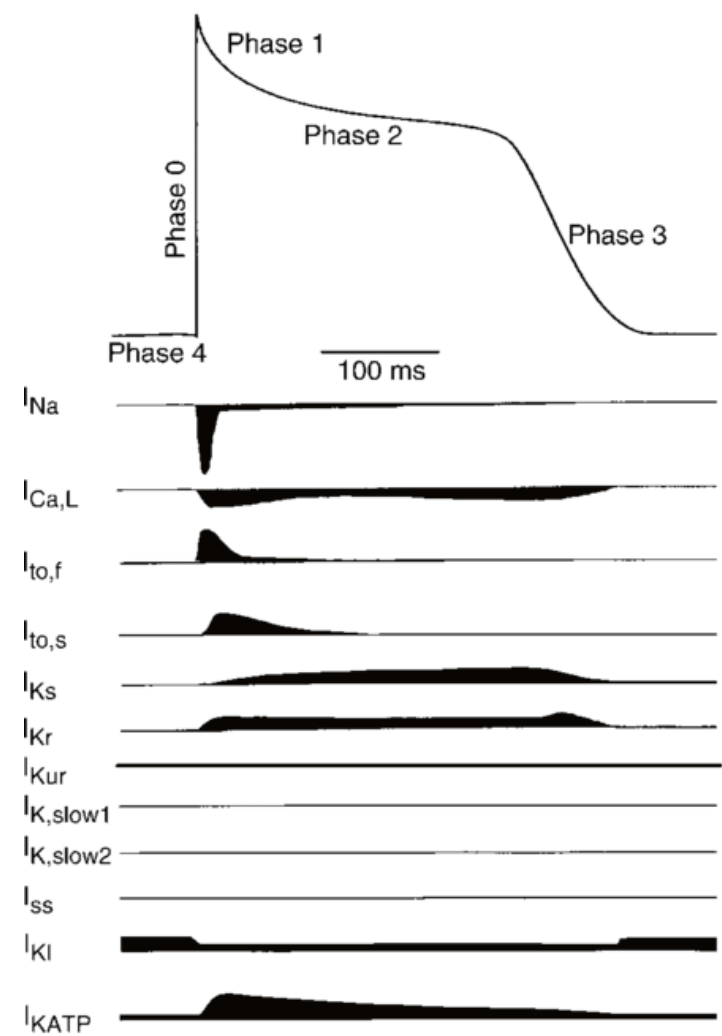

Figure 1. The cardiac action potential and its underlying ion currents (adapted from Nerbonne and Kass, 2005).

1. Phase 0 is the phase of rapid depolarization producing a rapid (less than $2 \mathrm{~ms}$ ) and positive shift in membrane voltage. In ventricular cells, this rapid repolarization is generated predominantly by the opening of voltage-gated $\mathrm{Na}^{+}$channels very briefly $(<1 \mathrm{~ms})$ at a threshold potential $(\sim-55 \mathrm{mV})$ and subsequently inducing a strong inward $\mathrm{Na}^{+}$current $\left(I_{\mathrm{Na}}\right)$ to increase membrane potential (Amin et al., 2010). A minor contributor to depolarization during phase 0 is $\mathrm{I}_{\mathrm{Ca}, \mathrm{L}}$, the influx of $\mathrm{Ca}^{2+}$ through L-type (low threshold type) channel (Boulpaep et al., 2009). 


\section{Chapter 1}

2. Phase 1 is a phase of rapid repolarization beginning with rapid inactivation of voltage-gated $\mathrm{Na}^{+}$channels that aborts inward $\mathrm{I}_{\mathrm{Na}}$. At the same time, a transient outward $\mathrm{K}^{+}$current, $\mathrm{I}_{\text {to }}$ (Rudy, 2008), by activating voltage-gated $\mathrm{K}^{+}$channels briefly, leads to a slight negative shift of membrane potential (Santana et al., 2010; Grant, 2009).

3. Phase 2 is the plateau phase. The slow delayed rectifier $\mathrm{K}^{+}$current, $\mathrm{I}_{\mathrm{Ks}}$ is slowly activated allowing $\mathrm{K}^{+}$efflux, which is partially balanced by the inward $I_{C a, L}$ activated at phase 0 . Moreover, the increased concentration of intracellular $\mathrm{Ca}^{2+}$ also activates $\mathrm{Ca}^{2+}$ channels on the sarcoplasmic reticulum (SR), the so-called Ryanodine receptors, allowing $\mathrm{Ca}^{2+}$ efflux move from SR to cytoplasm, a Ca ${ }^{2+}$ activated $\mathrm{Cl}^{-}$current (Hoffman, 1960) allowing $\mathrm{Cl}^{-}$into the cell, and ionic pumps like $\mathrm{Na}^{+}-\mathrm{Ca}^{2+}$ exchanger and $\mathrm{Na}^{+}-\mathrm{K}^{+}$pump. All these ionic movements result in the membrane potential remaining almost constant with a low level of membrane repolarizing (Grant, 2009; Grunnet, 2010).

4. Phase 3 is the phase of rapid repolarization because L-type $\mathrm{Ca}^{2+}$ channels close, while $\mathrm{I}_{\mathrm{ks}}$ remains activated and the negative change in membrane potential induces more $\mathrm{K}^{+}$currents, primarily the rapid delayed rectifier $\mathrm{K}^{+}$ current $\left(\mathrm{I}_{\mathrm{Kr}}\right)$ and the inward rectifier $\mathrm{K}^{+}$current $\left(\mathrm{I}_{\mathrm{K} 1}\right)$. The strong outward $\mathrm{K}^{+}$current brings the membrane potential back to its resting value. The voltage-gated delayed rectifier $\mathrm{K}^{+}$channels close at $\sim-85 \mathrm{mV}$, while $\mathrm{I}_{\mathrm{K} 1}$ remains active and helps to maintain the resting membrane potential (Grant, 2009; Kubo et al., 2005).

5. Phase 4 represents the resting phase. The resting membrane potential is stable and more or less constant at $\sim-80 \mathrm{mV}$, resulting from perfect balance between influx of ions (e.g. $\mathrm{Na}^{+}$and $\mathrm{Ca}^{2+}$ ) and efflux of ions (e.g. $\mathrm{K}^{+}, \mathrm{Cl}^{-}$ and $\mathrm{HCO3}^{-}$) (Santana, 2010; Morad and Tung, 1982).

Among these ion channels, the potassium channel family is the largest branch. It can be broadly divided into two subfamilies by its transmembrane structure features: the six-transmembrane-helix voltage-gated potassium channel $\left(\mathrm{K}_{\mathrm{v}}\right)$ and the two-transmembrane-helix inward rectifier potassium channel (K $\mathrm{K}_{\mathrm{IR}}$ ) (Ho et al., 1993). 


\section{Potassium channel trafficking}

A fully functional potassium channel needs to go through the forward trafficking pathway to reach the plasma membrane, and then be either recycled or degraded during the backward trafficking pathway (Figure 2). First of all, translated potassium channels are synthesized and assembled in the endoplasmic reticulum (ER). When the correctly folded proteins are released by their chaperones on the luminal and cytosolic sides of the ER, they are transported to the Golgi system where some channels undergo complex glycosylation before being expressed in the plasma membrane (Delisle et al., 2009; Vandenberg et al., 2012), whereas misfolded proteins are retained within the ER. Together with those expired channel proteins in the membrane surface and misfolded proteins, their degradation occurs via the ubiquitin-dependent and polyubiquitination way.

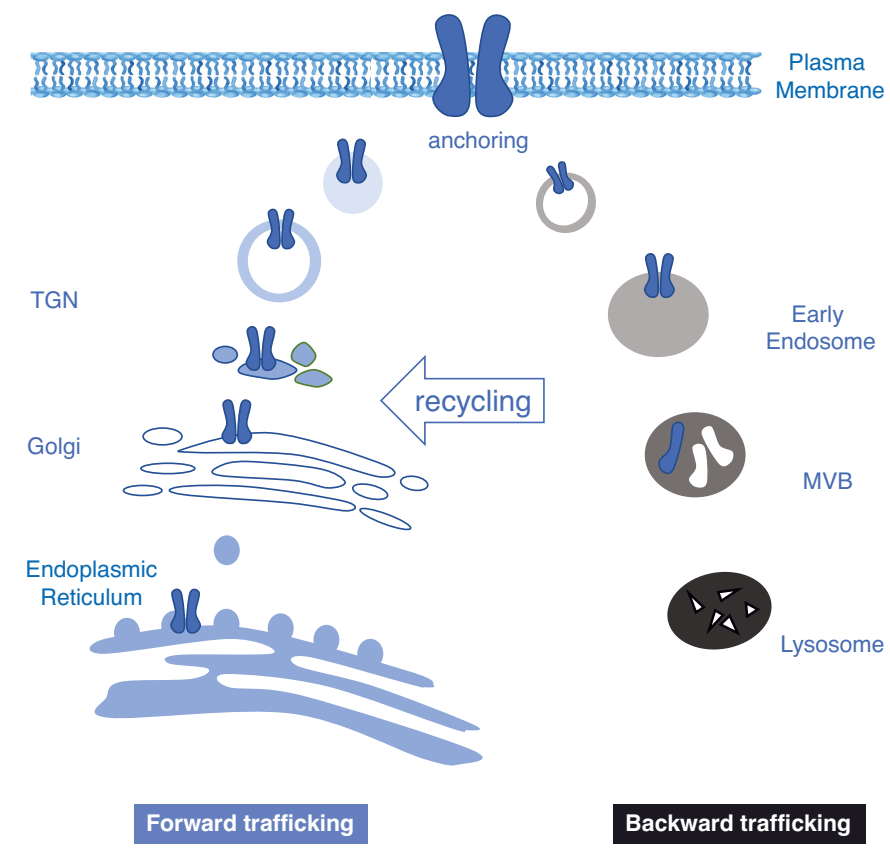

Figure 2. Schematic representation of intracellular trafficking pathways of $\mathbf{K}_{\mathrm{IR}}$ channels. TGN, trans-Golgi network; MVB, multivesicular body. (adapted from Eva-Maria Zangerl-Plessl et al., 2019).

These many steps and various properties, together with channel specificity (Heyden et al., 2018) makes channel trafficking become a 
promising drug target. Broadly speaking, the stabilization of correctly folded proteins, transportation to membrane, channel kinetic activities and recycling steps could all be seen as potential pharmacological intervention sites. However, there still is no detailed potassium channel trafficking pathway described completely, especially for inward rectifier channels. Hence, better understanding of ion channel trafficking pathways in general, and potassium channels in particular, will help us with intelligent drug design in order to rescue more patients from suffering. Nevertheless, one has to realize that correction of normal trafficking may be insufficient to completely ameliorate symptoms. Therefore, channel activators together with trafficking correctors will most likely yield better results, as demonstrated clinically already for the chloride channel defects causing cystic fibrosis (Ratjen et al., 2015).

\section{THESIS OUTLINE}

The main focus of this thesis is exploring the role of cardiac potassium channel trafficking in arrhythmia and new means to counteract the latter. The inward rectifier $\mathrm{K}_{\mathrm{IR}} 2 . \mathrm{x}$ and delayed rectifier $\mathrm{K}_{\mathrm{v}} 11.1$ (hERG) channels were emphasized. The role of ion channel trafficking from several aspects, for example, pharmacological activation and structure identification, was evaluated in separate chapters. Then, in anticipation to a leap forward, further elaborated in the general discussion section of this thesis. In addition, we reviewed current animal models applied in cardiac arrhythmia studies to find appropriate models to enable the transition of ion-channel trafficking studies from in vitro to in vivo systems.

Chapter 2 reviews current $\mathrm{K}_{\mathrm{IR}}$ trafficking associated mutations and indicates residues experimentally proven to be associated with trafficking defects via sequence alignment of all currently known $\mathrm{K}_{\mathrm{IR}}$ isoforms. And it turns out these residues concentrate in two regions, one region important for Golgi export and one region critical for optimal channel gating and/or proper protein folding, which show more severe clinical implications than other trafficking steps. In Chapter 3, we concentrate on several common animal models in cardiac arrhythmia studies and assessed their potential value in channel trafficking research. Chapter $\mathbf{4}$ concentrates on sequence- 
function relationships and identifies a new conserved domain in the Cterminus of the $\mathrm{K}_{\mathrm{IR}} 2.1$ channel protein, which plays a role in $\mathrm{I}_{\mathrm{K} 1}$ rectification.

In Chapter 5, the antiarrhythmic effects of a novel $\mathrm{K}_{\mathrm{v}} 11.1$ allosteric modulator/activator, LUF7244 against drug-induced torsade-de-pointes (TdP) arrhythmia, was characterized in the chronic atrioventricular block (CAVB) dog model. Besides, its channel selectivity was tested in vitro. By neutralizing the cardiac side effects of dofetilide, LUF7244 protected dogs from dofetilide-induced TdP. In Chapter 6 we continued to explore the chronic effect of LUF7244. Kv11.1 channel current inhibition by dofetilide was reversed by LUF7244 acutely, whereas the trafficking rescue properties of dofetilide remained to restore $\mathrm{K}_{\mathrm{v}} 11.1$ channel function in long-term application. Chapter $\mathbf{7}$ evaluated nine linear pentamidine analogues with predicted better drug-likeness parameters. And we explored the potential influence of certain structure modifications on $\mathrm{K}_{\mathrm{v}} 11.1$ channel trafficking, which may lead to new nontoxic chemotherapeutics against Pneumocystis jiroveci pneumonia. Finally, Chapter $\mathbf{8}$ summarizes and discusses the main findings of previous chapters. 


\section{REFERENCES}

Amin AS, Tan $\mathrm{HL}$, Wilde AA. Cardiac ion channels in health and disease. Heart Rhythm. 2010 Jan 1;7(1):117-26.

Anderson CL, Kuzmicki CE, Childs RR, Hintz CJ, Delisle BP, January CT. Large-scale mutational analysis of Kv11. 1 reveals molecular insights into type 2 long QT syndrome. Nature communications. 2014 Nov $24 ; 5(1): 1-3$.

Boulpaep EL, Boron WF, Caplan MJ, Cantley L, Igarashi P, Aronson PS, Moczydlowski E. Medical physiology a cellular and molecular approach. Signal Transduct. 2009;48:27.

de Git KC, de Boer TP, Vos MA, van der Heyden MA. Cardiac ion channel trafficking defects and drugs. Pharmacology \& therapeutics. 2013 Jul $1 ; 139(1): 24-31$.

Delisle BP, Underkofler HA, Moungey BM, Slind JK, Kilby JA, Best JM, Foell JD, Balijepalli RC, Kamp TJ, January CT. Small GTPase determinants for the Golgi processing and plasmalemmal expression of human ethera-go-go related (hERG) $\mathrm{K}+$ channels. Journal of Biological Chemistry. 2009 Jan 30;284(5):2844-53.

Global Health Estimates. Deaths by Cause, Age, Sex, by Country and by Region, 2000-2016.

Grant AO. Cardiac ion channels. Circulation: Arrhythmia and Electrophysiology. 2009 Apr 1;2(2):185-94.

Grunnet M. Repolarization of the cardiac action potential. Does an increase in repolarization capacity constitute a new anti-arrhythmic principle?. Acta physiologica. $2010 \mathrm{Feb} ; 198: 1-48$.

Hoffman BF. Cranefield. PF: Electrophysiology of the heart. New YorkToronto-London. 1960. 
Ho K, Nichols CG, Lederer WJ, Lytton J, Vassilev PM, Kanazirska MV, Hebert SC. Cloning and expression of an inwardly rectifying ATP-regulated potassium channel. Nature. 1993 Mar;362(6415):31-8.

Khurshid S, Choi SH, Weng LC, Wang EY, Trinquart L, Benjamin EJ, Ellinor PT, Lubitz SA. Frequency of cardiac rhythm abnormalities in a half million adults. Circulation: Arrhythmia and Electrophysiology. 2018 Jul; 11(7):e006273.

Kubo Y, Adelman JP, Clapham DE, Jan LY, Karschin A, Kurachi Y, Lazdunski $M$, Nichols CG, Seino S, Vandenberg CA. International Union of Pharmacology. LIV. Nomenclature and molecular relationships of inwardly rectifying potassium channels. Pharmacological reviews. 2005 Dec 1;57(4):509-26.

Morad M, Tung L. Ionic events responsible for the cardiac resting and action potential. The American journal of cardiology. 1982 Jan 1;49(3):58494.

Nerbonne JM, Kass RS. Molecular physiology of cardiac repolarization. Physiological reviews. 2005 Oct;85(4):1205-53.

Ratjen F, Bell SC, Rowe SM, Goss CH, Quittner AL, Bush A. Cystic fibrosis. Nature Reviews Disease Primers. 2015 May 14;1(1):1-9.

Rudy Y. Molecular basis of cardiac action potential repolarization. Annals of the New York Academy of Sciences. 2008 Mar;1123(1):113-8.

Santana LF, Cheng EP, Lederer WJ. How does the shape of the cardiac action potential control calcium signaling and contraction in the heart? Journal of molecular and cellular cardiology. $2010 \mathrm{Dec} ; 49(6): 901$.

Timmis A, Townsend N, Gale C, Grobbee R, Maniadakis N, Flather M, Wilkins E, Wright L, Vos R, Bax J, Blum M. European Society of Cardiology: cardiovascular disease statistics 2017. European heart journal. 2018 Feb 14;39(7):508-79. 


\section{Chapter 1}

Vandenberg JI, Perry MD, Perrin MJ, Mann SA, Ke Y, Hill AP. hERG K+ channels: structure, function, and clinical significance. Physiological reviews. 2012 Jul;92(3):1393-478.

Van der Heyden MA, Delisle BP, Abriel H. Ion Channel Trafficking and Cardiac Arrhythmias. Frontiers in physiology. 2018 Sep 25;9:1254.

Wijffels MC, Kirchhof $\mathrm{CJ}$, Dorland R, Allessie MA. Atrial fibrillation begets atrial fibrillation: a study in awake chronically instrumented goats. Circulation. 1995 Oct 1;92(7):1954-68.

World Health Organization. Political declaration of the High-level Meeting of the General Assembly on the Prevention and Control of Noncommunicable Diseases. 66th Session of the Unites Nations General Assembly. New York: WHO. 2011.

Zangerl-Plessl EM, Qile M, Bloothooft M, Stary-Weinzinger A, van der Heyden MA. Disease Associated Mutations in KIR Proteins Linked to Aberrant Inward Rectifier Channel Trafficking. Biomolecules. 2019 Nov;9(11):650. 



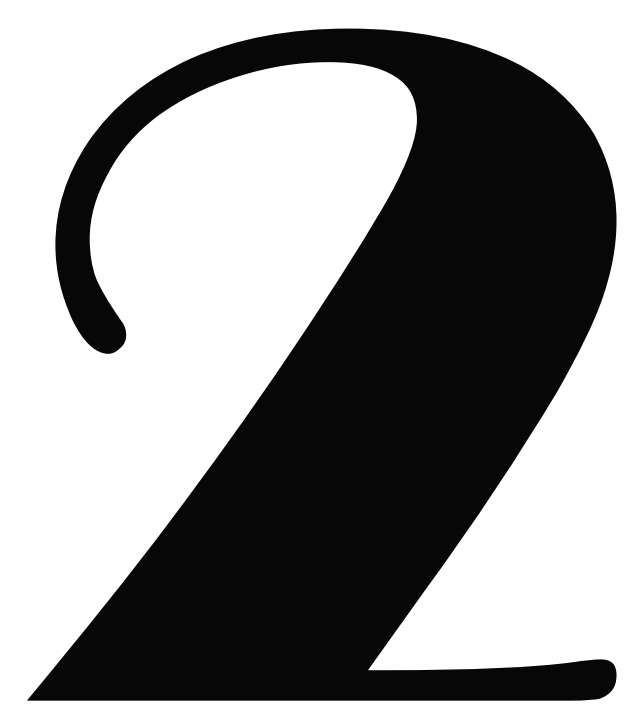




\section{Disease associated mutations in $K_{\text {IR }}$ proteins linked to aberrant inward rectifier channel trafficking}

Eva-Maria Zangerl-Plessl ${ }^{1{ }^{\dagger}}{ }^{+}$, Muge Qile ${ }^{2,{ }^{+}}$, Meye Bloothooft ${ }^{2}$, Anna Stary-Weinzinger ${ }^{1}$, Marcel A. G. van der Heyden ${ }^{2}$

${ }^{1}$ Department of Pharmacology and Toxicology, University of Vienna, Vienna, Austria

2 Department of Medical Physiology, Division of Heart \& Lungs, University Medical Center Utrecht, Utrecht, The Netherlands + These authors contributed equally to this work. 


\section{ABSTRACT}

The ubiquitously expressed family of inward rectifier potassium ( $\mathrm{K}_{\mathrm{IR}}$ ) channels, encoded by $\mathrm{KCNJ}$ genes, is primarily involved in cell excitability and potassium homeostasis. Channel mutations associate with a variety of severe human diseases and syndromes, affecting many organ systems including the central and peripheral neural system, heart, kidney, pancreas, and skeletal muscle. A number of mutations associate with altered ion channel expression at the plasma membrane, which might result from defective channel trafficking. Trafficking involves cellular processes that transport ion channels to and from their place of function. By alignment of all $\mathrm{K}_{\mathrm{IR}}$ channels, and depicting the trafficking associated mutations, three mutational hotspots were identified. One localized in the transmembranedomain 1 and immediately adjacent sequences, one was found in the Gloop and Golgi-export domain, and the third one was detected at the immunoglobulin-like domain. Surprisingly, only few mutations were observed in experimentally determined Endoplasmic Reticulum (ER)exit-, export-, or ER-retention motifs. Structural mapping of the trafficking defect causing mutations provided a 3D framework, which indicates that trafficking deficient mutations form clusters. These "mutation clusters" affect trafficking by different mechanisms, including protein stability. 


\section{INTRODUCTION}

Seventy years ago, Katz detected the inward rectification phenomenon for the first time [1]. Its unexpected property of conducting larger inward than outward potassium currents at similar deviations from the potassium equilibrium potential was unprecedented at that time. During the following decades, the understanding of inward rectifier channels was established further, stimulated by biophysical analysis and cloning of $\mathrm{K}_{\mathrm{IR}}$ genes. Inward rectifying channels-unlike voltage-gated potassium channels $\left(K_{v}\right)$ which open in response to alterations in transmembrane electrostatic potential $[2,3]$-are primarily gated by intracellular substances (e.g., polyamines and $\mathrm{Mg}^{2+}$ ). Spermine and spermidine-two polyamines for which micromolar concentrations are sufficient to reach physiological effective levels-cause stronger block of the outward current than $\mathrm{Mg}^{2+}$. The underlying molecular mechanism of rectification was first explained by Lopatin in 1994 [3]. Polyamines enter the channel pore from the cytoplasmic side and subsequently interact with six specific residues (i.e., KIR2.1 E224, D259, E299, F254, D255 and D172) [4] in the transmembrane pore domain and its cytosolic pore extension. A similar mechanism of pore-blocking is caused by $\mathrm{Mg}^{2+}$, but weaker.

The inward rectifier channel family consists of strong and weak rectifiers. Strong rectifiers, e.g., $\mathrm{K}_{\mathrm{IR}} 2$ and $\mathrm{K}_{\mathrm{IR}} 3$, are often expressed in excitable cells such as neuronal or muscle cells. Their rectifying properties enable cells to conserve $\mathrm{K}^{+}$during action potential formation and facilitate $\mathrm{K}^{+}$entry upon cell hyperpolarization. In addition, they contribute to repolarization and stabilization of the resting membrane potential. For example, application of $10 \mu \mathrm{M}$ barium, at that concentration rather specific for $\mathrm{K}_{\mathrm{IR}} 2$ channel inhibition, lengthened the action potential of guinea-pig papillary muscle preparations by $20 \mathrm{~ms}$ [5]. In the heart, $\mathrm{K}_{\mathrm{IR}} 2$ is strongly expressed in the ventricles and less in the atrioventricular node (AVN) [6]; $\mathrm{K}_{\mathrm{IR}} 3$ is mainly expressed in the atrium with much lower levels in the ventricle. Weak rectifier channels, e.g., $\mathrm{K}_{\mathrm{IR}} 1, \mathrm{~K}_{\mathrm{IR}} 4$, and $\mathrm{K}_{\mathrm{IR}} 5$, are mainly associated with potassium homeostasis and often regulate extracellular potassium concentrations to allow functioning of a number of ion (co)transporters. 
KIR channels are encoded by KCNJ genes. Various diseases associate with mutations in $K C N J$ genes. The aim of this review is to correlate disease associated mutations causing aberrant inward rectifier channel trafficking with protein domains important for trafficking by means of channel alignment, and finally to put mutational changes in a structural framework.

\section{Classification, structure, and expression}

The $\mathrm{K}_{\mathrm{IR}}$ family is divided into 7 subfamilies ( $\left.\mathrm{K}_{\mathrm{IR}} 1-7\right)$ according to their amino acid homology [4]. The sequence homology is $40 \%$ between subfamilies and rises to $70 \%$ within some subfamilies. The structural common features of these channels are that the channel pore is formed by a tetramer of subunits, most often homotetramers (Figure 1). Each subunit has two transmembrane domains ( 11 and $M 2$ ) which are separated by a pore-loop that contains the GYG (or GFG) potassium selectivity filter motif located close to the extracellular side of the membrane. Pore-loop stability depends strongly on one negatively and one positively charged residue, $\mathrm{E} 138$ and $\mathrm{R} 148$ respectively in $\mathrm{K}_{\mathrm{IR}} 2.1$ [7]. There is a relatively short $\mathrm{N}$ terminus linked to $\mathrm{M} 1$ and a longer $\mathrm{C}$-terminus linked to $\mathrm{M} 2$ which form the characteristic cytoplasmic extended pore domain (CTD). Despite their structural similarities, the KIR subfamilies also display divergent properties, e.g., sensitivity to extracellular $\mathrm{Ba}^{2+}$ or the response to regulatory signals.

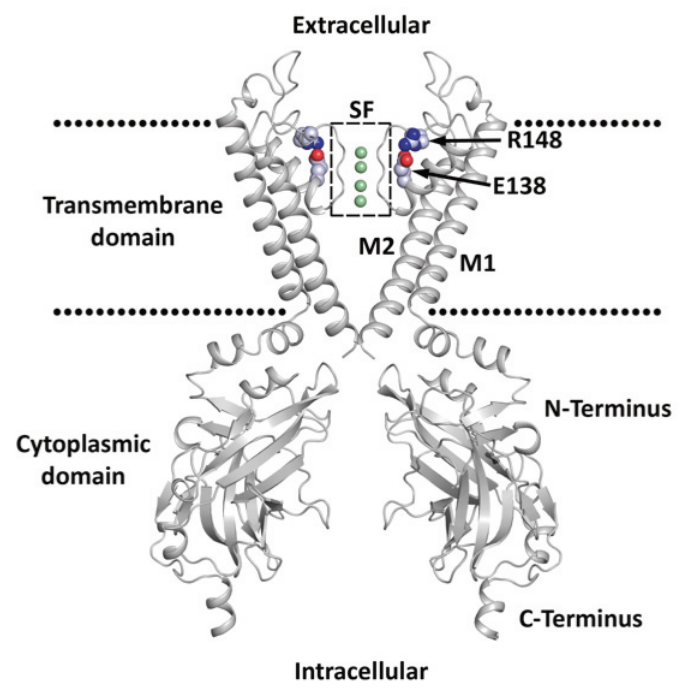

Figure 1. Two opposing domains of the $K_{I R}$ channel with structural common features highlighted. The membrane is indicated by dotted lines. The selectivity filter (SF) is highlighted by a dotted box. Ions inside the SF are shown as green spheres. Residues E138 and R148 ( $\mathrm{K}_{\mathrm{IR}} 2.1$ ) are shown as spheres. 
All $\mathrm{K}_{\mathrm{IR}}$ family members have a widespread expression pattern [4]. Neural tissues strongly express $\mathrm{K}_{\mathrm{IR}} 2, \mathrm{~K}_{\mathrm{IR}} 3, \mathrm{~K}_{\mathrm{IR}} 4$, and $\mathrm{K}_{\mathrm{IR}} 5$. Kidneys show high expression of $\mathrm{K}_{\mathrm{IR}} 4, \mathrm{~K}_{\mathrm{IR}} 5$, and $\mathrm{K}_{\mathrm{IR}} 6$, whereas pancreatic tissue highly expresses $\mathrm{K}_{\mathrm{IR}} 5$ and $\mathrm{K}_{\mathrm{IR}} 6$. The retina shows profound expression of $\mathrm{K}_{\mathrm{IR}} 7$. The heart displays strong expression of $\mathrm{K}_{\mathrm{IR}} 2, \mathrm{~K}_{\mathrm{IR}} 3$ and $\mathrm{K}_{\mathrm{IR}} 6 . \mathrm{K}_{\mathrm{IR}} 2$ subfamilymembers form the classical $I_{K 1}$ current in working ventricular and atrial cardiomyocytes, where they contribute to repolarization and resting membrane potential stability. $\mathrm{K}_{\mathrm{IR}} 3$ ( $\mathrm{I}_{\mathrm{KAch}}$ ) members are strongly expressed in the nodal tissues of the heart, where they are involved in heart rate regulation [8]. Further, they are widely expressed in the brain where they have numerous neurological functions [9]. $\mathrm{K}_{\mathrm{IR}} 6$ channels form octamers with the ATP/ADP sensing SUR subunits and couple cellular metabolic status to cardiac repolarization strength.

\section{Channel trafficking}

Following their translation in the endoplasmic reticulum (ER), correctly folded $\mathrm{K}_{\mathrm{IR}}$ channels are transported to the plasma-membrane, a process known as forward trafficking, where they exert their main biological role (Figure 2). Upon removal from the plasma-membrane, channel proteins can enter the degradation pathway in a process named backward trafficking. In addition, $\mathrm{K}_{\mathrm{IR}}$ channels can enter several recycling pathways. Each of these processes is well regulated and depends mainly on specific trafficking motifs in the channels primary sequence in concert with specific interacting proteins that direct and/or support subsequent trafficking steps. Incorrectly folded proteins will enter the endoplasmic-reticulum-associated protein degradation pathway.

ER-export signals have been determined in several $\mathrm{K}_{\mathrm{IR}}$ channels [1013], see also Section 5.3, with homology between subfamily members (e.g., FCYENE in $\mathrm{K}_{\mathrm{IR}} 2 . x$ channels), although not always among other $\mathrm{K}_{\mathrm{IR}}$ family members. Not all KIR members possess an ER-export signal, and some might even restrict forward trafficking or stimulate lysosomal breakdown when part of a heteromeric channel, as seen for $\mathrm{K}_{\mathrm{IR}} 3.3$ [12]. Other channels even have ER-retention signals that only become masked upon proper channel assembly, as seen for the $\mathrm{K}_{\mathrm{IR}} 6$ family [13]. 


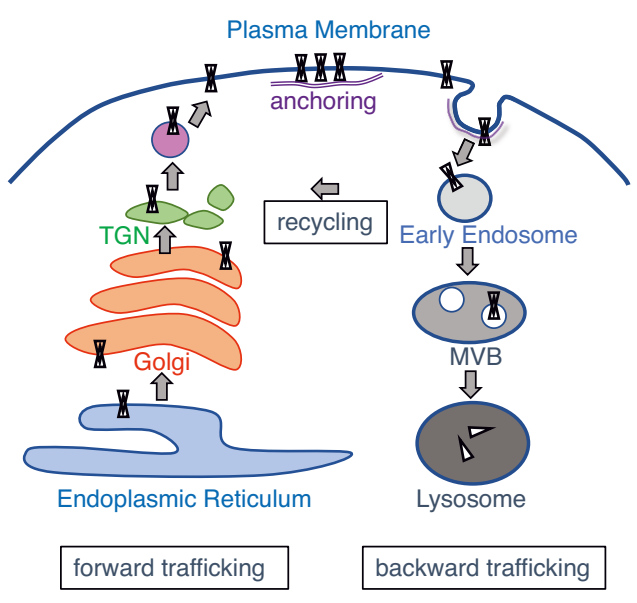

Figure 2. Schematic representation of intracellular trafficking pathways of $\mathbf{K}_{\mathrm{IR}}$ channels. TGN, trans-Golgi network; MVB, multivesicular body.

Trans-Golgi transport of several $\mathrm{K}_{\mathrm{IR}}$ channels has been demonstrated to depend on interaction with Golgi tethers that reside in the trans-Golgi network. For example, Golgin-160 interacts with the C-terminal domain of $\mathrm{K}_{\mathrm{IR}} 1.1$ channels which results in increased forward trafficking and an increase in $\mathrm{K}_{\mathrm{IR}} 1.1$ currents [14]. In a similar fashion, Golgin-97 was shown to interact with the C-terminus of $\mathrm{K}_{\mathrm{IR}} 2.1$ and promotes transport to the Golgi export sites [15]. Golgi export signals have been characterized in a few $\mathrm{K}_{\mathrm{IR}}$ channels $[16,17]$. By a combination of cytoplasmic $\mathrm{N}$ - and Cterminal domains, a so-called Golgi-export signal patch is formed that interacts with the AP-1 clathrin adaptor protein.

Protein motifs involved in backward trafficking have been studied less. $\mathrm{K}_{\mathrm{IR}} 1.1$ internalization depends on clathrin-dynamin mediated endocytosis which involved N375 in the $\mathrm{K}_{\mathrm{IR}} 1.1$ putative internalization motif NPN [18]. Internalized $\mathrm{K}_{\mathrm{IR}} 1.1$ channels depend on CORVET and ESCRT protein complexes for subsequent trafficking to the early endosome and the multivesicular body that eventually fuses with the lysosome, respectively [19]. KIR2.1 channels are regulated by the ESCRT machinery also [20]. It was demonstrated, by a pharmacological approach, that $\mathrm{K}_{\mathrm{IR}} 2.1$ degradation also depends on clathrin mediated endocytosis and lysosomal activity, and their inhibition resulted in enhanced $\mathrm{I}_{\mathrm{K} 1}$ currents $[21,22]$. The TPVT motif of the $\mathrm{K}_{\mathrm{IR}} 5.1$ channel protein binds the Nedd4-2 E3 ubiquitin ligase. In 
$\mathrm{K}_{\mathrm{IR}} 5.1 / \mathrm{K}_{\mathrm{IR}} 4.1$ heteromeric complexes, this was suggested to result in ubiquitination and subsequent degradation of $\mathrm{K}_{\mathrm{IR}} 4.1$ in the proteasome [23].

Finally, trafficking, anchoring and plasma membrane localization of $\mathrm{K}_{\mathrm{IR}}$ channels is regulated by their interaction with scaffolding proteins. The Cterminal $\mathrm{K}_{\mathrm{IR}} 2.2$ SEI PDZ-binding domain interacts with SAP97, PSD-95, Chapsyn-110, SAP102, CASK, Dlg2, Dlg3, Pals2, Veli1, Veli3, Mint1, and abLIM from rat brain lysates, and SAP97, CASK, Veli-3, and Mint1 from rat heart lysates [24-26]. Additionally, interactions between syntrophins, dystrobrevins and the $\mathrm{K}_{\mathrm{IR}} 2.2$ PDZ domain were shown by these authors. $\mathrm{K}_{\mathrm{IR}} 2.1$ and $\mathrm{K}_{\mathrm{IR}} 2.3$ also interact with SAP97 in the heart. Using an NMR approach, it was found that additional residues close to the $\mathrm{K}_{\mathrm{IR}} 2.1 \mathrm{PDZ}$ domain were involved in PSD-95 interaction [27]. Furthermore PSD-95 interacts with $\mathrm{K}_{\mathrm{IR}} 4.1$ and $\mathrm{K}_{\mathrm{IR}} 5.1$ in the optic nerve and brain, and PSD-95 interaction is essential for $\mathrm{K}_{\mathrm{IR}} 5.1$ expression at the plasma membrane of HEK293 cells $[28,29]$. The C-terminal PDZ-binding motif SNV interacts with PSD-95, and $\mathrm{K}_{\mathrm{IR}} 4.1$ mediated current density more than doubled upon PSD95 cotransfection in HEK293 cells, and increased even threefold upon SAP97 cotransfection [30]. Upon silencing of SAP97, the IK1 current decreased due to reduced plasma membrane expression of $\mathrm{K}_{\mathrm{IR}} 2.1$ and $\mathrm{K}_{\mathrm{IR}} 2.2$ ion channels [31]. Residues 307-326 of $\mathrm{K}_{\mathrm{IR}} 2.1$ are involved in interactions with the actin binding protein filamin A. Interestingly, these interactions are unaffected by the Andersen-Tawil deletion $\Delta 314 / 315$ [32]. In arterial smooth muscle cells, filamin $A$ and $K_{I R} 2.1$ colocalize in specific regions of the plasma membrane. Although filamin $A$ is not essential for $K_{I R} 2.1$ trafficking to the plasma membrane, its absence reduces the amount of $\mathrm{K}_{\mathrm{IR}} 2.1$ channels present at the plasma membrane [32].

Whereas this research field provided many new insights during the last two decades, one has to emphasize that no complete trafficking pathway for any $\mathrm{K}_{\mathrm{IR}}$ channel protein has been deciphered in detail yet. Furthermore, most of our current knowledge is derived from ectopic expressions systems rather than human native tissue or cells. Currently, we cannot exclude that $\mathrm{K}_{\mathrm{IR}}$ subtype and/or tissue specific pathways exist. The observations that several diseases associate with $\mathrm{K}_{\mathrm{IR}}$ channel trafficking malfunction might help us to further understand $\mathrm{K}_{\mathrm{IR}}$ protein trafficking processes in their natural environments in vivo. 


\section{Diseases and syndromes associated with $\mathrm{K}_{\mathrm{IR}}$ channel dysfunction}

A number of human diseases associate with mutations in $\mathrm{K}_{\mathrm{IR}}$ channels as indicated in Table 1. Bartter syndrome type II is a salt-losing nephropathy resulting in hypokalemia and alkalosis associated with loss-offunction mutations in $\mathrm{K}_{\mathrm{IR}} 1.1$ channel proteins. $\mathrm{K}_{\mathrm{IR}} 1.1$ channels are essential for luminal extrusion of $\mathrm{K}^{+}$in the thick ascending limb of Henle's loop, thereby permitting continued activity of the NKCC2 cotransporter important for sodium resorption [33]. Loss-of-function in $\mathrm{K}_{\mathrm{IR}} 2.1$ causes AndersenTawil syndrome characterized by periodic skeletal muscle paralysis, developmental skeletal abnormalities, as well as biventricular tachycardia with or without the presence of long QT. On the other hand, $\mathrm{K}_{\mathrm{IR}} 2.1$ gain-offunction mutations result in cardiac phenotypes, atrial fibrillation and short QT syndrome, explained by increased repolarization capacity and thus shortened cardiac action potentials [34,35]. Thyrotoxic hypokalemic periodic paralysis associated with $\mathrm{K}_{\mathrm{IR}} 2.6$ loss-of-function mutations affect skeletal muscle excitability under thyrotoxic conditions [36]. KeppenLubinsky syndrome is an extremely rare condition associated with $\mathrm{K}_{\mathrm{IR}} 3.2$ gain-of-function mutations. Its phenotype encompasses lipodystrophy, hypertonia, hyperreflexia, developmental delay and intellectual disability $[37,38]$. Familial hyperaldosteronism type III is associated with loss-offunction mutations in $\mathrm{K}_{\mathrm{IR}} 3.4$ channel proteins. The disease is characterized by early onset of severe hypertension and hypokalemia. Mutant $\mathrm{K}_{\mathrm{IR}} 3.4$ channels lack potassium specificity and the resulting inflow of $\mathrm{Na}^{+}$and accompanying cell depolarization of zona glomerulosa cells increases intracellular $\mathrm{Ca}^{2+}$ concentrations, which activates transcription pathways that raise aldosterone production [39]. Loss-of-function mutations in $\mathrm{K}_{\mathrm{IR}} 3.4$ associate with long QT syndrome 13, which indicates that these acetylcholine activated channels, mostly known from nodal tissues, also play a role in ventricular repolarization processes [40]. EAST (epilepsy, ataxia, sensorineural deafness, tubulopathy)/SeSAME syndrome is a saltlosing nephropathy combined with severe neurological disorders. The disease associated loss-of-function mutations in $\mathrm{K}_{\mathrm{IR}} 4.1$ channels expressed in the distal convoluted tubule, result in hypokalemic metabolic acidosis. Impaired $\mathrm{K}_{\mathrm{IR}} 4.1$ function in glial cells will increase neural tissue potassium levels giving rise to neuron depolarization, whereas reduced potassium concentration in the endolymph affect cochlear hair cell function [41]. Cantú 
syndrome results from gain-of-function of IKATP channels, either due to mutation in $\mathrm{K}_{\mathrm{IR}} 6.1$ or the SUR2 subunits. Many of these mutations decrease the sensitivity of the channel to ATP-dependent closure [42]. Insulin release by pancreatic beta-cells is regulated by their membrane potential and Ltype Calcium channel activity. Depolarization activates $\mathrm{Ca}^{2+}$ influx inducing insulin release from intracellular stores into the extracellular fluid. Loss-offunction mutations in $\mathrm{K}_{\mathrm{IR}} 6.2$ result in membrane depolarization and thus insulin release and associate with hyperinsulism and hypoglycemia. Gainof-function mutations on the other hand impair insulin release and associate with different forms of diabetes [43]. $\mathrm{K}_{\mathrm{IR}} 7.1$ channels are expressed in the apical membrane of retinal pigmented epithelial cells and contribute to $\mathrm{K}^{+}$ homeostasis in the subretinal space. Loss-of-function mutations in $\mathrm{K}_{\mathrm{IR}} 7.1$ associate with retinal dysfunction observed in Lever congenital amaurosis type 16 and Snowflake vitreoretinal degeneration [44].

In many of the above-mentioned diseases, loss-of-function has been associated with aberrant trafficking, most likely forward trafficking. Nonetheless, enhanced backward trafficking or impaired plasma-membrane anchoring cannot be excluded. However, most gain-of-function mutations are likely not related to trafficking abnormalities. Loss-of-specificity mutations, as seen in some $\mathrm{K}_{\mathrm{IR}} 3.4$ mutations, neither result from trafficking issues.

Table 1. Human diseases associated with abnormal $K_{I R}$ channel function

\begin{tabular}{|c|c|c|c|c|}
\hline Protein & Gene & $\begin{array}{l}\text { Syndrome/Disease } \\
\text { Character (OMIM) }^{1}\end{array}$ & Main Affected System(s) & $\begin{array}{l}\text { Recent } \\
\text { Review }\end{array}$ \\
\hline $\mathrm{K}_{\mathrm{IR}} 1.1$ & KCNJ1 & $\begin{array}{l}\text { Bartter syndrome, type } 2 \\
(241200)\end{array}$ & $\begin{array}{c}\text { Kidney; head; face; ear; eye; vascular; } \\
\text { gastrointestinal; skeleton; skeletal } \\
\text { muscle; CNS; platelets }\end{array}$ & [33] \\
\hline $\mathrm{K}_{\mathrm{IR}} 2.1$ & KCNJ2 & $\begin{array}{c}\text { Andersen syndrome }(170390) \\
\text { Familial atrium fibrillation } 9 \\
(613980) \\
\text { Short QT syndrome } 3 \\
(609622)\end{array}$ & $\begin{array}{l}\text { Head; face; ear; eye; teeth; heart; } \\
\text { skeleton; CNS }\end{array}$ & {$[34,35]$} \\
\hline $\mathrm{K}_{\mathrm{IR}} 2.2$ & KCNJ12 & Non-described & & \\
\hline $\mathrm{K}_{\mathrm{IR}} 2.3$ & KCNJ4 & Non-described & & \\
\hline $\mathrm{K}_{\mathrm{IR}} 2.4$ & KCNJ14 & Non-described & & \\
\hline $\mathrm{K}_{\mathrm{IR}} 2.6$ & KCNJ18 & $\begin{array}{l}\text { Thyrotoxic hypokalemic } \\
\text { periodic paralysis (613239) }\end{array}$ & $\begin{array}{c}\text { Cardiovascular; skeletal muscle; CNS; } \\
\text { eye }\end{array}$ & {$[36]$} \\
\hline $\mathrm{K}_{\mathrm{IR}} 3.1$ & KCNJ3 & Non-described & & \\
\hline $\mathrm{K}_{\mathrm{IR}} 3.2$ & KCNJ6 & $\begin{array}{c}\text { Keppen-Lubinsky Syndrome } \\
\text { (614098) }\end{array}$ & CNS; head; skin; skeleton; eye, face & $\begin{array}{l}\text { No review } \\
\text { available }\end{array}$ \\
\hline $\mathrm{K}_{\mathrm{IR}} 3.3$ & KCNJ9 & Non-described & & \\
\hline $\mathrm{K}_{\mathrm{IR}} 3.4$ & KCNJ5 & $\begin{array}{c}\text { Familial hyperaldosteronism } 3 \\
\text { (613677) } \\
\text { Long QT syndrome } 13 \\
(613485) \\
\end{array}$ & Cardiovascular; kidney; skeletal muscle & {$[39,40]$} \\
\hline
\end{tabular}


Table 1. Cont.

\begin{tabular}{|c|c|c|c|c|}
\hline Protein & Gene & $\begin{array}{l}\text { Syndrome/Disease } \\
\text { Character (OMIM) }\end{array}$ & Main Affected System(s) & $\begin{array}{l}\text { Recent } \\
\text { Review }\end{array}$ \\
\hline $\mathrm{K}_{\mathrm{IR}} 4.1$ & KCNJ10 & $\begin{array}{c}\text { Digenic enlarged vestibular } \\
\text { aqueduct (600791) } \\
\text { EAST/SESAME syndrome } \\
(612780)\end{array}$ & Ear (hearing); vascular; kidney; CNS & [41] \\
\hline $\mathrm{K}_{\mathrm{IR}} 4.2$ & KCNJ15 & Non-described & & \\
\hline $\mathrm{K}_{\mathrm{IR}} 5.1$ & KCNJ16 & Non-described & & \\
\hline $\mathrm{K}_{\mathrm{IR}} 6.1$ & KCNJ8 & Cantú syndrome (239850) & $\begin{array}{c}\text { Head; face; cardiovascular; skeleton; } \\
\text { hair; CNS }\end{array}$ & [42] \\
\hline $\mathrm{K}_{\mathrm{IR}} 6.2$ & KCNJ11 & $\begin{array}{c}\text { Transient neonatal diabetes } \\
\text { mellitus } 3 \text { (610582) } \\
\text { Permanent neonatal diabetes } \\
\text { with or } \\
\text { without neurologic features } \\
\text { (606176) } \\
\text { Familial hyperinsulinemic } \\
\text { hypoglycemia } 2(601820) \\
\text { Maturity-onset diabetes of the } \\
\text { young } 13 \text { (616329) } \\
\text { Susceptible to diabetes } \\
\text { mellitus } 2 \text { (125853) }\end{array}$ & Pancreas (beta-cells); CNS & [43] \\
\hline $\mathrm{K}_{\mathrm{IR}} 7.1$ & KCNJ13 & $\begin{array}{c}\text { Leber congenital amaurosis } \\
16(614186) \\
\text { Snowflake vitreoretinal } \\
\text { degeneration }(193230)\end{array}$ & Eye (retina) & [44] \\
\hline
\end{tabular}

OMIM $^{1}$ : OMIM ${ }^{\circledR}$ - Online Mendelian Inheritance in Man ${ }^{\circledR}$ https://omim.org assessed on 24 July 2019, CNS, central neural system.

\section{KIR protein alignment of trafficking associated disease mutations}

In order to identify potential protein domains associated with $\mathrm{K}_{\mathrm{IR}}$ trafficking defects in human disease, we aligned all $\mathrm{K}_{\mathrm{IR}}$ isoforms and highlighted residues (in red) of which mutations are experimentally proven to associate with trafficking defects (Figure 3, supplementary Figure S1). Furthermore, additional mutations in other $\mathrm{K}_{\mathrm{IR}}$ isoforms at homologues positions, but currently not related to impaired trafficking, are indicated (supplementary Figure S1, in green). Trafficking associated mutations are found dispersed along the protein sequence, with one "hotspot" in the Gloop and adjacent C-terminal region, and one "hotspot" in and around transmembrane domain 1. Additionally, from a structural point of view, there is another "hotspot" at the immunoglobulin-like domain (IgLD), which is described in Section 6.1. 


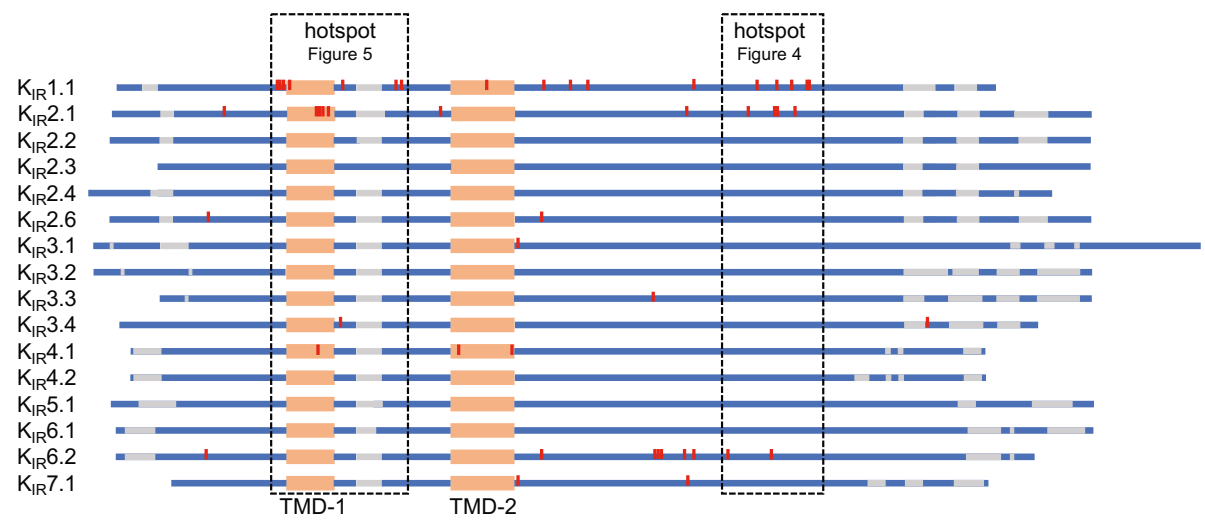

Figure 3. Schematic representation of inward rectifier channels ( $K_{\text {IR } 1-7)}$ sequence alignment. Red: mutations associated with aberrant trafficking; mutation hotspots are boxed. Orange: transmembrane domain; blue: $\mathrm{K}_{\mathrm{IR}}$ protein sequence; gray: sequence gap.

\section{C-Terminal Trafficking Mutation Hotspot}

Figure 4 depicts the alignment of the C-terminal hotspot, having ten trafficking associated mutations/deletions located in $\mathrm{K}_{\mathrm{IR}} 1.1, \mathrm{~K}_{\mathrm{IR}} 2.1$ and/or $\mathrm{K}_{\mathrm{IR}} 6.2$ over a stretch of 44 residues. This region also covers the filamin $\mathrm{A}$ interaction domain of $\mathrm{K}_{\mathrm{IR}} 2.1$ (307-326) [32]. The loss-of-function E282K mutation in $\mathrm{K}_{\mathrm{IR}} 6.2$ is associated with congenital hyperinsulinism [45]. This mutation affects normal function of a highly conserved di-acidic ER exit signal (DXE) that prevents mutant channels to enter ER exit sites, which thus fail to traffic to the plasma-membrane [45]. The Andersen-Tawil lossof-function $\mathrm{K}_{\mathrm{IR}} 2.1$ mutation $\mathrm{V} 302 \mathrm{M}$ is located in the G-loop and displays intracellular, but no plasma-membrane expression, upon transfection of HEK293 cells [46]. However, Ma et al., [47] demonstrated that the $\mathrm{K}_{\mathrm{IR}} 2.1$ V302M mutation does not affect trafficking. The Bartter syndrome associated loss-of-function A306T mutation in $\mathrm{K}_{\mathrm{IR}} 1.1$ is also located in the G-loop. Its expression in the Xenopus oocyte membrane is strongly reduced compared to wildtype channels [48]. At homologues positions, disease causing mutations have been found in $\mathrm{K}_{\mathrm{IR}} 2.1$ [49] and $\mathrm{K}_{\mathrm{IR}} 6.2$ [50] whose cause for loss- and gain-of-function, respectively, is unknown but may be caused by trafficking abnormalities. Hyperinsulinism associated $\mathrm{K}_{\mathrm{IR}} 6.2$ R301H/G/C/P loss-of-function mutations are located just C-terminal from 
the G-loop domain. These mutants display reduced surface expression when expressed in COSm6 or INS cells [51]. Interestingly, however, the R301A mutation displays normal expression at the plasma-membrane [51]. At homologues positions, mutations have also been found in $\mathrm{K}_{\mathrm{IR}} 1.1$ [52] and $\mathrm{K}_{\mathrm{IR}} 4.1$ [53].

\begin{tabular}{|c|c|c|}
\hline .1 & & \\
\hline $\mathrm{K}_{\mathrm{IR}} 2.1$ & NADFEIVVILEGMVEATAMTTQCRSSYLANEILWGHRYEPVLFE & \\
\hline 2.2 & TDDFEIVVILEGMVEATAMTTQARSSYLANEILWGH & \\
\hline 2.3 & EDFEIVVILEGMVEATAMTTQAR & \\
\hline R2. 4 & RADFELVVILEGMVEATAMTTOCRSSYLPGELLWGHRFEPVLFQ & \\
\hline .6 & TDDFEIVVILEGMVEATAMTTQARSSYLANEILWGHRFEF & \\
\hline 3.1 & ILEGIVETTGMTCQAR & \\
\hline 3.2 & KEELEIVVILEGMVEATGMTCOAAR & \\
\hline .3 & RDDFEIVVILEGMVEATGMTCQA & \\
\hline 3.4 & QEEFEVVVILEGMVEATGI & \\
\hline 4.1 & EGDFELVLILSGTVESTSATCOVRTSYLPEEILWGYEFTPAISL & \\
\hline & ESTSAVCQSR & \\
\hline 5.1 & KDNFEILVTFIYTGDSTGTSHOSRSSYVPREILWGHRFNDVLEV & \\
\hline $\mathrm{TR} 6.1$ & NQDLEVIVILEGVVETTGITTQARTSYIAEEIQWGHRFVSIVTE & \\
\hline & HQDLEI IVILEGVVETTGITTQARTSYLADEILWGQRFVPIVAE & \\
\hline .1 & PSHFELVVFLSAMQEGTGEICQRRTSYLPSEIMLHHCFASLLTR & \\
\hline & $\begin{array}{ccc}{\left[\mathrm{D}_{\mathrm{E}}-\mathrm{E}\right]} & {[-\mathrm{G}-\mathrm{LOOP}--]} & \begin{array}{c}\text { SY---EI-W } \\
\text { Golgi-expor }\end{array}\end{array}$ & \\
\hline
\end{tabular}

Figure 4. $\mathrm{K}_{\mathrm{IR}}$ 1-7 sequence alignment of the C-terminal mutation hotspot. Red: mutations associated with aberrant trafficking; Green: residues whose mutations are currently not related to impaired trafficking. Numbers at the right refer to the last amino-acid residue in the respective sequence shown. Conserved residues among all $\mathrm{K}_{\mathrm{IR}}$ members are shaded gray. Locations of the di-acidic ER exit, G-loop and the Golgi-Export signal sequence (see text) are indicated below the alignment.

By use of homology comparison and structure guided mutagenesis, a common Golgi export signal patch was found to be formed by a C-terminal stretch of hydrophobic residues and basic residues from the $\mathrm{N}$-terminus $[16,17]$. The C-terminal stretch sequence is formed by residues SYXXXEIXW indicated in Figure 4. Two Bartter syndrome associated $\mathrm{K}_{\mathrm{IR}} 1.1$ (Y314C; L320P) and two Andersen-Tawil syndrome associated $\mathrm{K}_{\mathrm{IR}} 2.1$ (delSY; W322S) confirmed trafficking mutations have been described in this region $[46,48,54]$. Interestingly, the $W$ residue is not conserved in the $K_{I R} 7.1$ channel protein, which may indicate $\mathrm{K}_{\mathrm{I}}$ subtype specific use of the entire Golgi-export signal motif. Two additional KIR 1.1 mutations leading to altered 
trafficking, R324L and F325C have been located directly C-terminal from the Golgi-export signal stretch $[48,52]$.

Fallen et al. [55] showed that mutations A198T and Y314C in the IgLD, located in the CTD of $\mathrm{K}_{\mathrm{IR}} 1.1$, are associated with defects in channel trafficking and gating, see also Section 6.1. Y314C is present within the Cterminal trafficking mutation hotspot and part of the Golgi-export signal as discussed above. If incorrectly folded, the aberrant $\mathrm{K}_{\mathrm{IR}} 1.1$ proteins will enter the endoplasmic-reticulum-associated protein degradation pathway [56].

\section{Transmembrane Region 1 Mutation Hotspot}

Figure 5 depicts the alignment of transmembrane domain 1 and adjacent sequences, containing 15 trafficking associated mutations located in $\mathrm{K}_{\mathrm{IR}} 1.1, \mathrm{~K}_{\mathrm{IR}} 2.1, \mathrm{~K}_{\mathrm{IR}} 3.4$ or $\mathrm{K}_{\mathrm{IR}} 4.1$. Three mutations in the cytoplasmic domain, positioned just in front of the first transmembrane region in $\mathrm{K}_{\mathrm{IR}} 1.1$ (T71M, V72M and D74Y), have been demonstrated to strongly decrease plasma-membrane expression and mutant channels were retained in the cytoplasm $[48,57]$. However, membrane expression of T71M in Xenopus oocytes could be rescued by increasing the amount of injected RNA, in contrast to the other two mutations. For $\mathrm{K}_{\mathrm{IR}} 1.1 \mathrm{~T} 71 \mathrm{M}$, mutations at the homologues positions were found in $\mathrm{K}_{\mathrm{IR}} 2.1$ (T75) [58-62] and $\mathrm{K}_{\mathrm{IR}} 6.2$ (T62) $[63,64]$ associated with Andersen-Tawil syndrome and Familial hyperinsulinemic hypoglycemia type 2, respectively. The $\mathrm{K}_{\mathrm{IR}} 2.1 \mathrm{~T}$ T5R protein was observed at the plasma membrane upon overexpression in HL1 cells [60]. Moreover, T75A, T75R and T75M channel proteins were also expressed at the plasma membrane in Xenopus oocytes, HEK293 or COS-7 cells $[58,61,65]$. In contrast, impaired plasma-membrane localization of T75M KIR2.1 was observed in HEK293 cells in another study [62]. Two $\mathrm{K}_{\mathrm{IR}} 2.1$ mutations, i.e., D78G and D78Y, are at the equivalent position as D74 in $\mathrm{K}_{\mathrm{IR}} 1.1$, and also D78Y was found at the plasma membrane in Xenopus oocytes and HEK293 cells $[59,65,66]$. These comparisons indicate that findings on plasma-membrane expression may be influenced by the degree of overexpression and cell type. $\mathrm{K}_{\mathrm{IR}} 2.1 \mathrm{~T} 75$ and D78 residues are positioned on the hydrophilic side of the slide helix that interacts with the cytoplasmic domain. The D78Y mutation disrupts this interaction [65]. 


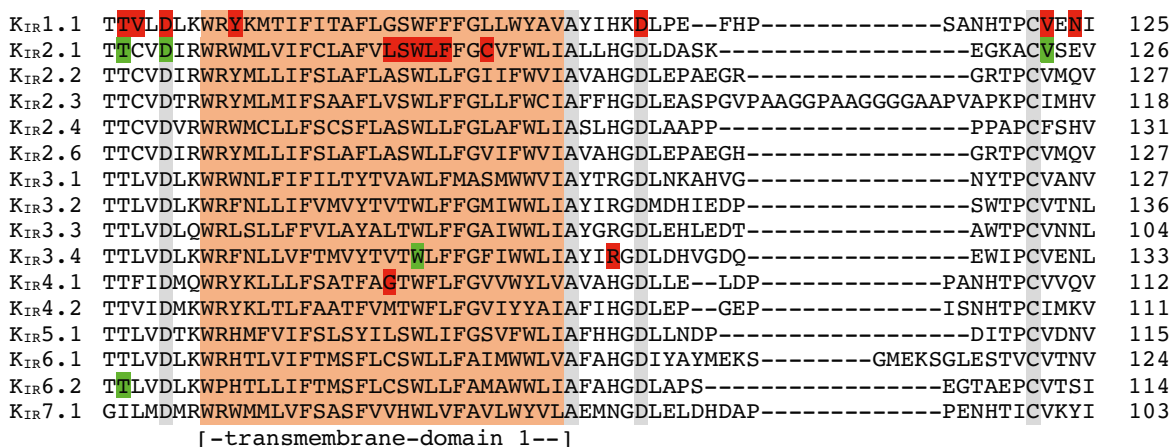

Figure 5. $K_{I R} 1-7$ sequence alignment of the transmembrane domain 1 mutation hotspot. Red: mutations associated with aberrant trafficking; Green: residues whose mutations are currently not related to impaired trafficking. Numbers at the right refer to the last amino-acid residue in the respective sequence shown. Conserved residues among all $\mathrm{K}_{\mathrm{IR}}$ members are shaded gray. Location of the transmembrane domain 1 (orange) is indicated below the alignment.

Trafficking associated mutations in the highly conserved transmembrane region 1 are described for $\mathrm{K}_{\mathrm{IR}} 1.1, \mathrm{~K}_{\mathrm{IR}} 2.1$ and $\mathrm{K}_{\mathrm{IR}} 4.1$ [46,48,67-69]. Expression of $\mathrm{K}_{\mathrm{IR}} 1.1 \mathrm{Y} 79 \mathrm{H}$ in the Xenopus oocyte plasmamembrane increases upon increasing the amount of RNA injection by tenfold [48]. The $\mathrm{K}_{\mathrm{IR}} 2.1 \mathrm{~L} 94 \mathrm{P}, \Delta 95-98$ and $\mathrm{K}_{\mathrm{IR}} 4.1 \mathrm{G} 77 \mathrm{R}$ channel proteins localize intracellularly $[46,68,69]$. The molecular mechanisms by which these mutations affect normal trafficking remain to be solved. However, interactions with wildtype subunits appear not to be affected and may explain the dominant negative properties of these mutations. The familial sinus node disease associated $\mathrm{K}_{\mathrm{IR}} 3.4 \mathrm{~W} 101 \mathrm{C}$ gain-of-function mutation is located at a position homologues to $\mathrm{K}_{\mathrm{IR}} 2.1$ W96 [70]. In an ectopic expression system, the $\mathrm{K}_{\mathrm{IR}} 3.4 \mathrm{~W} 101 \mathrm{C}$ protein is expressed at the plasma membrane, however it decreased surface expression of $\mathrm{K}_{\mathrm{IR}} 3.1$ when coexpressed [70].

Confirmed trafficking associated mutations C-terminal from the transmembrane region 1 are found in $\mathrm{K}_{\mathrm{IR}} 1.1$ and $\mathrm{K}_{\mathrm{IR}} 3.4[48,71,72]$. $\mathrm{K}_{\mathrm{IR}} 1.1$ $\mathrm{D} 108 \mathrm{H}$ and V122E mutants did not display membrane staining in Xenopus oocytes or HEK293 cells [48]. When comparing single channel characteristics with macroscopic currents, it was concluded that loss-of- 
function of $\mathrm{K}_{\mathrm{IR}} 1.1 \mathrm{~N} 124 \mathrm{~K}$ was caused by a reduction of functional channels at the plasma-membrane [71]. The $\mathrm{K}_{\mathrm{IR}} 3.4 \mathrm{R} 115 \mathrm{~W}$ mutation was obtained from aldosterone-producing adenoma linked to hyperaldosteronism, and displayed decreased plasma-membrane expression in HEK293 cells [72]. A mutation, at a position homologues to $\mathrm{V} 122$ in $\mathrm{K}_{\mathrm{IR}} 1.1$, has also been identified in $\mathrm{K}_{\mathrm{IR}} 2.1$ [59].

3. N-Terminal Golgi-Export Patch, $K_{I R} 2 . x$ ER Export, and $K_{I R} 6 . x$ ER Exit and Retention Signals

As indicated above, the so-called Golgi-export patch consists of interaction of a C-terminal and N-terminal domain $[16,17]$. Mutations in the C-terminal domain have been found (see Section 5.1). However, only few mutations have been described in the $\mathrm{N}$-terminal part ( $\mathrm{K}_{\mathrm{IR}} 2.1 \mathrm{G} 52 \mathrm{~V} ; \mathrm{K}_{\mathrm{IR}} 2.6$ $\mathrm{R} 43 \mathrm{C}$ ) that result in reduced plasma membrane expression by hampering Golgi export $[73,74]$. Thus far, no mutations of residue R20 in $\mathrm{K}_{\mathrm{IR}} 2.3$, which is required for Golgi export [17], or at the homologues position in any other $\mathrm{K}_{\mathrm{IR}}$ channel protein have been identified.

$\mathrm{K}_{\mathrm{IR}} 2 . x$ channels share a short C-terminal ER-export signal (FCYENE) $[10,11] . \quad \mathrm{K}_{\mathrm{IR}} 3.2$ contains $\mathrm{N}$-terminal (DQDVESPV) and C-terminal (ELETEEEE) ER-export signals, whereas $\mathrm{K}_{\mathrm{IR}} 3.4$ possesses the $\mathrm{N}$-terminal NQDMEIGV ER-export signal [12]. Remarkable, we did not encounter any trafficking associated mutations in any of these domains. In contrast, one mutation (E282K) was present in the di-acidic ER exit signal of $\mathrm{K}_{\mathrm{IR}} 6.2$ as discussed in Section 5.1. $\mathrm{K}_{\mathrm{IR}} 6 . \mathrm{x}$ and SURx channel proteins contain a Cterminal ER-retention signal (RKR) [13]. Upon channel assembly, retention signals from both proteins are shielded, supporting subsequent ER-export. No trafficking associated mutations were found in these retention signals in $\mathrm{K}_{\mathrm{IR}} 6 . \mathrm{x}$ channel proteins. We therefore propose that mutations in Golgiexport domains have more severe clinical implications than mutations in ER-export/retention signals.

\section{Structural mapping of trafficking defect causing mutants}

Disease causing mutations associated with trafficking deficiencies were mapped onto the common structural scaffold of a recently published high 
resolution $\mathrm{K}_{\mathrm{IR}} 2.2$ structure [75]. As illustrated in Figure 6, mutations are globaly distributed.

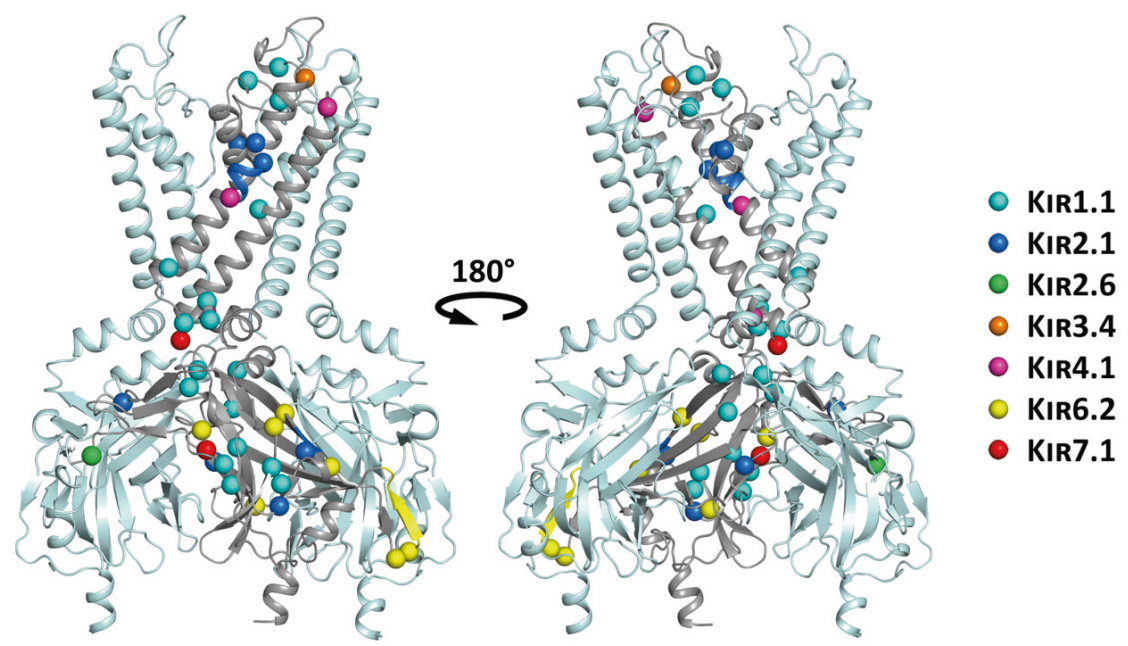

Figure 6. Structural mapping of trafficking mutants mapped on the $\mathrm{K}_{\mathrm{IR}} \mathbf{2 . 2}$ structure. For clarity reasons, only three of the four subunits are shown in side view, with the disease associated mutations highlighted in one subunit only. Mutations of different $\mathrm{K}_{\mathrm{IR}}$ channel family members are color-coded and shown as spheres of their respective $\mathrm{C} \alpha$ atoms. Deletions are indicated by colored regions on the secondary structure elements.

A group of mutations clusters at regions important for channel gating, including the $\mathrm{PIP}_{2}$ binding site (T71M, V72E, D74Y and $\mathrm{Y} 79 \mathrm{H}$ in $\mathrm{K}_{\mathrm{IR}} 1.1$ ), the helix bundle crossing gate (A167V in $\mathrm{K}_{\mathrm{IR}} 4.1$; R162W/Q in $\mathrm{K}_{\mathrm{IR}} 7.1$ )[76-78], as well as the G-loop gate (V302M, $\left.\mathrm{K}_{\mathrm{IR}} 2.1\right)$. It can be expected that these mutations have strong effects on the conformational equilibrium, thereby impairing normal protein function. It is likely that these mutants lead to structurally less-stable proteins, thereby making them more susceptible for degradation. Interestingly, $58 \%$ of the currently known trafficking defect causing mutations in $\mathrm{K}_{\mathrm{IR}}$ channel proteins cluster in the cytoplasmic domain, which has been shown to be crucial for efficient folding in KvAP channels [79].

Another cluster of mutants (D108H, V122E and N124K in KIR1.1; R115W in $\mathrm{K}_{\mathrm{IR}} 3.4 ; \mathrm{C} 140 \mathrm{R}$ in $\mathrm{K}_{\mathrm{IR}} 4.1$ ) is found on surface exposed loops of the channel. 
Except for C140R in $\mathrm{K}_{\mathrm{IR}} 4.1$ [68], which is part of a disulfide bridge [80], none of the mutations causes changes in polarity or is at important structural motifs, leaving it unclear why these mutants cause trafficking defects.

Mutations G77R in $\mathrm{K}_{\mathrm{IR}} 4.1$ [68] and $\mathrm{C} 101 \mathrm{R}$ in $\mathrm{K}_{\mathrm{IR}} 2.1$, located on the membrane facing side and near the center of transmembrane helix $M 1$, cause changes in the helical properties and hydrophobicity. It is thus conceivable that they severely affect helical stability and possibly membrane insertion. It has been shown in numerous studies that the cost for exposing arginine to lipid hydrocarbons is prohibitively high [81]. Interestingly, none of the identified disease mutations is located at the interface between subunits.

\section{Structure-Based Hotspot in the IgLD Beta Barrel of the CTD}

Two antenatal Bartter syndrome loss-of-function mutations A198T and Y314C, located in the IgLD have been shown to impair forward trafficking and gating of $\mathrm{K}_{\mathrm{IR}} 1.1$ channels, possibly influencing the core stability of this domain [55]. Interestingly, a trafficking affecting mutation in a homologous position to $\mathrm{K}_{\mathrm{IR}} 1.1 \mathrm{~A} 198$ has been identified in $\mathrm{K}_{\mathrm{IR}} 2.6$ (A200P) [74], and another mutation thus far not associated with trafficking has been identified in $\mathrm{K}_{\mathrm{IR}} 6.2$ (A187V). As shown in Figure 7, quite a large number of disease causing mutations, including A306T (implicated in trafficking) [48], R311W and $\mathrm{L} 320 \mathrm{P}$ in $\mathrm{K}_{\mathrm{IR}} 1.1$ (no data on trafficking), S314-Y315 deletion in $\mathrm{K}_{\mathrm{IR}} 2.1$ (implicated in trafficking) [16], E282K (prevents ER-export and surface expression of the channel) [45] or L241P in $\mathrm{K}_{\mathrm{IR}} 7.1$ (implicated in trafficking) [78], have been reported in literature. This, as well as previous work [55], suggests that this structural motif might be a crucial hotspot implicated in trafficking of $\mathrm{K}_{\mathrm{IR}}$ channels.

\section{CONCLUSIONS}

Mutations in $\mathrm{K}_{\mathrm{IR}}$ potassium ion channels associate with a variety of human diseases in which electrophysiological and potassium homeostasis aberrations are explaining etiology. Many of the mutations associate with abnormal, mostly decreased forward, ion channel trafficking. 


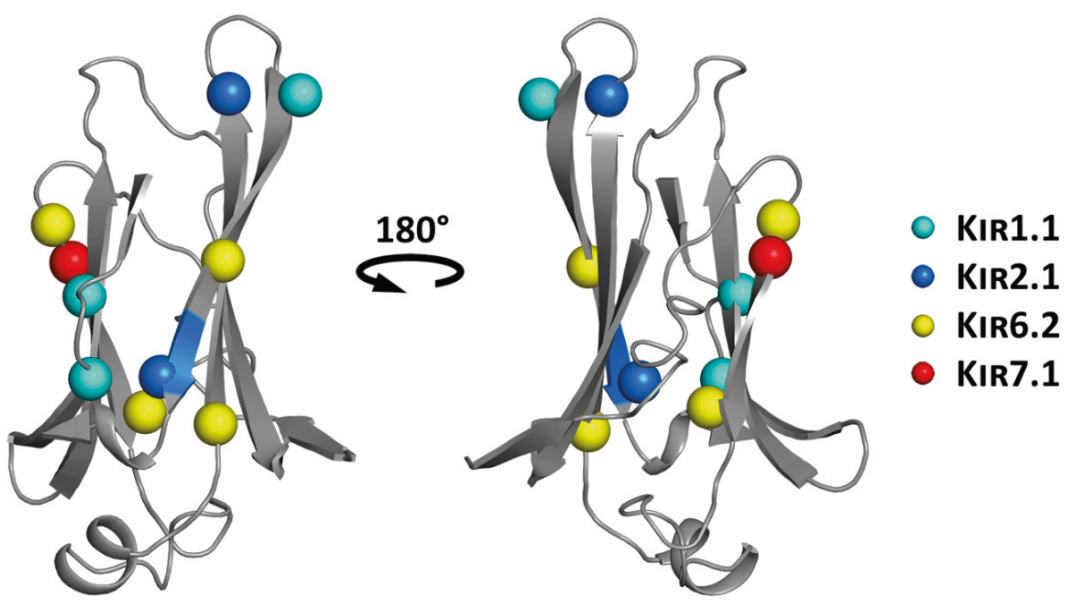

Figure 7. Structure based IgLD hotspot (mapped on the $\mathrm{K}_{\mathrm{IR}} 2.2$ structure), with disease associated mutations highlighted. Mutations of the different family members are color-coded and shown as spheres of their respective $\mathrm{C} \alpha$ atoms.

Trafficking associated mutations are present throughout the primary sequence, but they concentrate in cytoplasmic domains in which channel structures involved in Golgi-export are clinically more important than ERexport regions. Another group of mutations are found in regions important for gating and most likely affect protein folding and stability. Therefore, mutation associated $\mathrm{K}_{\mathrm{IR}}$ trafficking defects are likely caused by 1 ) defective interaction with the trafficking machinery due to mutations in specific trafficking motifs, and 2) channel misfolding, destabilization and subsequent endoplasmic-reticulum-associated protein degradation due to mutations in residues important for channel structure. 
Diseases associated with $\mathrm{K}_{\mathrm{IR}}$ channel trafficking mutations

\section{REFERENCES}

1. Katz, B. Les constantes électriques de la membrane du muscle. Arch. Sci. Physiol. 1949, 2, 285-299.

2. Matsuda, H.; Saigusa, A.; Irisawa, H. Ohmic conductance through the inwardly rectifying $\mathrm{K}$ channel and blocking by internal $\mathrm{Mg}^{2+}$. Nature 1987, 325, 156-159.

3. Lopatin, A.N.; Makhina, E.N.; Nichols, C.G. Potassium channel block by cytoplasmic polyamines as the mechanism of intrinsic rectification. Nature 1994, 372, 366-369.

4. De Boer, T.P.; Houtman, M.J.; Compier, M.; Van der Heyden, M.A. The mammalian $\mathrm{K}_{\mathrm{IR}} 2$. x inward rectifier ion channel family: expression pattern and pathophysiology. Acta Physiol. 2010, 199, 243-256.

5. Wang, L.; Chiamvimonvat, N.; Duff, H.J. Interaction between selected sodium and potassium channel blockers in guinea pig papillary muscle. J. Pharmacol. Exp. Ther. 1993, 264,1056-1062.

6. Kokubun, S.; Nishimura, M.; Noma, A.; Irisawa H. Membrane currents in the rabbit atrioventricular node cell. Pflügers Arch. 1982, 393, 15-22.

7. Yang, J.; Yu, M.; Jan, Y.N.; Jan, L.Y. Stabilization of ion selectivity filter by pore loop ion pairs in an inwardly rectifying potassium channel. Proc. Natl. Acad. Sci. USA. 1997, 94, 1568-1572.

8. Krapivinsky, G.; Gordon, E.A.; Wickman, K.; Velimirović, B.; Krapivinsky, L.; Clapham, D.E. The G-protein-gated atrial $\mathrm{K}^{+}$channel $\mathrm{I}_{\text {KACh }}$ is a heteromultimer of two inwardly rectifying $\mathrm{K}^{+}$-channel proteins. Nature 1995, 374, 135-141.

9. Lüscher, C.; Slesinger, P.A. Emerging roles for G protein-gated inwardly rectifying potassium (GIRK) channels in health and disease. Nat. Rev. Neurosci. 2010, 11, 301-315.

10. Ma, D.; Zerangue, N.; Lin, Y.F.; Collins, A.; Yu, M.; Jan, Y.N.; Jan, L.Y. Role of ER export signals in controlling surface potassium channel numbers. Science 2001, 291, 316-319.

11. Stockklausner, C.; Ludwig, J.; Ruppersberg, J.P.; Klöcker, N. A sequence motif responsible for ER export and surface expression of Kir2.0 inward rectifier K+ channels. FEBS Lett. 2001, 493, 129-133. 
12.Ma, D.; Zerangue, N.; Raab-Graham, K.; Fried, S.R.; Jan, Y.N.; Jan, L.Y. Diverse trafficking patterns due to multiple traffic motifs in $G$ protein-activated inwardly rectifying potassium channels from brain and heart. Neuron 2002, 33, 715-729.

13. Zerangue, N.; Schwappach, B.; Jan, Y.N.; Jan, L.Y. A new ER trafficking signal regulates the subunit stoichiometry of plasma membrane K(ATP) channels. Neuron 1999, 22, 537-548.

14. Bundis, F.; Neagoe, I.; Schwappach, B.; Steinmeyer, K. Involvement of Golgin-160 in cell surface transport of renal ROMK channel: coexpression of Golgin-160 increases ROMK currents. Cell. Physiol. Biochem. 2006, 17, 1-12.

15.Taneja, T.K.; Ma, D.; Kim, B.Y.; Welling, P.A. Golgin-97 Targets Ectopically Expressed Inward Rectifying Potassium Channel, Kir2.1, to the trans-Golgi Network in COS-7 Cells. Front. Physiol. 2018, 9, 1070.

16. Ma, D.; Taneja, T.K.; Hagen, B.M.; Kim, B.Y.; Ortega, B.; Lederer, W.J.; Welling, P.A. Golgi export of the Kir2.1 channel is driven by a trafficking signal located within its tertiary structure. Cell 2011, 145, 1102-1115.

17. Li X.; Ortega B.; Kim B.; Welling P.A. A Common Signal Patch Drives AP-1 Protein-dependent Golgi Export of Inwardly Rectifying Potassium Channels. J. Biol. Chem. 2016, 291, 14963-14972.

18.Zeng, W.Z.; Babich, V.; Ortega, B.; Quigley, R.; White, S.J.; Welling, P.A.; Huang, C.L. Evidence for endocytosis of ROMK potassium channel via clathrin-coated vesicles. Am. J. Physiol. Renal Physiol. 2002, 283, 630-639.

19. Mackie, T.D.; Kim, B.Y.; Subramanya, A.R.; Bain, D.J.; O'Donnell, A.F.; Welling, P.A.; Brodsky, J.L. The endosomal trafficking factors CORVET and ESCRT suppress plasma membrane residence of the renal outer medullary potassium channel (ROMK). J. Biol. Chem. 2018, 293, 32013217.

20. Kolb, A.R.; Needham, P.G.; Rothenberg, C.; Guerriero, C.J.; Welling, P.A.; Brodsky, JL. ESCRT regulates surface expression of the Kir2.1 potassium channel. Mol. Biol. Cell 2014, 25, 276-289.

21. Jansen, J.A.; de Boer, T.P.; Wolswinkel, R.; van Veen, T.A.; Vos, M.A.; van Rijen, H.V.M.; van der Heyden, M.A.G. Lysosome mediated Kir2.1 
breakdown directly influences inward rectifier current density. Biochem. Biophys. Res. Commun. 2008, 367, 687-692.

22. Varkevisser, R.; Houtman, M.J.; Waasdorp, M.; Man, J.C.; Heukers, R.; Takanari, H.; Tieland, R.G.; van Bergen En Henegouwen, P.M.; Vos, M.A.; van der Heyden, M.A. Inhibiting the clathrin-mediated endocytosis pathway rescues $\mathrm{K}(\mathrm{IR}) 2.1$ downregulation by pentamidine. Pflugers Arch. 2013, 465, 247-259.

23. Wang, M.X.; Su, X.T.; Wu, P.; Gao, Z.X.; Wang, W.H.; Staub, O.; Lin, D.H. Kir5.1 regulates Nedd4-2-mediated ubiquitination of Kir4.1 in distal nephron. Am. J. Physiol. Renal Physiol. 2018, 315, F986-F996.

24. Leonoudakis, D.; Mailliard, W.; Wingerd, K.; Clegg, D.; Vandenberg, C. Inward rectifier potassium channel Kir2.2 is associated with synapseassociated protein SAP97. J. Cell Sci. 2001, 114, 987-998.

25. Leonoudakis, D.; Conti, L.R.; Radeke, C.M.; McGuire, L.M.; Vandenberg, C.A. A multiprotein trafficking complex composed of SAP97, CASK, Veli, and Mint1 is associated with inward rectifier Kir2 potassium channels. J. Biol. Chem. 2004, 279, 19051-19063.

26. Leonoudakis, D.; Conti, L.R.; Anderson, S.; Radeke, C.M.; McGuire, L.M.; Adams, M.E.; Froehner, S.C.; Yates, J.R. $3^{\text {rd }}$; Vandenberg, C.A. Protein trafficking and anchoring complexes revealed by proteomic analysis of inward rectifier potassium channel (Kir2.x)-associated proteins. J. Biol. Chem. 2004, 279, 22331-22346.

27. Pegan, S.; Tan, J.; Huang, A.; Slesinger, P.A.; Riek, R.; Choe, S. NMR studies of interactions between C-terminal tail of Kir2.1 channel and PDZ1,2 domains of PSD95. Biochemistry 2007, 46, 5315-5322.

28. Brasko, C.; Hawkins, V.; De La Rocha, I.C.; Butt, A.M. Expression of Kir4.1 and Kir5.1 inwardly rectifying potassium channels in oligodendrocytes, the myelinating cells of the CNS. Brain Struct. Funct. 2017, 222, 41-59.

29. Tanemoto, M.; Fujita, A.; Higashi, K.; Kurachi, Y. PSD-95 mediates formation of a functional homomeric Kir5.1 channel in the brain. Neuron 2002, 34, 387-397.

30. Horio, Y.; Hibino, H.; Inanobe, A.; Yamada, M.; Ishii, M.; Tada, Y.; Satoh, E.; Hata, Y.; Takai, Y.; Kurachi, Y. Clustering and enhanced activity of an inwardly rectifying potassium channel, Kir4.1, by an 
anchoring protein, PSD-95/SAP90. J. Biol. Chem. 1997, 272, 1288512888.

31.Vaidyanathan, R.; Taffet, S.M.; Vikstrom; K.L.; Anumonwo, J.M. Regulation of cardiac inward rectifier potassium current (I(K1)) by synapse-associated protein-97. J. Biol. Chem. 2010, 285, 28000-28009.

32. Sampson, L.J.; Leyland, M.L.; Dart, C. Direct interaction between the actin-binding protein filamin-A and the inwardly rectifying potassium channel, Kir2.1. J. Biol. Chem. 2003, 278, 41988-41997.

33. Seyberth, H.W.; Weber, S.; Kömhoff, M. Bartter's and Gitelman's syndrome. Curr. Opin. Pediatr. 2017, 29, 179-186.

34. Nguyen, H.L.; Pieper, G.H.; Wilders, R. Andersen-Tawil syndrome: clinical and molecular aspects. Int. J. Cardiol. 2013, 170, 1-16.

35. Hancox, J.C.; Whittaker, D.G.; Du, C.; Stuart, A.G.; Zhang, H. Emerging therapeutic targets in the short QT syndrome. Expert Opin. Ther. Targets 2018, 22, 439-451.

36. Fialho, D.; Robert, C.G.; Emma, M. Periodic paralysis. In Handbook of clinical neurology. Elsevier, 2018; Vol. 148, pp. 505-520.

37. Masotti, A.; Uva, P.; Davis-Keppen, L.; Basel-Vanagaite, L.; Cohen, L.; Pisaneschi, E.; Celluzzi, A.; Bencivenga, P.; Fang, M.; Tian, M.; Xu, X.; Cappa, M.; Dallapiccola, B. Keppen-Lubinsky syndrome is caused by mutations in the inwardly rectifying $\mathrm{K}+$ channel encoded by KCNJ6. Am. J. Hum. Genet. 2015, 96, 295-300.

38. Horvath, G.A.; Zhao, Y.; Tarailo-Graovac, M.; Boelman, C.; Gill, H.; Shyr, C.; Lee, J.; Blydt-Hansen, I.; Drögemöller, B.I.; Moreland, J.; Ross, C.J. Gain-of-function KCNJ6 Mutation in a Severe Hyperkinetic Movement Disorder Phenotype. Neuroscience 2018, 384, 152-164.

39. Korah, H.E.; Scholl, U.I. An Update on Familial Hyperaldosteronism. Horm. Metab. Res. 2015, 47, 941-946.

40. Bohnen, M.S.; Peng, G.; Robey, S.H.; Terrenoire, C.; Iyer, V.; Sampson, K.J.; Kass, R.S. Molecular Pathophysiology of Congenital Long QT Syndrome. Physiol. Rev. 2017, 97, 89-134.

41. Abdelhadi, O.; Iancu, D.; Stanescu, H.; Kleta, R.; Bockenhauer, D. EAST syndrome: Clinical, pathophysiological, and genetic aspects of mutations in KCNJ10. Rare Dis. 2016, 4, e1195043. 
42. Nichols, C.G.; Singh, G.K.; Grange, D.K. KATP channels and cardiovascular disease: suddenly a syndrome. Circ. Res. 2013, 112, 1059-1072.

43. Tinker, A.; Aziz, Q.; Li, Y.; Specterman M. ATP-Sensitive Potassium Channels and Their Physiological and Pathophysiological Roles. Compr. Physiol. 2018, 8, 1463-1511.

44. Kumar, M.; Pattnaik, B.R. Focus on Kir7.1: physiology and channelopathy. Channels (Austin) 2014, 8, 488-495.

45. Taneja, T.K.; Mankouri, J.; Karnik, R.; Kannan, S.; Smith, A.J.; Munsey, T.; Christesen, H.B.; Beech, D.J.; Sivaprasadarao, A. Sar1-GTPasedependent ER exit of KATP channels revealed by a mutation causing congenital hyperinsulinism. Hum. Mol. Genet. 2009, 18, 2400-2413.

46. Bendahhou, S.; Donaldson, M.R.; Plaster, N.M.; Tristani-Firouzi, M.; Fu, Y.H.; Ptácek, L.J. Defective potassium channel Kir2.1 trafficking underlies Andersen-Tawil syndrome. J. Biol. Chem. 2003, 278, 5177951785.

47. Ma, D.; Tang, X.D.; Rogers, T.B.; Welling, P.A. An andersen-Tawil syndrome mutation in Kir2. 1 (V302M) alters the G-loop cytoplasmic K+ conduction pathway. J. Biol. Chem. 2007, 282, 5781-5789.

48. Peters, M.; Ermert, S.; Jeck, N.; Derst, C.; Pechmann, U.; Weber, S.; Schlingmann, K.P.; Seyberth H.W.; Waldegger S.; Konrad M. Classification and rescue of ROMK mutations underlying hyperprostaglandin E syndrome/antenatal Bartter syndrome. Kidney Int. 2003, 64, 923-932.

49. Choi, B.O.; Kim, J.; Suh, B.C.; Yu, J.S.; Sunwoo, I.N.; Kim, S.J.; Kim, G.H.; Chung, K.W. Mutations of KCNJ2 gene associated with AndersenTawil syndrome in Korean families. J. Hum. Genet. 2007, 52, 280-283.

50.Gloyn, A.L.; Pearson, E.R.; Antcliff, J.F.; Proks, P.; Bruining, G.J.; Slingerland, A.S.; Howard, N.; Srinivasan, S.; Silva, J.M.; Molnes, J.; Edghill, E.L.; Frayling, T.M.; Temple, I.K.; Mackay, D.; Shield, J.P.; Sumnik, Z.; van Rhijn, A.; Wales, J.K.; Clark, P.; Gorman, S.; Aisenberg, J.; Ellard, S.; Njølstad, P.R.; Ashcroft, F.M.; Hattersley, A.T. Activating mutations in the gene encoding the ATP-sensitive potassiumchannel subunit Kir6.2 and permanent neonatal diabetes. N. Engl. J. Med. 2004, 350, 1838-1849. 
51. Lin, Y.W.; Bushman, J.D.; Yan, F.F.; Haidar, S.; MacMullen, C.; Ganguly, A.; Stanley, C.A.; Shyng, S.L. Destabilization of ATP-sensitive potassium channel activity by novel KCNJ11 mutations identified in congenital hyperinsulinism. J. Biol. Chem. 2008, 283, 9146-9156.

52. Schulte, U.; Hahn, H.; Konrad, M.; Jeck, N.; Derst, C.; Wild, K.; Weidemann, S.; Ruppersberg, J.P.; Fakler, B.; Ludwig, J. pH gating of ROMK (K(ir)1.1) channels: control by an Arg-Lys-Arg triad disrupted in antenatal Bartter syndrome. Proc. Natl. Acad. Sci. USA. 1999, 96, 15298-15303.

53.Scholl, U.I.; Choi, M.; Liu, T.; Ramaekers, V.T.; Häusler, M.G.; Grimmer, J.; Tobe, S.W.; Farhi, A.; Nelson-Williams, C.; Lifton, R.P. Seizures, sensorineural deafness, ataxia, mental retardation, and electrolyte imbalance (SeSAME syndrome) caused by mutations in KCNJ10. Proc. Natl. Acad. Sci. USA. 2009, 106, 5842-5847.

54. Limberg, M.M.; Zumhagen, S.; Netter, M.F.; Coffey, A.J.; Grace, A.; Rogers, J.; Böckelmann, D.; Rinné, S.; Stallmeyer, B.; Decher, N.; Schulze-Bahr, E. Non dominant-negative KCNJ2 gene mutations leading to Andersen-Tawil syndrome with an isolated cardiac phenotype. Basic Res. Cardiol. 2013, 108, 353.

55. Fallen, K.; Banerjee, S.; Sheehan, J.; Addison, D.; Lewis, L.M.; Meiler, J.; Denton. J.S. The Kir channel immunoglobulin domain is essential for Kir1.1 (ROMK) thermodynamic stability, trafficking and gating. Channels (Austin) 2009, 3, 57-68.

56. O'Donnell, B.M.; Mackie, T.D.; Subramanya, A.R.; Brodsky, J.L. Endoplasmic reticulum-associated degradation of the renal potassium channel, ROMK, leads to type II Bartter syndrome. J. Biol. Chem. 2017, 292, 12813-12827.

57. Károlyi, L.; Konrad, M.; Köckerling, A.; Ziegler, A.; Zimmermann, D.K.; Roth, B.; Wieg, C.; Grzeschik, K.H.; Koch, M.C.; Seyberth, H.W.; Vargas, R.; Forestier, L.; Jean, G.; Deschaux, M.; Rizzoni, G.F.; Niaudet, P.; Antignac, C.; Feldmann, D.; Lorridon, F.; Cougoureux, E.; Laroze, F.; Alessandri, J.L.; David, L.; Saunier, P.; Deschenes, G.; Hildebrandt, F.; Vollmer, M.; Proesmans, W.; Brandis, M.; van den Heuvel, L.P.W.J.; Lemmink, H.H.; Nillesen, W.; Monnens, L.A.H.; Knoers, N.V.A.M.; GuayWoodford, L.M.; Wright, C.J.; Madrigal, G.; Hebert, S.C. Mutations in the gene encoding the inwardly-rectifying renal potassium channel, 
ROMK, cause the antenatal variant of Bartter syndrome: evidence for genetic heterogeneity. International Collaborative Study Group for Bartter-like Syndromes. Hum. Mol. Genet. 1997, 6, 17-26.

58. Fodstad, H.; Swan, H.; Auberson, M.; Gautschi, I.; Loffing, J.; Schild, L.; Kontula, K. Loss-of-function mutations of the $\mathrm{K}(+)$ channel gene KCNJ2 constitute a rare cause of long QT syndrome. J. Mol. Cell. Cardiol. 2004, 37, 593-602.

59. Davies, N.P.; Imbrici, P.; Fialho, D. ; Herd, C.; Bilsland, L.G.; Weber, A. ; Mueller, R.; Hilton-Jones, D.; Ealing, J.; Boothman, B.R.; Giunti, P.; Parsons, L.M.; Thomas, M.; Manzur, A.Y.; Jurkat-Rott, K.; LehmannHorn, F.; Chinnery, P.F.; Rose, M.; Kullmann, D.M.; Hanna, M.G. Andersen-Tawil syndrome: new potassium channel mutations and possible phenotypic variation. Neurology 2005, 65, 1083-1089.

60. Lu, C.W.; Lin, J.H.; Rajawat, Y.S.; Jerng, H.; Rami, T.G.; Sanchez, X.; DeFreitas, G.; Carabello, B.; DeMayo, F.; Kearney, D.L.; Miller, G.; Li, H. ; Pfaffinger, P.J.; Bowles, N.E.; Khoury, D.S.; Towbin, J.A. Functional and clinical characterization of a mutation in $\mathrm{KCNJ} 2$ associated with Andersen-Tawil syndrome. J. Med. Genet. 2006, 43, 653-659.

61. Eckhardt, L.L.; Farley, A.L.; Rodriguez, E.; Ruwaldt, K.; Hammill, D.; Tester, D.J.; Ackerman, M.J.; Makielski, J.C. KCNJ2 mutations in arrhythmia patients referred for LQT testing: a mutation T305A with novel effect on rectification properties. Heart Rhythm 2007, 4, 323-329.

62. Tani, Y.; Miura, D.; Kurokawa, J.; Nakamura, K.; Ouchida, M.; Shimizu, K.; Ohe, T.; Furukawa, T. T75M-KCNJ2 mutation causing AndersenTawil syndrome enhances inward rectification by changing $\mathrm{Mg}^{2+}$ sensitivity. J. Mol. Cell. Cardiol. 2007, 43, 187-196.

63. Snider, K.E.; Becker, S.; Boyajian, L.; Shyng, S.L.; MacMullen, C.; Hughes, N.; Ganapathy, K.; Bhatti, T.; Stanley, C.A.; Ganguly, A. Genotype and phenotype correlations in 417 children with congenital hyperinsulinism. J. Clin. Endocrinol. Metab. 2013, 98, 355-363.

64. Mohnike, K.; Wieland, I.; Barthlen, W.; Vogelgesang, S.; Empting, S.; Mohnike, W.; Meissner, T.; Zenker, M. Clinical and genetic evaluation of patients with KATP channel mutations from the German registry for congenital hyperinsulinism. Horm. Res. Paediatr. 2014, 81, 156-168.

65. Decher, N.; Renigunta, V.; Zuzarte, M.; Soom, M.; Heinemann, S.H.; Timothy, K.W.; Keating, M.T.; Daut, J.; Sanguinetti, M.C.; Splawski, I. 
Impaired interaction between the slide helix and the C-terminus of Kir2.1: a novel mechanism of Andersen syndrome. Cardiovasc. Res. 2007, 75, 748-757.

66. Yoon, G.; Oberoi, S.; Tristani-Firouzi, M.; Etheridge, S.P.; Quitania, L.; Kramer, J.H.; Miller, B.L.; Fu, Y.H.; Ptácek, L.J. Andersen-Tawil syndrome: prospective cohort analysis and expansion of the phenotype. Am. J. Med. Genet. A 2006, 140, 312-321.

67. Ballester, L.Y.; Benson, D.W.; Wong, B.; Law, I.H.; Mathews, K.D.; Vanoye, C.G.; George, A.L. Jr. Trafficking-competent and traffickingdefective KCNJ2 mutations in Andersen syndrome. Hum. Mutat. 2006, $27,388$.

68. Williams, D.M.; Lopes, C.M.; Rosenhouse-Dantsker, A.; Connelly, H.L.; Matavel, A.; O-Uchi, J.; McBeath, E.; Gray, D.A. Molecular basis of decreased Kir4.1 function in SeSAME/EAST syndrome. J. Am. Soc. Nephrol. 2010, 21, 2117-2129.

69. Takeda, I.; Takahashi, T.; Ueno, H.; Morino, H.; Ochi, K.; Nakamura, T.; Hosomi, N.; Kawakami, H.; Hashimoto, K.; Matsumoto, M. Autosomal recessive Andersen-Tawil syndrome with a novel mutation L94P in Kir2.1. Neurol. Clin. Neurosci. 2013, 1, 131-137.

70. Kuß, J.; Stallmeyer, B.; Goldstein, M.; Rinné, S.; Pees, C.; Zumhagen, S.; Seebohm, G.; Decher, N.; Pott, L.; Kienitz, M.C.; Schulze-Bahr, E. Familial Sinus Node Disease Caused by a Gain of GIRK (G-Protein Activated Inwardly Rectifying $\mathrm{K}+$ Channel) Channel Function. Circ. Genom. Precis. Med. 2019, 12, e002238.

71. Derst, C.; Wischmeyer, E.; Preisig-Müller, R.; Spauschus, A.; Konrad, M.; Hensen, P.; Jeck, N.; Seyberth, H.W.; Daut. J.; Karschin, A. A hyperprostaglandin $\mathrm{E}$ syndrome mutation in Kir1. 1 (renal outer medullary potassium) channels reveals a crucial residue for channel function in Kir1. 3 channels. J. Biol. Chem. 1998, 273, 23884-23891.

72. Cheng, C.J.; Sung, C.C.; Wu, S.T.; Lin, Y.C.; Sytwu, H.K.; Huang, C.L.; Lin, S.H. Novel KCNJ5 mutations in sporadic aldosterone-producing adenoma reduce Kir3.4 membrane abundance. J. Clin. Endocrinol. Metab. 2015, 100, E155-163.

73. Gélinas, R.; El Khoury, N.; Chaix, M.A.; Beauchamp, C.; Alikashani, A.; Ethier, N.; Boucher, G.; Villeneuve, L.; Robb, L.; Latour, F.; Mondesert, B.; Rivard, L.; Goyette, P.; Talajic, M.; Fiset, C.; Rioux, J.D. 
Characterization of a Human Induced Pluripotent Stem Cell-Derived Cardiomyocyte Model for the Study of Variant Pathogenicity: Validation of a KCNJ2 Mutation. Circ. Cardiovasc. Genet. 2017, 10, e001755.

74. Cheng, C.J.; Lin, S.H.; Lo, Y.F.; Yang, S.S.; Hsu, Y.J.; Cannon, S.C.; Huang, C.L. Identification and functional characterization of Kir2.6 mutations associated with non-familial hypokalemic periodic paralysis. J. Biol. Chem. 2011, 286, 27425-27435.

75. Lee, S.J.; Ren, F.; Zangerl-Plessl, E.M.; Heyman, S.; Stary-Weinzinger, A.; Yuan, P.; Nichols, C.G. Structural basis of control of inward rectifier Kir2 channel gating by bulk anionic phospholipids. J. Gen. Physiol. 2016, $148,227-237$.

76. Tanemoto, M.; Abe, T.; Uchida, S.; Kawahara, K. Mislocalization of $\mathrm{K}^{+}$ channels causes the renal salt wasting in EAST/SeSAME syndrome. FEBS Lett. 2014, 588, 899-905.

77. Pattnaik, B.R.; Tokarz, S.; Asuma, M.P.; Schroeder, T.; Sharma, A.; Mitchell, J.C.; Edwards, A.O.; Pillers, D.A. Snowflake vitreoretinal degeneration (SVD) mutation R162W provides new insights into Kir7.1 ion channel structure and function. PLoS One 2013, 8, 71744.

78. Sergouniotis, P.I.; Davidson, A.E.; Mackay, D.S.; Li, Z.; Yang, X.; Plagnol, V.; Moore, A.T.; Webster, A.R. Recessive mutations in KCNJ13, encoding an inwardly rectifying potassium channel subunit, cause leber congenital amaurosis. Am. J. Hum. Genet. 2011, 89, 183-190.

79. McDonald, S.K.; Levitz, T.S.; Valiyaveetil, F.I. A Shared Mechanism for the Folding of Voltage-Gated K+ Channels. Biochemistry 2019, 58, 1660-1671.

80. Cho, H.C.; Tsushima, R.G.; Nguyen, T.T.; Guy, H.R.; Backx, P.H. Two critical cysteine residues implicated in disulfide bond formation and proper folding of Kir2. 1. Biochemistry 2000, 39, 4649-4657.

81. Hristova, K.; Wimley, W.C. A look at arginine in membranes. J. Membr. Biol. 2011, 239, 49-56. 


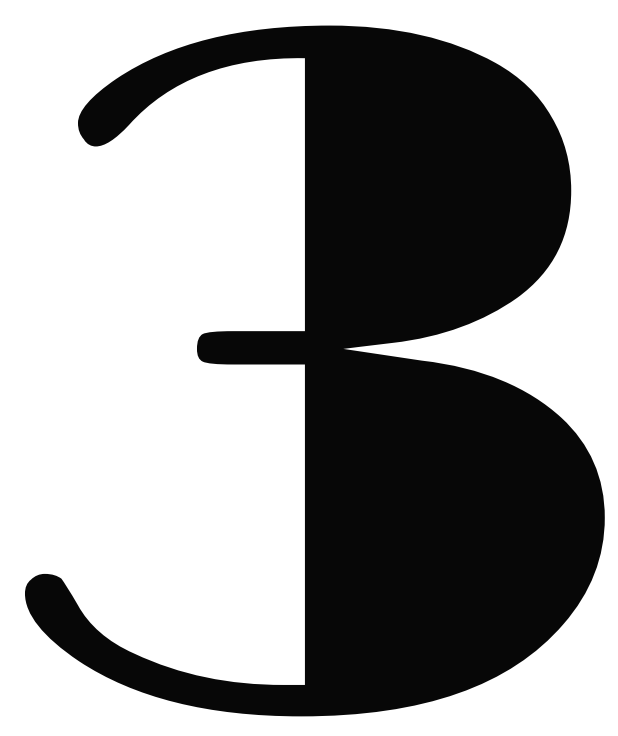


CHAPTER 3

\section{Applicability of current animal models for studying cardiac potassium channel trafficking}

Muge Qile and Marcel A. G. van der Heyden

Department of Medical Physiology, Division of Heart \& Lungs, University Medical Center Utrecht, Utrecht, The Netherlands 


\section{INTRODUCTION}

Cardiovascular diseases are affecting millions of people worldwide (Chugh et al., 2014). Arrhythmia is accounted as the main reason of sudden cardiac death. The prevalence of arrhythmias is $10 \%$ in elderly citizens (> 75 years old) (Bogle et al., 2016). Current therapy includes drug treatment, device implantation and catheter ablation (Kirchhof et al., 2016). It is difficult to investigate pathological conditions of the heart by use of cell cultures or even isolated cardiomyocytes. In vitro studies come with limitations, for example, the loss of interaction between organs. Given these limitations, it is hard to get a significant progress in therapeutics without good animal models. There can be no doubt, from a scientific point of view, that the advantages of an animal experiment far outweigh the disadvantages. However, the nature of the translational gap from animal models to clinical applications must be urgently clarified and closed. Currently, it is essential to acknowledge these substantial limitations when interpreting research outcomes. Here, in this review article, we will summarize the most common animal models in the field and evaluate its potential value in cardiac potassium channel trafficking studies.

\section{Prerequisites for ion channel trafficking studies in animal models}

Cardiac ion channel trafficking research in vivo is new. We do not consider trafficking studies in isolated cardiomyocytes, even from animals bearing mutant channels or that have been treated with trafficking affecting drugs, as a truly in vivo approach, given the potential cellular reorganization processes that likely will occur during cell isolation. While many animal models have been developed for cardiac research, including in the field of cardiac arrhythmias, trafficking studies require several additional components from the system. First, intracellular trafficking of ion channels must be visualized in the model. Two issues are apparent here. Most ion channel proteins, especially those that function at the plasma membrane, are expressed in relatively low abundance, compared to for example structural proteins or gap-junction proteins. Furthermore, the use of many, if not most of the current antibodies against ion channel proteins is hindered 
by insufficient sensitivity and/or species compatibility. These points hamper immune-based microscopy localization studies. Genetic systems may offer a solution by allowing the expression of tagged ion channels with superior antigenicity. These may even contain (fluorescent) tags that allow in vivo imaging. However, the transgenic ion channels must be compatible with the species' electrophysiological makeup. Secondly, when ex vivo analysis of subcellular ion channel expression is to be performed, tissue imaging techniques might require optimization of fixation and staining techniques to allow high resolution subcellular imaging within the tissues without prior disturbance of ion channel localization. Thirdly, drug-induced ion channel trafficking alterations are semi-acute at their best and even may require long-term drug exposure at relatively high dosages. These approaches must take (non-)cardiac toxicity in consideration.

\section{Zebrafish}

Zebrafish emerged as major genetic model based on its short life span characters. Especially its transparent properties provide us a much easier way to screen them and facilitate live imaging. The zebrafish Danio rerio with a recessive mutation, slow mo selectively disrupted $\mathrm{I}_{\mathrm{h}}$, a pacemaker current resulting in reduction of heart rate (Baker et al., 1997). A transgenic zebrafish stably expressing the human SCN5A-D1275N variant, which is a $\mathrm{Na}^{+}$channel mutation, exhibited bradycardia and atrio-ventricular conduction block (Huttner et al., 2013). Whereas this mutation provides normal expression in some ectopic expression systems, its total membrane expression in iPS cell derived cardiomyocytes is decreased, which could be reversed by treatment with a proteasome inhibitor, suggestive of a trafficking defect (Hayano et al., 2017). However, membrane preparations of the transgenic fish did not demonstrate differences in D $1275 \mathrm{~N}$ vs. WT $\mathrm{Na}_{v} 1.5$ expression (Huttner et al., 2013). Another recessive mutation, island beat, inactivated a-subunit of L-type calcium channels leading to abnormal atrium contraction, growth inhibition and electrical silence in ventricle (Rottbauer et al., 2001). KCNH2 (Kv11.1 or HERG) (ether-à-gogo-related gene) encodes the rapidly activating delayed rectifier $\mathrm{K}^{+}$channel, which has been proven to be the target of a wide range of QT-prolonging and pro-arrhythmic drugs (Towbin et al., 2001). Zebrafish expressing the orthologue of $\mathrm{K}_{\mathrm{v}} 11.1$ (Zerg) exhibited bradycardia and arrhythmia in response to several QT-prolonging drugs in a dose dependent manner, and 
the drug effects were highly specific and reproducible (Langheinrich et al., 2003) indicating that this zebrafish model can be a useful tool for cardiovascular risk assessment of drug candidates. Whether QT prolongation and arrhythmias associated with trafficking defects was not investigated in this study. Zebrafish harboring homogenous $\mathrm{KCNH} 2$ mutations (I462R, M521K) completely blocked the rapidly activating delayed rectifier $\mathrm{K}^{+}$current, $\mathrm{I}_{\mathrm{Kr}}$ and spontaneous action potential, while a human LQTS-like phenotype was observed in heterozygous mutant as prolongation of action potential and QT interval (Arnaout et al., 2007), which demonstrates the potential value of zebrafish models to study cardiac arrhythmia relevant for human disease. Whether these mutations, or their human homologues, are associated with trafficking defects in zebrafish or human is unknown.

\section{Mouse}

Since the nineties of last century, scientists started the establishment of cellular arrhythmia models with ion channel dysfunctions and inherited mutations in cultured cells via genetically expressing recombinant proteins (Splawski et al., 1997). But animal models would be unique and more beneficial to study mechanistic details and discover potential therapeutics as they are highly homologous to human and imitate cardiac electrophysiological properties, pathology, micro-environment and intra/extra-cardiac complicated interactions in patients (Wehrens et al., 2000). Compared to other mammalian models, genetic modifications in mice has been proven to be performed with relative ease and a high success rate, especially by genetically targeting at mouse embryos with CRISPR/Cas9 genome editing, which turns out to be a reproducible and time-saving method (Thomas et al., 1987; Xie et al., 2016). Besides, low cost, short breeding period, simple and safe operation as well as multiple medication methods are practical advantages of mouse models. In mouse hearts, the patterns of depolarization and repolarization are similar to those of human hearts (Liu et al., 2004). While unlike humans, the mouse has a significantly shorter interval duration and a higher heart rate because of differences in heart mass, body weight and oxygen consumption (Moreth et al., 2014). The major determinant of mouse repolarization is $I_{t o}$, whereas in humans $I_{k r}$ and $I_{k s}$ are essential to repolarization (Gussak et al., 2000; Choy et al., 2016). 
Numerous transgenic mice with $\mathrm{K}^{+}$channel alterations leading to long-QT (LQT) syndrome have been generated. A KCNQ1/- mouse model was displaying congenital QT prolongation in vivo, but not in isolated hearts (Casimiro et al., 2001). The KCNQ1 gene encodes a $\mathrm{K}^{+}$channel protein, which together with KCNE1 form the voltage-gated $\mathrm{K}^{+}$channel generating $\mathrm{I}_{\mathrm{Ks}}$ (Schroeder et al., 2000). By cloning a cardiac KCNQ1 human isoform with a very short amino-terminal and put it under the control of the amyosin heavy chain promoter to disrupt functional KCNQ1 encoding $\mathrm{K}^{+}$ channel, Demolombe et al. constructed a dominant-negative transgenic generating a phenotype of both LQT syndrome and unexpected atrioventricular block with impaired $\mathrm{I}_{\mathrm{Ks}}$ and $\mathrm{I}_{\mathrm{to}}$ (Demolombe et al., 2001). KCNE1 knockout also led to inherited QT prolongation in vivo, suggesting its effect on repolarization (Warth et al., 2002). Over-expressing LQT2-associated $\mathrm{K}_{\mathrm{v}} 11.1$ mutation (G628S) yielded a dominant-negative effect and prolonging repolarization in isolated cardiac cells but not in intact mice (Babij et al., 1998). Interestingly, the G628V mutation associates with a trafficking defect (Anderson et al., 2014). Furthermore, G628S-Kv11.1 expression in the mouse ventricular tissue was observed in perinuclear regions in many of the cardiomyocytes, unlike the endogenously expressed murine $\mathrm{K}_{\mathrm{v}} 11.1$ channel that was observed mainly at plasma membrane regions (Babij et al., 1998). In $\mathrm{K}_{\mathrm{v}} 1.4^{-/-}$mice over-expressing $\mathrm{K}_{\mathrm{v}} 4$ a subunits generated a dominant-negative signature of LQT syndrome, atrioventricular block, and tachycardia indicating the importance of $\mathrm{I}_{\text {to }}$ to cardiac repolarization (Guo et al., 2000).

\section{Rats, guinea pigs and hamsters}

The surgically and genetically modified rats are models of choice for cardiovascular research. The hypertrophic rat models by transverse aortic constriction (TAC) or by aortocaval shunt develop electrophysiological remodeling and pro-arrhythmic characteristics (Jin et al., 2010; Benes et al., 2011). Myocardial ischemia models in rats by ligating the left anterior descending coronary artery produce atrial and ventricular fibrillation (Zhang et al., 2014; Hundahl et al., 2017). Pulmonary hypertension in rats is established by injecting monocrotaline intraperitoneally leading to atrioventricular node dysfunction by downregulation of ion channels and related genes (Temple et al., 2016). Age-dependent arrhythmogenicity has 
been found in spontaneously hypertensive rats (Nguyen et al., 2016; Sayin et al., 2015).

In guinea pigs, ventricular arrythmia can be induced in the model of heart failure by descending aortic constriction (Wang et al., 2015). Remodeling of cardiac neuronal systems has been found in guinea pig models of chronic pressure overload and chronic myocardial infarction (Hardwick et al., 2012).

Hamsters are desirable experimental models as several commercial laboratory hamsters, developing inherited cardiovascular diseases by genetic modification, are available. The Syrian cardiomyopathic hamster models develop spontaneously dilated cardiomyopathy, cardiac hypertrophy and eventually heart failure due to oxidative stress, $\mathrm{Ca}^{2+}$ abnormality and electrophysiological dysfunctions (Ryoke et al., 1999; Escobales et al., 2008). The BIO-TO2 strain which is defective in $\delta$ sarcoglycan gene encoding a component of the dystrophin-associated glycoprotein complex disrupts membrane integrity, sarcoplasmic reticulum function resulting in calcium overload and contraction abnormality, and peripheral/coronary vasculature (Lipskaia et al., 2007; Escobales et al., 2008).

To which extent these models of acquired cardiac disease, including arrhythmia, demonstrate trafficking defects of cardiac potassium channels is unknown, but could be anticipated.

\section{Rabbits}

The rabbit is considered as an ideal animal model to study cardiac repolarization. The rabbit models are beneficial for in-vivo electrophysiological studies, therapeutic investigation and translational value in cardiovascular diseases as in contrast to smaller animal models (e.g. mice, rats). It is more applicable for device implantations and rabbit cardiac characteristics are more proximal to those of humans in a physiological aspect in terms of similar expression of repolarizing $\mathrm{K}^{+}$ currents ( $\mathrm{I}_{\mathrm{Kr}}$ and $\mathrm{I}_{\mathrm{Ks}}$ ) in hearts (Zicha et al., 2003), and cardiac outward current Ito (Varró et al., 1993). Furthermore, when compared to large animal models (e.g. pigs, dogs), it is more cost efficient and time-saving. 
Several rabbit models have been used for cardiovascular research. In cardiac hypertrophy models induced by transverse aortic constriction resulting in cardiac remodeling and eventually heart failure, inward $\mathrm{I}_{\mathrm{K} 1}$ current was reduced and ventricular tachycardia was attributed to $\mathrm{Ca}^{2+}$ imbalance by upregulation of $\mathrm{Na}^{+} / \mathrm{Ca}^{2+}$ exchanger (Pogwizd et al., 2001; Pogwiz et al., 1999). In another hypertrophic model generated by chronic AV block, ventricular arrhythmia like LQTs and spontaneous Torsades de Pointes was observed (Tsuji et al., 2002). A rabbit model of atrial fibrillation produced by rapid atrial stimulation, was described to induce significant atrial fibrosis (Zhao et al., 2013) and a shortening of atrial effective refractory period accompanied with increased $\mathrm{I}_{\mathrm{Ks}}$ (Jia et al., 2013). Cardiac electrophysiological remodeling associated with QT prolongation and increased vulnerability to ventricular fibrillation was induced by a hypercholesterolemia diet in rabbits (Liu et al., 2003). Transgenic rabbits expressing mutated $\mathrm{KCNQ} 1 / \mathrm{KCNH} 2$ in the heart developed LQTs, prolonged action potential duration, reduced $\mathrm{I}_{\mathrm{Kr}}$ and $\mathrm{I}_{\mathrm{Ks}}$ with a high incidence of spontaneous sudden cardiac death $(>50 \%$ at 1 year) resulting from polymorphic ventricular tachycardia (Brunner et al., 2008). One transgenic rabbit model expressed the G628S $\mathrm{K}_{\mathrm{v}} 11.1$ mutant also used in the transgenic mouse model indicated above. Apparently mature G628S- $\mathrm{K}_{\mathrm{v}} 11.1$ was present in membrane preparations obtained from the ventricle.

\section{Dogs, goats and pigs}

The dog, with ideal size of heart compared to humans, is widely used for studying circulatory physiology. The dog is used to build the CAVB model, sensitive for drug induced $\mathrm{TdP}$, to investigate basic mechanisms of cardiac arrhythmias, pro-arrhythmic co-factors and anti-arrhythmic strategies (Oros et al. 2008). However, there are much higher cost and societal acceptance issues associated with their use. Also, it is a time-consuming model and not readily applicable for gene modification.

In goats, experimental chronic atrioventricular block led to atrial enlargement, fibrillation and local conduction delays without affecting atrial refractoriness (Neuberger et al., 2005). Rapid pacing-induced AF in goats could cause changes in the mRNA expression level of $\mathrm{K}_{\mathrm{v}} 1.5$ (Velden et al., 2000). Similar findings have been shown in patients with persistent $A F$, and there are changes in mRNA level of the L-type $\mathrm{Ca}^{2+}$ channel (Brundel et al., 
1999). By implanting an aortic to left atrial shunt, the model of left atrial volume overload exhibited left atrial dilation and the majority of the animals showed prolonged $(>1 \mathrm{~h})$ or persistent ( $\geq 1$ week) atrial fibrillation with increased atrial effective refractory period (Remes et al., 2008).

In a pig model of cardiac hypertrophy induced by implantation of a bare metal stent in the descending aorta, a signature of cardiac remodeling and diastolic dysfunction with downregulation of sarcoplasmic/endoplasmic reticulum $\mathrm{Ca}^{2+}$ ATPase 2 was observed (Gyöngyösi et al., 2017), whereas surgical aortic banding did not generate abnormalities in systolic function and cardiac relaxation (Ishikawa et al., 2015). As for ischemia models in pigs, methods like microbead embolization which induces cardiac arrhythmia and complex electrophysiological remodeling (Eldar et al., 1994; Hegyi et al., 2018), and balloon occlusion of the left anterior descending coronary artery that generates ventricular fibrillation (Niemann et al., 2010) have been demonstrated. Electrical induction of cardiac fibrillation via (non-)implantable electrical devices is also a typical method in pigs, goats and sheep (Tang et al., 2006; Wijffels et al., 1995; Filgueiras-Rama et al., 2012).

\section{CONCLUSIONS}

Different animal models using a wide range of species have been established and validated in order to get better insights in human cardiac arrhythmia. Each model has its limitations however, and we need to be cautious when translating conclusions from bench to bedside. The landscape of ion channel trafficking research in vivo with the aid of animal models is almost empty. The zebrafish model that can produce transgenic models with proven in vitro trafficking defect channel proteins relative easily at low costs, might be a first choice. Especially given its promises for in vivo imaging and its "human shaped" action potential characteristics. Rabbit models might at this point be interesting in the field of acquired arrhythmia, given their electrophysiological properties, large body of knowledge from toxicology research, intervention options using human medical devices, and their potential for transgenesis. 
Applicability of animal models for $\mathrm{K}^{+}$channel trafficking study

\section{REFERENCES}

Anderson $\mathrm{CL}$, Kuzmicki CE, Childs RR, Hintz CJ, Delisle BP, January CT. Large-scale mutational analysis of Kv11. 1 reveals molecular insights into type 2 long QT syndrome. Nature communications. 2014 Nov $24 ; 5(1): 1-3$.

Arnaout R, Ferrer T, Huisken J, Spitzer K, Stainier DY, Tristani-Firouzi M, Chi NC. Zebrafish model for human long QT syndrome. Proceedings of the National Academy of Sciences. 2007 Jul 3;104(27):11316-21.

Babij P, Askew GR, Nieuwenhuijsen B, Su CM, Bridal TR, Jow B, Argentieri TM, Kulik J, DeGennaro LJ, Spinelli W, Colatsky TJ. Inhibition of cardiac delayed rectifier $\mathrm{K}+$ current by overexpression of the long-QT syndrome HERG G628S mutation in transgenic mice. Circulation research. 1998 Sep 21;83(6):668-78.

Baker K, Warren KS, Yellen G, Fishman MC. Defective "pacemaker" current (Ih) in a zebrafish mutant with a slow heart rate. Proceedings of the National Academy of Sciences. 1997 Apr 29;94(9):4554-9.

Benes Jr J, Melenovsky V, Skaroupkova P, Pospisilova J, Petrak J, Cervenka L, Sedmera D. Myocardial morphological characteristics and proarrhythmic substrate in the rat model of heart failure due to chronic volume overload. The Anatomical Record: Advances in Integrative Anatomy and Evolutionary Biology. 2011 Jan;294(1):102-11.

Bogle BM, Ning H, Mehrotra S, Goldberger JJ, Lloyd-Jones DM. Lifetime risk for sudden cardiac death in the community. Journal of the American Heart Association. 2016 Jun 29;5(7):e002398.

Brundel BJ, Van Gelder IC, Henning RH, Tuinenburg AE, Deelman LE, Tieleman RG, Grandjean JG, Van Gilst WH, Crijns HJ. Gene expression of proteins influencing the calcium homeostasis in patients with persistent and paroxysmal atrial fibrillation. Cardiovascular research. 1999 May 1;42(2):443-54. 


\section{Chapter 3}

Brunner M, Peng X, Liu GX, Ren XQ, Ziv O, Choi BR, Mathur R, Hajjiri M, Odening KE, Steinberg E, Folco EJ. Mechanisms of cardiac arrhythmias and sudden death in transgenic rabbits with long QT syndrome. The Journal of clinical investigation. 2008 Jun 2;118(6):2246-59.

Casimiro MC, Knollmann BC, Ebert SN, Vary JC, Greene AE, Franz MR, Grinberg A, Huang SP, Pfeifer K. Targeted disruption of the Kcnq1 gene produces a mouse model of Jervell and Lange-Nielsen Syndrome. Proceedings of the National Academy of Sciences. 2001 Feb $27 ; 98(5): 2526-31$.

Choy L, Yeo JM, Tse V, Chan SP, Tse G. Cardiac disease and arrhythmogenesis: mechanistic insights from mouse models. IJC heart \& vasculature. 2016 Sep 1;12:1-0.

Chugh SS, Havmoeller R, Narayanan K, Singh D, Rienstra M, Benjamin EJ, Gillum RF, Kim YH, McAnulty Jr JH, Zheng ZJ, Forouzanfar MH. Worldwide epidemiology of atrial fibrillation: a Global Burden of Disease 2010 Study. Circulation. 2014 Feb 25;129(8):837-47.

Demolombe S, Lande G, Charpentier F, van Roon MA, van den Hoff MJ, Toumaniantz G, Baro I, Guihard G, Le Berre N, Corbier A, de Bakker J. Transgenic mice overexpressing human KvLQT1 dominant-negative isoform Part I: Phenotypic characterisation. Cardiovascular research. 2001 May 1;50(2):314-27.

Eldar M, Ohad D, Bor A, VARDA-BLOOM NI, Swanson DK, Battler A. A closedchest pig model of sustained ventricular tachycardia. Pacing and Clinical Electrophysiology. 1994 Oct;17(10):1603-9.

Escobales N, Crespo MJ. Early pathophysiological alterations in experimental cardiomyopathy: the Syrian cardiomyopathic hamster. Puerto Rico health sciences journal. 2008;27(4).

Filgueiras-Rama D, Price NF, Martins RP, Yamazaki M, Avula UM, Kaur K, Kalifa J, Ennis SR, Hwang E, Devabhaktuni V, Jalife J. Long-term frequency gradients during persistent atrial fibrillation in sheep are 
associated with stable sources in the left atrium. Circulation: Arrhythmia and Electrophysiology. 2012 Dec;5(6):1160-7.

Guo W, Li H, London B, Nerbonne JM. Functional consequences of elimination of I to, $f$ and I to, s: early afterdepolarizations, atrioventricular block, and ventricular arrhythmias in mice lacking Kv1. 4 and expressing a dominant-negative Kv4 a subunit. Circulation research. $2000 \mathrm{Jul}$ 7;87(1):73-9.

Gussak I, Chaitman BR, Kopecky SL, Nerbonne JM. Rapid ventricular repolarization in rodents: electrocardiographic manifestations, molecular mechanisms, and clinical insights. Journal of electrocardiology. 2000 Apr 1;33(2):159-70.

Gyöngyösi M, Pavo N, Lukovic D, Zlabinger K, Spannbauer A, Traxler D, Goliasch G, Mandic L, Bergler-Klein J, Gugerell A, Jakab A. Porcine model of progressive cardiac hypertrophy and fibrosis with secondary postcapillary pulmonary hypertension. Journal of translational medicine. 2017 Dec;15(1):202.

Hardwick JC, Southerland EM, Girasole AE, Ryan SE, Negrotto S, Ardell JL. Remodeling of intrinsic cardiac neurons: effects of $\beta$-adrenergic receptor blockade in guinea pig models of chronic heart disease. American Journal of Physiology-Regulatory, Integrative and Comparative Physiology. 2012 Nov 1;303(9):R950-8.

Hayano M, Makiyama T, Kamakura T, Watanabe H, Sasaki K, Funakoshi S, Wuriyanghai $Y$, Nishiuchi S, Harita T, Yamamoto $Y$, Kohjitani H. Development of a patient-derived induced pluripotent stem cell model for the investigation of SCN5A-D1275N-related cardiac sodium channelopathy. Circulation Journal. 2017 Nov 24;81(12):1783-91.

Hegyi B, Bossuyt J, Griffiths LG, Shimkunas R, Coulibaly Z, Jian Z, Grimsrud KN, Sondergaard CS, Ginsburg KS, Chiamvimonvat N, Belardinelli L. Complex electrophysiological remodeling in postinfarction ischemic heart failure. Proceedings of the National Academy of Sciences. 2018 Mar 27;115(13):E3036-44. 


\section{Chapter 3}

Hundahl LA, Tfelt-Hansen J, Jespersen T. Rat models of ventricular fibrillation following acute myocardial infarction. Journal of cardiovascular pharmacology and therapeutics. 2017 Nov;22(6):51428.

Huttner IG, Trivedi G, Jacoby A, Mann SA, Vandenberg JI, Fatkin D. A transgenic zebrafish model of a human cardiac sodium channel mutation exhibits bradycardia, conduction-system abnormalities and early death. Journal of molecular and cellular cardiology. 2013 Aug $1 ; 61: 123-32$.

Ishikawa K, Aguero J, Oh JG, Hammoudi N, A. Fish L, Leonardson L, Picatoste B, Santos-Gallego CG, M. Fish K, Hajjar RJ. Increased stiffness is the major early abnormality in a pig model of severe aortic stenosis and predisposes to congestive heart failure in the absence of systolic dysfunction. Journal of the American Heart Association. 2015 May 20;4(5):e001925.

Jia X, Zheng S, Xie X, Zhang Y, Wang W, Wang Z, Zhang Y, Wang J, Gao $M$, Hou $Y$. MicroRNA-1 accelerates the shortening of atrial effective refractory period by regulating KCNE1 and KCNB2 expression: an atrial tachypacing rabbit model. PLoS One. 2013;8(12).

Jin $H$, Chemaly ER, Lee A, Kho C, Hadri L, Hajjar RJ, Akar FG. Mechanoelectrical remodeling and arrhythmias during progression of hypertrophy. The FASEB Journal. 2010 Feb;24(2):451-63.

Kirchhof P, Benussi S, Kotecha D, Ahlsson A, Atar D, Casadei B, Castella M, Diener HC, Heidbuchel H, Hendriks J, Hindricks G. 2016 ESC Guidelines for the management of atrial fibrillation developed in collaboration with EACTS. European journal of cardio-thoracic surgery. 2016 Nov $1 ; 50(5): e 1-88$.

Langheinrich $U$, Vacun G, Wagner T. Zebrafish embryos express an orthologue of HERG and are sensitive toward a range of QT-prolonging drugs inducing severe arrhythmia. Toxicology and applied pharmacology. 2003 Dec 15;193(3):370-82. 
Lipskaia L, Pinet C, Fromes Y, Hatem S, Cantaloube I, Coulombe A, Lompré AM. Mutation of $\delta$-sarcoglycan is associated with $\mathrm{Ca} 2+$-dependent vascular remodeling in the Syrian hamster. The American journal of pathology. 2007 Jul 1;171(1):162-71.

Liu G, Iden JB, Kovithavongs K, Gulamhusein R, Duff HJ, Kavanagh KM. In vivo temporal and spatial distribution of depolarization and repolarization and the illusive murine T wave. The Journal of physiology. 2004 Feb 15;555(1):267-79.

Liu YB, Wu CC, Lu LS, Su MJ, Lin CW, Lin SF, Chen LS, Fishbein MC, Chen PS, Lee YT. Sympathetic nerve sprouting, electrical remodeling, and increased vulnerability to ventricular fibrillation in hypercholesterolemic rabbits. Circulation research. 2003 May 30;92(10):1145-52.

Moreth K, Fischer R, Fuchs H, Gailus-Durner V, Wurst W, Katus HA, Bekeredjian R, de Angelis $\mathrm{MH}$. High-throughput phenotypic assessment of cardiac physiology in four commonly used inbred mouse strains. Journal of Comparative Physiology B. 2014 Aug 1;184(6):763-75.

Neuberger HR, Schotten U, Verheule S, Eijsbouts S, Blaauw Y, van Hunnik A, Allessie M. Development of a substrate of atrial fibrillation during chronic atrioventricular block in the goat. Circulation. 2005 Jan $4 ; 111(1): 30-7$.

Nguyen TP, Sovari AA, Pezhouman A, Iyer S, Cao H, Ko CY, Bapat A, Vahdani N, Ghanim M, Fishbein MC, Karagueuzian HS. Increased susceptibility of spontaneously hypertensive rats to ventricular tachyarrhythmias in early hypertension. The Journal of physiology. 2016 Mar 15;594(6):1689-707.

Niemann JT, Rosborough JP, Youngquist ST, Shah AP. Transthoracic defibrillation potential gradients in a closed chest porcine model of prolonged spontaneous and electrically induced ventricular fibrillation. Resuscitation. 2010 Apr 1;81(4):477-80. 


\section{Chapter 3}

Oros A, Beekman JD, Vos MA. The canine model with chronic, complete atrio-ventricular block. Pharmacology \& therapeutics. 2008 Aug $1 ; 119(2): 168-78$.

Pogwizd SM, Schlotthauer K, Li L, Yuan W, Bers DM. Arrhythmogenesis and contractile dysfunction in heart failure: roles of sodium-calcium exchange, inward rectifier potassium current, and residual $\beta$ adrenergic responsiveness. Circulation research. 2001 Jun 8;88(11):1159-67.

Pogwizd SM, Qi M, Yuan W, Samarel AM, Bers DM. Upregulation of $\mathrm{Na}+/ \mathrm{Ca} 2+$ exchanger expression and function in an arrhythmogenic rabbit model of heart failure. Circulation research. 1999 Nov 26;85(11):1009-19.

Remes J, van Brakel TJ, Bolotin G, Garber C, de Jong MM, van der Veen $\mathrm{FH}$, Maessen JG. Persistent atrial fibrillation in a goat model of chronic left atrial overload. The Journal of thoracic and cardiovascular surgery. 2008 Oct $1 ; 136(4): 1005-11$.

Rottbauer W, Baker K, Wo ZG, Mohideen MA, Cantiello HF, Fishman MC. Growth and function of the embryonic heart depend upon the cardiacspecific L-type calcium channel a1 subunit. Developmental cell. 2001 Aug $1 ; 1(2): 265-75$.

Ryoke T, Gu Y, Mao L, Hongo M, Clark RG, Peterson KL, Ross Jr J. Progressive cardiac dysfunction and fibrosis in the cardiomyopathic hamster and effects of growth hormone and angiotensin-converting enzyme inhibition. Circulation. 1999 Oct 19;100(16):1734-43.

Sayin H, Scridon A, Oréa V, Chapuis B, Chevalier P, Barrès C, Julien C. Pyridostigmine enhances atrial tachyarrhythmias in aging spontaneously hypertensive rats. Clinical and Experimental Pharmacology and Physiology. 2015 Oct;42(10):1084-91.

Schroeder BC, Waldegger S, Fehr S, Bleich M, Warth R, Greger R, Jentsch TJ. A constitutively open potassium channel formed by KCNQ1 and KCNE3. Nature. 2000 Jan;403(6766):196-9. 
Splawski I, Tristani-Firouzi M, Lehmann MH, Sanguinetti MC, Keating MT. Mutations in the hminK gene cause long QT syndrome and suppress I Ks function. Nature genetics. 1997 Nov;17(3):338-40.

Tang W, Snyder D, Wang J, Huang L, Chang YT, Sun S, Weil MH. One-shock versus three-shock defibrillation protocol significantly improves outcome in a porcine model of prolonged ventricular fibrillation cardiac arrest. Circulation. 2006 Jun 13;113(23):2683-9.

Temple IP, Logantha SJ, Absi M, Zhang Y, Pervolaraki E, Yanni J, Atkinson A, Petkova M, Quigley GM, Castro S, Drinkhill M. Atrioventricular node dysfunction and ion channel transcriptome in pulmonary hypertension. Circulation: Arrhythmia and Electrophysiology. 2016 Dec;9(12):e003432.

Thomas KR, Capecchi MR. Site-directed mutagenesis by gene targeting in mouse embryo-derived stem cells. Cell. 1987 Nov 6;51(3):503-12.

Towbin JA, Vatta M. Molecular biology and the prolonged QT syndromes. The American journal of medicine. 2001 Apr 1;110(5):385-98.

Tsuji Y, Opthof T, Yasui K, Inden Y, Takemura H, Niwa N, Lu Z, Lee JK, Honjo $\mathrm{H}$, Kamiya $\mathrm{K}$, Kodama I. Ionic mechanisms of acquired QT prolongation and torsades de pointes in rabbits with chronic complete atrioventricular block. Circulation. 2002 Oct 8;106(15):2012-8.

Varró A, Lathrop DA, Hester SB, Nanasi PP, Papp JG. Ionic currents and action potentials in rabbit, rat, and guinea pig ventricular myocytes. Basic research in cardiology. 1993 Mar 1;88(2):93-102.

Van der Velden HM, Van der Zee LU, Wijffels MC, Van Leuven CA, Dorland $R$, Vos MA, Jongsma $H J$, Allessie MA. Atrial fibrillation in the goat induces changes in monophasic action potential and mRNA expression of ion channels involved in repolarization. Journal of cardiovascular electrophysiology. 2000 Nov;11(11):1262-9.

Wang Y, Yuan J, Qian Z, Zhang X, Chen Y, Hou X, Zou J. $\beta 2$ adrenergic receptor activation governs cardiac repolarization and 


\section{Chapter 3}

arrhythmogenesis in a guinea pig model of heart failure. Scientific reports. 2015 Jan 8;5(1):1-7.

Warth R, Barhanin J. The multifaceted phenotype of the knockout mouse for the KCNE1 potassium channel gene. American Journal of PhysiologyRegulatory, Integrative and Comparative Physiology. 2002 Mar $1 ; 282(3):$ R639-48.

Wehrens XH, Kirchhoff S, Doevendans PA. Mouse electrocardiography: an interval of thirty years. Cardiovascular research. 2000 Jan 1;45(1):2317.

Wijffels MC, Kirchhof $\mathrm{CJ}$, Dorland R, Allessie MA. Atrial fibrillation begets atrial fibrillation: a study in awake chronically instrumented goats. Circulation. 1995 Oct 1;92(7):1954-68.

Xie C, Zhang YP, Song L, Luo J, Qi W, Hu J, Lu D, Yang Z, Zhang J, Xiao J, Zhou B. Genome editing with CRISPR/Cas9 in postnatal mice corrects PRKAG2 cardiac syndrome. Cell research. 2016 Oct;26(10):1099-111.

Zhang Y, Dedkov EI, Lee III B, Li Y, Pun K, Gerdes AM. Thyroid hormone replacement therapy attenuates atrial remodeling and reduces atrial fibrillation inducibility in a rat myocardial infarction-heart failure model. Journal of cardiac failure. 2014 Dec 1;20(12):1012-9.

Zhao Y, Gu TX, Zhang GW, Liu HG, Wang C. Losartan affects the substrate for atrial fibrillation maintenance in a rabbit model. Cardiovascular Pathology. 2013 Sep 1;22(5):383-8.

Zicha S, Moss I, Allen B, Varro A, Papp J, Dumaine R, Antzelevich C, Nattel $\mathrm{S}$. Molecular basis of species-specific expression of repolarizing $\mathrm{K}+$ currents in the heart. American Journal of Physiology-Heart and Circulatory Physiology. 2003 Oct;285(4):H1641-9. 



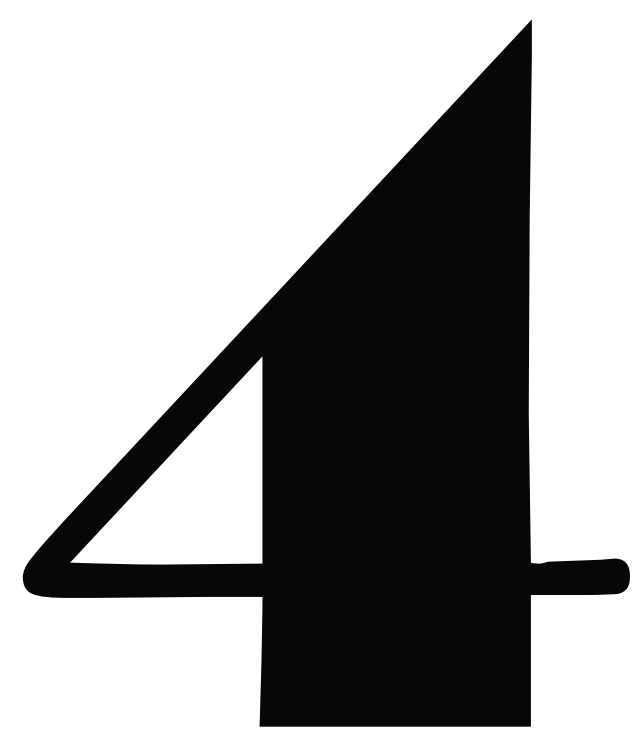




\section{CHAPTER 4}

\section{Identification of a PEST sequence in vertebrate $\mathrm{K}_{\mathrm{IR}} 2.1$ that modifies rectification}

Muge Qile, Yuan Ji, Marien J. C. Houtman, Marlieke Veldhuis, Fee Romunde, Bart Kok and Marcel A. G. van der Heyden 


\section{ABSTRACT}

$\mathrm{K}_{\mathrm{IR}} 2.1$ potassium channels, producing inward rectifier potassium current $\left(I_{K 1}\right)$, are important for final action potential repolarization and a stable resting membrane potential in excitable cells like cardiomyocytes. Abnormal $\mathrm{K}_{\mathrm{IR}} 2.1$ expression, either decreased or increased, associates with diseases such as Andersen-Tawil syndrome, long and short QT syndromes. $\mathrm{K}_{\mathrm{IR}} 2.1$ ion channel protein trafficking and subcellular anchoring depends on intrinsic specific short amino acid sequences. We hypothesized that combining an evolutionary based sequence comparison and bioinformatics will identify new functional domains within the C-terminus of the $\mathrm{K}_{\mathrm{IR}} 2.1$ protein, which function could be determined by mutation analysis. We determined PEST domain signatures, rich in proline (P), glutamic acid (E), serine ( $S$ ), and threonine ( $T$ ), within $\mathrm{K}_{\mathrm{IR}} 2.1$ sequences using the "epestfind" webtool. WT and $\triangle$ PEST KIR2.1 channels were expressed in HEK293T and COS-7 cells. Patch-clamp electrophysiology measurements were performed in the inside-out mode on excised membrane patches and whole cell mode using AxonPatch 200B amplifiers. KIR2.1 protein expression levels were determined by western blot analysis. Immunofluorescence microscopy was used to determine $\mathrm{K}_{\mathrm{IR}} 2.1$ subcellular localization. An evolutionary conserved PEST domain was identified in the C-terminus of the $\mathrm{K}_{\mathrm{IR}} 2.1$ channel protein displaying positive PEST scores in vertebrates ranging from fish to human. No similar PEST domain was detected in $\mathrm{K}_{\mathrm{IR}} 2.2, \mathrm{~K}_{\mathrm{IR}} 2.3$ and $\mathrm{K}_{\mathrm{IR}} 2.6$ proteins. Deletion of the PEST domain in California kingsnake and human $\mathrm{K}_{\mathrm{IR}} 2.1$ proteins $(\triangle \mathrm{PEST})$, did not affect plasma membrane localization. Coexpression of WT and $\triangle \mathrm{PEST} \mathrm{K}_{\mathrm{IR}} 2.1$ proteins resulted in heterotetrametric channel formation. Deletion of the PEST domain did not increase protein stability in cycloheximide assays [T $1 / 2$ from $2.64 \mathrm{~h}(\mathrm{WT})$ to $1.67 \mathrm{~h}(\triangle \mathrm{PEST})$, n.s.]. WT and $\triangle P E S T$ channels, either from human or snake, produced typical $I_{K 1}$, however, human $\triangle$ PEST channels displayed stronger intrinsic rectification. The current observations suggest that the PEST sequence of $\mathrm{K}_{\mathrm{IR}} 2.1$ is not associated with rapid protein degradation, and has a role in the rectification behavior of $I_{\mathrm{K} 1}$ channels. 


\section{INTRODUCTION}

Since its cloning in the early 1990s (Kubo et al., 1993), many domains of the $\mathrm{K}_{\mathrm{IR}} 2.1$ primary protein sequence, encoded by $K C N J 2$, have been attributed to biological function and molecular structure, but not all. KIR2.1 expression is found in a variety of excitable and non-excitable cells, like skeletal, smooth and cardiac muscle cells, neuronal cells, juxtaglomerular, and endothelial cells (De Boer et al., 2010). The resulting inward rectifying potassium current $\left(I_{\mathrm{K} 1}\right)$ is characterized by a larger inward than outward current from equal negative and positive deflections from the potassium equilibrium potential. This property allows for action potential formation in excitable cells, while providing a stable resting membrane potential in between action potentials (Van der Heyden and Jespersen, 2016). $\mathrm{K}_{\mathrm{IR}} 2.1$ carried potassium inward rectifying channels are tetramers of four $\mathrm{K}_{\mathrm{IR}} 2.1$ subunits. Other $\mathrm{K}_{\mathrm{IR}} 2 . \mathrm{x}$ isoforms may form homotetramers also, and some can combine with $\mathrm{K}_{\mathrm{IR}} 2.1$ to form heterotetramers with slightly altered conductive characteristics compared to their respective homotetramers (e.g., Preisig-Müller et al., 2002). Mutations in $\mathrm{K}_{\mathrm{IR}} 2.1$ associate with Andersen-Tawil Syndrome and congenital atrial fibrillation in patients. Therefore, more understanding of the functions of different protein domains might provide new avenues for therapeutic approaches.

Several discrete domains within the $\mathrm{K}_{\mathrm{IR}} 2.1$ sequence have been associated with certain functions, like potassium selectivity [amino acid (aa) 144-146], Endoplasmic Reticulum (ER) export (aa 374-379, Ma et al., 2001; Stockklausner et al., 2001), Golgi export (aa 44-61 and 314-322, Hofherr et al., 2005, Ma et al., 2011), a PDZ binding domain (aa 425-427, Leonoudakis et al., 2004), a Caveolin3 binding motif (aa 81-88, Vaidyanathan et al., 2018). $\mathrm{K}_{\mathrm{IR}} 2.1$ and $\mathrm{K}_{\mathrm{IR}} 2.2$ crystal structure and homology modeling provided additional 3-dimensional information and showed a $\mathrm{K}_{\mathrm{IR}} 2.1$ channel containing a transmembrane pore domain with a long intracellular pore extension formed by the so-called cytoplasmic pore domain (Pegan et al., 2005; Hanssen et al., 2011; Lee et al., 2013). Furthermore, the structures provided compelling mechanistic insights into essential residues/domains involved in rectification (Tao et al., 2009). Three amino acids (D172, E224 and E299) in the pore regions are essential for rectification, i.e., reducing outward potassium flow upon depolarization. D172 is located in the transmembrane domain and is involved in so-called 
deep pore polyamine and $\mathrm{Mg}^{2+}$ binding, whereas E224 and E299 are located in the cytoplasmic pore domain and also bind polyamines and $\mathrm{Mg}^{2+}$.

PEST domains are regions rich in proline $(P)$, glutamic acid $(E)$, aspartic acid (D), serine (S), and threonine $(T)$ confined by two positively charged amino acids, lysine $(K)$, arginine $(R)$ or histidine $(H)$. These domains were first identified in short living proteins and the PEST domain function was therefore deduced as protein instability domains (Rogers et al., 1986). Indeed, in many short living proteins, mutation of the PEST domain resulted in stabilization of the protein (Rechsteiner and Rogers, 1996). Furthermore, in a number of proteins PEST domains appeared to function as anchor site of E3 ubiquitin ligases (Xing et al., 2010, Meyer et al., 2011; Li et al., 2018) required for, but not limited to, ubiquitin dependent protein degradation. However, specific deletion of PEST domains does not always increase protein half live (Nixon et al., 1995), PEST domains were found also in many long-lived proteins and additional or alternative functions have been attributed to PEST domains, like intracellular sorting, binding of the SUMO conjugating protein Ubc9 or binding of the second plastoquinone electron acceptor (Nixon et al., 1995; Bies et al., 2002; Zhuang et al., 2012). Upon cloning and aligning of a large number of $\mathrm{K}_{\mathrm{IR}} 2.1$ protein sequences (Houtman et al., 2014) we noticed an amino acid stretch that might fulfill the criteria of a PEST domain. We hypothesized that $\mathrm{K}_{\mathrm{IR}} 2.1$ proteins contain a PEST domain in the C-terminus and set out to determine its biological function.

\section{MATERIALS AND METHODS}

\section{PEST domain identification}

Protein sequences were individually loaded in the EMBOSS program ePESTfind tool (http://emboss.bioinformatics.nl/cgi-bin/emboss/epestfind, assessed on April 6, 2018) using the standard settings.

\section{Mutations}

Human $H S \mathrm{~K}_{\mathrm{IR}} 2.1 \triangle \mathrm{PEST}$ was constructed by PCR amplification of a part of HsKCNJ2 (Jansen et al., 2008) from pGEM-T-easy using T7 forward and a specifically designed reverse primer (CAGTCATATCTCCGACTCTCGCCGTA 
AGGGCCTGGGCTCTAGAGGTACACTTGCCTGGTTGCTTGTGAGGGCAACTTC). The amplification product contained the entire human $K C N J 2$ open reading frame sequence with an in-frame deletion of the complete PEST sequence (KEEDDSENGVPESTSTDTPPDIDLH) and was cloned in pGEM-T-easy and subsequently subcloned into pcDNA4 (Life-Technologies). The similar procedure was followed for constructing California kingsnake $L g \mathrm{~K}_{\mathrm{IR}} 2.1 \triangle \mathrm{PEST}$ using $L g K C N J 2$ (Houtman et al., 2014) and the designed reverse primer (CAGAGTCATATTTCAGATTCTCGCCTTAAAGGTCTTGGTTCTA GGGGCACCCCTGCTTGGCTAAGATGGTCCATCTCTGGGCCCGCAAGGGCAACT TC) that resulted in deletion of the complete snake $\mathrm{K}_{\mathrm{IR}} 2.1$ PEST sequence (KEEEDSDNGVPESTSTDTH).

\section{Cell culture}

HEK293T and COS-7 cells were cultured in Dulbecco's Modified Eagles Medium (DMEM; Lonza, Breda, Netherlands) supplemented with $10 \%$ fetal calf serum (FCS; Sigma-Aldrich, Zwijndrecht, Netherlands), $2 \mathrm{mM}$ Lglutamine (Lonza), and $50 \mathrm{U} / \mathrm{mL}$ penicillin and $50 \mathrm{mg} / \mathrm{mL}$ streptomycin (both Lonza) at $37{ }^{\circ} \mathrm{C}$ with $5 \% \mathrm{CO}_{2}$. In time course experiments, cells for each time point were seeded on the same day, and drugs were added for the indicated time prior to harvest of all samples. For patch clamp electrophysiology, 3 days prior to measurements, HEK293T cells were grown on poly-L-lysine (Sigma-Aldrich) coated $\varnothing 12 \mathrm{~mm}$ cover slips and transfected with human $\mathrm{K}_{\mathrm{IR}} 2.1$ (WT or $\triangle \mathrm{PEST}$ ) using Lipofectamine 2000 (Invitrogen, Breda, Netherlands) according to the manufacturer's protocol. Recordings were performed $24 \mathrm{~h}$ after transfection. In western blot experiments, HEK293T cells were grown on $60 \mathrm{~mm}$ tissue culture dishes and transfected using linear PEI as described earlier (Ji et al., 2017a). In immunofluorescence microscopy experiments, COS-7 cells were grown on $\varnothing 15 \mathrm{~mm}$ coverslips, pre-coated with poly-L-lysine (Sigma-Aldrich), and transfected with $\mathrm{K}_{\mathrm{IR}} 2.1$ (WT or $\triangle \mathrm{PEST}$ ) using Lipofectamine according to the manufacturer's protocol.

\section{Drugs}

Chloroquine (Sigma, St. Louis, MO, United States, cat. No. C6628) was dissolved in sterile water at a concentration of $10 \mathrm{mM}$ and stored at $-20{ }^{\circ} \mathrm{C}$. Cyclohexamide (Sigma, cat. No. C7698) was dissolved in ethanol at a concentration of $5 \mathrm{mg} / \mathrm{mL}$, stored and aliquoted at $-20^{\circ} \mathrm{C}$ until use. 
SPM was prepared in DEPC water at a concentration of $50 \mathrm{mM}$. All drugs were diluted on the day used.

\section{Immunohistochemistry and fluorescence microscopy}

COS-7 cells were stained essentially as described earlier ( $\mathrm{Ji}$ et al., 2017a). Antibodies used were $\mathrm{K}_{\mathrm{IR}} 2.1$ (1:250; Santa Cruz Biotechnology, Heidelberg, Germany, cat. no. sc-18708), Pan-Cadherin (1:800, SigmaAldrich, St. Louis MO, United States, cat. No. C1821). Cell nuclei were stained with 4',6-diamidino-2-phenylindole (DAPI; 1:50.000; Molecular Probes, Leiden, Netherlands) during secondary antibody incubation. Secondary antibodies used were donkey anti-mouse DyLight (1:250; Jackson ImmunoResearch Laboratories Inc., West Grove, PA, United States) or donkey anti-goat Alexa Red (1:400; Jackson ImmunoResearch Laboratories Inc.). Conventional fluorescence microscopy was performed on a Nikon eclipse 80i light microscope equipped with a $40 \times$ objective (NA 0.75). Confocal images were obtained using a Zeiss Axiovert $200 \mathrm{M}$ confocal microscope (Carl Zeiss Microscopy $\mathrm{GmbH}$, Germany) equipped with a $63 \times$ water immersion objective (NA 1.2) plus 29 digital zoom. Excitation was performed with an air-cooled Argon ion laser (LASOS, RMC 7812Z, $488 \mathrm{~nm}$ ) for GFP and a HeNE (LASOS, SAN 7450A, $543 \mathrm{~nm}$ ) laser for DyLight.

\section{Western blot}

Cell lysis, western blot and subsequent analysis was performed as described earlier (Ji et al., 2017b). KIR 2.1 antibody used was identical as used for immunofluorescence microscopy. Equal protein loading was determined by Ponceau staining.

\section{Patch-clamp electrophysiology}

HEK293T cells were transfected with WT or $\triangle \mathrm{PEST} \mathrm{K}_{\mathrm{IR}} 2.1$ expression constructs together with a GFP expression construct to identify transfected cells. Inside-out patch clamp measurements on excised membrane patches were performed using an AxoPatch 200B amplifier controlled by pClamp9 software (Molecular devices, Sunnyvale, CA, United States) at $21^{\circ} \mathrm{C}$ as described before ( $\mathrm{Ji}$ et al., 2017b). To record $\mathrm{K}_{\mathrm{IR}} 2.1$ currents, inside-out patch-clamp measurements were performed using a ramp protocol ranging from -100 to $+100 \mathrm{mV}$ over $5 \mathrm{~s}$ from a holding potential of $-40 \mathrm{mV}$. Bath solution contained (in mM): $125 \mathrm{KCl}, 4$ EDTA, $2.8 \mathrm{KH}_{2} \mathrm{PO}_{4}, 7.2 \mathrm{~K}_{2} \mathrm{HPO}_{4}(\mathrm{pH}$ 
7.2 with $\mathrm{KOH})$, and pipette solution contained (mM): $145 \mathrm{KCl}, 5$ HEPES, 1 $\mathrm{CaCl}_{2}(\mathrm{pH} 7.4$ with $\mathrm{KOH})$. Excised patches were placed in close proximity of the inflow region of the perfusion chamber. Measurements were started following washout of polyamines $/ \mathrm{Mg}^{2+}$ from the channel pore, observed by the disappearance of current rectification.

Whole cell patch clamp measurements were done as described before (Houtman et al., 2012) using an AxoPatch 200B amplifier controlled by pClamp9 software at $21{ }^{\circ} \mathrm{C}$. Whole cell $\mathrm{I}_{K I R} 2.1$ measurements were performed by applying $1 \mathrm{~s}$ test pulses ranging between -120 and $+30 \mathrm{mV}$, in $10 \mathrm{mV}$ increments, from a holding potential of $-40 \mathrm{mV}$, and with series resistance compensation of at least $70 \%$. Signals were low-pass filtered at $2 \mathrm{kHz}$ and sampled at $4 \mathrm{kHz}$. Liquid junction potential (LJP) was determined with the built in "Junction Potential Calculator"application of pCLAMP. Using the current solutions, LJP was $14.7 \mathrm{mV}$. Steady state current at the end of the pulse was normalized to cell capacitance and plotted versus test potential (corrected for LJP).

\section{Statistics}

Group averages are presented as mean \pm S.E.M, unless indicated otherwise. Differences between groups were tested by (un)paired Student's t-test or two-way ANOVA followed by a post hoc Bonferroni test. Results with $P<0.05$ were considered as statistically significant. Statistically analyses were performed using Prism 6 (GraphPad, CA, United States).

\section{RESULTS}

\section{Vertebrate KIR2.1 proteins contain a conserved PEST- domain}

We aligned $31 \mathrm{~K}_{\mathrm{IR}} 2.1$ amino acid sequences covering the phyla from fish to man (Houtman et al., 2014). Least sequence identity was observed between residues 380 and 415 in the C-terminal domain. However, since we noticed that this region was enriched in proline $(P)$, glutamate $(E)$, aspartate (D), serine (S), and threonine (T) residues, a hallmark of socalled PEST domains (Rechsteiner and Rogers, 1996), individual sequences were screened according to a PEST finding algorithm using the EMBOSS 
program epestfind. With a PEST score above 5, an amino-acid sequence will be considered as a genuine PEST domain. This revealed that all 31 sequences are characterized by a potential PEST domain having scores ranging between 8.7 (rainbow trout) and 24.5 (Opossum) with an average score of 19. 4 (median 21.7) (Table 1 ). In addition, we added predicted $\mathrm{K}_{\mathrm{IR}} 2.1$ sequences of the lobe finned fish Coelacanth (XP_005992210) and of the primitive cartilaginous fish elephant shark (XP_007886827) whose sequences also contained PEST domains with a high PEST score (10.11 and 24.10 respectively) (Table 1 ). In contrast, no PEST domains were found in human $\mathrm{K}_{\mathrm{IR}} 2.2, \mathrm{~K}_{\mathrm{IR}} 2.3$ or $\mathrm{K}_{\mathrm{IR}} 2.6$ channel proteins, while $\mathrm{K}_{\mathrm{IR}} 2.4$ contains a PEST domain (residues 378-424) with a PEST score of 9.39 that starts upstream from the $\mathrm{K}_{\mathrm{IR}} 2.1$ PEST domain (Figure 1).

Table 1. PEST scores of 33 vertebrate $K_{I R} 2.1$ protein sequences

\begin{tabular}{|c|c|c|c|c|}
\hline Code & Scientific name & Common name & PEST sequence & Score \\
\hline Hs & Homo sapiens & Human & KEEDDSENGVPESTSTDTPPDIDLH & 21.76 \\
\hline $\mathrm{Pt}$ & Pan troglodytes & Chimpanzee & KEEDDSENGVPESTSTDTPPDIDLH & 21.76 \\
\hline $\mathrm{MaMu}$ & Macaca mulatta & Macaca & KEEDDSENGVPESTSTDTPPDIDLH & 21.76 \\
\hline Eq & Equus caballus & Horse & KEEDDSENGVPESTSTDTPPDIDLH & 21.76 \\
\hline $\mathrm{Bt}$ & Bos taurus & Bovine & KEEDDSENGVPESTSTDTPPDIDLH & 21.76 \\
\hline Ss & Sus scrofa & Pig & KEEDDSENGVPESTSTDTPPDIDLH & 21.76 \\
\hline $\mathrm{Cf}$ & Canis familiaris & Dog & KEEDDSENGVPESTSTDTPPDLDLH & 21.95 \\
\hline $\mathrm{Ua}$ & Ursus americanus & American Black bear & KEEDDSDNGVPESTSTDTPPDIDLH & 21.60 \\
\hline Et & Echinops telfairi & Madagascar Hedgehog & KEEDDSENGLPESTSTDTPPDMDLH & 21.71 \\
\hline Oc & Oryctolagus cuniculus & European Rabbit & KEEDDSENGVPESTSTDTPPDIDLH & 21.76 \\
\hline Ml & Myotis lucifugus & Little brown bat & KEEDDSDNGVPESTSTDTPPDLDLH & 21.78 \\
\hline Dn & Dasypus novemcinctus & Armadillo & KEEDDSENGVPESTSTDTPPDINLH & 19.18 \\
\hline $\mathrm{Mm}$ & Mus musculus & Mouse & KEEEEDSENGVPESTSTDSPPGIDLH & 21.07 \\
\hline $\mathrm{Rn}$ & Rattus norvegicus & Norwegian rat & KEEEDSENGVPESTSTDSPPGIDLH & 19.51 \\
\hline St & Spermophilus tridecemlineatus & Thirteenlined ground squirrel & KEEEDSENGVPESTSTDTPPDIDLH & 21.92 \\
\hline $\mathrm{Cp}$ & Cavia porcellus & Guinea pig & KEEDDSENGVPESTSTDTPPDIDLH & 21.76 \\
\hline $\mathrm{Dm}$ & Monodelphis domestica & Opossum & KEEDDSENGLPESTSTDTPPDIDH & 24.52 \\
\hline Oa & Ornithorhynchus anatinus & Platypus & HGVPESTSTDSPPDIDH & 15.94 \\
\hline Gg & Gallus gallus & Chicken & KEEDEIDTGVPESTSTDTH & 21.83 \\
\hline $\mathrm{Cj}$ & Coturnix japonica & Japanese quail & KEEDEIDTGVPESTSTDTH & 21.83 \\
\hline $\mathrm{Cl}$ & Columba livia & Domestic pigeon & KEEDEIDTGVPESMSTDTH & 17.21 \\
\hline $\mathrm{Tg}$ & Taeniopygia guttata & Zebra finch & KEEDEIDTGVPESMSTDTH & 17.21 \\
\hline Tse & Trachemys scripta elegans & Red-eared Slider & KEEDESDNGVPESMSTDTLPDMDH & 17.67 \\
\hline $\mathrm{Lg}$ & Lampropeltis getula californiae & California Kingsnake & KEEEDSDNGVPESTSTDTH & 24.28 \\
\hline $\mathrm{Xt}$ & Xenopus tropicalis & West-african Clawed frog & KEEEGSDNGVPDSMSTDMH & 11.36 \\
\hline $\mathrm{Bb}$ & Blicca bjoerkna & White bream & KEEGNGDSLGPGGTNTDTSSDSDH & 16.26 \\
\hline $\mathrm{Cc}$ & Cyprinus carpio & Common carp & KEEGTGDSLGPGGTNTDTSSDSDH & 18.38 \\
\hline $\operatorname{Dr}$ & Danio rerio & Zebrafish & KEEGHGDSLGPGGTNTETSSDSEH & 14.34 \\
\hline Om & Oncorhynchus mykiss & Rainbow Trout & KEETDEGNGGSVGPDVTH & 8.70 \\
\hline $\mathrm{Fr}$ & Takifugu rubripes & Pufferfish & KEDTDEGNGGSVGPDGTQTDNISENEH 13.71 & \\
\hline $\mathrm{Ol}$ & Oryzias latipes & Medaka & KEDMDEGNGSSVGPDGTQTDNISDTEH 13.55 & \\
\hline Lc & Latimeria chalumnae & Coelacanth & KEEDDSDNGVPEIMSTDMH & 10.11 \\
\hline $\mathrm{Cm}$ & Callorhinchus milii & Elephant shark & KDEEESEGGSPETVSAEAPPSTDH & 24.10 \\
\hline
\end{tabular}

PEST scores were determined with aid of the epestfind webtool at http://mobyle.pasteur.fr/cgibin/portal.py?form=epestfind 


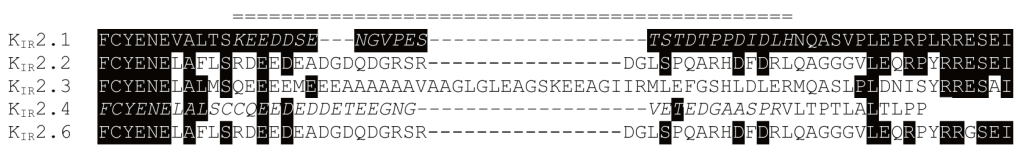

Figure 1. Amino acid alignment of C-termini of human $K_{I R} 2.1, K_{I R} 2.2$, $K_{I R} 2.3, K_{I R} 2.4$ and $K_{I R} 2.6$ encompassing the PEST domain region of $K_{I R} 2.1$ indicated by double line above the alignment. Amino acid sequences are depicted in single letter code. Identical residues with respect to $\mathrm{K}_{\mathrm{IR}} 2.1$ are depicted in white font on a black background. $\mathrm{K}_{\mathrm{IR}} 2.4$ contains a potential PEST sequence extending from 378 to 424 (KSSFPGSLTAFCYENELALSCCQEEDEDDETEEGNGVETE DGAASPR). PEST domains in $\mathrm{K}_{\mathrm{IR}} 2.1$ and $\mathrm{K}_{\mathrm{IR}} 2.4$ are indicated in italic. PEST scores are depicted at the right side of the sequences.

\section{The KIR2.1 PEST domain is not required for normal channel protein expression, subcellular localisation, response to chloroquine, or rapid protein turnover rate}

A human $\mathrm{K}_{\mathrm{IR}} 2.1$ protein lacking the complete PEST domain ( $\triangle \mathrm{PEST}$ ) was constructed to gain insight into the biological role of the PEST domain. Upon transfection in HEK293T cells, $\triangle$ PEST channel protein was detected on Western blot using an antibody against the $\mathrm{N}$-terminus having, as expected, a lower apparent Mw as compared to WT channel proteins (Figure 2A). We next addressed the subcellular localization of $\triangle$ PEST $K_{I R} 2.1$ channel proteins upon ectopic expression in COS-7 cells. Twenty-four hour following transfection of cells with either WT or $\triangle$ PEST, immunostaining was performed using the N-terminal antibody against $\mathrm{K}_{\mathrm{IR}} 2.1$. Signals was found throughout the cells, but also in membrane ruffles indicative for plasma membrane localisation (Figure 2B).

To determine the potential of heterotetramerization, we co-transfect GFP-tagged WT $\mathrm{K}_{\mathrm{IR}} 2.1$ in HEK293T with either non-tagged WT or $\triangle$ PEST encoding construct and performed co-IP with GFP antibody. We were able to co-immunoprecipitate non-tagged WT, but also $\triangle$ PEST channel proteins, as detected using the $\mathrm{N}$-terminal directed antibody for western blot (Figure 2C). Therefore, we conclude that the PEST domain is not required for interaction between $\mathrm{K}_{\mathrm{IR}} 2.1$ channel protein subunits. 
A

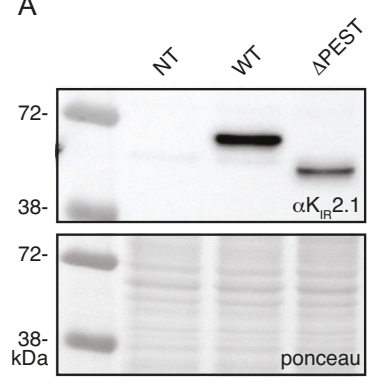

B

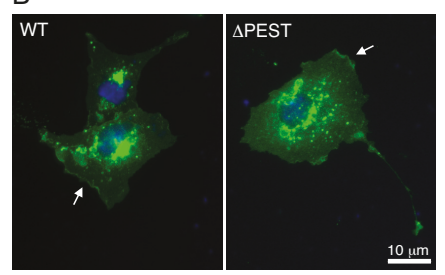

C

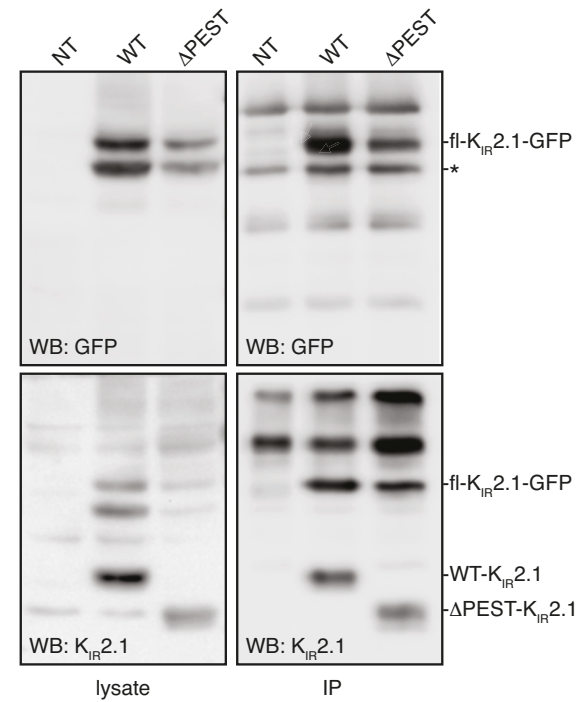

Figure 2. Expression analysis and channel formation of human WT and $\triangle$ PEST KIR2.1 protein. (A) Western blot depicting WT (approximately $50 \mathrm{kDa}$ ) and $\triangle$ PEST (approximately $47 \mathrm{kDa}$ ) K KR 2.1 proteins expressed in HEK293T cells. Non-transfected cells (NT) were used as negative control. Ponceau staining depicts loading control. (B) Subcellular localization of ectopically expressed WT and $\triangle$ PEST $\mathrm{K}_{\mathrm{IR}} 2.1$ channel proteins in COS-7 cells. Arrows indicate membrane ruffles with $\mathrm{K}_{\mathrm{IR}} 2.1$ expression. (C) HEK293T cells were co-transfected with GFP-tagged murine $\mathrm{K}_{\mathrm{IR}} 2.1$ either WT or $\triangle \mathrm{PEST} \mathrm{K}_{\mathrm{IR}} 2.1$. Non-transfected cells (NT) were used as negative control. KIR2.1-GFP was detected by GFP antibody (WB: GFP) for IP control, and N-terminal $\mathrm{K}_{\mathrm{IR}} 2.1$ antibody (WB: $\mathrm{K}_{\mathrm{IR}} 2.1$ ) was used to detect $\mathrm{K}_{\mathrm{IR}} 2.1$ GFP either WT or $\triangle \mathrm{PEST}$ non-tagged $\mathrm{K}_{\mathrm{IR}} 2.1$ protein. Positions of $\mathrm{K}_{\mathrm{IR}} 2.1-\mathrm{GFP}, \mathrm{WT}-$ $\mathrm{K}_{\mathrm{IR}} 2.1$ and $\triangle \mathrm{PEST}-\mathrm{K}_{\mathrm{IR}} 2.1$ are indicated. Lysate blots serve as immune-precipitation input control. * indicates IgG heavy chain.

$\mathrm{K}_{\mathrm{IR}} 2.1$ proteins are degraded by lysosomal degradation (Jansen et al., 2008; Varkevisser et al., 2013). Chloroquine application results in $\mathrm{K}_{\mathrm{IR}} 2.1$ accumulation upon chronic exposure (Jansen et al., 2008, Varkevisser et al., 2013). We next assessed the response of $\triangle P E S T K_{I R} 2.1$ protein to chloroquine exposure of $10 \mu \mathrm{M}$ for $24 \mathrm{~h}$ in COS-7 cells by confocal microscopy. Both WT and $\triangle \mathrm{PEST} \mathrm{K}_{\mathrm{IR}} 2.1$ proteins displayed similar responses (Figure 3). Intracellular $\mathrm{K}_{\mathrm{IR}} 2.1$ accumulation was observed in what appeared as vesicle like structures, presumably lysosomes. 


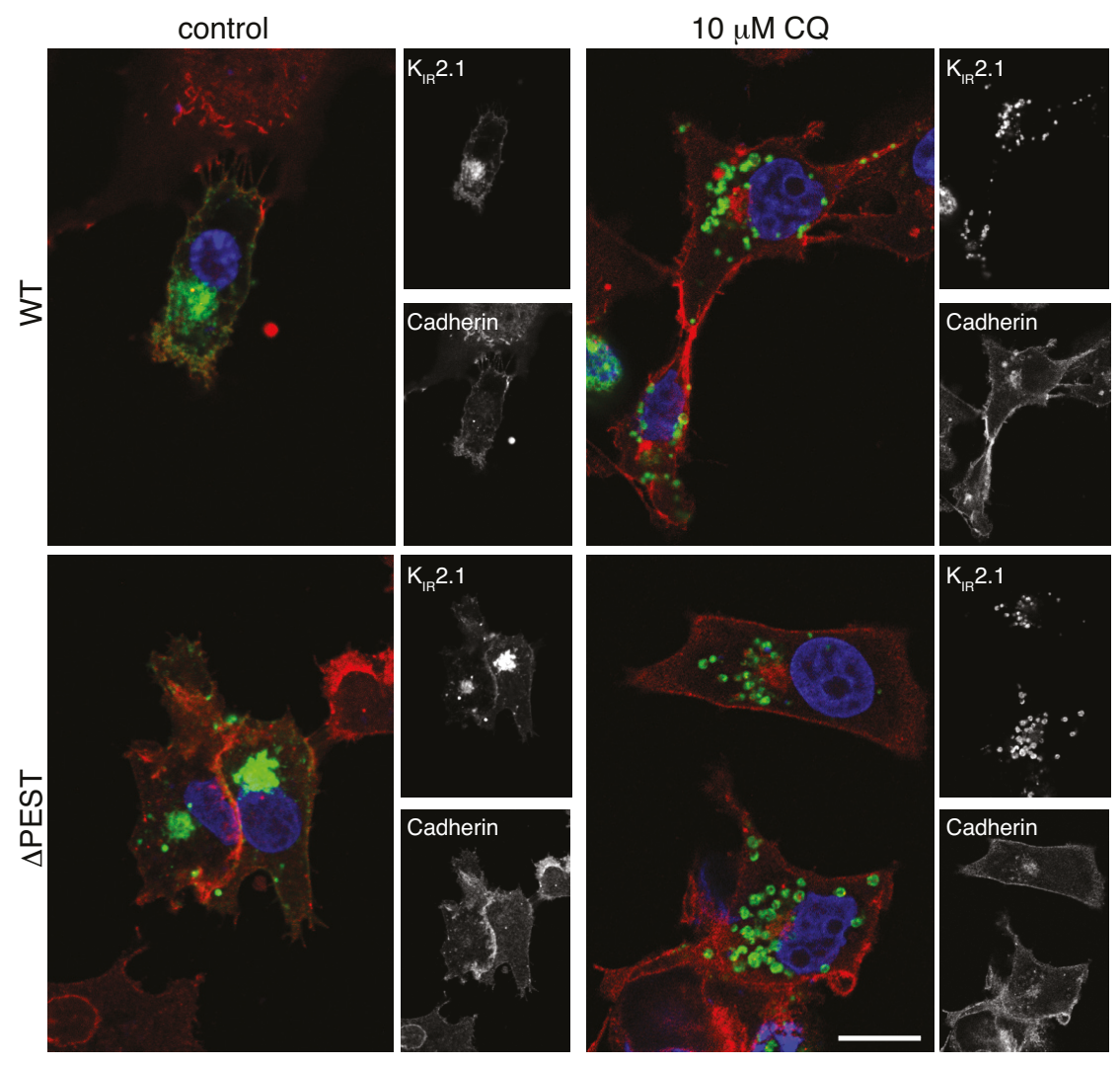

Figure 3. CQ treatment induces intracellular accumulation of WT and $\triangle P E S T K_{I R} 2.1$ in cos-7 cells. Confocal images of WT and $\triangle P E S T K_{I R} 2.1$ detected by N-terminal $\mathrm{K}_{\mathrm{IR}} 2.1$ antibody (green), and Cadherin (membrane staining) by PanCadherin antibody (red). Single staining results are depicted on the right by $b / w$ images. Scale bar indicates $10 \mu \mathrm{m}$.

PEST domains have been associated in protein turnover rate, i.e., many short-lived proteins contain a PEST domain (Sandoval et al., 2006; Belizario et al., 2008; Meyer et al., 2011). Therefore, we tested protein turnover rates in transiently transfected HEK293T cells in the presence of $200 \mu \mathrm{g} / \mathrm{mL} \mathrm{CHX}$. WT and $\triangle$ PEST proteins displayed a time-dependent decrease in expression. Following $1 \mathrm{~h}$ of $\mathrm{CHX}$ treatment, a stronger decrease in $\triangle$ PEST expression compared to WT was found, however, no significant differences were detected on later time-points neither was there a significant difference in half life ( $T 1 \frac{1}{2}$ of $2.6 \mathrm{~h}$ vs. $1.7 \mathrm{~h}$ for the WT and $\triangle P E S T$ 
$\mathrm{K}_{\mathrm{IR}} 2.1$ protein, respectively) (Figure 4). Thus, removing the PEST domain from the $\mathrm{K}_{\mathrm{IR}} 2.1$ protein does not decrease protein turnover rate.

A

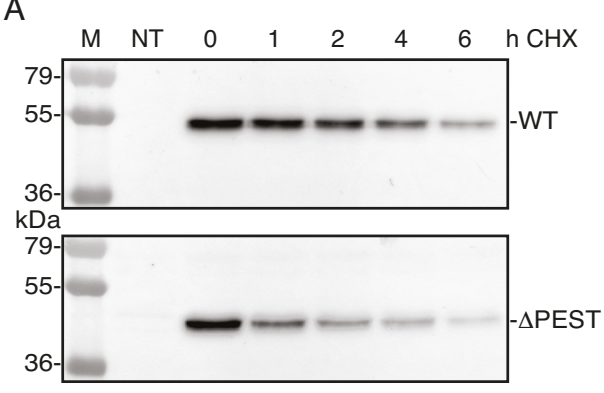

$\mathrm{B}$

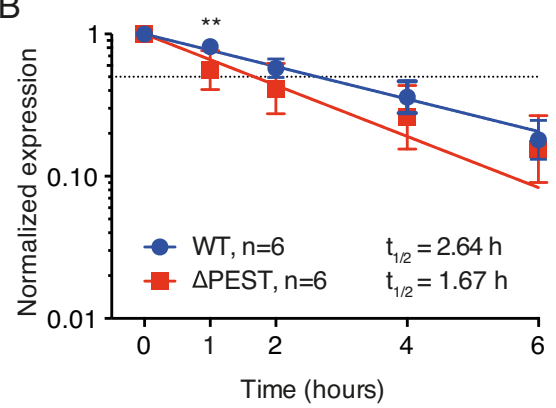

Figure 4. Cycloheximide ( $\mathrm{CHX}$ ) assay of $\mathrm{K}_{\mathrm{IR}} 2.1$ degradation in transfected HEK293T cells. (A) Example of WT and $\triangle \mathrm{PEST} \mathrm{K}_{\mathrm{IR}} 2.1$ protein degradation after exposure to $200 \mu \mathrm{g} / \mathrm{mL} \mathrm{CHX}$ for different time intervals. Non-transfected (NT) cell were used as negative control. (B) Quantification of $\mathrm{CHX}$ assays to depict normalized $\mathrm{K}_{\mathrm{IR}} 2.1$ expression vs. timed $\mathrm{CHX}$ treatment. Dotted line indicates $50 \%$ of initial normalized $\mathrm{K}_{\mathrm{IR}} 2.1$ protein signal. ${ }^{* *} P<0.01 \mathrm{WT}$ vs. $\triangle \mathrm{PEST}$.

\section{Human KIR2.1 $\triangle P E S T$ channels produce yypical inward rectifying potassium currents with enhanced rectification}

We assessed inward rectifier current formation of WT and $\triangle$ PEST channels by whole cell patch clamp electrophysiology on transiently transfected HEK293T cells. Both channel types resulted in the formation of typical inwardly rectifying potassium currents and corresponding IV curves (Figure 5A). Comparison of rectification (maximal outward current vs. maximal inward current) indicated no statistical difference in rectification between WT and $\triangle$ PEST channels in the whole cell mode (at $-60 \mathrm{mV}, 0.119$ \pm 0.022 vs. $0.085 \pm 0.014(P=0.31)$ for $\mathrm{WT}$ and $\triangle \mathrm{PEST}$, respectively) (Figure 5B).

To better assess inward rectification properties, inside-out measurements of WT and $\triangle \mathrm{PEST} \mathrm{K}_{\mathrm{IR}} 2.1$ channels were performed in the absence of polyamines and $\mathrm{Mg}^{2+}$ using a ramp protocol from -100 to +100 $\mathrm{mv}$ (Figure $5 \mathrm{C}$ ). Under baseline conditions almost straight voltage-current relationships were observed between -100 and $+50 \mathrm{mV}$. Between +50 and 
+100 mV some rectification was observed for WT channels. In contrast, $\triangle \mathrm{PEST} \mathrm{K}_{\mathrm{IR}} 2.1$ channels produced more pronounced rectification between +40 and $+100 \mathrm{mV}$ (Figure 5C). Quantification demonstrated a significantly stronger rectification (inward at $-80 \mathrm{mV}$ /outward at $+50 \mathrm{mV}$ ) for $\triangle$ PEST compared to WT $\mathrm{K}_{\mathrm{IR}} 2.1$ channels $(2.7 \pm 1.2$ vs. $1.7 \pm 0.2 ; P<0.01, n=$ 10 , mean \pm SD) (Figure 5D). Upon application of $5 \mu \mathrm{M}$ spermine, both types of channels displayed strong rectification ( $28.8 \pm 15.6$ vs. $41.7 \pm 32.6$; n.s. for $\triangle \mathrm{PEST}$ and WT currents) (Figure 5E). Finally, we observed a similar dose-dependent decrease in remaining current at $+50 \mathrm{mV}$ upon perfusion with $0.1,1$ and $5 \mu \mathrm{M}$ spermine, respectively (Fig 5F) ((WT: baseline vs. 0.1 $\mu \mathrm{M}: P<0.0001,0.1 \mu \mathrm{M}$ vs. $1 \mu \mathrm{M}$ and $5 \mu \mathrm{M}: P<0.0001,1 \mu \mathrm{M}$ vs. $5 \mu \mathrm{M}: P$ $<0.05 ; \triangle$ PEST: baseline vs. $0.1 \mu \mathrm{M}: P<0.0001,0.1 \mu \mathrm{M}$ vs. $1 \mu \mathrm{M}$ and 5 $\mu \mathrm{M}: P<0.05$ and $P<0.0001$, respectively, $1 \mu \mathrm{M}$ vs. $5 \mu \mathrm{M}$ : n.s.). The strongest decrease in current was observed upon perfusion with $0.1 \mathrm{mM}$ spermine $\left(0.26 \pm 0.05\right.$ and $0.33 \pm 0.19$ fold for WT and $\triangle \mathrm{PEST} \mathrm{K}_{\mathrm{IR}} 2.1$ current, respectively).

\section{Snake $\triangle$ PEST KIR2.1 channels}

Given the high level of conservation of the PEST domain across the vertebrate phyla, we hypothesized that enhanced rectification in $\triangle \mathrm{PEST}$ channels could also be observed in the previously cloned snake KIR 2.1 channel (Houtman et al., 2014). For this purpose, a snake $\triangle P E S T K_{I R} 2.1$ was generated similarly, as its human counterpart. Figure $6 A, B$ depicts expression of snake WT and $\triangle$ PEST channels in HEK293T cells (Figure 6A) and COS-7 cells (Figure 6B) by Western blot and immunofluorescence microscopy, respectively.

Both WT and $\triangle$ PEST channels from snake produced typical $\mathrm{K}_{\mathrm{IR}} 2.1$ currents as demonstrated by whole cell patch clamp electrophysiology (Figure 6C). When using inside-out patch clamp measurements in the absence of polyamines and $\mathrm{Mg}^{2+}$ no statistical difference in rectification index was observed $(1.9 \pm 0.4$ vs. $2.4 \pm 1.3 ; P=0.13$ for WT and PEST, respectively, mean $\pm \mathrm{SD}$ ) (Figures $6 \mathrm{D}, \mathrm{E}$ ). Distribution analysis of rectification index of each patch measured, demonstrated a larger variation 
A

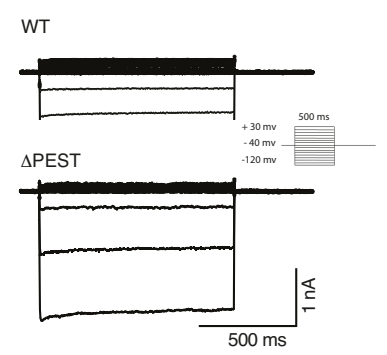

。

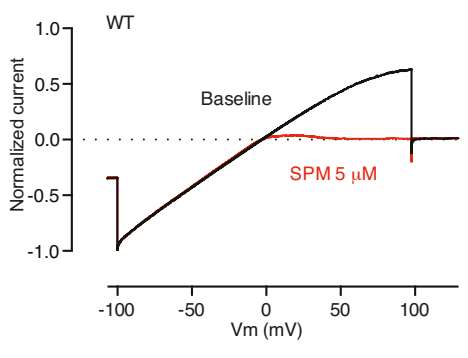

D

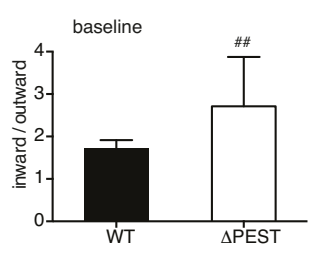

E

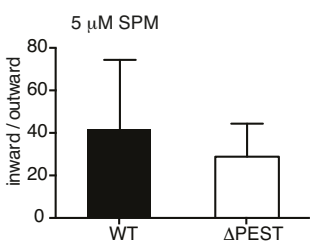

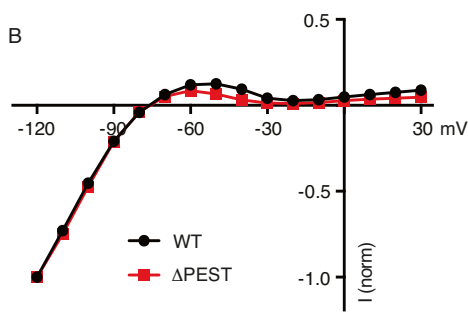

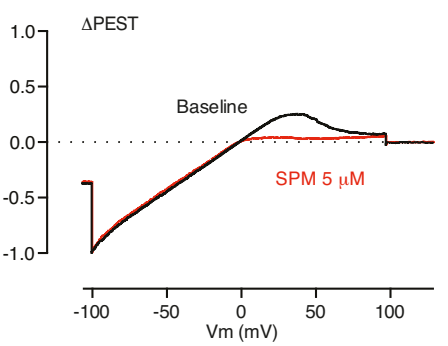

F

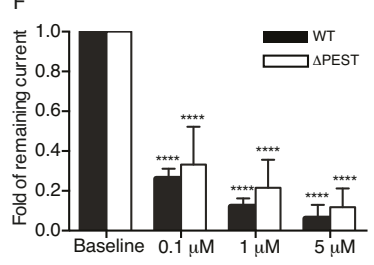

Figure 5. Electrophysiological analysis of human WT and $\triangle P E S T$ KIR 2.1 channels transiently transfected in HEK293T cells. (A) Representative current traces of WT and $\triangle$ PEST $I_{K I R 2.1}$ recorded in whole cell mode. (B) Normalized current-voltage relation curve of WT and $\triangle \mathrm{PEST} \mathrm{I}_{\text {KIR2.1 }}$ (mean $\pm \mathrm{SEM}$; WT $n=18$, $\triangle$ PEST $n=18$ ), note that error bars are smaller than symbols at each point. (C) Steady state $\mathrm{I}_{K I R 2.1}$ traces from WT and $\triangle \mathrm{PEST}$ channel containing inside-out patches elicited by a voltage ramp protocol from -100 to $+100 \mathrm{mV}$ over $5 \mathrm{~s}$, under baseline conditions (black) and upon application of $5 \mu \mathrm{M}$ spermidine (red). (D,E) Quantification of rectification index (inward current at $-80 \mathrm{mV}$ divided by outward current at $+50 \mathrm{mV}$ ) of WT and $\triangle \mathrm{PEST} \mathrm{I}_{K I R 2.1}$ from ramp protocol elicited currents in inside-out mode without ( $D$, baseline) and in the presence of $5 \mu \mathrm{M}$ spermidine (E) (mean $\pm \mathrm{SD}, \mathrm{WT} n=10, \triangle \mathrm{PEST} n=10$ ). (F) Quantification of normalized outward current (at $+50 \mathrm{mV}$ ) from WT and $\triangle$ PEST channels in inside-out patch clamp under baseline conditions and with increasing spermidine concentrations. 
${ }^{\#} P<0.01$ vs. WT; $* * * * P<0.0001$ vs. baseline (mean $\pm \mathrm{SD}, \mathrm{WT} n=10, \triangle \mathrm{PEST}$ $n=10)$.

and rightward shift in $\triangle \mathrm{PEST}$ channels compared to WT channels, although not as prominent as found for the human variants (Supplement Figure S1). As for the human channels, application of spermidine dose-dependently enhanced rectification (Figure 6E) (WT: baseline vs. $0.1 \mu \mathrm{M}$ : $P<0.05,0.1$ $\mu \mathrm{M}$ vs. $1 \mu \mathrm{M}$ and $5 \mu \mathrm{M}: P<0.05$ and $P<0.0001$, respectively, $1 \mu \mathrm{M}$ vs. 5 $\mu \mathrm{M}$ : n.s.; $\triangle \mathrm{PEST}$ : baseline vs. $0.1 \mu \mathrm{M}: P<0.05,0.1 \mu \mathrm{M}$ vs. $1 \mu \mathrm{M}$ and $5 \mu \mathrm{M}$ : $P<0.01$ and $P<0.0001$, respectively, $1 \mu \mathrm{M}$ vs. $5 \mu \mathrm{M}$ : n.s.).

\section{DISCUSSION}

In the current work we established the existence of a conserved PEST domain in the $\mathrm{C}$-terminus of the $\mathrm{K}_{\mathrm{IR}} 2.1$ potassium ion channel protein. The PEST domain is not essential for normal plasma membrane expression of $\mathrm{K}_{\mathrm{IR}} 2.1$ protein, tetramerization with wildtype channel proteins, intracellular $\mathrm{K}_{\mathrm{IR}} 2.1$ accumulation in response to chronic chloroquine treatment or rapid protein degradation. However, deletion of the PEST domain increases rectification behavior of the human $\mathrm{K}_{\mathrm{IR}} 2.1$ channels.

PEST domains are defined by a specific signature, i.e., a stretch of amino acids rich in $P, E, D, S$ and $T$ most often confined by positively charged residues on both sides, rather than by a determined sequence motif. This may explain why this domain has not been recognized in the $\mathrm{K}_{\mathrm{IR}} 2.1$ protein before. Following the identification of PEST domains, the notification of the presence of PEST domains in many short living proteins stood at the basis of the PEST hypothesis, stating that PEST domains destabilize the protein in which they are present (Rogers et al., 1986). However, the identification of PEST domains in long-living proteins did not favor the PEST hypothesis, neither did the observations that deleting a PEST domain did not necessarily increase half-life (e.g., Pakdel et al., 1993; Xiao et al., 2014). Upon ectopic expression in HEK293 cells, $\mathrm{K}_{\mathrm{IR}} 2.1$ proteins have a short halflife $(2.64 \mathrm{~h})$. Deletion of the PEST domain did not increase $T^{1} 1 / 2$ which is in contrast to the original PEST domain hypothesis as mentioned above. From these results we conclude that the PEST domain in $\mathrm{K}_{\mathrm{IR}} 2.1$ proteins does not 
promote protein instability and is not responsible for rapid protein degradation.

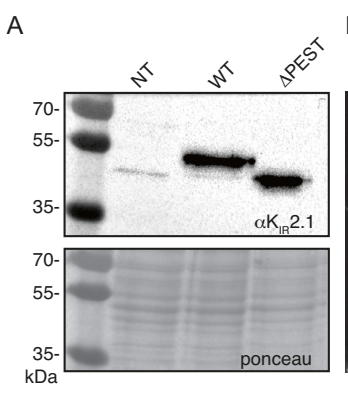

B
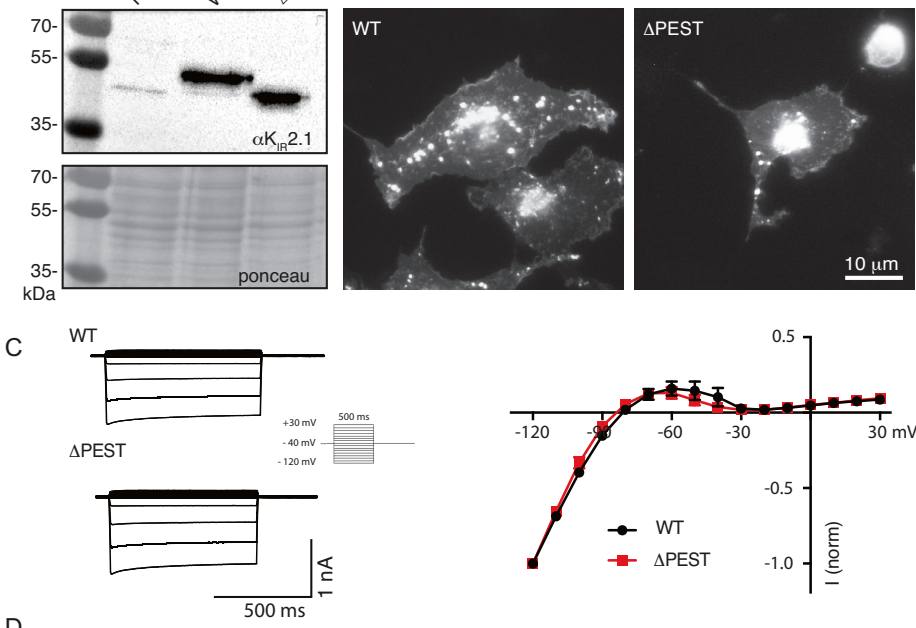

D
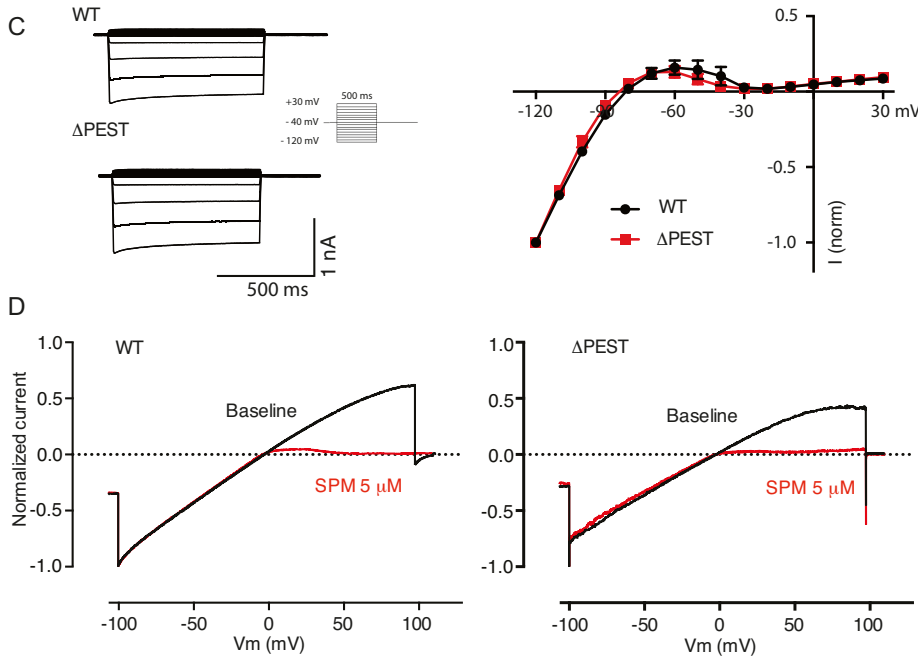

E
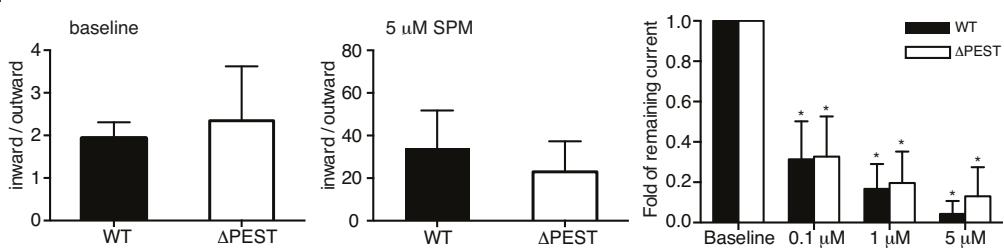

Figure 6. Expression analysis and channel formation of snake WT and $\triangle$ PEST K KR 2.1 protein and electrophysiological analysis of formed channels in transiently transfected HEK293T cells and COS-7 cells. (A) Western blot depicting WT (approximately $50 \mathrm{kDa}$ ) and $\triangle \mathrm{PEST}$ (approximately $47 \mathrm{kDa}$ ) $\mathrm{K}_{\mathrm{IR}} 2.1$ protein. Non-transfected cells (NT) were used as negative control. Ponceau staining depicts loading control. (B) Subcellular localization of ectopically expressed WT and $\triangle \mathrm{PEST} \mathrm{K}_{\mathrm{IR}} 2.1$ channel proteins in COS-7 cells. Apart from 
plasma membrane staining, intracellular aggregates are observed. (C) Representative current traces of WT and $\triangle$ PEST I IIR2.1 recorded in whole cell mode (left) and normalized current-voltage relation curves of WT and $\triangle P E S T$ I KIR2.1 $_{\text {(right) }}$

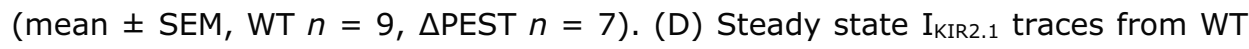
and $\triangle$ PEST channel containing inside-out patches elicited by a voltage ramp protocol from -100 to $+100 \mathrm{mV}$, under baseline conditions (black) and upon application of $5 \mu \mathrm{M}$ spermidine (red). (E) Quantification of rectification index (inward current at $-80 \mathrm{mV}$ divided by outward current at $+50 \mathrm{mV}$ ) of WT and $\triangle$ PEST I IIR2.1 from ramp protocol elicited currents in inside-out mode without (left panel) and in the presence of $5 \mu \mathrm{M}$ spermidine (middle panel) (mean \pm SD, WT $n$ $=11, \triangle$ PEST $n=24$ ). Quantification of normalized outward current (at $+50 \mathrm{mV}$ ) from WT and $\triangle$ PEST channels in inside-out patches under baseline conditions and with increasing spermidine concentrations (right panel). $* P<0.05$ vs. baseline (mean \pm SD, WT $n=10, \triangle$ PEST $n=10$ ).

The human KIR2.1 PEST domain (residues 385-409) is located between the ER export signal FCYENE (374-379) and the PDZ binding domain ESEI (425-427). Similarly, the snake $K_{I R} 2.1$ PEST (383-401) is located between ER export signal (372-377) and PDZ binding domain (422425). In crystallization studies, the last 57 residues of the mouse $\mathrm{K}_{\mathrm{IR}} 2.1$ channels were found to lack intrinsic structural rigidity, and is was suggested that this domain might require interactions with other regions of the protein and/or cytoplasmic proteins to adopt one or more defined conformations (Pegan et al., 2005). Therefore, the proline-rich PEST domain by itself might form a flexible linker domain between the two sequence conserved domains, and might allow for protein-protein interactions without affecting other structural domains of the channel. We can speculate that this would allow interaction with of the PDZ domains with a range of different proteins depending on the cell type in which the channel is expressed. If so, this will provide versatility to this channel which is expressed in many different cell types and tissues (De Boer et al., 2010). The question then remains however, why the $\mathrm{K}_{\mathrm{IR}} 2.2, \mathrm{~K}_{\mathrm{IR}} 2.3$ and $\mathrm{K}_{\mathrm{IR}} 2.6$ channel proteins do not contain a PEST domain between its ER export and PDZ domains. Furthermore, it does not explain evolutionary conservation of the PEST motif if only a flexible linker in this region of the $\mathrm{K}_{\mathrm{IR}} 2.1$ channel would serve the same purpose. On the other hand, domain linker regions may also serve an important function in the interplay between different domains (Gokhale and Khosla, 2000). 
Inward rectification in $\mathrm{K}_{\mathrm{IR}} 2.1$ channels depends on polyamines entering the channel from the cytosolic side. Enormous progress in the understanding of the mechanism has been obtained but knowledge of all mechanisms involved at the molecular level is far from complete and consensus not reached (Nichols and Lee, 2018). As rectification at strong positive potentials is stronger in $\triangle$ PEST channels than in WT using insideout patches following spermidine washout, enhanced rectification appears an intrinsic property of the PEST domain lacking channels. Nevertheless, upon spermidine application, strong rectification ensues in $\triangle$ PEST channels demonstrating that the basic mechanism of (bulk) rectification is not affected. We can only speculate on the mechanism of stronger rectification. Deletion of the PEST domain may have a charge effect on the protein that results in altered structural adaptations upon depolarization and thus induce subtle effects on rectification. Furthermore, the deletion may affect interactions with, not yet identified, cellular constituents at this site that play a role in rectification. Rectification effects in the snake $\mathrm{K}_{\mathrm{IR}} 2.1$ channel upon PEST deletion are less prominent, which might be related to the reduced length of the PEST domain in this species. However, the size of the PEST domain seems unrelated to evolutionary pathways followed. In the same phylum PEST domains have different lengths (e.g., rainbow trout, 18 residues vs. white bream, 24; California kingsnake, 19 vs. red-eared slider, 24).

A potential physiological role for the PEST domain in $\mathrm{K}_{\mathrm{IR}} 2.1$ channels awaits further work, in which in vivo models with ubiquitous expression of $\triangle$ PEST channels may provide first clues into which of the many cell types that express $\mathrm{K}_{\mathrm{IR}} 2.1$ channel proteins, the PEST domain plays a prominent role. Only then can clinical implications be envisioned. 


\section{REFERENCES}

Belizario, J. E., Alves, J., Garay-Malpartida, M., and Occhiucci, J. M. (2008). Coupling caspase cleavage and proteasomal degradation of proteins carrying PEST motif. Curr. Protein Pept. Sci. 9, 210-220. doi: $10.2174 / 138920308784534023$

Bies, J., Markus, J., and Wolff, L. (2002). Covalent attachment of the SUMO1 protein to the negative regulatory domain of the c-Myb transcription factor modifies its stability and transactivation capacity. J. Biol. Chem. 277, 8999-9009. doi: 10.1074/jbc.M110453200

De Boer, T. P., Houtman, M. J., Compier, M., and Van der Heyden, M. A. G. (2010). The mammalian $\mathrm{K}_{\mathrm{IR}} 2 \cdot \mathrm{x}$ inward rectifier ion channel family: expression pattern and pathophysiology. Acta Physiol. (Oxf). 199, 243256. doi: $10.1111 /$ j.1748-1716.2010.02108.x

Gokhale, R. S., and Khosla, C. (2000). Role of linkers in communication between protein modules. Curr. Opin. Chem. Biol. 4, 22-27. doi: 10.1016/S1367-5931(99)00046-0

Hansen, S. B., Tao, X., and Mackinnon, R. (2011). Structural basis of PIP2 activation of the classical inward rectifier $\mathrm{K}^{+}$channel Kir2.2. Nature 477, 495-8. doi: 10.1038/nature10370.

Hofherr, A., Fakler, B., and Klöcker, N. (2005). Selective Golgi export of Kir2.1 controls the stoichiometry of functional Kir2.x channel heteromers, J. Cell Sci. 118, 1935-1943. doi: 10.1242/jcs.02322

Houtman, M. J., Takanari, H., Kok, B. G., Van Eck, M., Montagne, D. R., Vos, M. A., De Boer, T. P., and Van der Heyden, M. A. G. (2012). Experimental mapping of the canine $\mathrm{KCNJ} 2$ and $\mathrm{KCNJ} 12$ gene structures and functional analysis of the canine $\mathrm{K}_{\mathrm{IR}} 2.2$ ion channel. Front. Physiol. 3, 9. doi: 10.3389/fphys.2012.00009

Houtman, M. J., Korte, S. M., Ji, Y., Kok, B., Vos, M. A., Stary-Weinzinger, A., and Van der Heyden, M. A. G. (2014). Insights in $\mathrm{K}_{\mathrm{IR}} 2.1$ channel structure and function by an evolutionary approach; cloning and 
functional characterization of the first reptilian inward rectifier channel $\mathrm{K}_{\mathrm{IR}} 2.1$, derived from the California kingsnake (Lampropeltis getula californiae). Biochem. Biophys. Res. Commun. 452, 992-997. doi: 10.1016/j.bbrc.2014.09.031

Jansen, J. A., De Boer, T. P., Wolswinkel, R., Van Veen, T. A., Vos, M. A., Van Rijen, H. V., and Van der Heyden, M. A. G. (2008). Lysosome mediated Kir2.1 breakdown directly influences inward rectifier current density. Biochem. Biophys. Res. Commun. 367, 687-692. doi: 10.1016/j.bbrc.2007.12.168

Ji, Y., Takanari, H., Qile, M., Nalos, L., Houtman, M. J. C., Romunde, F. L., Heukers, R., Van Bergen en Henegouwen, P. M. P., Vos, M. A., and Van der Heyden, M. A. G. (2017a). Class III antiarrhythmic drugs amiodarone and dronedarone impair $\mathrm{K}_{\mathrm{IR}} 2.1$ backward trafficking. J. Cell. Mol. Med. 21, 2514-2523. doi: 10.1111/jcmm.13172

Ji, Y., Veldhuis, M.G., Zandvoort, J., Romunde, F.L., Houtman, M. J. C., Duran, K., Van Haaften, G., Zangerl-Plessl, E. M., Takanari, H., StaryWeinzinger, A., and Van der Heyden, M. A. G. (2017b). PA-6 inhibits inward rectifier currents carried by V93I and D172N gain-of-function $\mathrm{K}_{\mathrm{IR}} 2.1$ channels, but increases channel protein expression. J. Biomed. Sci. 24, 44. doi: 10.1186/s12929-017-0352-x

Kubo, Y., Baldwin, T. J., Jan, Y. N., and Jan, L. Y. (1993). Primary structure and functional expression of a mouse inward rectifier potassium channel. Nature 36, 127-133. doi: 10.1038/362127a0

Lee, S. J., Wang, S., Borschel, W., Heyman, S., Gyore, J., and Nichols, C. G. (2013). Secondary anionic phospholipid binding site and gating mechanism in Kir2.1 inward rectifier channels. Nat. Commun. 4, 2786. doi: $10.1038 /$ ncomms3786

Leonoudakis, D., Conti, L. R., Radeke, C. M., McGuire, L. M., and Vandenberg, C. A. (2004). A multiprotein trafficking complex composed of SAP97, CASK, Veli, and Mint1 is associated with inward rectifier Kir2 potassium channels. J. Biol. Chem. 279, 19051-19063. doi: $10.1074 /$ jbc.M400284200 
Li, Y., Jin, K., Bunker, E., Zhang, X., Luo, X., Liu, X., and Hao, B. (2018). Structural basis of the phosphorylation-independent recognition of cyclin D1 by the SCFFBXO31 ubiquitin ligase. Proc. Natl. Acad. Sci. USA 115, 319-324. doi: 10.1073/pnas. 1708677115

Ma, D., Taneja, T. K., Hagen, B. M., Kim, B. Y., Ortega, B., Lederer, W. J., and Welling, P. A. (2011). Golgi export of the Kir2.1 channel is driven by a trafficking signal located within its tertiary structure. Cell 145, 1102-1115. doi: 10.1016/j.cell.2011.06.007

Ma, D., Zerangue, N., Lin, Y. F., Collins, A., Yu, M., Jan, Y. N., and Jan, L. Y. (2001). Role of ER export signals in controlling surface potassium channel numbers. Science 291, 316-319. doi: 10.1126/science.291.5502.316

Meyer, R. D., Srinivasan, S., Singh, A. J., Mahoney, J. E., Gharahassanlou, K. R., and Rahimi, N. (2011). PEST motif serine and tyrosine phosphorylation controls vascular endothelial growth factor receptor 2 stability and downregulation. Mol. Cell. Biol. 31, 2010-2025. doi: 10.1128/MCB.01006-10

Nichols, C. G., and Lee, S. J. (2018). Polyamines and potassium channels: A 25-year romance. J. Biol. Chem. 293, 18779-18788. doi: 10.1074/jbc.TM118.003344

Nixon, P. J., Komenda, J., Barber, J., Deak, Z., Vass, I., and Diner, B. A. (1995). Deletion of the PEST-like region of photosystem two modifies the QB-binding pocket but does not prevent rapid turnover of D1. J. Biol. Chem. 270, 14919-14927. doi: 10.1074/jbc.270.25.14919

Pakdel, F., Le Goff, P., and Katzenellenbogen, B. S. (1993). An assessment of the role of domain $\mathrm{F}$ and PEST sequences in estrogen receptor halflife and bioactivity. J. Steroid Biochem. Mol. Biol. 46, 663-672. doi: 10.1016/0960-0760(93)90307-I

Pegan, S., Arrabit, C., Zhou, W., Kwiatkowski, W., Collins, A., Slesinger, P. A., and Choe, S. (2005). Cytoplasmic domain structures of Kir2.1 and 


\section{Chapter 4}

Kir3.1 show sites for modulating gating and rectification. Nat. Neurosci. 8, 279-287. DOI: $10.1038 / \mathrm{nn} 1411$

Preisig-Müller, R., Schlichthörl, G., George, T., Heinen, S., Brüggemann, A., Rajan, S., Derst, C., Veh, R. W., and Daut, J. (2002). Heteromerization of Kir2.x potassium channels contributes to the phenotype of Andersen's syndrome. Proc. Natl. Acad. Sci. USA 99, 7774-7779. doi: 10.1073/pnas. 102609499

Qile, M., Ji, Y., Houtman, M. J. C., Romunde, F., Veldhuis, M., Kok, B., Vos, M. A., and Van der Heyden, M. A. G. (2017). P1077 Identification of a PEST domain in the inward rectifier channel $\mathrm{K}_{\mathrm{IR}} 2.1$ involved in protein stability. EP. Europace 19, Suppl. 3, iii238 (abstract). doi: 10.1093/ehjci/eux150

Rechsteiner, M., and Rogers, S. W. (1996). PEST sequences and regulation by proteolysis. Trends Biochem. Sci. 21, 267-271. doi: 10.1016/S0968-0004(96)10031-1

Rogers, S., Wells, R., and Rechsteiner, M. (1986). Amino acid sequences common to rapidly degraded proteins: The PEST hypothesis. Science 234, 364-368. doi: 10.1126/science. 2876518

Sandoval, A., Oviedo, N., Tadmouri, A., Avila, T., De Waard, M., and Felix, R. (2006). Two PEST-like motifs regulate $\mathrm{Ca}^{2+} /$ calpain-mediated cleavage of the Cavbeta3 subunit and provide important determinants for neuronal $\mathrm{Ca}^{2+}$ channel activity. Eur. J. Neurosci. 23, 2311-2320. doi: $10.1111 / j .1460-9568.2006 .04749 . x$

Stockklausner, C., Ludwig, J., Ruppersberg, J. P., and Klöcker, N. (2001). A sequence motif responsible for ER export and surface expression of Kir2.0 inward rectifier $\mathrm{K}^{+}$channels,. FEBS Lett. 493, 129-133. doi: 10.1016/S0014-5793(01)02286-4

Tao, X., Avalos, J. L., Chen, J., and MacKinnon, R. (2009). Crystal structure of the eukaryotic strong inward-rectifier $\mathrm{K}^{+}$channel Kir2.2 at $3.1 \mathrm{~A}$ resolution. Science 326, 1668-1674. doi: 10.1126/science. 1180310 
Vaidyanathan, R., Van Ert, H., Haq, K. T., Morotti, S., Esch, S., McCune, E. C., Grandi, E., and Eckhardt, L. L. (2018). Inward rectifier potassium channels (Kir2.x) and caveolin-3 domain-specific interaction: implications for Purkinje cell-dependent ventricular arrhythmias. Circ. Arrhythm. Electrophysiol. 11, e005800. doi: 10.1161/CIRCEP.117.005800

Van der Heyden, M. A. G., and Jespersen, T. (2016). Pharmacological exploration of the resting membrane potential reserve: Impact on atrial fibrillation. Eur. J. Pharmacol. 771, 56-64. doi: 10.1016/j.ejphar.2015.11.026

Varkevisser, R., Houtman, M. J., Waasdorp, M., Man, J. C., Heukers, R., Takanari, H., Tieland, R. G., Van Bergen en Henegouwen, P. M. P., Vos, M. A., and Van der Heyden, M. A. G. (2013). Inhibiting the clathrinmediated endocytosis pathway rescues $\mathrm{K}_{\mathrm{IR}} 2.1$ downregulation by pentamidine. Pflugers Arch. 465, 247-259. doi: 10.1007/s00424-0121189-5

Xiao, K., Chen, P., and Chang, D.C. (2014). The VTLISFG motif in the BH1 domain plays a significant role in regulating the degradation of $\mathrm{Mcl}-1$. FEBS Open Bio. 4, 147-152. doi: 10.1016/j.fob.2014.01.006

Xing, H., Hong, Y., and Sarge, K. D. (2010). PEST sequences mediate heat shock factor 2 turnover by interacting with the Cul3 subunit of the Cul3-RING ubiquitin ligase. Cell Stress Chaperones 15, 301-308. doi: 10.1007/s12192-009-0144-7.

Zhuang, X., Northup, J. K., and Ray, K. (2012). Large putative PEST-like sequence motif at the carboxyl tail of human calcium receptor directs lysosomal degradation and regulates cell surface receptor level. J. Biol. Chem. 287, 4165-4176. doi: 10.1074/jbc.M111.271528. 


\section{SUPPLEMENTARY MATERIAL}

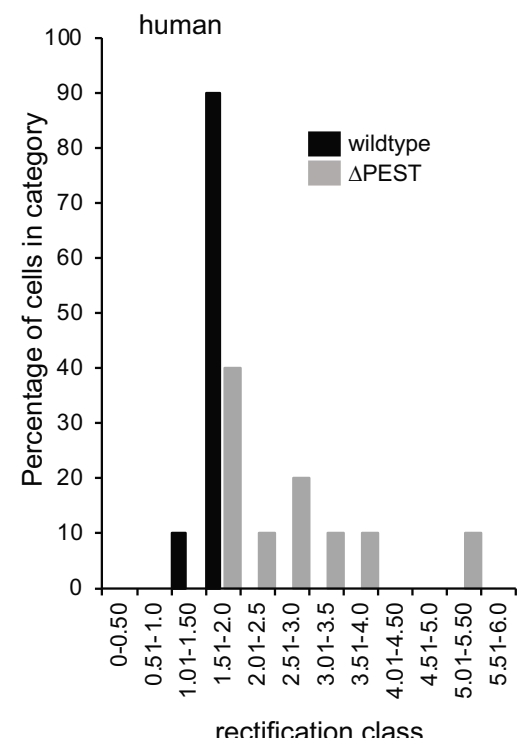

rectification class

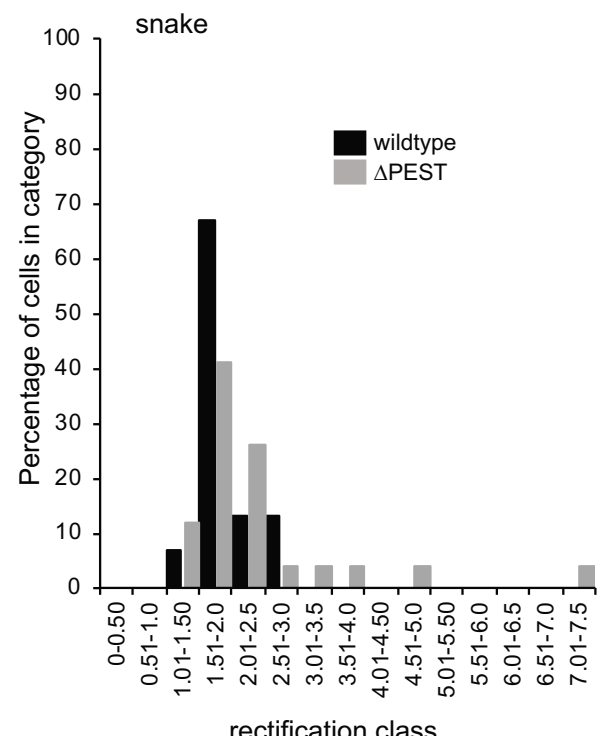

rectification class

Figure S1. Distribution analysis of rectification classes of individual cell patches from human (left panel) and snake (right panel) WT and $\triangle$ PEST channel currents measured in the inside-out mode. Rectification indexes (inward current at $-80 \mathrm{mV}$ divided by outward current at $+50 \mathrm{mV}$ ) from individual measurements were categorized in fifteen equal discrete classes from 0.0 to 8.0. The percentage of cell patches belonging to an individual class (all patches $=100 \%$ ) are indicated on the $y$-axis. Whereas in most cell inside-out patches containing human WT $\mathrm{K}_{\mathrm{IR}} 2.1$, rectification indexes were found to be between 1.0 and 2.0, all human $\triangle \mathrm{PEST}$ patches displayed rectification indexes of 1.5 and higher. In snake $\mathrm{K}_{\mathrm{IR}} 2.1 \mathrm{WT}$ and $\triangle \mathrm{PEST}$ patches, the distribution of rectification classes displayed more overlap. Distribution analysis quantified from measurements depicted as mean values in Figures 5D,E and 6E. 



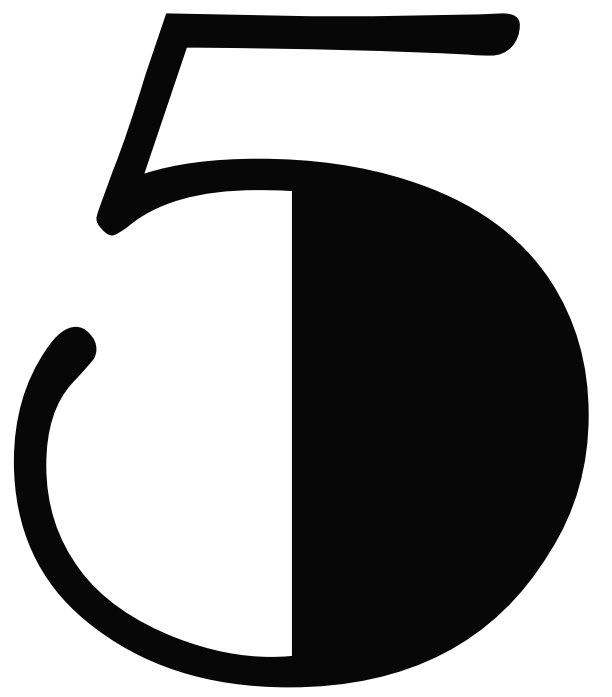




\section{LUF7244, an allosteric modulator/activator of $K_{v} 11.1$ channels, counteracts dofetilide- induced torsades de pointes arrhythmia in the chronic atrioventricular block dog model}

Muge Qile ${ }^{1}$, Henriette D.M. Beekman ${ }^{1}$, David J. Sprenkeler ${ }^{1}$, Marien J.C. Houtman ${ }^{1}$, Willem B. van Ham ${ }^{1,2}$, Anna StaryWeinzinger ${ }^{2}$, Stanislav Beyl ${ }^{2}$, Steffen Hering ${ }^{2}$, Dirk-Jan van den Berg ${ }^{3}$, Elizabeth C.M. de Lange $^{3}$, Laura H. Heitman ${ }^{4}$, Ad P. IJzerman ${ }^{4}$, Marc A. $\operatorname{Vos}^{1}$, Marcel A.G. van der Heyden ${ }^{1}$

${ }^{1}$ Department of Medical Physiology, Division of Heart \& Lungs, University Medical Center Utrecht, Utrecht, The Netherlands 2 Department of Pharmacology and Toxicology, University of Vienna, Vienna, Austria

${ }^{3}$ Division of Systems Biomedicine and Pharmacology, Leiden Academic Centre for Drug Research, Leiden University, Leiden, The Netherlands

${ }^{4}$ Division of Drug Discovery and Safety, Leiden Academic Centre for Drug Research, Leiden University, Leiden, The Netherlands 


\section{ABSTRACT}

Background and Purpose: $K_{v} 11.1$ (hERG) channel blockade is an adverse effect of many drugs and lead compounds, associated with lethal cardiac arrhythmias. LUF7244 is a negative allosteric modulator/activator of $\mathrm{K}_{\mathrm{v}} 11.1$ channels that inhibits early afterdepolarizations in vitro. We tested LUF7244 for anti-arrhythmic efficacy and potential proarrhythmia in a dog model.

Experimental Approach: LUF7244 was tested in vitro for a) increasing human $\mathrm{I}_{\mathrm{Kv} 11.1}$ and canine $\mathrm{I}_{\mathrm{Kr}}$ and $\mathrm{b}$ ) decreasing dofetilide-induced action potential lengthening and early afterdepolarizations in cardiomyocytes derived from human induced pluripotent stem cells and canine isolated ventricular cardiomyocytes. In vivo, LUF7244 was given intravenously to anaesthetized dogs in sinus rhythm with chronic atrioventricular block.

Key Results: LUF7244 (0.5-10 $\mu \mathrm{M})$ concentration dependently increased

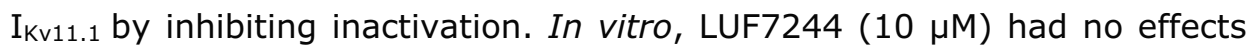
on $\mathrm{I}_{\mathrm{KIR} 2.1}, \mathrm{I}_{\mathrm{Nav1.5}}$, $\mathrm{I}_{\mathrm{Ca}-\mathrm{L}}$, and $\mathrm{I}_{\mathrm{Ks}}$, doubled $\mathrm{I}_{\mathrm{Kr}}$, shortened human and canine action potential duration by approximately $50 \%$, and inhibited dofetilideinduced early afterdepolarizations. LUF7244 $\left(2.5 \mathrm{mg} \cdot \mathrm{kg}^{-1} .15 \mathrm{~min}^{-1}\right)$ in dogs with sinus rhythm was not proarrhythmic and shortened, non-significantly, repolarization parameters (QTc: $-6.8 \%$ ). In dogs with chronic atrioventricular block, LUF7244 prevented dofetilide-induced torsades de pointes arrhythmias in 5/7 animals without normalization of the QTC. Peak LUF7244 plasma levels were $1.75 \pm 0.80$ during sinus rhythm and $2.34 \pm$ $1.57 \mu \mathrm{M}$ after chronic atrioventricular block.

Conclusions and Implications: LUF7244 counteracted dofetilide-induced early afterdepolarizations in vitro and torsades de pointes in vivo. Allosteric modulators/activators of $\mathrm{K}_{\mathrm{v}} 11.1$ might neutralize adverse cardiac effects of existing drugs and newly developed compounds that display QTC lengthening. 


\section{INTRODUCTION}

Drug-induced torsades de pointes (TdP) can degenerate into ventricular fibrillation and sudden cardiac death. This toxicity generated strict regulations that limited the use of several existing, otherwise efficient drugs, along with difficulties in the development of new drugs (Salvi, Karnad, Panicker, \& Kothari, 2010). The structural characteristics of the $K_{v} 11.1$ (human ether-a-go-go-related gene [hERG]) channel, responsible for the delayed rectifier $\mathrm{K}^{+}$current $\mathrm{I}_{\mathrm{Kr}}$, make it a common target for a variety of drugs which frequently results in unintended cardiac side effects, such as the TdP arrhythmias (Perry, Sanguinetti, \& Mitcheson, 2010; Sanguinetti \& Tristani-Firouzi, 2006). Blockade of the $\mathrm{I}_{\mathrm{kr}}$ prolongs action potential duration (APD), which is manifested as a lengthening of the QT interval on the ECG. This effect is considered as a surrogate marker of cardiotoxicity and for this reason incorporated in regulatory agency guidelines (i.e., ICHS7B, ICH-E14, and EMEA). Many drugs, although effective for their intended application, have been withdrawn from the market, such as astemizole and cisapride or are restricted in their use, such as terfenadine and haloperidol, due to observed QT prolongation and/or the induction of TdP (Darpö, 2001). Furthermore, the current, stringent preclinical guidelines have stopped the development of promising drug candidates, beause they block $I_{\mathrm{Kr}}$ and/or lengthen QT interval. Therefore, initiatives to develop effective agents to counteract those side effects of (preclinical) drugs are ongoing (Grunnet, Hansen, \& Olesen, 2008) and their efficacy and safety in vivo needs to be established.

Allosteric modulators are a class of ligands that bind to an allosteric site and thereby modulate the binding of an orthosteric ligand on the receptor. Compared with a normal, competitively binding agent, allosteric modulators tend to display higher subtype selectivity and a ceiling effect (Conn, Christopoulos, \& Lindsley, 2009). Negative allosteric modulators for $\mathrm{K}_{\mathrm{v}} 11.1$ channels would reduce affinity of the ion channel for its inhibitors and counteract drug-induced blockade. Recently, LUF7244, one out of a series of novel negative allosteric modulators of $\mathrm{K}_{\mathrm{v}} 11.1$ channels, was synthetized, and some of its functional properties were analysed (Yu, Klaasse, Heitman, \& IJzerman, 2014). LUF7244 might be able to prevent cardiac proarrhythmias due to $I_{k r}$ blockade in vivo because it (a) decreased the affinity of the $K_{v} 11.1$ channel blockers cisapride, astemizole, dofetilide, 


\section{Chapter 5}

and sertindole for binding to these channels and (b) induced APD shortening in neonatal rat ventricular myocytes and inhibited early afterdepolarization (EAD) formation following astemizole exposure (Yu et al., 2016).

Ikr has an important role in cardiac repolarization in the dog. Specific blockade of the current carried by Kv11.1 channels results in a marked increase in QTc (see Opstal, Leunissen, Wellens, \& Vos, 2001; Schneider, Hauser, Andreas, Linz, \& Jahnel, 2005). In the chronic atrioventricular block (CAVB) dog model, repolarization is further compromised (Schoenmakers et al., 2003) resulting in high propensity for ventricular arrhythmias upon pharmacological blockade of $\mathrm{I}_{\mathrm{kr}}$ (Oros, Beekman, \& Vos, 2008). These characteristics makes the CAVB dog model appropriate for defining potential anti-arrhythmic properties of newly developed pharmacological agents (Bossu et al., 2018), which might apply to negative allosteric modulators of $\mathrm{K}_{\mathrm{v}} 11.1$ channels as well.

The research described here aimed (a) to use relevant cellular models (i.e., cardiomyocytes derived from human induced pluripotent stem cells (hiPSC) and ventricular cardiomyocytes, isolated from dogs) in which $\mathrm{K}_{\mathrm{v}} 11.1$ channels make an important contribution to APD and, therewith, study the effects of LUF7244 application on human-(like) cellular electrophysiology and (b) to determine anti-arrhythmic capacities of LUF7244 administration in CAVB dogs against dofetilide-induced TdP arrhythmias.

\section{METHODS}

\section{In vitro studies}

Cell culture

For determining the effects of LUF7244 on $\mathrm{I}_{\mathrm{Kv} 11.1}, \mathrm{I}_{\mathrm{KIR} 2.1}$, and $\mathrm{I}_{\text {Nav1.5, }}$ stable HEK293 (CLS Cat\# 300192/p777_HEK293, RRID:CVCL_0045) cell lines were used instead of isolated canine ventricular cardiac myocytes. The HEK293 cells were used here because, for the latter, determination of the individual currents requires specific pharmacological isolation of the current for which potential pharmacological interactions with LUF7244 are unknown. 
The HEK-hERG cell line (Zhou, Gong, Epstein, \& January, 1998) was derived from HEK-293T cells and stably expresses human $\mathrm{K}_{\mathrm{v}} 11.1$ protein. The HEKKWGF cell line stably expresses C-terminal GFP-tagged murine $\mathrm{K}_{\mathrm{IR}} 2.1$ (De Boer et al., 2006). The HEK-Nav1.5 cell line (a kind gift of Dr. H. Abriel, Bern University, Switzerland) stably expresses human Nav1.5. HEK-hERG cells, KWGF cells, and HEK-Nav1.5 were cultured in DMEM with $10 \%$ fetal calf serum, $2 \mathrm{mM}$ L-glutamine, $50 \mathrm{U} \cdot \mathrm{mL}^{-1}$ penicillin, and $50 \mathrm{mg} \cdot \mathrm{mL}^{-1}$ streptomycin and passaged twice a week. During experiments, the amount of DMSO added to the cells was below $0.1 \%$.

Optical action potential measurements in hiPSC-CMCs

We used commercial Cor. $4 \mathrm{U} \circledast$ human-induced pluripotent stem cellderived cardiomyocytes (hiPSC-CMCs; Ncardia, Cologne, Germany) as described before (Baburin et al., 2018). Cells were transiently loaded with the voltage-sensitive dye FluoVolt, and the multi-well plate was placed in an environmentally controlled stage incubator $\left(37^{\circ} \mathrm{C}, 5 \% \mathrm{CO}_{2}\right.$, watersaturated air atmosphere; Okolab Inc, Burlingame, CA, USA). The FluoVolt fluorescence signals were recorded from $0.2 \times 0.2-\mathrm{mm}$ areas using a $40 \times$ (NA 0.6) objective lens at excitation wavelength $470 \pm 10 \mathrm{~nm}$ provided by a LED, and emitted light was collected by photomultiplier at 510-560. LED, photomultiplier, associated power supplies and amplifiers were supplied by Cairn Research Ltd (Kent, UK). Fluorescence signals were digitized at 10 $\mathrm{kHz} ; 20-\mathrm{s}$ recordings of spontaneous APs were taken in single drug and competition protocols and repeated five times. pClamp (RRID:SCR_011323) software package v.10.0 (Molecular Devices, Inc., Sunnyvale, CA, USA) was used for offline analysis of APD at $90 \%$ of repolarization. To investigate possible time-dependent effect of vehicle on AP parameters, we compared APs in control and in the presence of vehicle 5, 15 and 30 minutes after vehicle application. All estimated AP parameters $\left(\mathrm{APD}_{30}, \mathrm{APD}_{50}\right.$, and $\left.A P D_{90}\right)$ in control and at the presence of vehicle were statistically not significantly different at any measured time point (data not shown).

Patch clamp

Current was recorded with an Axon-patch 200B amplifier (Molecular Devices, CA, USA) and analysed with ClampFit 10.2 software (Molecular 


\section{Chapter 5}

Devices, CA, USA). I I Kv11.1, I $\mathrm{I}_{\mathrm{KIR} 2.1}, \mathrm{I}_{\mathrm{Nav1.5}}$, and $\mathrm{I}_{\mathrm{Ca}-\mathrm{L}}$ were measured under room temperature $\left(22^{\circ} \mathrm{C}\right)$. Action potential and $\mathrm{I}_{\mathrm{K}}$ were measured at $37^{\circ} \mathrm{C}$.

IKv11.1 recording

HEK-hERG cells were grown on $\varnothing 12$-mm cover slips coated with $0.1 \%$ gelatin. Cells were perfused with Tyrode's solution (mM): $140 \mathrm{NaCl}, 4 \mathrm{KCl}$, 10 HEPES, $2 \mathrm{CaCl}_{2}, 1 \mathrm{MgCl}_{2}(\mathrm{pH} 7.4, \mathrm{NaOH})$. The intracellular (pipette) solution contained (mM): 10 EGTA, $110 \mathrm{KCl}, 10$ HEPES, $4 \mathrm{~K}_{2}$-ATP, 5.17 $\mathrm{CaCl}_{2}, 1.42 \mathrm{MgCl}_{2}(\mathrm{pH} 7.2, \mathrm{KOH}) . \mathrm{K}_{\mathrm{v}} 11.1$ current was measured with whole cell voltage clamp and its pulse protocol ranging from $-80 \mathrm{mV}$ to $+60 \mathrm{mV}$ for $4,000 \mathrm{~ms}$ followed by a $5,000-\mathrm{ms}$ deactivation pulse at $-50 \mathrm{mV}$. The interpulse interval was $10 \mathrm{~s}(0.1 \mathrm{~Hz})$. Cell capacitance and series resistance were calculated in each cell.

\section{I $\mathrm{KIR2.1}$ recording}

KWGF cells were cultured on coated cover slips. $\mathrm{I}_{\mathrm{KIR} 2.1}$ measurements were performed in bath solution containing $(\mathrm{mM})$ : $140 \mathrm{NaCl}, 5.4 \mathrm{KCl}, 1$ $\mathrm{CaCl}_{2}, 1 \mathrm{MgCl}_{2}, 17.5 \mathrm{NaHCO}_{3}, 15$ HEPES, 6 Glucose (pH 7.4, NaOH). Pipette solution contained $(\mathrm{mM}): 125 \mathrm{~K}$-Gluconate, $10 \mathrm{KCl}, 5$ HEPES, 5 EGTA, 0.6 $\mathrm{CaCl}_{2}, 2 \mathrm{MgCl}_{2}, 4 \mathrm{Na}_{2} \mathrm{ATP}(\mathrm{pH} 7.2, \mathrm{NaOH}$ ). I I IR2.1 was measured by 1-s voltage steps from $-120 \mathrm{mV}$ to $+30 \mathrm{mV}$ with $10-\mathrm{mV}$ increments, from a holding potential of $-40 \mathrm{mV}$. The interpulse interval was $3 \mathrm{~s}(0.33 \mathrm{~Hz})$. Signals were low pass filtered at $2 \mathrm{kHz}$.

\section{INav1.5 recording}

I Nav1.5 was recorded at $20^{\circ} \mathrm{C}$ from HEK-Nav 1.5 cells. The extracellular solution contained $(\mathrm{mM}): 140 \mathrm{NaCl}, 5 \mathrm{CsCl}, 1.8 \mathrm{MgCl}_{2}, 5$ glucose, 5 HEPES, and 0.002 Nifedipine $(\mathrm{pH} 7.3, \mathrm{CsOH})$. Pipette solution contained $(\mathrm{mM}): 5$ $\mathrm{NaCl}, 133 \mathrm{CsCl}, 2 \mathrm{MgATP}, 20$ tetraethylammonium chloride, 10 EGTA, 5 HEPES ( $\mathrm{pH} 7.3, \mathrm{CsOH})$. Sodium currents were measured by 20-ms step pulses ranging from $-80 \mathrm{mV}$ to $+40 \mathrm{mV}$, from a holding potential of -120 $\mathrm{mV}$ and an interpulse interval of $4 \mathrm{~s}(0.25 \mathrm{~Hz})$. 
Action potential recording

Only isolated CMCs that were rod-shaped with clear striation and sharp edges and that showed no spontaneous activity were used. Action potentials were triggered in whole cell current clamp mode with 2-ms current injections at $0.5 \mathrm{~Hz}$ and recorded. All measurements were performed at $37^{\circ} \mathrm{C}$ using a temperature-controlled perfusion chamber (Cell Microcontrols). Tyrode's solution was used as bath solution containing (mM): $137 \mathrm{NaCl}, 5.4 \mathrm{KCl}, 1.8 \mathrm{CaCl}_{2}, 11.8$ HEPES, 10 glucose, $\mathrm{pH} 7.4$ adjusted with $\mathrm{NaOH}$. Pipette solution contained (mM) $10 \mathrm{NaCl}, 130 \mathrm{KCl}, 10$ HEPES, 5 $\mathrm{MgCl}_{2}, \mathrm{pH} 7.2$ adjusted with $\mathrm{KOH}$. For prevention experiments, four different concentrations of LUF7244 were administrated to CMCs via an additional rapid solution exchange system (ALA Scientific Instruments, Long Island, NY, USA). For suppression experiments, four concentrations of LUF7244 were perfused subsequent to EADs occurrence after $1-\mu \mathrm{M}$ Dofetilide perfusion. Incidence of EADs was calculated for each group. All APD (measured at $80 \%$ of repolarization) and short-term variability of repolarization duration (STV) were analysed with Matlab (Mathworks, MA, USA).

IK recording

For IK measurements on CMCs, bath solution contained $(\mathrm{mM}): 4 \mathrm{KCl}$, $145 \mathrm{NaCl}, 1.8 \mathrm{CaCl}_{2}, 1 \mathrm{MgCl}_{2}, 10$ HEPES, 11 glucose, 0.005 Nifedipine $(\mathrm{pH}$ 7.4, $\mathrm{NaOH}$ ) and piptte solution contained (mM): $125 \mathrm{~K}$-aspartate, $1 \mathrm{MgCl}_{2}$,

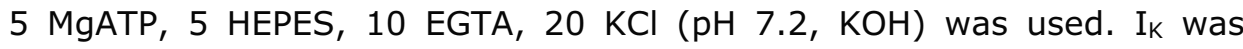
recorded using step pulses ranging between $-20 \mathrm{mV}$ and $+60 \mathrm{mV}$, from a holding potential of $-80 \mathrm{mV}$.

ICa-L recording

L-type calcium currents were measured in bath solution containing (mM): 140 NMDG, $4 \mathrm{KCl}, 1 \mathrm{CaCl}_{2}, 1 \mathrm{MgCl}_{2}, 6$ glucose, $17.5 \mathrm{NaHCO}_{3}, 15$ HEPES $(\mathrm{pH} \mathrm{7.4,} \mathrm{HCl})$. The pipette solution contained $(\mathrm{mM}): 120 \mathrm{CsCl}, 10$ tetraethylammonium chloride, $1 \mathrm{CaCl}_{2}, 3 \mathrm{MgCl}_{2}, 2 \mathrm{Na}_{2} \mathrm{ATP}, 10$ EGTA, 5 HEPES (pH 7.2, CsOH). I Ia-L was recorded by applying 500 ms pulses 


\section{Chapter 5}

ranging from $-60 \mathrm{mV}$ to $+40 \mathrm{mV}$ with $10 \mathrm{mV}$ increments, from a holding potential of $-80 \mathrm{mV}$.

\section{Molecular modeling}

Molecular docking was carried out using the $\mathrm{K}_{\mathrm{v}} 11.1$ cryo-EM structure (PDB code: 5va1) and GOLD (RRID:SCR_000188) v.5.6.2 (Jones, Willett, Glen, Leach, \& Taylor, 1997). Given the similarity of LUF7244 to the known Kv11.1 channel activator ICA-105574, we assumed that they might share overlapping/related binding sites. Thus, residue F557 of one of the four subunits was set as binding site, with a binding radius of $10 \AA$. Residues F557, F619, T623, Y652, and F656 within the radius were set to flexible. For the two scoring functions used, ChemPLP and Goldscore, 100 runs were done each, with 125.000 Gold algorithm operations. The top 15 scoring poses of both functions were inspected and reviewed on their proposed interactions. Visualization of results was done using PyMol (RRID:SCR_000305) 1.7.2 (Schrödinger, 2017).

Molecular dynamics simulations

Building of the molecular dynamics (MD) system as well as ligand parametrization was done using CHARMM-GUI (Jo, Kim, Iyer, \& Im, 2008). The $\mathrm{K}_{\mathrm{v}} 11.1 \mathrm{hERG}$ structure was embedded in a POPC bilayer and solvated with TIP3P water, and ions were added to create a $\mathrm{KCl}$ concentration of 0.15 M. $\mathrm{K}^{+}$ions in the selectivity filter were placed at sites S0, S2 and S4, with water molecules at sites S1 and S3. Energy minimization, 20 ns equilibration and production runs were performed using GROMACS (RRID:SCR_014565) v.5.1.2 (A Abraham, Hess, van der Spoel, \& Lindahl, 2015). The coordinates of the docking pose of LUF7244 was implemented in the system. Production runs were performed for 50 ns with the charmm36 forcefield (Vanommeslaeghe et al., 2010). Electrostatics were modelled using Particle Mesh Ewald (Darden, York, \& Pedersen, 1993), and LINCS was used to constrain H-bonds (Hess, Bekker, Berendsen, \& Fraaije, 1997). Temperature was maintained at $310 \mathrm{~K}$ using V-rescale (Bussi, Donadio, \& Parrinello, 2007), and semi-isotropic pressure coupling was done using the Parrinello-Rahman barostat (Parrinello \& Rahman, 1981). 
MD trajectories were analysed using VMD v.1.9.2 (Humphrey, Dalke, \& Schulten, 1996) and GROMACS.

\section{In vivo studies}

Animals

All animal care and experimental procedures were approved by the Committee for Experiments on Animals of Utrecht University and conformed to the Directive 2010/63/EU of the European Parliament. Animal studies are reported in compliance with the ARRIVE guidelines (Kilkenny, Browne, Cuthill, Emerson, \& Altman, 2010) and with the recommendations made by the British Journal of Pharmacology. The current study has no implications for replacement, refinement, or reduction.

Animal handling

Dogs were housed in pairs in kennels and provided with wooden bedding material. Dogs had access to water $a b$ libitum and received dog food pellets twice a day. Playing toys were provided as enrichment. Dogs were allowed to play outside in groups once a day. Welfare assessment was checked every day, and the body weight was monitored once a week. Animals were fasted fir the day before a surgery (from 4:00 PM).

A total of 10 adult mongrel dogs (Marshall, New York, USA; four females and six males; body weight $24 \pm 4 \mathrm{~kg} ; 13 \pm 3$ months old) were included for serial experiments with at least 2 weeks in between as a recovery interval (Figure 1). Sex-associated differences in QTc have not been documented in this species (Salama \& Bett, 2014), and as per our unpublished observations, sex has no influence on the dofetilide inducibility of arrhythmias. Premedication included atropine (i.m. $0.02 \mathrm{mg} \cdot \mathrm{kg}^{-1}$ ), methadone (i.m. $0.5 \mathrm{mg} \cdot \mathrm{kg}^{-1}$ ), and acepromazine (i.m. $0.5 \mathrm{mg} \cdot \mathrm{kg}^{-1}$ ). To limit risk of infection, antibiotic was given (ampicillin 1,000 mg, before and after the operation, i.v. and i.m. respectively). Analgesia was provided by buprenorphine (Temgesic, $0.3 \mathrm{mg}$ i.m.) after operation. General anesthesia was induced by pentobarbital sodium (Nembutal, $25 \mathrm{mg} \cdot \mathrm{kg}^{-1}$, i.v.) and maintained by $1.5 \%$ isoflurane in a mixture of $\mathrm{O}_{2}$ and $\mathrm{N}_{2} \mathrm{O}(1: 2)$. 
Atrioventricular block was induced by radiofrequency ablation as described before (Oros et al., 2008).

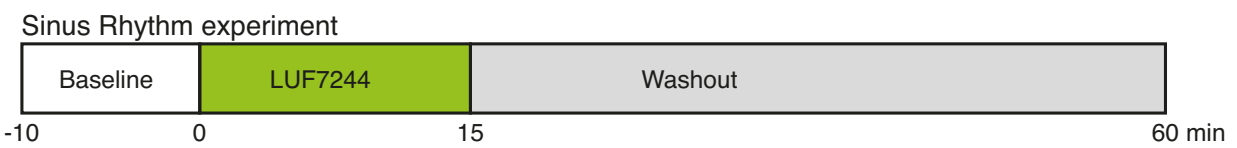

CAVB inducibility experiment

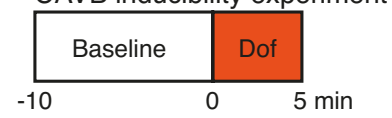

CAVB prevention experiment

\begin{tabular}{|l|c|c|c|cc|}
\hline Baseline & $\begin{array}{c}\text { LUF } \\
\# 1\end{array}$ & $\begin{array}{c}\text { LUF } \\
+ \text { Dof }\end{array}$ & $\begin{array}{c}\text { LUF } \\
\# 2\end{array}$ & Washout & \\
\hline
\end{tabular}

Figure 1. Experimental set-up for in vivo studies.

Drug dosing

The hERG activator ICA-105574 shows structural similarities with LUF7244 and has been analyzed in anesthetized dogs at 1 and $10 \mathrm{mg} \cdot \mathrm{kg}^{-}$ $1.10 \mathrm{~min}^{-1}$, previously (Asayama et al., 2013). ICA-105574 caused QTC shortening only at the highest concentration. Based on these results, we decided for conservative application and infused LUF7244 at $2.5 \mathrm{mg} \cdot \mathrm{kg}^{-1} \cdot 15$ $\mathrm{min}^{-1}$ in the in vivo experiments. In total, 1 -mL LUF7244 $\left(2.5 \mathrm{mg} \cdot \mathrm{kg}^{-1}\right.$, i.v.) has been infused at a $40 \mathrm{~mL} \cdot \mathrm{h}^{-1}$ infusion rate. LUF7244 and dofetilide were infused by two different front limb (i.v.) and two separate syringes in an infusion dock.

Dogs with sinus rhythm

Under general anaesthe sia, after monophasic action potential (MAP) catheters were introduced into the left (LV) and right ventricle (RV), a 10min baseline recording was started followed by a 15-min LUF7244 infusion $\left(2.5 \mathrm{mg} \cdot \mathrm{kg}^{-1}\right)$. The infusion protocol was followed by $30 \mathrm{~min}$ washout (Figure 1, top panel). During the entire loading and washout procedure, ECG parameters and LV/RV MAP were recorded. Blood samples were collected every 5 min to determine the plasma level of LUF7244. 
Dogs with CAVB

Ventricular remodelling following CAVB was allowed for at least 2 weeks under idioventricular rhythm (Oros et al., 2008) before serial experiments were conducted (Figure 1).

Inducibility experiment

Dofetilide infusion $\left(0.025 \mathrm{mg} \cdot \mathrm{kg}^{-1} \cdot 5 \mathrm{~min}^{-1}\right)$ was stopped either after 5 min of infusion or with the first occurrence of TdP (Figure 1, middle panel). Dogs that showed at least three TdPs within 10 min after the start of dofetilide infusion were considered as inducible. Dogs were defibrillated when severe, not self-terminating arrhythmia events occurred. ECG and LV/RV MAP signals were recorded during the whole procedure.

Prevention experiment

Only inducible dogs were selected to undergo the subsequent prevention experiment. After 10-min baseline recording, a 15-min infusion of LUF7244 (2.5 mg. $\left.\mathrm{kg}^{-1}\right)$ was started, during which time dofetilide $(0.025$ $\mathrm{mg} \cdot \mathrm{kg}^{-1}$ ) was infused between $t=5 \mathrm{~min}$ and $t=10 \mathrm{~min}$ (Figure 1 , bottom panel). The ECG and LV/RV MAP signals were recorded. Blood samples were collected during the infusion periods ( $t=0 / 15 / 30 / 45 \mathrm{~min}$ ).

Data analysis

ECG parameters from lead II (RR, PQ, QRS and QT) were measured manually with EPTracer (Cardiotek, Maastricht, the Netherlands) and were quantified every $5 \mathrm{~min}$ from start of baseline recording. Electrophysiological parameters were the average from five consecutive beats (except RV/LV STV were based on 30 consecutive beats). ECG intervals and MAP signals were recorded with a sampling rate of $1 \mathrm{kHz}$. QT interval was corrected by Van de Water's formula QTC $=$ QT $-0.087 *(R R-1,000)$. LV and RV MAPD80 were analysed semi-automatically with the custom-made software AutoMAPD (Matlab (RRID:SCR_001622), Mathworks, MN, USA). Beat-tobeat variability of repolarization was quantified as STV. It (based on 30 
consecutive beats) was calculated with the formula STV $=\sum\left|D_{n+1}-D_{n}\right| /$ $(30 * \sqrt{ } 2$ ) in which $D$ represents APD. Arrhythmia score (Stams et al., 2016) was used to quantify arrhythmia severity. The arrhythmia score is the average of three most severe arrhythmia events during $10 \mathrm{~min}$. One regular beat scored as 1 point, and single ectopic beats were counted as 2 points. Multiple ectopic beats were scored 3-50 points. One, two, or more defibrillation scored as 50,75, and 100. In the absence of arrhythmic events in all animals within one group, arrhythmia score is 1 with SD of 0.

Animals were not randomized in the present study. Each dog served as its own control under sinus rhythm (SR) and CAVB conditions. Addition of another group of animals (continuously receiving saline/vehicle) would not be justified ethically (3Rs) or scientifically. In this study, operators and data analysts were not blinded. In SR dog experiments, all dogs received LUF7244 consecutively for $15 \mathrm{~min}$. In CAVB dog inducibility experiments, dofetilide was administered in all dogs and resulted in at least $3 \mathrm{TdP}$ arrhythmias of 5 or more beats in all dogs. TdP arrhythmias are immediately evident on the surface ECG running during the expeirments. In CAVB dog prevention experiments, LUF7244 and dofetilide were administered in all dogs. Successful suppression of TdP upon LUF7244 infusion is evident during the experiment (ECG monitor) and from the recorded ECG. Therefore, blinding is not applicable.

Isolation of CMCs

Following the final in vivo experiment, heparin (10,000 I.U., i.v.) was administered, right sided thoracotomy was performed, and the heart was excised. For the current study, ventricular CMCs were enzymatically isolated from 44 dogs (Table S2), either from dogs in the currently described protocol or from dogs present in other approved study protocols from our institute, as described before (Varkevisser et al., 2012). The excised heart was washed with $\mathrm{Ca}^{2+}$ free buffer $(\mathrm{mM}): 130 \mathrm{NaCl}, 5.4 \mathrm{KCl}, 1.2 \mathrm{KH}_{2} \mathrm{PO}_{4}, 1.2$ $\mathrm{MgSO}_{4}, 6$ HEPES, 20 glucose (pH 7.2, NaOH). The left coronary artery was tightened into the Langendorff system and perfused with warm $\left(37^{\circ} \mathrm{C}\right) \mathrm{Ca}^{2+}$ free buffer solution for $10 \mathrm{~min}$ and then perfused for 25-35 min with the enzymatic solution containing $420 \mathrm{mg}$ collagenase A (Roche, the Netherlands) and $32 \mathrm{mg}$ protease (Sigma-Aldrich, the Netherlands) in 2.5\% 
trypsin $400 \mu \mathrm{L}$, in $400 \mathrm{~mL}$ buffer solution. Finally, $0.2 \mathrm{mM} \mathrm{Ca}^{2+}$ buffer solution was perfused for $10 \mathrm{~min}$. Ventricular CMCs were harvested from midmyocardial tissue of ventricular free wall and filtered. The freshly obtained CMCs were stored in $\mathrm{Ca}^{2+}$ buffer solution at room temperature until use.

Plasma concentration analysis

The analysis of LUF7244 was performed with UHPLC and UV detection. Separation was performed on a C-18 UHPLC Kinetex EVO column (100 $\times$ $2.1 \mathrm{~mm}, 2.6 \mu \mathrm{m}$ ) from Phenomenex (Utrecht, the Netherlands). The composition of the mobile phase was $34 \%$ acetonitrile with $0.2 \%$ formic acid $(\mathrm{v} / \mathrm{v})$ which was used at a flow of $0.8 \mathrm{~mL} \cdot \mathrm{min}^{-1}$ and a temperature of $30^{\circ} \mathrm{C}$. Sample preparation was performed by mixing $50 \mu \mathrm{L}$ of plasma with $50 \mu \mathrm{L}$ of mobile phase. After vortexing briefly with $1,000 \mu \mathrm{L}$ of acetonitrile, the samples were centrifuged at $20,000 \times \mathrm{g}$ during $10 \mathrm{~min}$. The supernatants were evaporated in a Centrivap vacuum centrifuge from Labconco (Kansas City, Missouri). The samples were reconstituted in $50 \mu \mathrm{L}$ of mobile phase ( $34 \%$ acetonitrile, $0.2 \%$ formic acid) by vortexing briefly at high speed. Subsequently, after centrifuging at $20,000 \times \mathrm{g}$ for $10 \mathrm{~min}$, $45 \mu \mathrm{L}$ of the supernatant of each sample was transferred to a glass microinsert $(31 \times 6 \mathrm{~mm})$ from BGB science (Harderwijk, the Netherlands). A volume of $10 \mu \mathrm{L}$ was injected onto the column using a Nexera-I HPLC system from Shimadzu ('s-Hertogenbosch, the Netherlands).

Calibration was performed by a calibration curve in mobile phase ( $34 \%$ acetonitrile with $0.2 \%$ formic acid $(\mathrm{v} / \mathrm{v})$ ). The concentrations used for calibration were $10,20,50,100,200,500$, and $1,000 \mathrm{ng} \cdot \mathrm{mL}^{-1}$. To that end, LUF7244 was dissolved in methanol with $0.05 \%$ formic acid ( $/ \mathrm{v}$ ) and diluted in order to prepare the calibration solutions. Blank dog plasma aliquots were mixed with these calibration solutions and further processed as samples. Quality controls were prepared at the concentration levels of a low, medium, and high concentration (50, 200 and $\left.1,000 \mathrm{ng} \cdot \mathrm{mL}^{-1}\right)$. The quality controls were stored in the $-80^{\circ} \mathrm{C}$ freezer until used for quality control along with the actual sample concentration measurements.

\section{Data and statistical analysis}


The data and statistical analysis comply with the recommendations on experimental design and analysis on pharmacology (Curtis et al., 2018). Data are represented as mean \pm SD or mean \pm SEM. Two-way ANOVA and Bonferroni post hoc test were used for APDgo results from hiPSC. Post hoc tests were carried out only if $F$ was significant and there was no variance in homogeneity. A non-parametric paired $t$ test was used for group comparisons and arrhythmia score in the in vivo study. All statistical analysis was performed by Prism 6 (GraphPad, CA, USA; GraphPad Prism, RRID:SCR_002798). $P$ values $<0.05$ were considered as statistically significant.

\section{MATERIALS}

LUF7244 was synthesized according to a previously published procedure ( $\mathrm{Yu}$ et al., 2014). For cellular experiments, LUF7244 was dissolved in DMSO to obtain a stock solution of $100 \mathrm{mM}$ that was filter sterilized $(0.22 \mu \mathrm{m})$ and stored at $-20^{\circ} \mathrm{C}$ until use. The amount of DMSO added to the cells was below $0.1 \%$. For use in animals, LUF7244 was dissolved in DMSO and polyethylene glycol $400(1: 1, \mathrm{v} / \mathrm{v})$ solution to final concentration and was filter sterilized $(0.45 \mu \mathrm{m})$. The final solution is $10 \mathrm{~mL}$ in total ( $5 \mathrm{~mL}$ DMSO and $5 \mathrm{~mL}$ PEG400). Iks blocker HMR1556 (Sanofi Aventis, Gouda, the Netherlands) was dissolved in DMSO at $10 \mathrm{mM}$ as stock solution and stored at $-20^{\circ} \mathrm{C}$ until use.

For cellular experiments, dofetilide (Sigma-Aldrich, Zwijndrecht, the Netherlands) was dissolved in DMSO at $10 \mathrm{mM}$ as stock solution and stored at $-20^{\circ} \mathrm{C}$. For in vivo experiments, dofetilide was dissolved in $100-\mu \mathrm{L} \mathrm{HCl}$ $(0.1 \mathrm{M})$ and then diluted into saline (19-29 $\mathrm{mL}$, depends on body weight) to the final concentration. Solutions for the in vivo experiments were freshly prepared before using. All the other chemicals were of analytical grade and obtained from standard commercial sources.

For the plasma sample analysis of LUF7244, methanol, acetonitrile, and formic acid were used in LC-MS grade and purchased from Biosolve (Valkenswaard, the Netherlands). Nanopure lab water was derived from an ELGA Purelab Flex water purification system from Veolia Nederland (Nieuwegein, the Netherlands). 


\section{Nomenclature of targets and ligands}

Key protein targets and ligands in this article are hyperlinked to corresponding entries in http://www.guidetopharmacology.org, the common portal for data from the IUPHAR/BPS Guide to PHARMACOLOGY (Harding et al., 2018), and are permanently archived in the Concise Guide to PHARMACOLOGY 2017/18 (Alexander et al., 2017).

\section{RESULTS}

\section{LUF7244 is predicted to bind $K_{v} 11.1$ and increased $I_{K v 11.1}$ in HEK293 cells}

Docking and subsequent MD studies suggested LUF7244 (Figure 2b) binds between the $\mathrm{K}_{\mathrm{v}} 11.1$ pore helices of two adjacent subunits, thereby stabilizing the channel in the conductive state (Figure $2 \mathrm{~b}$ ). In the predicted binding mode, the compound favourably interacts with aromatic residues F557 (S5), F619 (P-helix), and Y652 residues (S6) from neighbouring subunits. Further, close contacts to selectivity filter residue T623 and S649 (S6) are predicted. The functional effects of LUF7244 on human $\mathrm{I}_{\mathrm{Kv} 11.1}$ were tested on the HEK-hERG cell line by use of whole-cell patch clamp. Three different concentration of LUF7244 $(0.5,3$, and $10 \mu \mathrm{M})$ were applied to cells resulting in a concentration-dependent increase of the steady-state current at the end of the depolarizing current (Figure 2c,d). Moreover, LUF7244 affected rectification and altered tail current kinetics upon the deactivation pulse (Figure 2c,d). 10- $\mu$ M LUF7244 has no effect on I KIR2.1 $_{\text {or I I }}$ (Nav1.5 (Figure $2 e, f)$.

\section{LUF7244 reduced APD and dofetilide induced prolongation in hiPSC-CMCs}

We characterized the effects of LUF7244 on action potentials of human origin in hiPS-CMC using the voltage-sensitive fluorescent dye FluoVolt. LUF7244 $(10 \mu \mathrm{M})$ significantly shortened the APD at $90 \%$ of the repolarisation phase (APD 90 ; Figure $3 a$, left, and $3 b)$. In hiPS-CMC challenged with 30-nM dofetilide, APD was profoundly increased after 5 and 


\section{Chapter 5}

15 min (Figure 3a, middle, and 3b). LUF7244 co-application decreased dofetilide-induced APD prolongation, although values did not return to baseline (Figure 3a, right, and $3 b$ ). Vehicle time controls did not display effects on AP parameters.

A

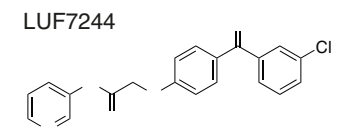

Dofetilide

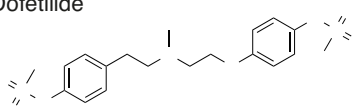

C

baseline
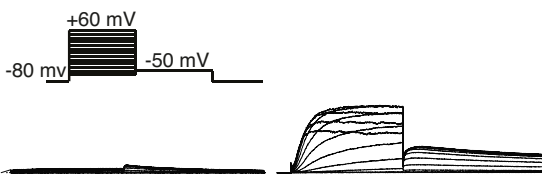

$3 \mu \mathrm{M}$ LUF7244

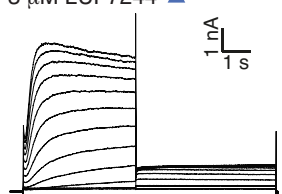

$10 \mu \mathrm{M}$ LUF7244

E

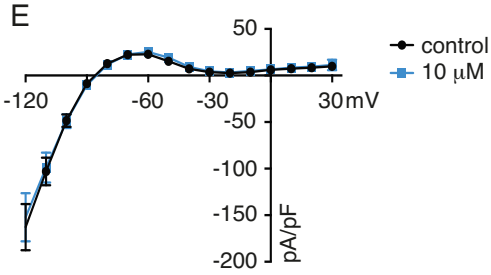

B

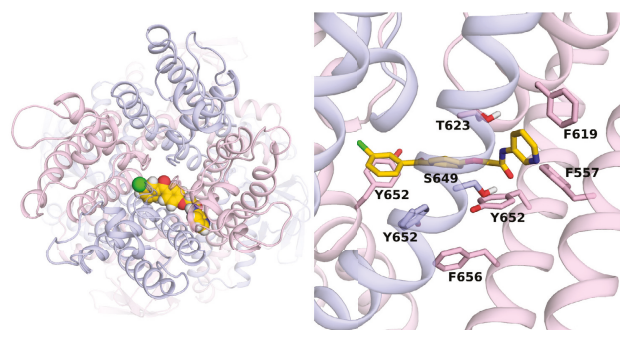

D. 6007 control

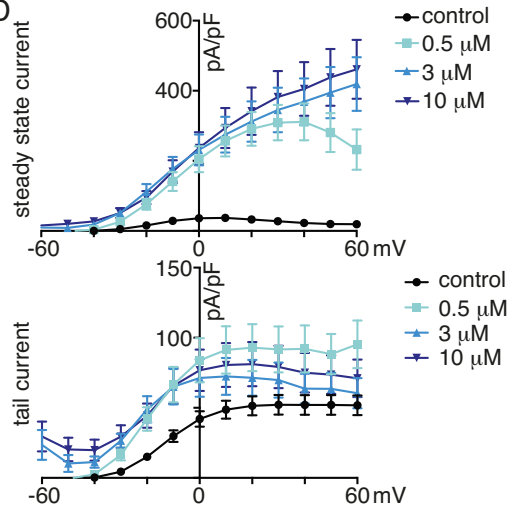

$\mathrm{F}$

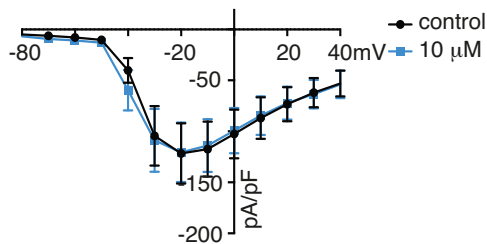

Figure 2. LUF7244 increases steady-state $I_{\text {Kv11.1 }}$ in HEK-hERG cells. (a) Chemical structure of LUF7244 and dofetilide. (b) Docking pose of LUF7244, after 50 ns of molecular dynamics simulation to the cryo-EM structure of hERG. (c) Representative traces of $\mathrm{K}_{\mathrm{v}} 11.1$ current with or without infusion of LUF7244 (0.5, 3 , and $10 \mu \mathrm{M}$ ). Stimulation protocol is shown on top panel. (d) I-V relationship curve of $\mathrm{I}_{\mathrm{Kv} 11.1}$ under baseline conditions and in the presence of LUF7244 $(0.5,3$, 
and $10 \mu \mathrm{M} ; n=14,13$ and 12 cells). (e) I-V curve of $\mathrm{I}_{\mathrm{KIR} 2.1}$ currents obtained from KWGF cells under baseline conditions and in the presence of $10 \mu \mathrm{M}$ LUF7244 ( $n=$ 9 cells). (f) I-V relationship curve of $\mathrm{I}_{\mathrm{Nav} 1.5}$ measured in HEK-Nav 1.5 cells under baseline conditions and $10 \mu$ M LUF7244 treatment ( $n=10$ cells). Raw current data were normalized by each cell's membrane capacitance for current density, for comparisons. Values are shown as mean \pm SEM.

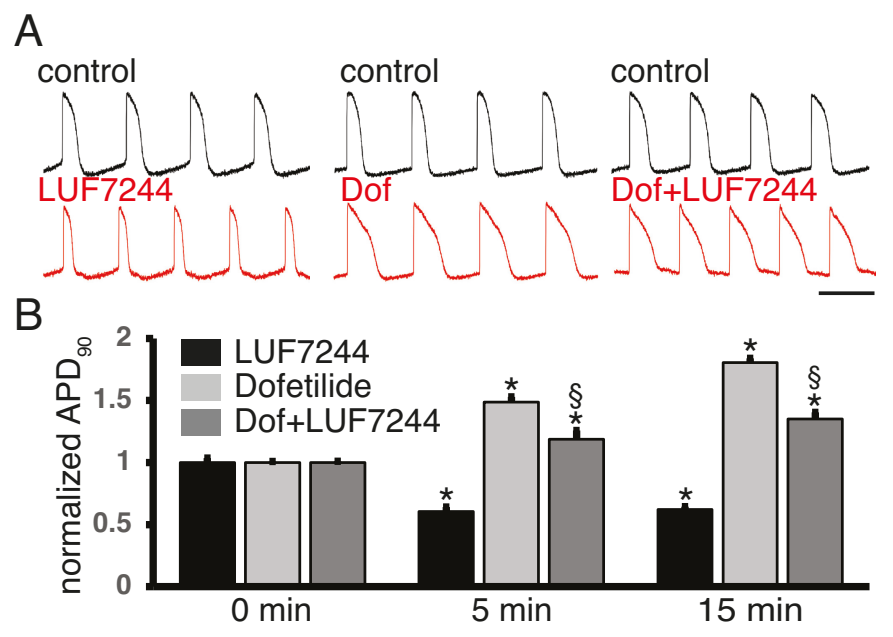

Figure 3. LUF7244 shortens APD and suppresses APD prolongation in hiPS-CMCs. (a) AP recordings in control and after 5-min incubation with the indicated drug or drug combinations (red) at $10 \mu \mathrm{M}$ LUF7244 and $30 \mathrm{nM}$ dofetilide. Horizontal bar indicates $1 \mathrm{~s}$. (b) The bar graphs represent changes in normalized APD $_{90}$ observed with each drug, or drug combination tested $(n=5)$. Values are shown as mean \pm SEM. ${ }^{*} P<0.05$, significantly different from the same drug(s) at 0 min. ${ }^{\S} P<0.05$, dofetilide + LUF7244 significantly different from dofetilide

\section{LUF7244 shortened APD and reduced dofetilide induced EAD in isolated canine CMCs}

Because we aimed to analyse the potential antiarrhythmic properties of LUF7244 in the CAVB dog model, we first analysed the effects of LUF7244 on adult native canine APD (Figure 4). LUF7244 was applied at 0.5, 1, 3, and $10 \mu \mathrm{M}$ in isolated ventricular CMCs from SR and CAVB dogs. It showed dose-dependent reduction in both APD and STV. In the EAD suppression experiment with the SR hearts, we used dofetilide-inducible cells continuously perfused with dofetilide and LUF7244. 10- $\mu \mathrm{M}$ LUF7244 successfully suppressed EADs in all seven cells (Figure $4 b$, right panel). In 
the EAD suppression experiment with the CAVB hearts, LUF7244 reduced the incidence of EADs to $8 / 10$ and $9 / 11$ at 3 and $10 \mu \mathrm{M}$, respectively (Figure $4 c$, right panel).
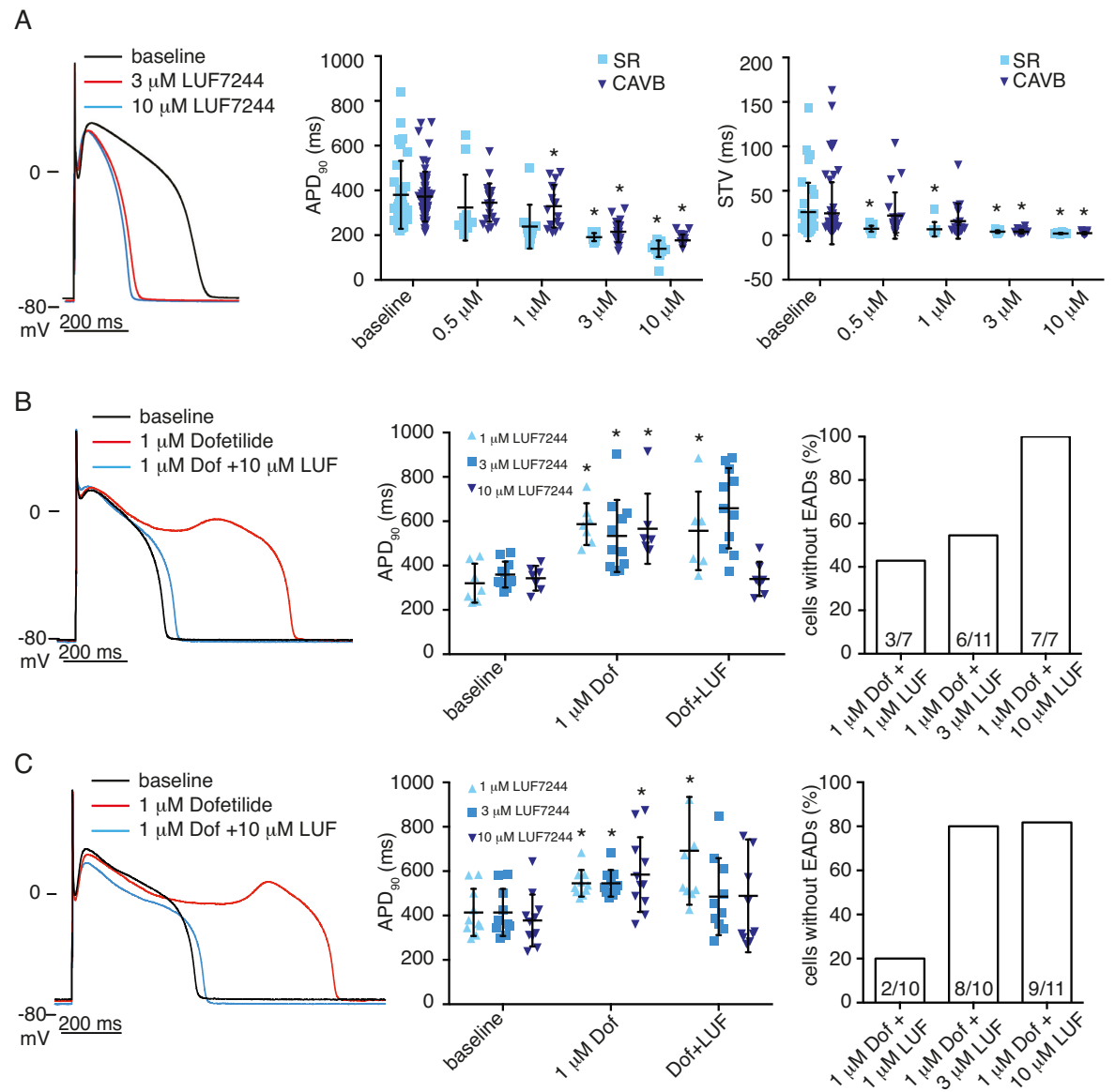

Figure 4. LUF7244 shortens APD and reduces dofetilide-induced EAD in isolated canine cardiomyocytes. (a) Representative examples of LUF7244 induced shortening of APD in cardiomyocytes (left panel). Summarized results of $\mathrm{APD}_{90}$ (middle panel) and STV (right panel) after LUF7244 application to SR and CAVB cardiomyocytes. In SR cardiomyocytes, $n=11,10,13$ and 14 cells were treated with $0.5,1,3$, and $10 \mu \mathrm{M}$ LUF7244, respectively. In CAVB cardiomyocytes, $n=20,16,22$ and 17. (b) LUF7244 dose dependently suppressed dofetilideinduced EAD in SR cardiomyocytes (left panel). Summarized results of APD 90 (middle panel) and incidence of EADs after dofetilide infusion in SR cardiomyocytes 
(right panel). Data are represented as number of cells without EADs/total number of cells showing EADs upon dofetilide. $n=7,11$ and 7 cells for 1,3 and $10 \mu \mathrm{M}$ LUF7244, respectively. (c) 1, 3, and $10 \mu \mathrm{M}$ LUF7244 suppressed dofetilide-induced APD prolongation and EADs in CAVB cardiomyocytes. Summarized results of APD 90 (middle panel) and incidence of EADs after dofetilide infusion in CAVB cardiomyocytes (right panel), $n=10,10$, and 11 cells, respectively. APD 90 , action potential duration (measured at $90 \%$ repolarization); STV, short term variability of repolarization duration. Data shown are individual values with means $\pm \mathrm{SD},{ }^{*} P$ $<0.05$, significantly different from baseline.

\section{LUF7244 increases $I_{K}$ in isolated canine CMCs and has no effect on ICa-L}

We performed both prevention and suppression experiment on CMCs to test effects of LUF7244 on a group of repolarizing currents, namely, IK and its HMR1556 and dofetilide-sensitive components (Figure $5 a, b$ ). In the first experiment, LUF7244 $(10 \mu \mathrm{M})$ was administrated for 5 min after baseline recording. Next either $1-\mu \mathrm{M}$ dofetilide ( $\mathrm{I}_{\mathrm{kr}}$ blocker) or $500-\mathrm{nM}$ HMR1556 ( $\mathrm{I}_{\mathrm{ks}}$ blocker) combined with LUF7244 was perfused. The basal $\mathrm{I}_{\mathrm{K}}$ current was approximately doubled after LUF7244, and this increase was totally inhibited by dofetilide, but not by HMR1556, indicating that the LUF7244 induced $I_{K}$ increase was more likely to result from $I_{\mathrm{Kr}}$ (dofetilide sensitive) and not $\mathrm{I}_{\mathrm{Ks}}$ (HMR1556 sensitive). In a second experimental setup, $I_{K}$ tail current was first inhibited by dofetilide and HMR 1556 to determine the contribution of $\mathrm{I}_{\mathrm{Kr}}$ and $\mathrm{I}_{\mathrm{Ks}}$ to total $\mathrm{I}_{\mathrm{K}}$. Then 10- $\mu \mathrm{M}$ LUF7244 was perfused and did not significantly increase $I_{K}$ (Dofetilide + HMR1556 compared with Dofetilide + HMR1556 + LUF7244; Figure 5b). Collectively, these finding indicate that LUF7244 increases $\mathrm{I}_{\mathrm{Kr}}$ in isolated CMCs and can partly overcome dofetilide-mediated inhibition of $\mathrm{I}_{\mathrm{K}}$. Finally, we tested for potential effects of LUF7244 on ICa-L from CMCs. After baseline recording, 5-min LUF7244 $(10 \mu \mathrm{M})$ was applied and followed with 5 - $\mu \mathrm{M}$ Nifedipine (Figure 5c). Next, time control experiments were performed separately for 10 min to determine run-down. No significant differences in ICa-L densities were obtained between $10 \mu \mathrm{M}$ LUF7244 and time matched controls, whereas remaining current was blocked by Nifedipine afterwards (Figure $5 d)$. 


\section{Chapter 5}
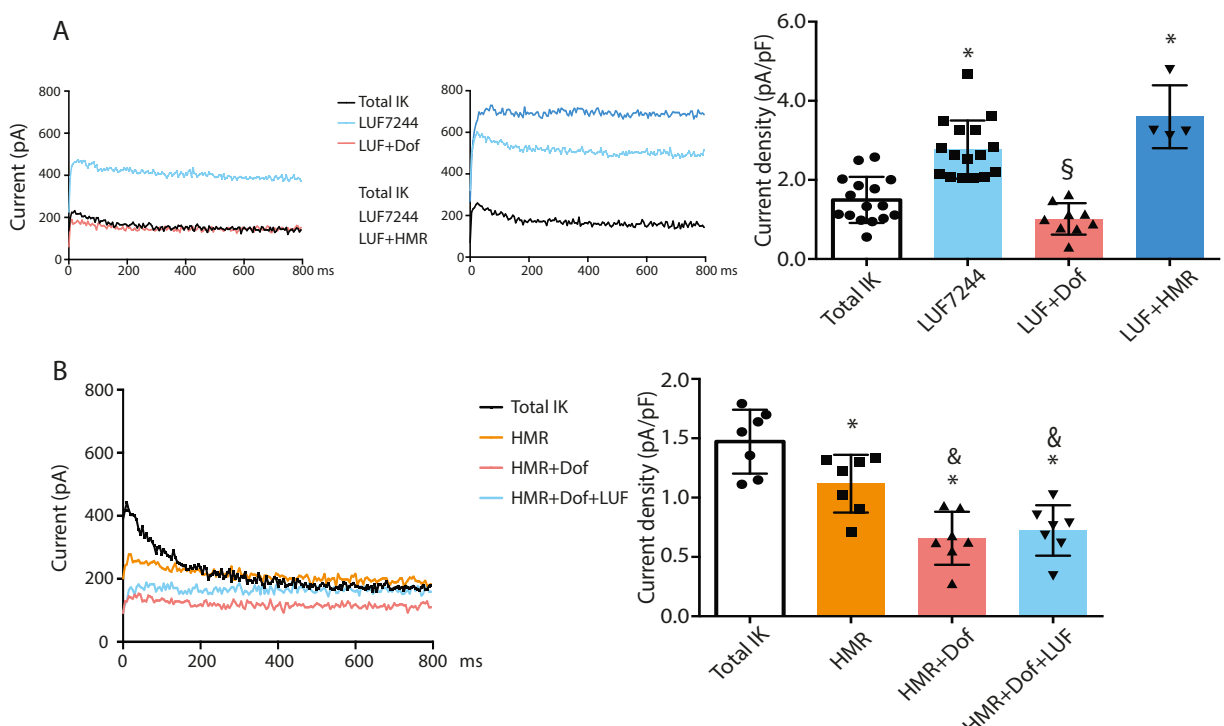

C
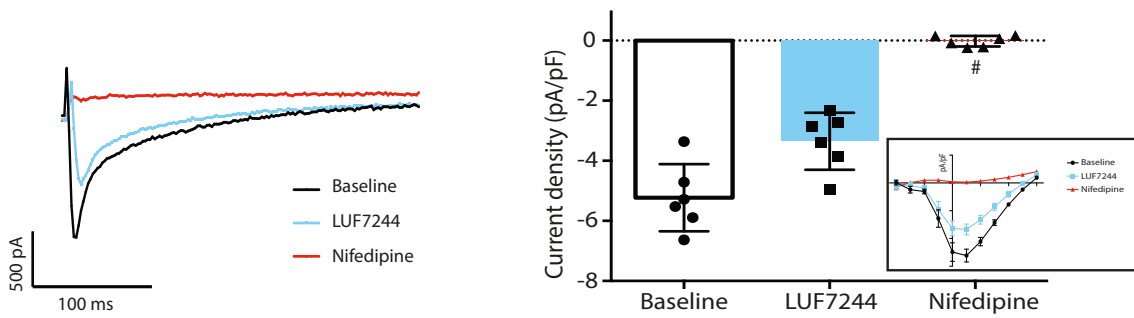

D
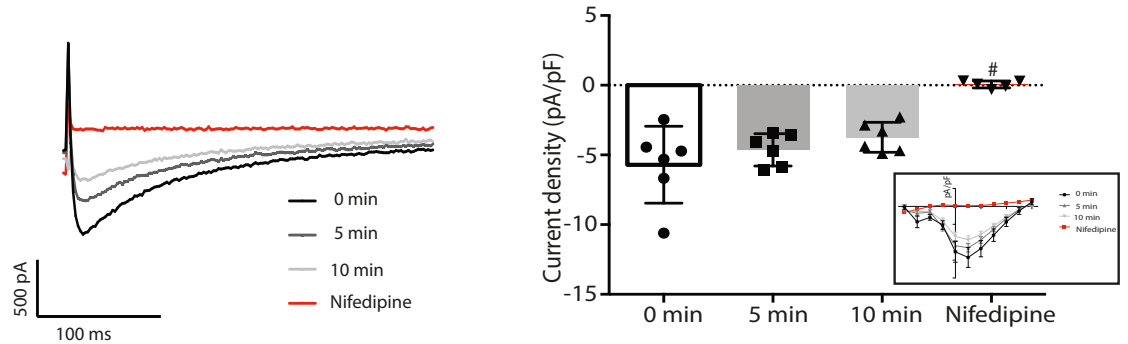

Figure 5. LUF7244 increases dofetilide-sensitive $I_{K}$ in isolated CMCs and

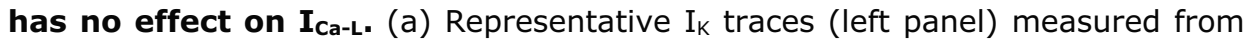
canine cardiomyocytes. Summarized $\mathrm{I}_{\mathrm{K}}$ current density at $+60 \mathrm{mV}$ is shown in right panel $(n=7)$. (b) Representative $I_{K}$ traces (left panel) measured from canine cardiomyocytes. HMR1556 (500 nM) inhibited $I_{K s}$ form total $I_{K}$. The total $I_{K}$ was 
further blocked after $1-\mu \mathrm{M}$ dofetilide was applied. Summarized $\mathrm{I}_{\mathrm{K}}$ current density at $+60 \mathrm{mV}$ after different treatment is shown in right panel ( $n=7$ cells). (c) $\mathrm{I}_{\mathrm{Ca}-\mathrm{L}}$ measured under baseline conditions or in presence of $10-\mu \mathrm{M}$ LUF7244 or $5 \mu \mathrm{M}$ Nifedipine $(n=6)$. (d) Rundown measurement of $\mathrm{I}_{\mathrm{Ca}-\mathrm{L}}$ after $0 \mathrm{~min}, 5 \mathrm{~min}$ or 10 $\min (n=6)$. Current inhibition by $5-\mu \mathrm{M}$ Nifedipine at the end of the rundown experiment. Left panel: representative traces. Right panel: peak $\mathrm{I}_{\mathrm{Ca}-\mathrm{L}}$ density distribution at $+10 \mathrm{mV}$ and corresponding I-V curves (in box) of ICa-L. Data shown are individual values with mean \pm SEM. ${ }^{*} P<0.05$, significantly different from total $\mathrm{I}_{\mathrm{K}},{ }^{\S} P<0.05$, significantly different from LUF7244, ${ }^{\&} P<0.05$, significantly different from HMR, ${ }^{\#} P<0.05$, significantly different from baseline.

\section{LUF7244 decreased repolarization parameters in SR dogs}

In SR dogs $(n=5)$, infusion of LUF7244 (2.5 $\left.\mathrm{mg} \cdot \mathrm{kg}^{-1} \cdot 15 \mathrm{~min}^{-1}\right)$ slightly, but not reaching significance, decreased RR duration, QTc duration, LVMAPD80 and RVMAPD80 without affecting LV STV (Figure 6, Table 1). No changes were observed in PQ and QRS interval duration or LV STV. Figure S1 displays RR and QTc data for individual animals, all showing decreases upon LUF7244 application and normalization upon washout. During infusion, LUF7244 total plasma concentration rapidly increased $(0.94 \pm 0.34 \mu \mathrm{M}$; $1.17 \pm 0.50 \mu \mathrm{M}$ at $t=5$ and $t=10 \mathrm{~min}$. respectively), peaked at the end of the infusion $(1.75 \pm 0.80 \mu \mathrm{M}$ at $t=15)$ and then LUF7244 plasma concentrations rapidly decreased $(0.27 \pm 0.45 \mu \mathrm{M}$ at $t=20 ; 0.02 \pm 0.02$ $\mu \mathrm{M}$ at $t=25)$.

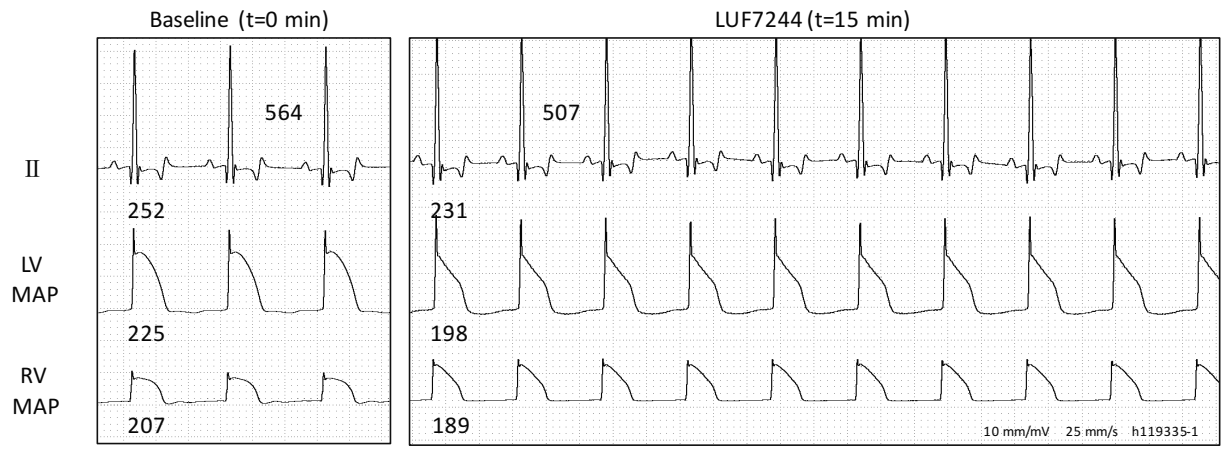

Figure 6. Electrophysiological effects of LUF7244 in dogs with sinus rhythm ( $\boldsymbol{n}=\mathbf{5}$ ). Representative traces of ECG measured from leadII and LV/RV MAP under baseline infusion and at end of LUF7244 $\left(2.5 \mathrm{mg} \cdot \mathrm{kg}^{-1} \cdot 15 \mathrm{~min}^{-1}\right)$ infusion, 


\section{Chapter 5}

respectively. Values of $\mathrm{QT}, \mathrm{RR}$ and $\mathrm{LV} / \mathrm{RV}$ MAPD are presented next to corresponding traces. Horizontal line corresponds to $1 \mathrm{~s}$.

Table 1. Electrophysiological parameters (in $\mathrm{ms}$ ) in sinus rhythm dogs $(n=5)$ under baseline condition and LUF7244 (15 min) administration

\begin{tabular}{|l|cc|}
\cline { 2 - 3 } \multicolumn{1}{c|}{} & Baseline & LUF7244 \\
\hline RR & $585 \pm 57$ & $513 \pm 31$ \\
PQ & $130 \pm 21$ & $122 \pm 22$ \\
QRS & $74 \pm 2$ & $72 \pm 2$ \\
QT & $260 \pm 20$ & $233 \pm 20$ \\
QTc & $296 \pm 17$ & $276 \pm 17$ \\
LV $_{\text {MAPD80 }}^{a}$ & $200 \pm 20$ & $180 \pm 19$ \\
RV $_{\text {MAPD80 }}$ & $183 \pm 19$ & $169 \pm 17$ \\
LV $_{\text {STV }}$ & $0.3 \pm 0.0$ & $0.4 \pm 0.1$ \\
RV $_{\text {STV }}$ & $1.0 \pm 0.2$ & $0.4 \pm 0.0$ \\
\hline
\end{tabular}

Note. Data are expressed as mean \pm SD.

avan de Water QTc $=$ QT $-0.087 *(\mathrm{RR}-1,000)$.

\section{LUF7244 displayed antiarrhythmic effects against dofetilide- induced TdP arrhythmias in CAVB dogs}

Antiarrhythmic properties of LUF7244 in vivo were sequentially tested; arrhythmia inducibility by the $\mathrm{I}_{\mathrm{kr}}$ inhibitor dofetilide was tested in the first experiment, whereas in the second experiment, prevention of dofetilideinduced arrhythmias by LUF7244 was evaluated.

Inducibility experiment

In CAVB dogs $(n=7)$, dofetilide was administered as the proarrhythmia challenge (Figure 7a). As the duration of the dofetilide infusion was different in the seven inducibility experiments due to the occurrences of TdP (see Section 2), measurements were quantified at the average infusion time of $t=3.9 \mathrm{~min}$ to determine the effects on the electrophysiological parameters in the inducibility experiments. Dofetilide infusion resulted in reproducible TdP and prolonged RR and QTc interval (Table 2) and successfully induced TdP in seven out of seven animal concomitant with an increase in arrhythmia score $(1.2 \pm 0.4$ to $39.1 \pm 12.4$, 
$P<0.05)$. In addition, Dofetilide significantly increased repolarization and arrhythmia parameters, including $\mathrm{RV}_{\text {MAPD80 }}$ and QTC (Table 2).
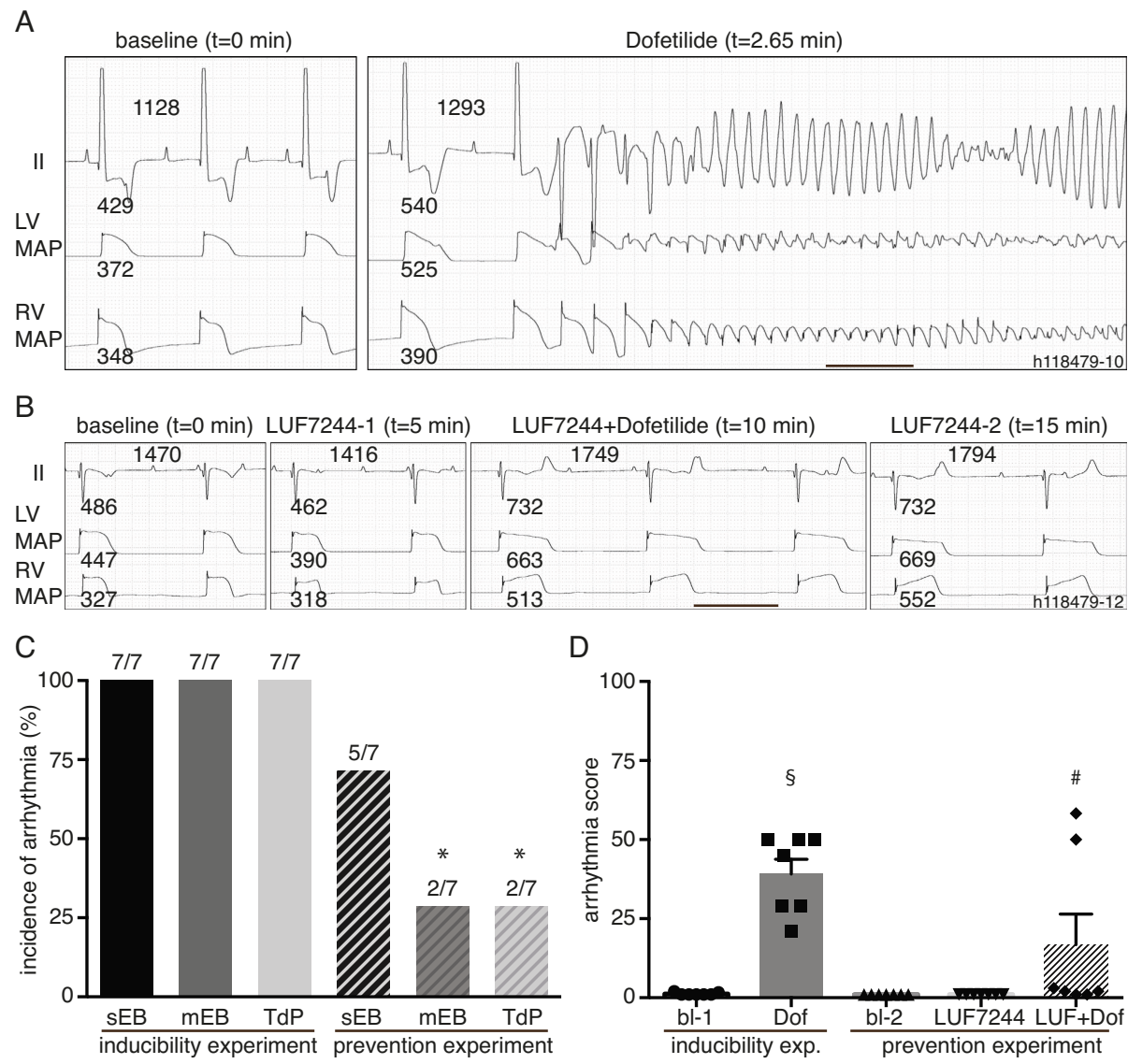

Figure 7. LUF7244 counteracts dofetilide-induced TdP arrhythmia in CAVB dogs ( $\boldsymbol{n}=7$ ). (a) Representative example of ECG (leadII and LV/RV MAP) under baseline infusion and at the first TdP induced by dofetilide $\left(0.025 \mathrm{mg} \cdot \mathrm{kg}^{-1} .5 \mathrm{~min}\right.$ ${ }^{1}$ ). (b) The combined infusion of dofetilide and LUF7244 did not evoke TdP arrhythmia. Values of QT, RR, and LV/RV MAPD are presented next to corresponding traces. Horizontal line corresponds to 1s. Quantification of incidence of single (sEB), multiple (mEB) ectopic beats and torsades de pointes ( $T d P$ ) arrhythmia (c) and arrhythmia score (d) from both inducibility and prevention experiments. Data shown are means \pm SEM, with individual values in (d). ${ }^{*} P<$ 0.05, significantly different from TdP in inducibility experiment, ${ }^{*} P<0.05$, 


\section{Chapter 5}

significantly different from Baseline-2, \#\#\#<0.05, significantly different from Baseline-1.

\section{Prevention experiment}

In TdP inducible CAVB dogs ( $n=7)$, the combination of LUF7244 and dofetilide infusion decreased the incidence of TdP (two out of seven dogs, $P$ $<0.05$ ) (Figure $7 b, c)$ with a decrease in arrhythmia score (39.1 \pm 12.4 to $16.8 \pm 25.7$ ) in comparison to the inducibility experiment (Figure 7d). Single ectopic beats remained present in five dogs. Electrophysiological parameters were determined at $8.9 \mathrm{~min}$ (5-min LUF7244 + 3.9-min LUF7244/Dofetilide), to allow comparison with the inducibility experiment. LUF7244 did not alleviate the dofetilide-induced increase in QTc duration and RR interval. Moreover, LV/RV MAPD80 and LV/RV STV were significantly increased (Table 2). During the initial phase of LUF7244 infusion (0-5 min), $\mathrm{LV} / \mathrm{RV}_{\mathrm{STV}}$ was unchanged. At the end of administration $(t=15)$, LUF7244 plasma levels were $2.34 \pm 1.57 \mu \mathrm{M}$, whereas at $t=30$ no LUF7244 could be detected anymore. The two dogs in which TdP remained showed the lowest LUF7244 plasma concentration at $t=15(0.33$ and $0.85 \mu \mathrm{M})$. Average LUF7244 plasma levels in the five dogs free of TdP arrhythmias was $3.04 \pm$ $1.24 \mu \mathrm{M}$ at $t=15$ (see Table S3 for individual values).

Table 2. Electrophysiological parameters (in ms) in CAVB dogs $(n=7)$ under baseline condition, Dofetilide, LUF7244, and LUF7244 + Dofetilide administration

\begin{tabular}{|l|cc|ccc|}
\cline { 2 - 6 } \multicolumn{1}{c|}{} & \multicolumn{2}{c|}{ Inducibility experiment } & \multicolumn{2}{c|}{ Prevention experiment } \\
\hline $\begin{array}{l}\text { Parameters } \\
(\mathrm{ms})\end{array}$ & $\begin{array}{c}\text { Baseline-1 } \\
(0 \mathrm{~min})\end{array}$ & $\begin{array}{c}\text { Dofetilide } \\
(3.9 \mathrm{~min})\end{array}$ & $\begin{array}{c}\text { Baseline-2 } \\
(0 \mathrm{~min})\end{array}$ & $\begin{array}{c}\text { LUF7244 } \\
(5 \mathrm{~min})\end{array}$ & $\begin{array}{c}\text { LUF7244 } \\
\text { +Dofetilide } \\
(8.9 \mathrm{~min})\end{array}$ \\
\hline RR & $1248 \pm 366$ & $1428 \pm 393$ & $1485 \pm 352$ & $1412 \pm 319$ & $1741 \pm 284$ \\
QT & $429 \pm 71$ & $546 \pm 69 *$ & $419 \pm 64$ & $407 \pm 56$ & $616 \pm 45 *$ \\
QTC $^{\text {a }}$ & $401 \pm 53$ & $498 \pm 44 *$ & $372 \pm 58$ & $367 \pm 54$ & $544 \pm 48 *$ \\
LV $_{\text {MAPD80 }}$ & $283 \pm 33$ & $423 \pm 148$ & $324 \pm 55$ & $329 \pm 63$ & $514 \pm 79 *$ \\
RV $_{\text {MAPD80 }}$ & $244 \pm 25$ & $334 \pm 70 *$ & $272 \pm 26$ & $269 \pm 32$ & $410 \pm 68 *$ \\
LV $_{\text {STV }}$ & $1.3 \pm 1.0$ & $3.3 \pm 2.0$ & $1.1 \pm 0.6$ & $1.1 \pm 0.6$ & $7.6 \pm 6.7 *$ \\
RV $_{\text {STV }}$ & $2.2 \pm 2.2$ & $3.8 \pm 3.8$ & $1.0 \pm 0.4$ & $0.9 \pm 0.5$ & $5.9 \pm 5.5 *$ \\
\hline
\end{tabular}

Note. Values are represented as mean \pm SD.

avan de Water QTC $=$ QT $-0.087 *($ RR - 1,000).

$* P<0.05$, significantly different from baseline. 


\section{DISCUSSION}

In the present study, we evaluated the in vivo antiarrhythmic effect of LUF7244 for the first time. We found that LUF7244 increased I I $\mathrm{Kv11.1}_{1.1}$ in HEK-hERG cells and shortened APD in both hiPS-CMC and isolated ventricular canine cardiomyocytes. LUF7244 $(10 \mu \mathrm{M})$ had no effects on $\mathrm{I}_{\mathrm{KIR} 2.1}, \mathrm{I}_{\text {Nav1.5, }} \mathrm{I}_{\mathrm{Ca}-\mathrm{L}}$ and $\mathrm{I}_{\mathrm{Ks}}$ but doubled $\mathrm{I}_{\mathrm{Kr}}$. Moreover, LUF7244 protected $71 \%$ of the tested dogs from dofetilide-induced TdP. In those five CAVB dogs with higher LUF7244 plasma concentration, LUF7244 protected 5/5 dogs from dofetilide-induced TdP.

Allosteric modulators bind to a site topographically distinct from the endogenous or orthosteric site, leading to a change in receptor conformation. For a negative allosteric modulator of the $\mathrm{K}_{\mathrm{v}} 11.1$ channel, this will result in reduced affinity for inhibitors. Indeed, previous work demonstrated that LUF7244 decreased $\mathrm{K}_{\mathrm{v}} 11.1$ affinity for astemizole, sertindole, cisapride, or dofetilide ( $Y u$ et al., 2016). While the latter was confirmed in our studies, it was also found that LUF7244 is a $\mathrm{K}_{\mathrm{v}} 11.1$ channel activator that enhances $I_{\text {Kv11.1 }}$ even in the absence of orthosteric inhibitors. Furthermore, at a concentration above $3 \mu \mathrm{M}$, LUF7244 caused APD shortening in hiPS-CMCs and isolated canine cardiomyocytes suggesting also that LUF7244 can directly act as a $\mathrm{K}_{\mathrm{v}} 11.1$ activator in cardiomyocytes. A number of other $K_{v} 11.1$ activators have been described, including RPR260243, (Kang et al., 2005), PD-118057 (Zhou et al., 2005), PD307243 (Gordon et al., 2008), NS1643 (Hansen et al., 2006), A-935142 (Su et al., 2009), Vu0405601 (Potet et al. 2012), NS3623 (Hansen, Olesen, Rønn, \& Grunnet, 2008), and ICA-105574 (Gerlach,Stoehr, \& Castle, 2009). Collectively, these show that activators can work via distinct or combined mechanisms such as slowing of deactivation, removal of inactivation, and facilitation of activation (Sanguinetti, 2014). Our data indicate that LUF7244 results in a decrease of rapid inactivation. The structurally closely related LUF7346 is thought to increase $I_{\mathrm{Kr}}$ by a rightward shift of voltage dependence of inactivation and a slowing of deactivation kinetics (Sala et al., 2016). Furthermore, ICA-105574 and ML-T531 (Zhang et al., 2012), two other structurally related activators, demonstrated type 2 activator properties (Perry et al., 2010), that is, primarily attenuating inactivation (Gerlach, Stoehr, \& Castle, 2009; Zhang et al., 2012). We demonstrated earlier (Garg, Stary-Weinzinger, \& Sanguinetti, 2013) that ICA-105574, an 
activator with related chemical structure, might bind at the interface between two subunits, with residue $\mathrm{F} 557$ being a key binding determinant. Our docking studies with LUF7244 suggest a highly similar binding mode between these two compounds. The main difference between these two compounds is the size of the molecule. Due to the larger size of LUF7244, this compound is predicted to protrude partially into the hERG cavity, where it might disturb/influence dofetilide binding. Importantly, we have recently shown that dofetilide indeed can interact not only with aromatic side chains in the cavity but with F557 from helix S5 (Saxena et al., 2016). The amino acid sequence of the LUF7244 binding sites is completely conserved between dog and human, which is also in line with the similar effects of LUF7244 in human iPS derived CMCs compared to isolated canine CMCs. Whether LUF7244 binding to this site is responsible for the decrease in affinity of astemizole, sertindole, cisapride, or dofetilide remains to be elucidated.

At the cellular level, LUF7244 effectively suppressed dofetilideinduced EADs in single ventricular dog CMCs at 3 and $10 \mu \mathrm{M}$, isolated either from normal (SR) or remodeled (CAVB) hearts. At $10 \mu \mathrm{M}$ the antiarrhythmic properties clearly go along with normalization of APD compared to baseline. In a prevention set-up, LUF7244 $(10 \mu \mathrm{M})$ was able to avert astemizole-, sertindole-, or cisapride-induced EADs in neonatal rat ventricular CMCs (Yu et al., 2016). LUF7346 (3 $\mu \mathrm{M})$ counteracted astemizole-induced EADs in predisposed hiPS-CMC bearing a proarrhythmic KCNQ1 mutation (Sala et al., 2016).

In our prevention set-up using CAVB dogs, LUF7244 prevented the occurrence of dofetilide-induced TdP arrhythmias in the majority of animals $(5 / 7)$, although single ectopic beats remained present in five animals. APD remained prolonged compared to baseline. This might indicate that the antiarrhythmic action of LUF7244 becomes apparent at lower concentrations than its effect on counteracting dofetilide-induced AP prolongation, just as observed at the single cell level. Only ICA-105574 has been tested on organ level and in vivo. ICA-105574 prevents ventricular tachycardia/ventricular fibrillation in Langendorff-perfused guinea pig hearts treated with moxifloxacin or chromanol 293B under hypokalaemic conditions (Meng, Shi, Li, Du, \& Xu, 2013). The authors noted that ICA105574-mediated restriction of drug-induced increases in transmural 
dispersion of repolarization and instability of the QT interval might contribute to the antiarrhythmic mechanism (Meng, Shi, Li, Du, \& Xu, 2013). In anesthetized dogs, ICA-105574 decreased QT(c) (20\% at maximal effect) at $10 \mathrm{mg} \cdot \mathrm{kg}^{-1} \cdot 10 \mathrm{~min}^{-1}$, but not at $3 \mathrm{mg} \cdot \mathrm{kg}^{-1}$, and increased heart rate (Asayama et al., 2013). ICA-105574 free plasma level at maximal response was $1.7 \mu \mathrm{M}$. In our SR dogs, LUF7244 administration $\left(2.5 \mathrm{mg} \cdot \mathrm{kg}^{-1} \cdot 15 \mathrm{~min}^{-1}\right)$ was accompanied by, although not reaching significance, heart rate increase (14\%) and shortened QTc (6.8\%). Total plasma concentration was $1.75 \mu \mathrm{M}$ at $t=15$. We have not determined free plasma concentrations.

Antiarrhythmic properties in CAVB dogs correlate with total plasma concentration, but the source of the large variation in plasma concentrations in our seven CAVB animals is unclear. From plasma sampling in the $S R$ animals, it is clear that $T 1 / 2$ is extremely short and even small variations in sampling time might have strong effects. In itself, a short $T_{1 / 2}$ can be beneficial for a drug that is administered intravenously, as stopping the infusion terminates the effect providing full control to the interventionist.

The anti-arrhythmic mechanism deployed by LUF7244 is unclear thus far. Temporal dispersion, determined as STV, in baseline is not decreased at the cell level, neither in whole animals. Also, no effect on the dofetilideinduced increase in spatial dispersion (LVMAPD80-RV $V_{\text {MAPD80 }}$ ) was observed in CAVB animals (39 vs. $89 \mathrm{~ms}$ in inducibility experiment [baseline vs. Dofetilide] and 52 vs. 60 vs. $104 \mathrm{~ms}$ in prevention experiment [baseline vs. LUF7244 vs. LUF7244 + Dofetilide]). Enhanced spatial resolution in APD sampling (e.g., Bossu et al., 2018; Dunnink et al., 2016) will be necessary to determine whether local dispersion (either temporal or spatial) is targeted by LUF7244 to generate its antiarrhythmic effects.

LUF7244 may represent a novel pharmacological strategy to eliminate the unintended cardiac side effect of noncardiac drugs. Potentially, it could save numerous effective drugs. Furthermore, there are numbers of compounds that cannot pass the preclinical test because of blockade of $\mathrm{I}_{\mathrm{kr}}$. The combination of existing proarrhythmic drugs with LUF7244 would be an approach to prevent arrhythmia due to drug-induced blockade of $\mathrm{I}_{\mathrm{kr}}$. Finally, LUF7244 and similar compounds may find a use in relieving some of the effects of long QT syndrome. 
Chapter 5

\section{Limitations}

The in vivo experiments were performed in CAVB dogs under anaesthesia. The anaesthetics are known to inhibit $\mathrm{I}_{\mathrm{kr}}$ current whose actions might interfere with LUF7244 action. Only a single dose of LUF7244 was tested in this study. 


\section{REFERENCES}

Abraham M, Hess B, van der Spoel D, Lindahl E (2015). USER MANUAL Version 5.0. 7. The GROMACS Development Teams at the Royal Institute of Technology and Uppsala University, Sweden.

Alexander, S. P.H., Striessnig, J., Kelly, E., Marrion, N. V., Peters, J. A., Faccenda, E., et al. (2017). The Concise Guide to PHARMACOLOGY 2017/18: Voltage-gated ion channels. Br J Pharmacol 174:S160-S194.

Asayama M, Kurokawa J, Shirakawa K, Okuyama H, Kagawa T, Okada J-i, et al. (2013). Effects of an hERG activator, ICA-105574, on electrophysiological properties of canine hearts. J Pharmacol Sci 121: $1-8$.

Baburin I, Varkevisser R, Schramm A, Saxena P, Beyl S, Szkokan P, et al. (2018). Dehydroevodiamine and hortiamine, alkaloids from the traditional Chinese herbal drug Evodia rutaecarpa, are IKr blockers with proarrhythmic effects in vitro and in vivo. Pharmacol Res 131: 150-163.

Bossu A, Houtman MJ, Meijborg VM, Varkevisser R, Beekman HD, Dunnink A, et al. (2018). Selective late sodium current inhibitor GS-458967 suppresses Torsades de Pointes by mostly affecting perpetuation but not initiation of the arrhythmia. $\mathrm{Br}$ J Pharmacol 175: 2470-2482.

Bussi G, Donadio D, Parrinello M (2007). Canonical sampling through velocity rescaling. J Chem Phys 126: 014101.

Conn PJ, Christopoulos A, Lindsley CW (2009). Allosteric modulators of GPCRs: a novel approach for the treatment of CNS disorders. Nat Rev Drug Discov 8: 41-54.

Curtis MJ, Alexander S, Cirino G, Docherty JR, George CH, Giembycz MA, et al. (2018). Experimental design and analysis and their reporting II: updated and simplified guidance for authors and peer reviewers. $\mathrm{Br} J$ Pharmacol, 175(7), 987-993. 


\section{Chapter 5}

Darden T, York D, Pedersen L (1993). Particle mesh Ewald: An N. log (N) method for Ewald sums in large systems. J Chem Phys 98: 1008910092.

Darpö B (2001). Spectrum of drugs prolonging QT interval and the incidence of torsades de pointes. Eur Heart J Suppl 3: K70-K80.

De Boer TP, van Veen TA, Houtman MJ, Jansen JA, van Amersfoorth SC, Doevendans PA, et al., (2006). Inhibition of cardiomyocyte automaticity by electrotonic application of inward rectifier current from Kir2.1 expressing cells. Med Biol Eng Comput 44: 537-542.

Dunnink A, Stams TR, Bossu A, Meijborg VM, Beekman JD, Wijers SC, et al. (2016). Torsade de pointes arrhythmias arise at the site of maximal heterogeneity of repolarization in the chronic complete atrioventricular block dog. Europace 19: 858-865.

Garg V, Stary-Weinzinger A, Sanguinetti MC (2013). ICA-105574 interacts with a common binding site to elicit opposite effects on inactivation gating of EAG and ERG potassium channels. Mol Pharmacol 83:805813.

Gerlach AC, Stoehr SJ, Castle NA (2009). Pharmacological Removal of hERG Potassium Channel Inactivation by ICA-105574. Mol Pharmacol 77:5868.

Gordon E, Lozinskaya IM, Lin Z, Semus SF, Blaney FE, Willette RN, et al. (2008). 2-[2-(3, 4-dichloro-phenyl)-2, 3-dihydro-1H-isoindol-5ylamino]-nicotinic acid (PD-307243) causes instantaneous current through human ether-a-go-go-related gene potassium channels. Mol Pharmacol 73: 639-651.

Grunnet M, Hansen RS, Olesen S-P (2008). hERG1 channel activators: a new anti-arrhythmic principle. Prog Biophys Mol Biol 98: 347-362.

Hansen RS, Diness TG, Christ T, Demnitz J, Ravens U, Olesen SP, et al. (2006). Activation of human ether-a-go-go-related gene potassium 
channels by the diphenylurea 1, 3-bis-(2-hydroxy-5-trifluoromethylphenyl)-urea (NS1643). Mol Pharmacol 69: 266-277.

Hansen RS, Olesen S-P, Rønn LCB, Grunnet M (2008). In Vivo Effects of the IKr Agonist NS3623 on Cardiac Electrophysiology of the Guinea Pig. J Cardiovasc Pharmacol 52: 35-41.

Harding, S. D., Sharman, J. L., Faccenda, E., Southan, C., Pawson, A. J., Ireland, S., et al. (2018). The IUPHAR/BPS Guide to PHARMACOLOGY in 2018: Updates and expansion to encompass the new guide to IMMUNOPHARMACOLOGY. Nucleic Acids Research 46: D1106.

Hess B, Bekker H, Berendsen HJC, Fraaije JGEM (1997). LINCS: a linear constraint solver for molecular simulations. J Comput Chem 18: 14631472.

Humphrey W, Dalke A, Schulten K (1996). VMD: visual molecular dynamics. J Mol Graph 14: 33-38.

Jo S, Kim T, Iyer VG, Im W (2008). CHARMM-GUI: a web-based graphical user interface for CHARMM. J Comput Chem 29: 1859-1865.

Jones G, Willett P, Glen RC, Leach AR, Taylor R (1997). Development and validation of a genetic algorithm for flexible docking. J Mol Biol 267: 727-748.

Kang J, Chen X-L, Wang $H$, Ji J, Cheng $H$, Incardona J, et al. (2005). Discovery of a small molecule activator of the human ether-a-go-gorelated gene (HERG) cardiac K+ channel. Mol Pharmacol 67: 827-836.

Kilkenny C, Browne W, Cuthill IC, Emerson M, Altman DG (2010). Animal research: reporting in vivo experiments: the ARRIVE guidelines. $\mathrm{Br}$ J Pharmacol 160: 1577-1579.

Meng J, Shi C, Li L, Du Y, Xu Y (2013). Compound ICA-105574 prevents arrhythmias induced by cardiac delayed repolarization. Eur J Pharmacol 718: 87-97. 


\section{Chapter 5}

Opstal JM, Leunissen JDM, Wellens HJJ, Vos MA (2001). Azimilide and dofetilide produce similar electrophysiological and proarrhythmic effects in a canine model of Torsade de Pointes arrhythmias. Eur J Pharmacol 412: 67-76.

Oros A, Beekman JD, Vos MA (2008). The canine model with chronic, complete atrio-ventricular block. Pharmacol Ther 119: 168-178.

Parrinello M, Rahman A (1981). Polymorphic transitions in single crystals: A new molecular dynamics method. J Appl Phys 52: 7182-7190.

Perry M, Sanguinetti M, Mitcheson J (2010). Symposium review: revealing the structural basis of action of hERG potassium channel activators and blockers. J Physiol 588: 3157-3167.

Potet F, Lorinc AN, Chaigne S, Hopkins CR, Venkataraman R, Stepanovic $S Z$, et al. (2012). Identification and Characterization of a Compound That Protects Cardiac Tissue from Human Ether-à-go-go-related Gene (hERG)-related Drug-induced Arrhythmias. J Biol Chem 287: 3961339625.

Sala L, Yu Z, Ward-van Oostwaard D, van Veldhoven JP, Moretti A, Laugwitz $\mathrm{KL}$, et al. (2016). A new hERG allosteric modulator rescues genetic and drug-induced long-QT syndrome phenotypes in cardiomyocytes from isogenic pairs of patient induced pluripotent stem cells. EMBO Mol Med 8: $1065-1081$.

Salama G, Bett GC. (2014). Sex differences in the mechanisms underlying long QT syndrome. Am J Physiol Heart Circ Physiol 307: H640-648.

Salvi V, Karnad DR, Panicker GK, Kothari S (2010). Update on the evaluation of a new drug for effects on cardiac repolarization in humans: issues in early drug development. $\mathrm{Br} \mathrm{J}$ Pharmacol 159: 3448.

Sanguinetti MC (2014). HERG1 channel agonists and cardiac arrhythmia. Curr Opin Pharmacol 15: 22-27. 
Sanguinetti MC, Tristani-Firouzi M (2006). hERG potassium channels and cardiac arrhythmia. Nature 440: 463-469.

Saxena P, Zangerl-PlessI EM, Linder T, Windisch A, Hohaus A, Timin E, et al. (2016). New potential binding determinant for hERG channel inhibitors. Sci Rep 6: 24182.

Schneider J, Hauser R, Andreas J-O, Linz K, Jahnel U (2005). Differential effects of human ether-a-go-go-related gene (HERG) blocking agents on QT duration variability in conscious dogs. Eur J Pharmacol 512: 5360 .

Schoenmakers M, Ramakers C, van Opstal JM, Leunissen JDM, Londoño C, Vos MA (2003). Asynchronous development of electrical remodeling and cardiac hypertrophy in the complete AV block dog. Cardiovasc Res 59: 351-359.

Schrödinger LLC (2017). The PyMOL molecular graphics system, Version 1.8. 2015.

Stams TRG, Oosterhoff $P$, Heijdel A, Dunnink A, Beekman JDM, van der Nagel R, et al. (2016). Beat-to-Beat Variability in Preload Unmasks Latent Risk of Torsade de Pointes in Anesthetized Chronic Atrioventricular Block Dogs. Circ J 80: 1336-1345.

Su Z, Limberis J, Souers A, Kym P, Mikhail A, Houseman K, et al. (2009). Electrophysiologic characterization of a novel hERG channel activator. Biochem Pharmacol 77: 1383-1390.

Vanommeslaeghe K, Hatcher E, Acharya C, Kundu S, Zhong S, Shim J, et al. (2010). CHARMM general force field: A force field for drug-like molecules compatible with the CHARMM all-atom additive biological force fields. J Comput Chem 31: 671-690.

Varkevisser R, Wijers SC, van der Heyden MAG, Beekman JDM, Meine M, Vos MA (2012). Beat-to-beat variability of repolarization as a new biomarker for proarrhythmia in vivo. Heart Rhythm 9: 1718-1726. 


\section{Chapter 5}

Yu Z, Klaasse E, Heitman LH, IJzerman AP (2014). Allosteric modulators of the hERG $\mathrm{K}+$ channel: Radioligand binding assays reveal allosteric characteristics of dofetilide analogs. Toxicol Appl Pharmacol 274: 7886.

Yu Z, Liu J, van Veldhoven JPD, IJzerman AP, Schalij MJ, Pijnappels DA, et al. (2016). Allosteric modulation of Kv11. 1 (hERG) channels protects against drug-induced ventricular arrhythmias. Circ Arrhythm Electrophysiol 9: e003439.

Zhang H, Zou B, Yu H, Moretti A, Wang X, Yan W, et al. (2012). Modulation of $h E R G$ potassium channel gating normalizes action potential duration prolonged by dysfunctional KCNQ1 potassium channel. Proc Natl Acad Sci USA 109: 11866-11871.

Zhou J, Augelli-Szafran CE, Bradley JA, Chen X, Koci BJ, Volberg WA, et al. (2005). Novel potent human ether-a-go-go-related gene (hERG) potassium channel enhancers and their in vitro antiarrhythmic activity. Mol Pharmacol 68: 876-884.

Zhou Z, Gong Q, Epstein ML, January CT. (1998). HERG channel dysfunction in human long QT syndrome. Intracellular transport and functional defects. J Biol Chem 273: 21061-21066. 


\section{SUPPLEMENTARY MATERIAL}

Supplemental Table S1. Characteristics of dogs $(n=10)$ involved in in vivo experiment.

\begin{tabular}{|c|c|c|c|c|}
\hline \multicolumn{5}{|c|}{ Sinus Rhythm experiment } \\
\hline No. & Type & sex & Dog number & weight \\
\hline 1 & SR & $\mathrm{m}$ & 119335 & $25 \mathrm{~kg}$ \\
\hline 2 & SR & $\mathrm{m}$ & 119394 & 27 kg \\
\hline 3 & SR & $f$ & 124291 & $20 \mathrm{~kg}$ \\
\hline 4 & SR & $f$ & 136272 & $19 \mathrm{~kg}$ \\
\hline 5 & SR & $\mathrm{f}$ & 141209 & $23 \mathrm{~kg}$ \\
\hline \multicolumn{5}{|c|}{ Inducibility experiment } \\
\hline No. & Type $^{a}$ & sex & Dog number & weight \\
\hline 1 & CAVB2 & $m$ & 119335 & $26 \mathrm{~kg}$ \\
\hline 2 & CAVB2 & $\mathrm{m}$ & 119394 & $26 \mathrm{~kg}$ \\
\hline 6 & CAVB2 & $\mathrm{m}$ & 118860 & $27 \mathrm{~kg}$ \\
\hline 7 & CAVB2 & $\mathrm{m}$ & 118487 & $26 \mathrm{~kg}$ \\
\hline 8 & CAVB2 & $\mathrm{m}$ & 118479 & $29 \mathrm{~kg}$ \\
\hline 9 & CAVB2 & $\mathrm{m}$ & 119840 & $27 \mathrm{~kg}$ \\
\hline 10 & CAVB2 & $f$ & 133702 & $20 \mathrm{~kg}$ \\
\hline \multicolumn{5}{|c|}{ Prevention experiment } \\
\hline No. & Type $^{a}$ & sex & Dog number & weight \\
\hline 1 & CAVB4 & $\mathrm{m}$ & 119335 & $25 \mathrm{~kg}$ \\
\hline 2 & CAVB5 & $\mathrm{m}$ & 119394 & $26 \mathrm{~kg}$ \\
\hline 6 & CAVB6 & $\mathrm{m}$ & 118860 & $29 \mathrm{~kg}$ \\
\hline 7 & CAVB6 & $\mathrm{m}$ & 118487 & $27 \mathrm{~kg}$ \\
\hline 8 & CAVB5 & $\mathrm{m}$ & 118479 & $28 \mathrm{~kg}$ \\
\hline 9 & CAVB4 & $\mathrm{m}$ & 119840 & $27 \mathrm{~kg}$ \\
\hline 10 & CAVB4 & $\mathrm{f}$ & 133702 & $20 \mathrm{~kg}$ \\
\hline
\end{tabular}

a number indicates weeks of CAVB 


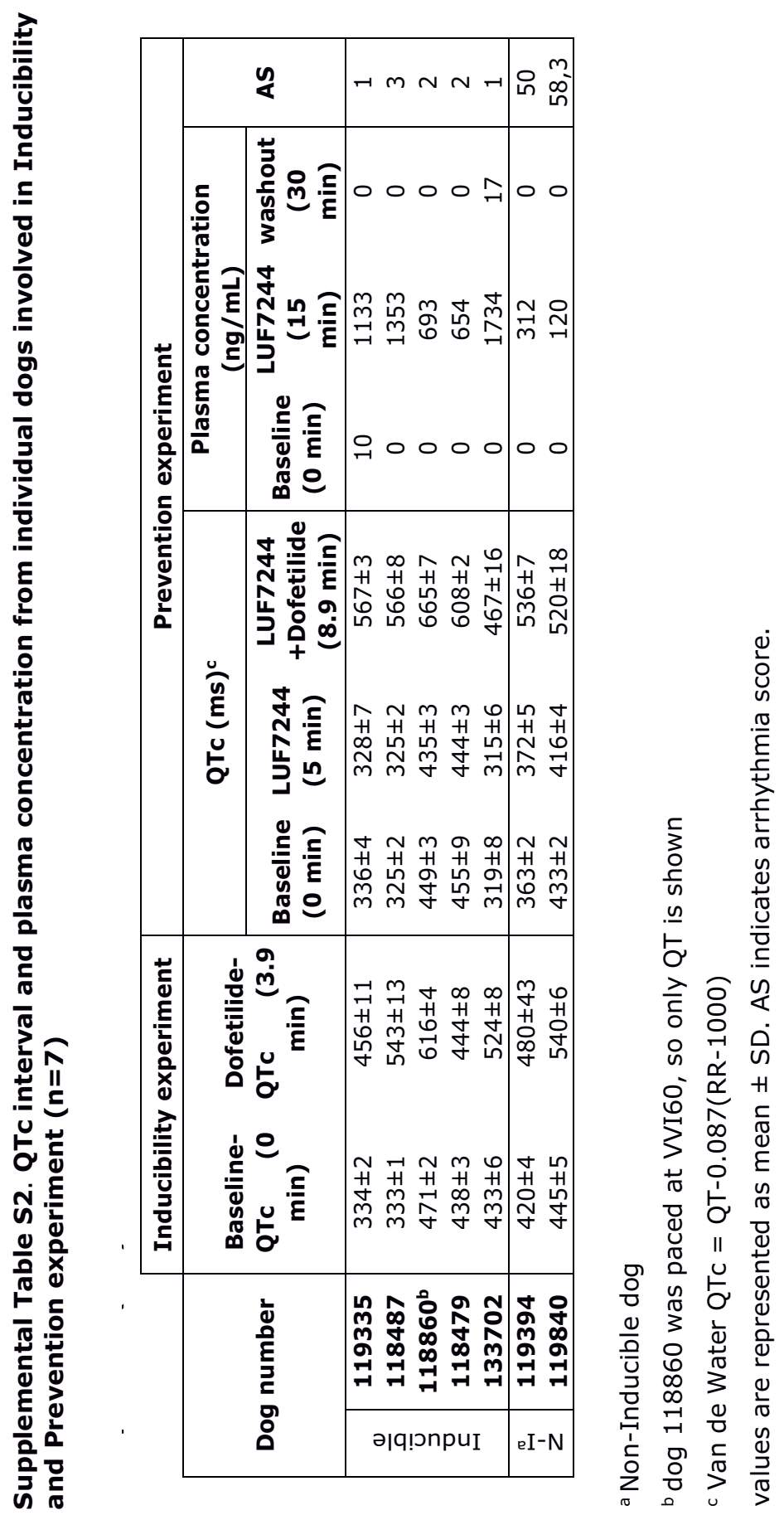


QTC

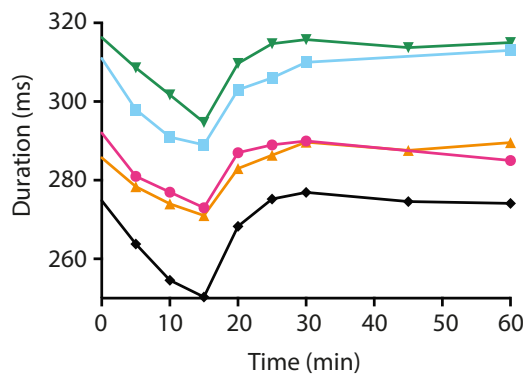

RR

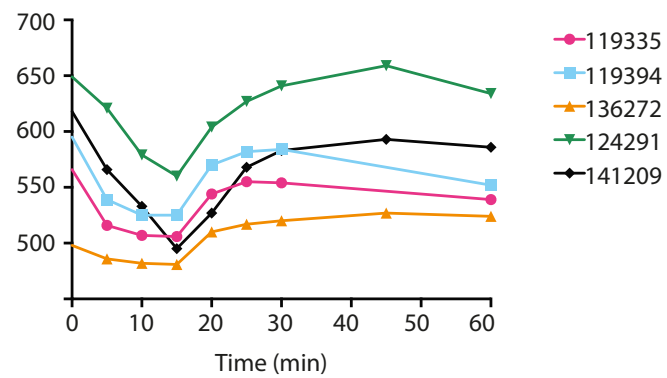

Supplemental Figure S1. QTC (left panel) and RR (right panel) interval in individual SR dogs receiving LUF7244 (2.5 $\left.\mathrm{mg} \cdot \mathrm{kg}^{-1} \cdot 15 \mathrm{~min}^{-1}, 0-15 \mathrm{~min}\right)$ and washout (15-60 $\mathrm{min}$ ). Dog identification numbers are indicated on the right. 


$$
\boldsymbol{G}
$$




\section{LUF7244 plus dofetilide rescues aberrant $K_{v} 11.1$ trafficking and produces functional $I_{\text {Kv11.1 }}$}

M. Qile ${ }^{1,}{ }^{*}$, Y. Ji ${ }^{1,}{ }^{*}$, T.D. Golden ${ }^{2}$, M.J.C. Houtman ${ }^{1}$, F. Romunde ${ }^{1}$, D. Fransen ${ }^{1}$, W.B. van Ham ${ }^{1,3}$, A.P. IJzerman ${ }^{4}$, C.T. January ${ }^{5}$, L.H. Heitman ${ }^{4}$, A. Stary-Weinzinger ${ }^{3}$, B.P. Delisle ${ }^{2}$, M.A.G. van der Heyden ${ }^{1}$

1 Department of Medical Physiology, Division of Heart \& Lungs,

University Medical Center Utrecht, Utrecht, The Netherlands 2 Department of Physiology, University of Kentucky, Lexington, Kentucky 3 Department of Pharmacology and Toxicology, University of Vienna, Vienna, Austria

4 Leiden Academic Centre for Drug Research,

Division of Drug Discovery and Safety, Leiden, The Netherlands 5 Department of Medicine, University of Wisconsin, Madison, Wisconsin * These authors contributed equally to this work 


\section{MOLECULAR}

\section{PHARMACOLOGY}

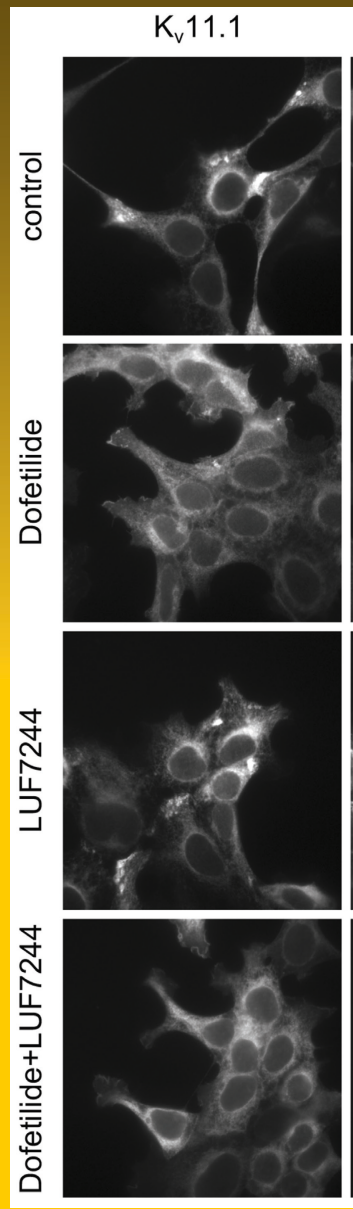

Cadherin

merge

linescan
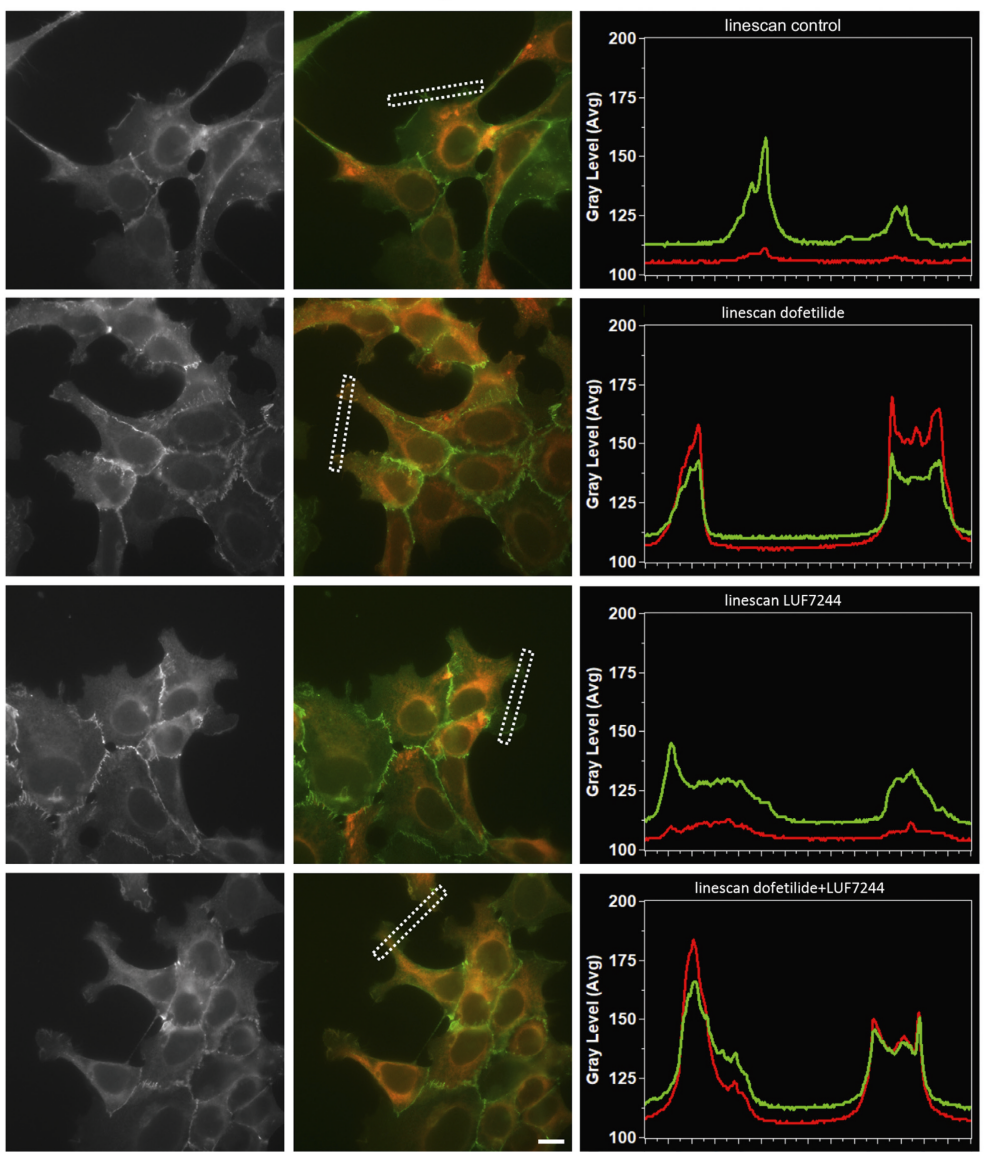

A Publication of the American Society for Pharmacology and Experimental Therapeutics 


\section{ABSTRACT}

Voltage-gated potassium 11.1 (Kv11.1) channels play a critical role in repolarization of cardiomyocytes during the cardiac action potential (AP). Drug-mediated $\mathrm{K}_{\mathrm{v}} 11.1$ blockade results in AP prolongation, which poses an increased risk of sudden cardiac death. Many drugs, like pentamidine, interfere with normal $\mathrm{K}_{\mathrm{v}} 11.1$ forward trafficking and thus reduce functional $\mathrm{K}_{\mathrm{v}} 11.1$ channel densities. Although class III antiarrhythmics, e.g., dofetilide, rescue congenital and acquired forward trafficking defects, this is of little use because of their simultaneous acute channel blocking effect. We aimed to test the ability of a combination of dofetilide plus LUF7244, a $\mathrm{K}_{\mathrm{v}} 11.1$ allosteric modulator/activator, to rescue $\mathrm{K}_{\mathrm{v}} 11.1$ trafficking and produce functional $K_{v} 11.1$ current. LUF7244 treatment by itself did not disturb or rescue wild type (WT) or G601S- $\mathrm{K}_{\mathrm{v}} 11.1$ trafficking, as shown by Western blot and immunofluorescence microcopy analysis. Pentamidine-decreased maturation of WT $K_{v} 11.1$ levels was rescued by $10 \mu \mathrm{M}$ dofetilide or $10 \mu \mathrm{M}$ dofetilide $+5 \mu \mathrm{M}$ LUF7244. In trafficking defective G601S-Kv11.1 cells, dofetilide $(10 \mu \mathrm{M})$ or dofetilide + LUF7244 $(10+5 \mu \mathrm{M})$ also restored $\mathrm{K}_{\mathrm{v}} 11.1$ trafficking, as demonstrated by Western blot and immunofluorescence microscopy. LUF7244 $(10 \mu \mathrm{M})$ increased $I_{\text {Kv11.1 }}$ despite the presence of dofetilide $(1 \mu \mathrm{M})$ in WT $\mathrm{K}_{\mathrm{v}} 11.1$ cells. In G601S-expressing cells, long-term treatment (24-48 hour) with LUF7244 $(10 \mu \mathrm{M})$ and dofetilide $(1 \mu \mathrm{M})$ increased $\mathrm{I}_{\mathrm{Kv11.1}}$ compared with nontreated or acutely treated cells. We conclude that dofetilide plus LUF7244 rescues $\mathrm{K}_{\mathrm{v}} 11.1$ trafficking and produces functional $\mathrm{I}_{\mathrm{Kv} 11.1}$. Thus, combined administration of LUF7244 and an $I_{\mathrm{kv} 11.1}$ trafficking corrector could serve as a new pharmacological therapy of both congenital and drug-induced $\mathrm{K}_{\mathrm{v}} 11.1$ trafficking defects. 


\section{INTRODUCTION}

Human $\mathrm{K}_{\mathrm{v}} 11.1$ potassium ion channels (also known as human ethera-go-go related gene (hERG) channels) stand at the basis of the rapidly activating delayed rectifier current $\left(\mathrm{I}_{\mathrm{Kr}}\right)$, which is involved in phase three repolarization of the action potential (AP) in working cardiomyocytes (Vandenberg et al., 2012). Interference with normal $\mathrm{I}_{\mathrm{Kr}}$ function can either shorten (gain-of-function) or prolong (loss-of-function) the process of ventricular repolarization, as evident from QT-shortening or lengthening, respectively, on the ECG (Vandenberg et al., 2012). I $\mathrm{kr}$ inhibition in humans, e.g., by the class III agent dofetilide, is associated with life-threatening ventricular arrhythmias (Torp-Pedersen et al., 1999). Fundamentally different mechanisms of $\mathrm{I}_{\mathrm{Kr}}$ inhibition have been identified: 1) direct inhibition of potassium flow through the channel and 2) decreased plasma membrane expression of channel proteins, which both can result from mutations (de novo or congenital) or environmental factors (acquired, mostly drug-induced) (Sanguinetti and Tristani-Firouzi, 2006; De Git et al., 2013). For these reasons, cardiac safety assessment of new chemical entities and preclinical drugs still has a strong focus on $\mathrm{K}_{\mathrm{v}} 11.1$ channel function (Bossu et al., 2016) and mainly aims at detection of (semi)acute pore block. Interestingly, the vast majority (approximately $90 \%$ of 167 tested) of congenital $\mathrm{K}_{\mathrm{v}} 11.1$ loss-of-function missense mutations result in trafficking defects as a cause of $\mathrm{I}_{\mathrm{Kr}}$ impairment (Anderson et al., 2006, 2014). For example, the G601S missense mutation in $K_{v} 11.1$, located in the $\mathrm{S} 5$-pore helix linker, results in reduced expression of functional $\mathrm{I}_{\mathrm{Kr}}$, leading to hypomorphic LQT2 (the second most common long QT syndrome) (Ficker et al., 2002). Also a number of drugs ( $>40 \%$ of 100 tested) limit expression of $\mathrm{K}_{\mathrm{v}} 11.1$ at the plasma membrane by inhibiting its forward trafficking, with or without concomitant pore block (Wible et al., 2005). The antitrypanosomiasis/leishmanias drug pentamidine is currently used as a $\mathrm{K}_{\mathrm{v}} 11.1$ trafficking inhibitor without acute channel inhibition (Cordes et al., 2005; Kuryshev et al., 2005; Nalos et al., 2011; Himmel 2013; Varkevisser et al., 2013a,b; Obergrussberger et al., 2016). Pentamidine inhibits $\mathrm{K}_{\mathrm{v}} 11.1$ forward trafficking at the level of endoplasmic reticulum exit in a process that involves the high-affinity drug binding site F656 (Dennis et al., 2012). As a result, cells mainly express intracellularly localized core-glycosylated $\mathrm{K}_{\mathrm{v}} 11.1$ with an apparent molecular mass of $135 \mathrm{kDa}$. 
High-affinity $\mathrm{K}_{\mathrm{v}} 11.1$ pore blockers such as E4031, dofetilide, cisapride and astemizole are able to rescue forward trafficking defects caused by either mutations or drugs (Zhou et al., 1999; Ficker et al., 2002; Varkevisser et al., 2013a; Yan et al., 2015). This will result in $\mathrm{K}_{\mathrm{v}} 11.1$ maturation, seen as a fully glycosylated protein with an apparent molecular weight of $155 \mathrm{kDa}$. The underlying mechanisms have not been clarified completely thus far, although it is found that channel inhibition potency correlates with rescue efficacy and that drug-channel interactions via high affinity binding sites are essential (Ficker et al., 2002; Rajamani et al., 2002; Dennis et al., 2012; Yan et al., 2015). Furthermore, EC $_{50}$ values for rescue are generally much higher than IC $_{50}$ values for acute pore block (e.g., astemizole, $\mathrm{IC}_{50}=6-13 \mathrm{nM}$; $\mathrm{EC}_{50}$ for rescue $=335 \pm 33 \mathrm{nM}$ with $10 \mu \mathrm{M}$ pentamidine) (Ficker et al., 2002; Dennis et al., 2012). Therefore, this strategy will not result in rescue of $\mathrm{I}_{\mathrm{Kr}}$ function as long as the high-affinity blocker remains present, whereas its withdrawal will not resolve the underlying trafficking defects. Activators and negative allosteric modulators of $\mathrm{K}_{\mathrm{v}} 11.1$ have been developed as a strategy to counteract undesired $\mathrm{I}_{\mathrm{Kr}}$ blockade and thus potentially could "save" numerous (pre)clinical drugs with proven Ikr liability (Yu et al., 2014, 2016; Sala et al., 2016; Qile et al., 2019). Allosteric modulators interact with the $K_{v} 11.1$ channel at a site different than that used by the high-affinity inhibitors, and thereby modulate binding affinities for the canonical binding site of the latter. Activators interact with $\mathrm{K}_{\mathrm{v}} 11.1$ at various sites (Sanguinetti, 2014), and some share overlapping high-affinity molecular determinants (Casis et al, 2006; Perry et al, 2007; Garg et al, 2013) with classical pore blockers. We have developed the negative allosteric modulator/activator LUF7244, which indeed is able to counteract drug-induced AP prolongation and proarrhythmia in vitro (Yu et al., 2015, 2016) and drug-induced ventricular arrhythmia in vivo (Qile et al., 2019). Specifically, application of $10 \mu \mathrm{M}$ LUF7244 decreased the affinity of $\mathrm{K}_{\mathrm{v}} 11.1$ for cisapride, astemizole, dofetilide, and sertindole by $4.0-, 3.8-, 3.2-$, and 2.2 -fold, respectively (Yu et al., 2016). We hypothesized that LUF7244 would not interfere in $\mathrm{K}_{\mathrm{v}} 11.1$ trafficking by itself and would also not interfere in dofetilide-mediated rescue of defective forward trafficking, but it maintains its ability to increase $\mathrm{I}_{\mathrm{Kr}}$ in the presence of dofetilide. 


\section{MATERIALS AND METHODS}

\section{Chemicals}

LUF7244 was custom synthesized at the Division of Drug Discovery and Safety, Leiden Academic Centre for Drug Research, Leiden University, The Netherlands, as described earlier (Yu Z et al., 2016), and was dissolved in DMSO at $100 \mathrm{mM}$. Dofetilide was purchased from Sigma-Aldrich (Zwijndrecht, The Netherlands) and dissolved at $10 \mathrm{mM}$ in DMSO. E4031 was dissolved in DMSO at $1 \mathrm{mM}$. Pentamidine-isethionate (Pentacarinat 300; Sanofi Aventis, Gouda, The Netherlands) was dissolved in water to provide a stock solution of $100 \mathrm{mM}$. All compounds were sterilized by filtration $(0.22$ $\mu \mathrm{m})$, aliquoted, and stored at $-20^{\circ} \mathrm{C}$ until use.

\section{Molecular modeling}

Compounds LUF7244 and dofetilide were docked into the hERG cryogenic electron microscopy (cryo-EM) structure (Protein Data Bank code: 5va1, Wang and Mackinnon, 2017) using the GOLD software v.5.6.2. (Jones et al., 1997), essentially as described before (Qile et al., 2019). Two scoring functions, ChemPLP and Goldscore, were used, and 100 poses collected per run with 125.000 Gold algorithm operations. The top 15 scoring poses each were analysed using PyMol 1.7.2 (Schrödinger, 2015).

\section{Molecular dynamics simulations}

Simulations were essentially performed as described earlier (Qile et al., 2019) with a few small modifications. The $K_{v} 11.1$ hERG structure was embedded in a phosphatidylcholines bilayer and solvated with transferable intermolecular potential with 3 points water using the CHARMM-GUI (Jo et al., 2008). $\mathrm{KCl}(150 \mathrm{mM})$ was added to the system and potassium ions in the selectivity filter where placed at sites S0, S2, and S4, with water molecules at sites S1 and S3. Steepest descent energy minimization, followed by 2 nanoseconds of equilibration and 50 nanoseconds of production runs, were performed using GROMACS v.5.1.2 (Abraham et al., 2015) and the charmm 36 force field (Vanommeslaeghe et al., 2010). 
Electrostatics were modeled using particle mesh Ewald (Darden et al., 1993), and linear constraint solver was used to constrain $\mathrm{H}$-bonds (Hess et al., 1997). V-rescale (Bussi et al., 2007) was used to keep the temperature at $310 \mathrm{~K}$, and semi-isotropic pressure coupling was done using the Parrinello-Rahman barostat (Parrinello and Rahman, 1981).

\section{Cells}

Human embryonic kidney (HEK)-hERG cells, which is the HEK293T cell line stably expressing human $\mathrm{K}_{\mathrm{v}} 11.1$ protein, and hERG-G601S cells (HEK293T cell line stably expressing forward trafficking-deficient $\mathrm{K}_{\mathrm{v}} 11.1$ protein) were cultured in Dulbecco's modified Eagle Medium (DMEM) (Gibco-Fisher Scientific, Landsmeer, The Netherlands) supplemented with $10 \%$ fetal calf serum (Sigma-Aldrich), $2 \mathrm{mM}$ L-glutamine, $50 \mathrm{U} \cdot \mathrm{mL}^{-1}$ penicillin, and $50 \mu \mathrm{g} \cdot \mathrm{mL}^{-1}$ streptomycin (all three; Lonza, Breda, The Netherlands) as described before (Varkevisser et al., 2013a).

\section{Patch clamp electrophysiology}

HEK-hERG and hERG-G601S cells were grown on Ø12-mm glass cover slips coated with poly-L-lysine (Sigma-Aldrich, German) and placed in a perfusion chamber (Cell Microcontrols, Norfolk, VA). Functional analyses were done by using standard whole-cell patch-clamp technique on HEK293T cells stably expressing wild type (WT)- or G601S- $\mathrm{K}_{\mathrm{v}} 11.1$ channels. The external solution contained (mM) $137 \mathrm{NaCl}, 4 \mathrm{KCl}, 1.8 \mathrm{CaCl}_{2}, 1 \mathrm{MgCl}_{2}, 10$ glucose, and 10 HEPES ( $\mathrm{pH} 7.4$ adjusted with $\mathrm{NaOH}$ ), and the internal pipette solution contained (mM) $130 \mathrm{KCl}, 1 \mathrm{MgCl}_{2}, 5 \mathrm{EGTA}, 5 \mathrm{MgATP}$, and 10 HEPES ( $\mathrm{pH} 7.2$ adjusted with $\mathrm{KOH}$ ). An Axopatch-200B patch clamp amplifier (Axon Instruments, Union City, CA) was used to measure macroscopic currents and cell capacitance. The pipette resistances were 1-3 M $\Omega$, and series resistance was compensated up to $90 \%$. The pCLAMP 10 software (Axon Instruments) was used to generate the different voltage protocols, acquire current signals, and for data analyses. We determined the impact that dofetilide and LUF7244 had on $\mathrm{K}_{\mathrm{v}} 11.1$ currents compared with control by applying step-like pulses from $-80 \mathrm{mV}$ to $+60 \mathrm{mV}$ in $+10-$ $\mathrm{mV}$ increments for 5 seconds, followed by a "tail" pulse to $-50 \mathrm{mV}$ for 5 seconds. The maximal I Ivv11.1 measured during the tail pulse was plotted as 
a function of the step-pulse potential to generate the corresponding I-V relations.

\section{Western blot}

Cell lysates were prepared in buffer D [20 mM HEPES, $125 \mathrm{mM} \mathrm{NaCl}$, $10 \%$ glycerol, $1 \mathrm{mM}$ EGTA, $1 \mathrm{mM}$ dithiothreitol, $1 \mathrm{mM}$ EDTA, and 1\% Triton $\mathrm{X}-100$ ( $\mathrm{pH}$ 7.6)] supplemented with $1 \mathrm{mM}$ phenylmethylsulfonyl flouride (PMSF) and $10 \mu \mathrm{g} \cdot \mathrm{mL}^{-1}$ aprotinin. Protein lysate $(25 \mu \mathrm{g})$ was mixed with Laemmli sample buffer, separated by 7\% SDS-PAGE, and blotted onto a nitrocellulose membrane. Ponceau staining was used to reveal equal protein loading and subsequent quantification. Blots were blocked with 5\% Protifar dissolved in Tris-buffered saline/Tween 20 [20 mM Tris- $\mathrm{HCl}(\mathrm{pH} 8.0), 150$ $\mathrm{mM} \mathrm{NaCl}, 0.05 \%$ Tween-20 (v/v)] for 1 hour at room temperature. $\mathrm{K}_{\mathrm{v}} 11.1$ protein was detected by polyclonal anti-hK $\mathrm{K}_{\mathrm{v}} 11.1$ (human $\mathrm{Kv} 11.1$ channel) primary antibody (catalogue number APC-062, 1:3000; Alomone Laboratories, Jerusalem, Israel) and peroxidase-conjugated anti-rabbit secondary antibody (1:10000; Jackson ImmunResearch Laboratories Inc., West Baltimore Pike West Grove, PA). Final detection was performed using a standard enhanced chemiluminescent procedure (GE Lifescience, Marlborough, MA) with ChemiDocXRS system (BioRad Laboratories, Veenendaal, The Netherlands). Quantification analysis was performed using Image $1.48 \mathrm{~V}$ software (National Institute of Health).

\section{Immunofluorescence microscopy}

HERG-G601S cells were grown on $\varnothing 15-\mathrm{mm}$ cover slips, coated with poly-L-Lysine, and fixated with $3 \%$ paraformaldehyde dissolved in PBS containing $1 \mathrm{mM} \mathrm{Ca}{ }^{2+}$ and $1 \mathrm{mM} \mathrm{Mg}^{2+}(\mathrm{pH}$ 7.4) for 20 minutes. Permeabilization was performed with $0.5 \%$ Triton X-100 in PBS for 3 minutes, and $50 \mathrm{mM}$ glycine-PBS was used as a quenching agent, and cells were subsequently blocked with NET-gel $[150 \mathrm{mM} \mathrm{NaCl}, 5 \mathrm{mM}$ EDTA, 50 $\mathrm{mM}$ Tris- $\mathrm{HCl}$ ( $\mathrm{pH} 7.4$ ), $0.05 \%$ Igepal, $0.25 \%$ gelatin, $0.02 \% \mathrm{NaN}_{3}$ ]. Then, the cells were incubated with polyclonal anti-hK 11.1 (human Kv11.1 channel) (1:3000, APC-062; Alomone Laboratories) and anti-Pan-cadherin (1:800, Sigma-Aldrich, St Louis, MO) primary antibody overnight in NETgel, followed by incubation with secondary antibody of anti-mouse Alexa488 
(Thermofisher Scientific, Landsmeer, The Netherlands) and anti-rabbit Alexa568 (Thermofisher Scientific) for 2 hours.

The cover slips were mounted with Vectashield (Vector Laboratories Inc. Burlingame, $\mathrm{CA}$ ), and fluorescent microscopy images were obtained using a Nikon ECLIPSE Ti2-E inverted microscope equipped with a $\times 60$ oil immersion objective (numerical aperture 1.49) (CAIRN research, Faversham, UK). Excitation was performed with diode lasers (Omicron LuxX $488 \mathrm{~nm}, 200 \mathrm{~mW}$ for Alexa488 and an OBIS $561 \mathrm{~nm}, 100 \mathrm{~mW}$ for Alexa561). Colocalization between $\mathrm{K}_{\mathrm{v}} 11.1$ and Cadherin in cell extensions was quantified by determining Pearson's coefficient $(r)$ with the Costes automated threshold method provided by the Coloc_2 plug-in for the Image J software (1.52p) using Fiji.

\section{Statistics}

All averages values are expressed as mean \pm S.D., unless indicated otherwise. All statistical analyses were carried out by using SPSS version 21 and Graphpad Prism version 5. A difference was considered significant with $P<0.05$. Differences among groups were evaluated using either oneway ANOVA with Dunnett's test for Western blot and immunofluorescence microscopy data or two-way ANOVA with Tukey's test for electrophysiology data. Post hoc tests were carried out only if $F$ was significant and there was no variance in homogeneity.

\section{RESULTS}

\section{Docking and molecular dynamics simulation-based prediction of binding mode of dofetilide and its interaction with LUF7244}

Overview representations of $\mathrm{K}_{\mathrm{v}} 11.1$ channel interaction with dofetilide and LUF7244 at the structural level, as viewed from the extracellular side, are shown in Fig. 1, A and B. To investigate how LUF7244 might lower the channel's affinities for dofetilide (Yu et al., 2016), we compared two binding modes of dofetilide and LUF7244. Figure 1, C and D displays two alternative 
A

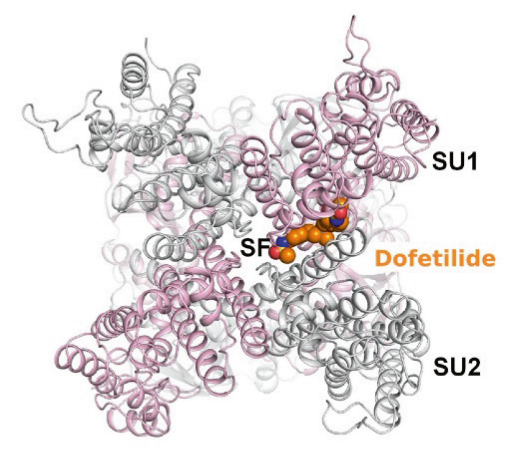

C

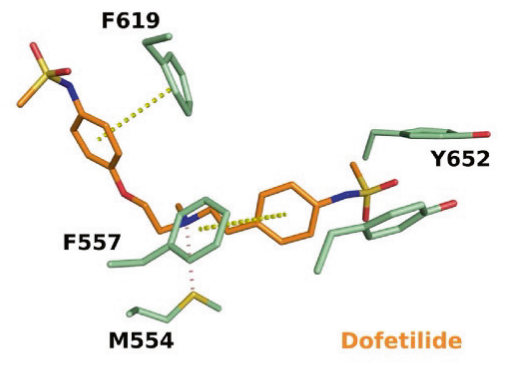

E

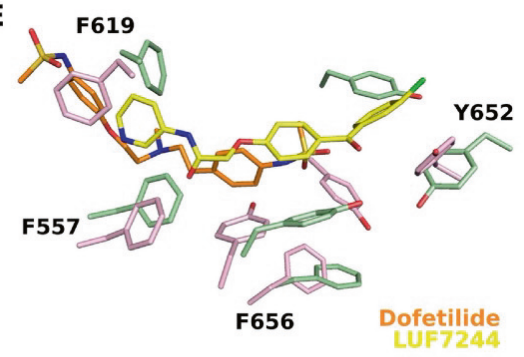

G

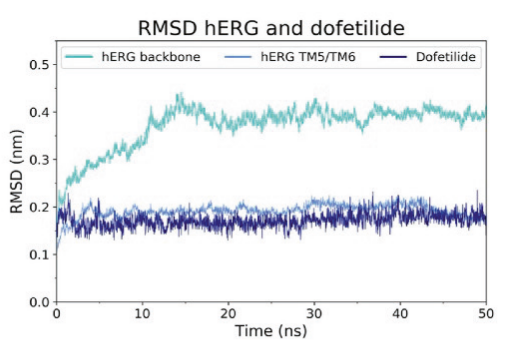

B

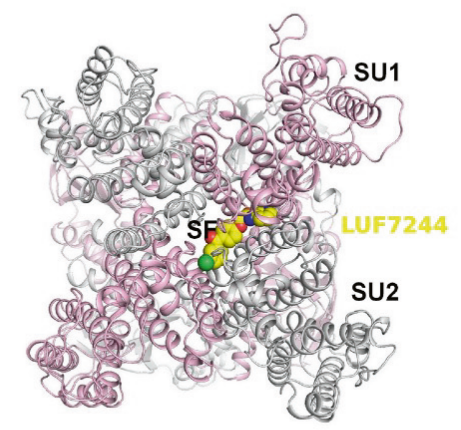

D

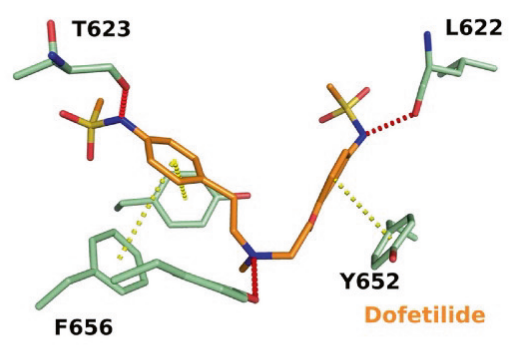

$\mathbf{F}$

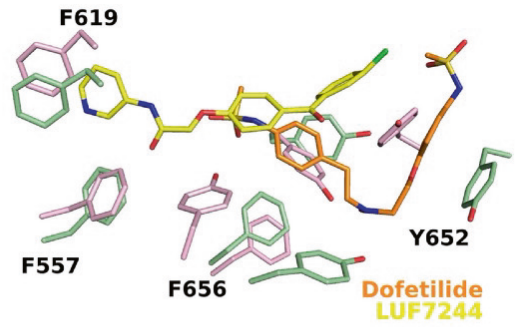

H

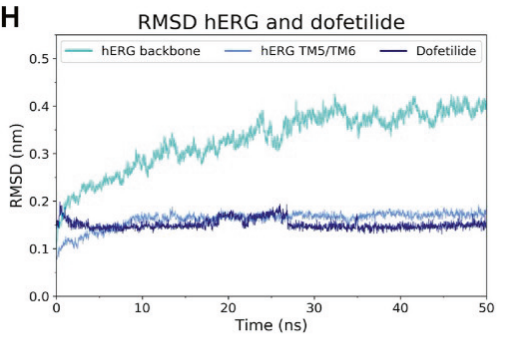

Figure 1. Molecular dynamics simulation-based prediction of binding mode of dofetilide/LUF7244 and $K_{v}$ 11.1. (A) Overview of the hERG structure (top view), with bound dofetilide at the fenestration, shown as orange spheres. (B) Overview of the hERG structure (top view), with bound LUF7244. (C) Predicted binding modes for dofetilide at the fenestration. (D) Predicted "classical" binding 
mode for dofetilide in the inner cavity of hERG. Yellow dotted lines indicate putative $\Pi-\Pi$ interactions; red dotted lines indicate H-bonds. (E) and (F) superposition of dofetilide binding modes, with predicted LUF7244 binding mode. (G) and (H) Root mean square deviation (RMSD) of $\mathrm{K}_{\mathrm{v}} 11.1$ and dofetilide docked into the fenestration or cavity, respectively.

binding modes of dofetilide in the near-atomic resolution cryo-EM structure $(3.4 \AA)$ of the $\mathrm{K}_{\mathrm{v}} 11.1 \mathrm{~K}^{+}$channel, in agreement with experimental data: in the cavity (Fig. 1D), which is the classical assumed binding mode for blockers (Kamiya et al., 2006; Imai et al., 2009), or in the fenestrations sticking into the cavity (Fig. 1C), as suggested recently, based on hERG homology models (Saxena et al., 2016). Both binding modes can be recapitulated in docking studies to the cryo-EM structure, and the drug is stable in 50 nanoseconds of molecular dynamics (Fig. 1, G and $\mathrm{H}$ ) in both sites. We have recently reported that LUF7244 might bind between the pore helices of two adjacent subunits, thereby stabilizing the conductive state of the channel (Qile et al, 2019). Comparison of the proposed binding modes of dofetilide with that of LUF7244 (Fig. 1, E and F) suggests that the allosteric negative inhibitor/activator could prevent the inhibitor from binding to the fenestration site (Fig. 1E), whereas there is almost no overlap when dofetilide is bound to the central cavity (Fig. 1F).

\section{LUF7244 has no effect on $K_{v} 11.1$ forward trafficking and does not interfere in dofetilide-mediated rescue of Pentamidine-induced trafficking defects}

Application of LUF7244 $(0.05,0.1,1,3$, and $5 \mu \mathrm{M})$ for 48 hours did not obviously affect $\mathrm{K}_{\mathrm{v}} 11.1$ ratio of mature/immature protein as shown in Fig. 2A. We demonstrated earlier that dofetilide rescues pentamidineinduced $\mathrm{K}_{\mathrm{v}} 11.1$ forward trafficking defects (Varkevisser et al., 2013a). To determine whether LUF7244 can restore mature $\mathrm{K}_{\mathrm{v}} 11.1$ expression, different concentrations of LUF7244 were applied to HEK-hERG cells in the continuous presence of $10 \mu \mathrm{M}$ pentamidine. However, treatment with LUF7244 up to $5 \mu \mathrm{M}$ did not restore mature $\mathrm{K}_{\mathrm{v}} 11.1$ protein levels (Fig. 2B).

Because LUF7244 by itself could not restore normal forward $\mathrm{K}_{\mathrm{v}} 11.1$ channel trafficking and was found to counteract dofetilide-mediated $\mathrm{I}_{\mathrm{Kr}}$ blockade (Qile et al., 2019), we questioned whether LUF7244 would 
influence dofetilide-mediated rescue of pentamidine induced trafficking defects. To test this hypothesis, the same dose range of LUF7244 was applied in combination with $1 \mu \mathrm{M}$ dofetilide and $10 \mu \mathrm{M}$ pentamidine for 48 hours. Interestingly, pentamidine decreased mature WT $\mathrm{K}_{\mathrm{v}} 11.1$ protein $[0.24 \pm 0.07$ vs. $0.54 \pm 0.11$ (control)], which was rescued by $1 \mu \mathrm{M}$ dofetilide ( $0.44 \pm 0.09$ vs. $0.24 \pm 0.07)$ and also by the combination of 1 $\mu \mathrm{M}$ dofetilide and $5 \mu \mathrm{M}$ LUF7244 ( $0.45 \pm 0.10$ vs. $0.24 \pm 0.07$ ) (Fig. $2 \mathrm{C}$ ). All the separate mature or immature $\mathrm{K}_{\mathrm{v}} 11.1$ protein expression levels, quantified from same blots, are shown in the right panel.

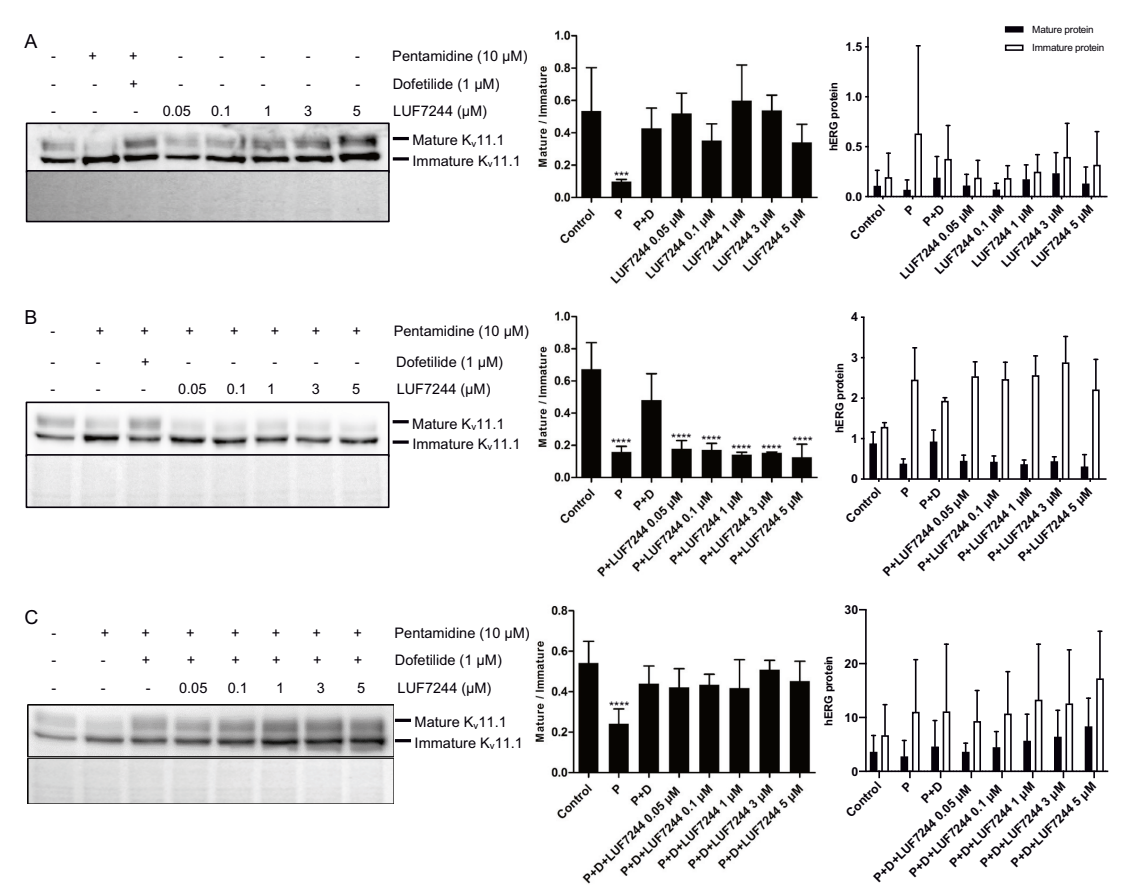

Figure 2. LUF7244 alone has no effect on $K_{v} 11.1$ trafficking and does not disturb dofetilide-mediated rescue of forward trafficking. (A) Western blot showing that treatment of pentamidine-exposed $(10 \mu \mathrm{M}, 48 \mathrm{~h})$ HEK-hERG cells with $1 \mu \mathrm{M}$ dofetilide restored mature $\mathrm{K}_{\mathrm{v}} 11.1$ expression. LUF7244 alone has no effect on $\mathrm{K}_{\mathrm{v}} 11.1$ expression ( $\left.\mathrm{n}=3\right)$. Mature (plasma membrane expressed) and immature (intracellular) $K_{v} 11.1$ western blot signals are displayed in left panel. Bar graphs in the middle depict ratio of mature/immature $K_{v} 11.1$ at different conditions. The right panel displays separate values for mature and immature $\mathrm{K}_{\mathrm{v}} 11.1$. (B) 
LUF7244 does not rescue pentamidine-induced $K_{v} 11.1$ trafficking defects $(n=3)$. (C) Combination of pentamidine, dofetilide and LUF7244 restores $\mathrm{K}_{\mathrm{v}} 11.1$ mature protein after $48 \mathrm{~h}(\mathrm{n}=6)$. Total protein staining (Ponceau) was used as a loading control. $* * * P<0.001, * * * * P<0.0001$ vs. control. Values are shown as mean \pm S.D. One-way ANOVA with Dunnett's test was applied for group comparison.
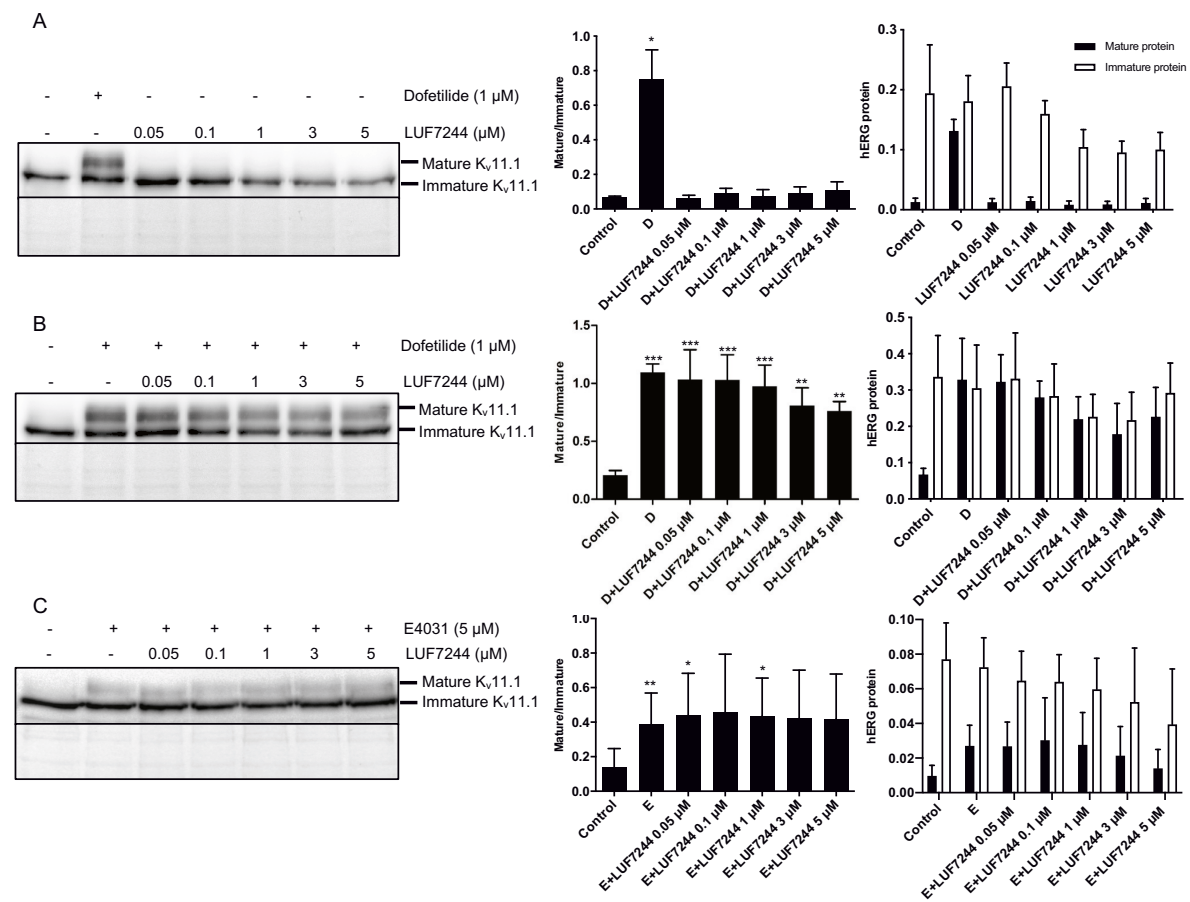

Figure 3. LUF7244 combined with dofetilide or E4031 rescues trafficking defective $K_{v}$ 11.1-G601S maturation. (A) Western blot analysis of equal amounts $(25 \mu \mathrm{g})$ of total protein from $\mathrm{K}_{\mathrm{v}} 11.1-\mathrm{G} 601 \mathrm{~S}$ cells. G601S cells only present a core-glycosylated immature protein of $135 \mathrm{kDa}$. Dofetilide restores expression of the full-glycosylated mature protein after $48 \mathrm{~h}$. LUF7244 does not change the mature $K_{v} 11.1$ protein levels compared with control $(n=3)$. (B) The combination of dofetilide and LUF7244 rescues mature $K_{v} 11.1$ protein in G601S cells $(n=3)$. (C) Increased mature $K_{v} 11.1$ levels in G601S cells treated with E4031 or E4031+LUF7244 (48h) $(n=6)$. The right panel displays separate values for mature and immature $\mathrm{K}_{\mathrm{v}} 11.1$. Total protein staining (Ponceau) was used as a loading control. $* P<0.05, * * P<0.01, * * * P<0.001$ vs. control. Values are shown as mean \pm S.D. One-way ANOVA with Dunnett's test was applied for group comparison. 


\section{LUF7244 and dofetilide/E4031 rescue G601S-K 11.1 maturation}

To test the effects of LUF7244 on a congenital $\mathrm{K}_{\mathrm{v}} 11.1$ loss-of-function missense mutation which results in defective forward trafficking, we coapplied five different concentrations of LUF7244 and $1 \mu \mathrm{M}$ dofetilide on hERG-G601S cells. According to Western blot result, trafficking deficiency was observed, which means only $135 \mathrm{kDa}$ core-glycosylated immature protein was detected (Fig. 3A). After 48 hours of administration of LUF7244 $(0.05,0.1,1,3$, and $5 \mu \mathrm{M})$, mature $\mathrm{K}_{\mathrm{v}} 11.1$ protein level was not changed compared with control (Fig. 3A), whereas application of $1 \mu \mathrm{M}$ dofetilide greatly increased mature protein expression. Furthermore, $1 \mu \mathrm{M}$ dofetilide combined with LUF7244 $(0.05-5 \mu \mathrm{M})$ also resulted in expression of the fully glycosylated mature protein (Fig. 3B). To expand our findings to other $\mathrm{I}_{\mathrm{Kr}}$ blockers, we used E4031. We applied $5 \mu \mathrm{M}$ E4031 without or with LUF7244 $(0.05,0.1,1,3$, and $5 \mu \mathrm{M})$ for 48 hours. Under all rescue conditions, the level of the $155 \mathrm{kDa}$ fully glycosylated mature protein was increased (Fig. 3C), although not to the same extent as seen with dofetilide. The separate mature or immature $\mathrm{K}_{\mathrm{v}} 11.1$ protein expression level can be found in the right panel.

Immunofluorescence staining was used to determine the subcellular localization of the G601S- $\mathrm{K}_{\mathrm{v}} 11.1$ protein. In untreated control hERG-G601S cells, no $K_{v} 11.1$ protein was detected at the cell membrane structures such like membrane ruffles, in contrast to the transmembrane protein Cadherin (Figure 4) (Pearson coefficient of colocalization $r=0.20 \pm 0.35, n=6$ ). After 24 hours of treatment with $10 \mu \mathrm{M}$ dofetilide or $10 \mu \mathrm{M}$ dofetilide +3 $\mu M$ LUF7244, normal trafficking was restored, as evidenced by plasma membrane expression of $\mathrm{K}_{\mathrm{v}} 11.1$ in membrane ruffles, where it colocalized with Cadherin (Fig. 4) $[r=0.85 \pm 0.08(n=6)$ and $0.86 \pm 0.06(n=6)$, respectively, both $P<0.01$ vs. control or LUF7244]. LUF7244-only treatment yielded no rescue of forward trafficking $(r=0.13 \pm 0.31$, n.s. vs. control). A lower concentration of LUF7244 was used to maintain intact cell structure in these experiments. 

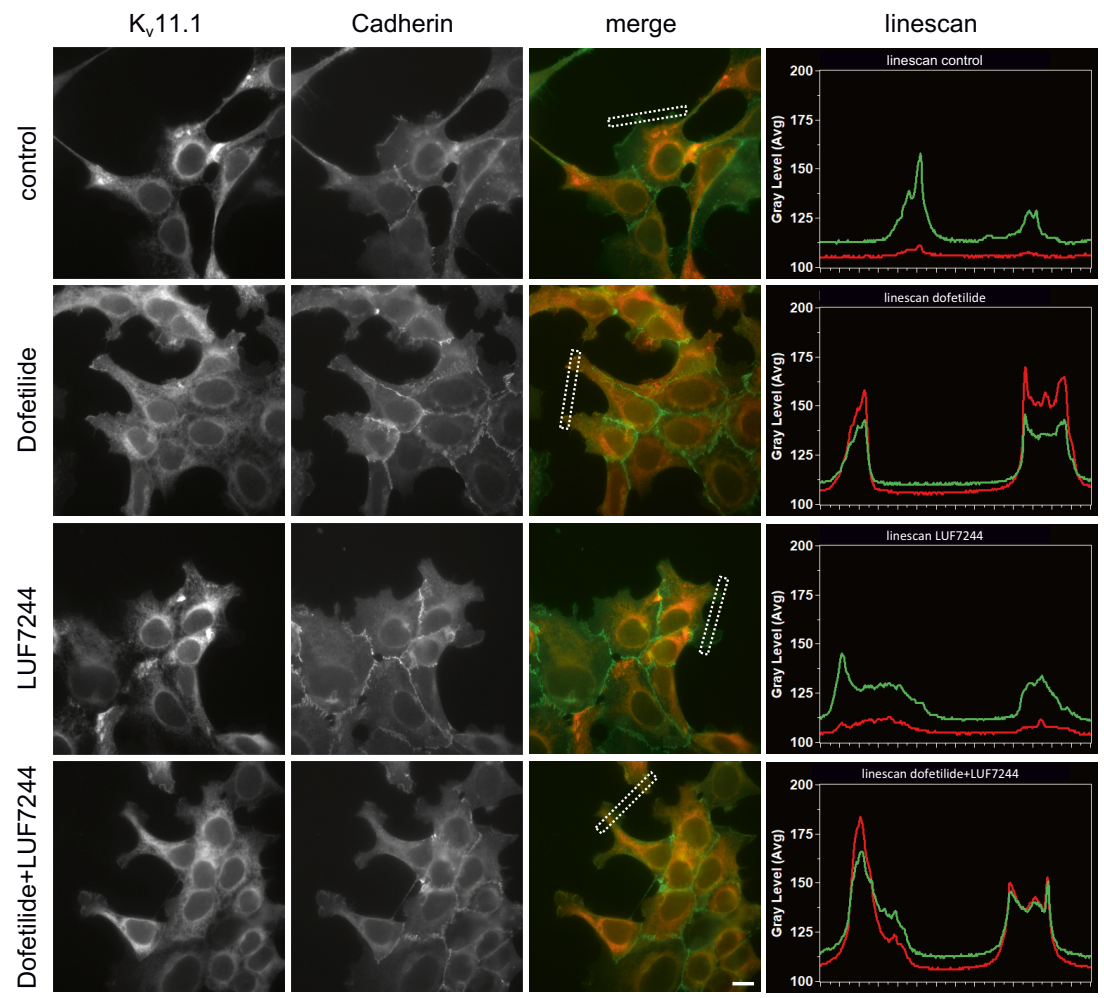

Figure 4. G601S cells were either non-treated (control), treated with $10 \mu \mathrm{M}$ Dofetilide, $3 \mu \mathrm{M}$ LUF7244, or $10 \mu \mathrm{M}$ Dof $+3 \mu \mathrm{M}$ LUF for 24 hours. $\mathrm{K}_{\mathrm{v}} 11.1$ channels were labelled (left column) along with Cadherin as a pseudo-membrane marker (Cadherin). Linescans of selected regions at cell extensions (containing membrane ruffles) are indicated in the merged pictures by boxes. Results of the linescan recordings are given on the right panels. Scale bar represents $10 \mu \mathrm{m}$.

\section{LUF7244 increases $I_{\text {Kv11.1 }}$ in the presence of dofetilide}

Lastly, the impact of dofetilide and LUF7244 on $\mathrm{I}_{\mathrm{Kv} 11.1}$ was determined (Fig. 5). The use of $10 \mu$ M LUF7244 in electrophysiology experiment is based on strong Ikv11.1 blockade effect of dofetilide. To counteract dofetilide's effect, we needed to use relatively higher concentration than what we used in Western blot experiments. On the other hand, $10 \mu$ M LUF7244 was used in 


\section{Chapter 6}

our previous work (Qile et al., 2019), which was based on the concentration that was used for its structural similar compound ICA-105574.

Figure 5A shows representative current traces measured from cells expressing $W T-K_{v} 11.1$ channel proteins in control conditions or with application of dofetilide $(1 \mu \mathrm{M})$, LUF7244 $(10 \mu \mathrm{M})$ or a combination to the extracellular recording solution as acute treatment. Cells are voltageclamped at a holding potential of $-80 \mathrm{mV}$ and depolarized to voltages between -80 and $60 \mathrm{mV}$ for 5 seconds to activate $I_{\mathrm{kv} 11.1}$ (prepulse). The cells are then clamped to $-50 \mathrm{mV}$ for 5 seconds to record a tail current (test

A.

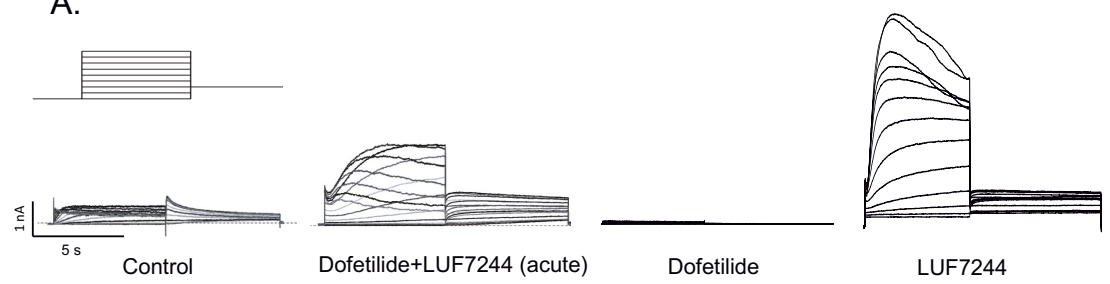

B.

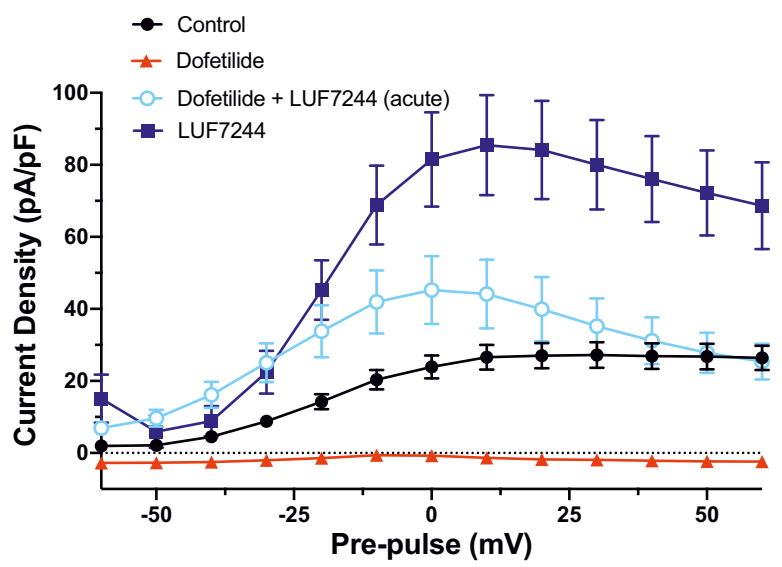

Figure 5. LUF7244 combined with dofetilide acutely rescued $I_{\text {Kv11.1 }}$ in HEKhERG cells. (A) Shown are representative currents from cells expressing WT$\mathrm{K}_{\mathrm{v}} 11.1$ channel proteins using the voltage protocol in the inset. Cells were recorded in control conditions or in dofetilide + LUF7244 (acute application). In B shown are the mean I-V relations, based on peak tail $\mathrm{I}_{\mathrm{kv} 11.1}$ amplitude following repolarization, recorded from cells expressing WT- $\mathrm{K}_{\mathrm{v}} 11.1$ channel proteins. Cells were recorded in control conditions $(n=10)$ or in dofetilide + LUF7244 (acute) $(n=10)$. Data 
are shown as mean \pm S.E.M. Compared to control cells, cells recorded in dofetilide + LUF7244 increased $\mathrm{I}_{\mathrm{Kv} 11.1}$ following pre-pulses from -70mV to $10 \mathrm{mV}(P<0.05)$. Two-way ANOVA with Tukey's test was applied.

pules). As shown for control cells in Fig. 5A, during depolarizing and tail pulses, an outward current was activated at voltages positive to $-40 \mathrm{mV}$, and the current amplitude of the $\mathrm{I}_{\mathrm{kv} 11.1}$ measured during the tail pulse increases with a maximum $\mathrm{I}_{\mathrm{kv} 11.1}$ current after depolarizing pulses to $>10$ $\mathrm{mV}$. The peak tail $\mathrm{I}_{\mathrm{Kv} 11.1}$ amplitude after repolarization was used to construct the activation curve shown in Fig. 5B. The activation curve measured for control cells shows that the threshold voltage for I I $\mathrm{Kv}_{11.1}$ activation is about $-40 \mathrm{mV}$ and that it is fully activated after voltage pulses to $10 \mathrm{mV}$.

Dofetilide and LUF7244 dramatically alter the activation and kinetic properties of $\mathrm{I}_{\mathrm{Kv} 11.1}$. The outward $\mathrm{I}_{\mathrm{kv} 11.1}$ measured during the depolarization and tail pulses is larger than control from $-70 \mathrm{mV}$ to $10 \mathrm{mV}$; there is a negative shift in the corresponding $\mathrm{I}-\mathrm{V}$ relation; but $\mathrm{I}_{\mathrm{Kv} 11.1}$ gets smaller after depolarizing pulses $>0 \mathrm{mV}$. The changes in the Ikv11.1 measured using this protocol in the presence of these drugs show complex changes consistent with both the activating properties of LUF7244 and blocking properties of dofetilide. The relevant LUF7244/dofetilide alone control study are shown in Fig. 5.

Figure $6 \mathrm{~A}$ shows representative current traces measured from cells expressing G601S- $\mathrm{K}_{\mathrm{v}} 11.1$ channel proteins in control conditions and with acute or long-term application of dofetilide + LUF7244 or LUF7244 only to the extracellular recording solution. There was no statistical difference in I $_{\mathrm{kv} 11.1}$ between the control conditions and acute application of dofetilide + LUF7244. Therefore, we tested the long-term effects of these drugs on I $_{\text {Kv11.1. }}$. We incubated cells in dofetilide + LUF7244 for $24-48$ hours and then recorded I I kv11.1 from cells with these drugs in the extracellular recording solution. The mean I-V relations, based on peak tail $\mathrm{I}_{\mathrm{kv11.1}}$ amplitude after repolarization, for cells expressing G601S- $\mathrm{K}_{\mathrm{v}} 11.1$ channel proteins in the different conditions indicate that long-term dofetilide + LUF7244 treatment increased $\mathrm{I}_{\mathrm{kv} 11.1}$. Dofetilide only treatment had a minimal effect (Fig. 6B) indicating the presence of only few functional channels at the plasma membrane without prior pharmacological correction of trafficking. Interestingly, however, LUF7244-only treatment produced $\mathrm{I}_{\mathrm{Kv11.1}}$ under such condition (Fig. 6). Compared with control cells, cells cultured and 
recorded in dofetilide + LUF7244 increased $I_{\text {Kv11.1 }}$ after prepulses to $-40 \mathrm{mV}$ to $60 \mathrm{mV}(P<0.05)$, and cells treated with LUF7244 increased I I 11.1 after prepulses from $-80 \mathrm{mV}$ to $60 \mathrm{mV}(P<0.05)$. Compared with cells recorded in dofetilide, cells cultured and recorded in dofetilide + LUF7244 increased $\mathrm{I}_{\mathrm{Kv} 11.1}$ after prepulses to $-40 \mathrm{mV}$ to $60 \mathrm{mV}(P<0.05)$, and cells recorded in LUF7244 increased $\mathrm{I}_{\mathrm{kv} 11.1}$ after prepulses from $-80 \mathrm{mV}$ to $60 \mathrm{mV}(P<0.05)$. Compared with cells recorded in dofetilide + LUF7244, cells cultured and recorded in dofetilide + LUF7244 increased $I_{\text {Kv11.1 }}$ after prepulses to $-30 \mathrm{mV}$ to $30 \mathrm{mV}(P<0.05)$, and cells recorded in LUF7244 increased I I 11.1 after prepulses from $-80 \mathrm{mV}$ to $60 \mathrm{mV}(P<0.05)$. Compared with cells cultured and recorded in LUF7244 cells, cells recorded in LUF7244 increased $I_{\text {Kv11.1 }}$ after prepulses from $-80 \mathrm{mV}$ to $60 \mathrm{mV}(P<0.05)$.

A.
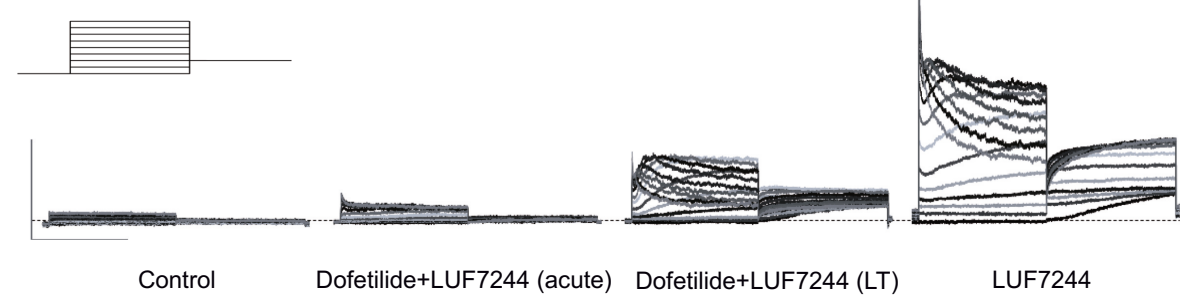

B.

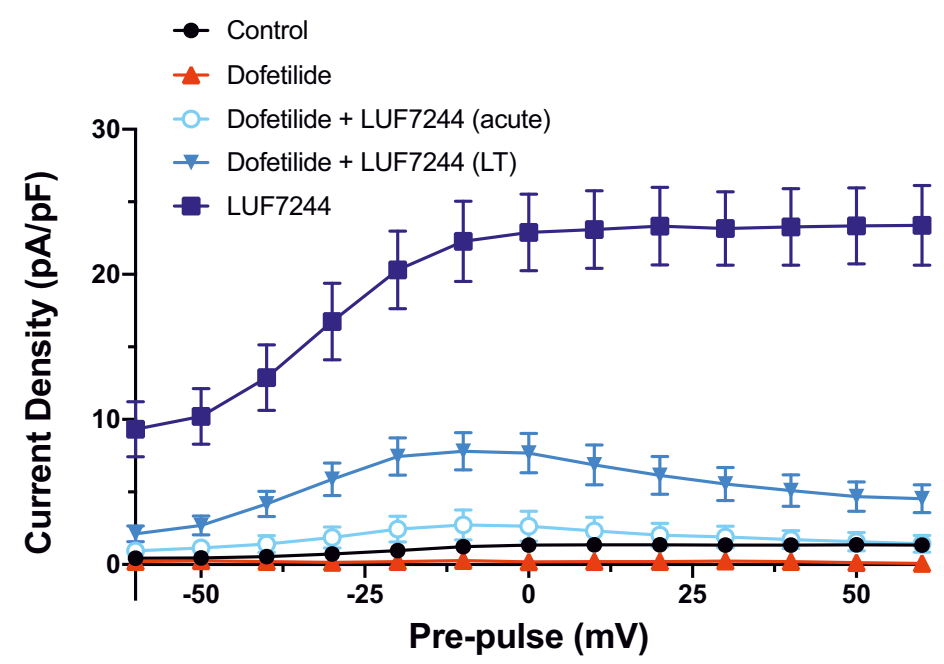

Figure 6. Long-term (24-48 h) exposure of LUF7244 combined with dofetilide rescued $I_{\text {Kv11.1 }}$ in G601S cells. (A) Shown are representative currents from cells expressing G601S- $K_{v} 11.1$ channel proteins using the voltage protocol in 
the inset. Cells were recorded in control conditions, in dofetilide + LUF7244 (acute), in dofetilide + LUF7244 after being cultured in dofetilide + LUF7244 for long-term (LT), or in LUF7244 (acute). (B) Shown are the mean I-V relations, based on peak tail $\mathrm{I}_{\mathrm{Kv} 11.1}$ amplitude following repolarization, recorded from cells expressing G601S-K $K_{v} 11.1$ channel proteins. Cells were recorded in control conditions $(n=10)$, in dofetilide $(n=8)$, dofetilide + LUF7244 (acute) $(n=10)$, in dofetilide + LUF7244 after being cultured in dofetilide + LUF7244 for 24-48 hours (LT) ( $n=10)$, or in LUF7244 $(n=7)$. Data are shown as mean \pm SEM. Two-way ANOVA with Tukey's test was applied.

\section{DISCUSSION}

$\mathrm{K}_{\mathrm{v}} 11.1$ activators and negative allosteric modulators use mechanistically different ways to increase or maintain normal $I_{K r}$ levels in the presence of a $\mathrm{K}_{\mathrm{v}} 11.1$ channel inhibitor. A number of compounds have been demonstrated as $K_{v} 11.1$ activators (Perry et al., 2010). Activators influence gating kinetics and can, for example, slow down or remove inactivation and/or facilitate activation (Sanguinetti, 2014). $\mathrm{K}_{\mathrm{v}} 11.1$ activators normally interact with a region distant from the inner cavity (Perry et al., 2010), but they can bind to several distinct sites of the channel (Perry et al., 2007; Guo et al., 2015; Gardner et al., 2017). Negative allosteric modulators decrease the binding affinity of $\mathrm{I}_{\mathrm{Kr}}$ blockers, either by increasing dissociation rates, lowering association rates, or both (Christopoulos et al., 2014). In our previous study, and also shown here, LUF7244 alone can dose dependently increase $K_{v} 11.1$ current and reduce inactivation of $K_{v} 11.1$ at higher concentration (Qile et al., 2019). In the current study, instead of the blockade effect of dofetilide, dofetilide + LUF7244 treatment led to a statistically significant increase in I $_{\mathrm{Kv} 11.1}$ level in HEK-hERG cell. In G601S cells, dofetilide + LUF7244 treatment increased (not statistically significantly) steady-state current as well. Furthermore, long-term exposure increased $\mathrm{I}_{\mathrm{Kv11.1}}$ continuously, which indicates that $\mathrm{I}_{\mathrm{Kr}}$ inhibitors' acute channel blockade could be reversed by LUF7244 and that its trafficking rescue characteristic might further functionally benefit $\mathrm{K}_{\mathrm{v}} 11.1$ for long-term administration.

We observed a stronger IKv11.1 increase for G601S channels than for WT channels (Fig. 5 and 6) which could not be explained by methodological means. Although speculative, we can envision that, besides an effect on 
trafficking, the G601S mutation may result in increased binding affinity for LUF7244, or show subtly different channel kinetics in response to LUF7244 compared with WT. Whether these effects are mutation specific are points for further investigation. Furthermore, the finding that LUF7244 can strongly activate the low amount of G601S channels that do reach the plasma membrane in cells not treated with dofetilide may shortcut the need for complete restoration of trafficking.

Modeling suggests that LUF7244 disrupts drug block at the fenestration via binding close to the protein-lipid interface (Fig. 1F). Drug binding to this site has recently been reported for Ivabradine, a $\mathrm{K}_{\mathrm{v}} 11.1$ blocker (Perissinotti et al., 2019) with low umolar affinity. It has been reported that this drug interacts with lipid-facing residues in the fenestration, including F557 and F656, in a state-dependent manner. Even though dofetilide is unlikely to access the $K_{v} 11.1$ cavity, via this fenestration, as has been shown for the more lipophilic drug Ivabradine, residue F557 has been shown to reduce binding affinity $>50$-fold when mutated to a leucine (Saxena et al., 2016). This suggests that this lipid-facing residue is critical for high-affinity block of different hERG inhibitors. Our modeling proposes that LUF7244 could disrupt coupling between state-dependent dynamics of $\mathrm{F} 557$ and $\mathrm{F} 656$ and interfere with dofetilide binding to the fenestration (Fig. 1E). Given the impact of LUF7244 on inactivation, one plausible scenario would be that the negative allosteric inhibitor prevents dofetilide from binding or accessing the "high-affinity" inactivated state in the fenestration, but this will require further modeling of the inactivated state(s).

However, based on the current simulations of 50 nanoseconds, we cannot exclude that $\mathrm{K}_{\mathrm{v}} 11.1$ has additional LUF7244 binding sites. Additional binding sites may explain the dual character of LUF7244 as a negative allosteric modulator (Yu et al., 2016) and activator (Qile et al., 2019, this study). Additional experimental analyses that may require in-depth NMR studies on drug-channel interaction are necessary to resolve this issue. The I $\mathrm{kr}$ activator ICA-105574 has structural similarities with LUF7244 and has also similar functional characteristics (Gerlach et al., 2010). It was shown that ICA-105574 enhanced $K_{v} 11.1$ currents via a mechanism that seems to prevent or limit the inactivation gating process. Additionally, ICA-105574 dose dependently shortened the AP duration in isolated guinea pig 
ventricular cardiomyocytes. It also remarkably suppressed the $\mathrm{K}_{\mathrm{v}} 11.1$ channel inhibitor E4031-induced AP lengthening. In this perspective, it would be interesting to compare these two compounds with respect to the mechanism of action on $\mathrm{K}_{\mathrm{v}} 11.1$ channels.

Besides, in view of its predicted binding site, LUF7244 by itself had no effects on $\mathrm{K}_{\mathrm{v}} 11.1$ channel trafficking, and it neither inhibited pentamidine-associated trafficking defects nor affected dofetilide-mediated rescue. Previously, we demonstrated that pentamidine-induced $\mathrm{K}_{\mathrm{v}} 11.1$ forward trafficking defects could be rescued by dofetilide and that both compounds may compete for the same binding site within the $\mathrm{K}_{\mathrm{v}} 11.1$ channel (Varkevisser et al., 2013a). Defective $K_{v} 11.1$ forward trafficking can be restored by a number of $\mathrm{K}_{\mathrm{v}} 11.1$ inhibitors that stabilize the channel via binding to the inner pore, close to the selectivity filter (e.g., Perry et al., 2010; Varkevisser et al., 2013a). We demonstrated that dofetilide analogs with higher affinity tended to provide better rescue in $\mathrm{K}_{\mathrm{v}} 11.1$ trafficking defects, while LUF7244 reduced the $\mathrm{K}_{\mathrm{v}} 11.1$ channel affinity for dofetilide (Yu et al., 2016). Interestingly, in our current study, the combination of dofetilide and LUF7244 still rescued pentamidine-induced $\mathrm{K}_{\mathrm{v}} 11.1$ trafficking defects. One possible reason may be that LUF7244 can not completely reduce the binding of dofetilide to the trafficking-inhibited channels by which the capacity of dofetilide to rescue $\mathrm{K}_{\mathrm{v}} 11.1$ trafficking remained. Another possibility is the absence of LUF7244 binding to intracellularly localized, immature, and only core-glycosylated $K_{v} 11.1$ channels. This may also explain 1) the absence of effects of LUF7244 on defective G601S trafficking, 2) the lack of interference of pentamidine-mediated trafficking defects by LUF7244, and 3) permitting dofetilide- and E4031-mediated rescue of $K_{v} 11.1$ trafficking. Recent preliminary data indicate that dofetilide specifically binds to membrane preparations of G601S cells, which is in line with the observed trafficking rescue effect. It now has to be determined to which extent this binding is sensitive to LUF7244. We hypothesize that LUF7244 will certainly not completely inhibit dofetilide binding to intracellularly localized $\mathrm{K}_{v} 11.1$; otherwise, dofetilide + LUF7244 would not provide any rescue of maturation, membrane staining, and $\mathrm{I}_{\mathrm{kv} 11.1}$, as shown in the current manuscript.

Negative allosteric modulators and activators can be considered as therapeutic options to prevent drug-induced arrhythmia (Sanguinetti 2014; 
Yu et al., 2016). Recently, we have shown that LUF7244 suppressed astemizole-induced early after depolarizations (EADs) and AP prolongation in neonatal rat ventricular myocytes (Yu et al., 2016). Additionally, LUF7244 pretreatment prevented the occurrence of astemizole-induced EADs, whereas LUF7244 per se did not shorten AP duration (APD) or strongly affect dispersion of $\mathrm{APD}_{40}$ in neonatal rat ventricular myocytes at $10 \mu \mathrm{M}$ (Yu $Z$ et al., 2016). In contrast, in isolated canine ventricular cardiomyocytes and human pluripotent stem cells (iPS)-derived cardiomyocytes, LUF7244 remarkably shortened the $A P D_{90}$, which is in line with its activator characteristics (Qile et al., 2019). Moreover, we demonstrated that LUF7244 suppressed EADs in isolated canine ventricular myocytes and prevented dofetilide-induced ventricular arrhythmias in the dog with chronic atrioventricular node block (Qile et al., 2019).

In conclusion, the current study demonstrates that LUF7244, and possibly also other negative allosteric modulators and activators, might also have a role in suppression or preventing arrhythmia caused by defective forward trafficking. Thus, the negative allosteric modulator/activator LUF7244 in combination with a genuine $\mathrm{K}_{\mathrm{v}} 11.1$ inhibitor could provide a new pharmacological treatment to functionally correct both congenital and acquired $\mathrm{K}_{\mathrm{v}} 11.1$ trafficking defects.

\section{ACKNOWLEDGEMENTS}

The authors thank Jacobus P. van Veldhoven from Leiden University for the synthesis of LUF7244. 
LUF7244 plus dofetilide rescues aberrant $K_{v} 11.1$ trafficking

\section{REFERENCES}

Abraham M, Hess B, van der Spoel D, and Lindahl E (2015). USER MANUAL Version 5.0. 7. The GROMACS Development Teams at the Royal Institute of Technology and Uppsala University, Sweden.

Anderson $\mathrm{CL}$, Delisle BP, Anson BD, Kilby JA, Will ML, Tester DJ, Gong Q, Zhou Z, Ackerman MJ, and January CT (2006) Most LQT2 mutations reduce $\mathrm{K}_{\mathrm{v}} 11.1$ (hERG) current by a class 2 (trafficking-deficient) mechanism. Circulation 113:365-373.

Anderson $\mathrm{CL}$, Kuzmicki CE, Childs RR, Hintz CJ, Delisle BP, and January CT (2016) Large-scale mutational analysis of $\mathrm{K}_{\mathrm{v}} 11.1$ reveals molecular insights into type 2 long QT syndrome. Nat Commun 5:5535.

Bossu A, van der Heyden MAG, de Boer TP, and Vos MA (2016) A 2015 focus on preventing drug-induced arrhythmias. Expert Rev Cardiovasc Ther 14:245-253.

Bussi G, Donadio D, and Parrinello M (2007) Canonical sampling through velocity rescaling. J Chem Phys 126:014101.

Casis O, Olesen SP, and Sanguinetti MC (2006) Mechanism of action of a novel human ether-a-go-go-related gene channel activator. $\mathrm{Mol}$ Pharmacol, 69:658-665.

Christopoulos A, Changeux JP, Catterall WA, Fabbro D, Burris TP, Cidlowski JA, Olsen RW, Peters JA, Neubig RR, Pin JP, and Sexton PM (2014) Multisite pharmacology: recommendations for the nomenclature of receptor allosterism and allosteric ligands. Pharmacol Rev 66:918-947.

Cordes JS, Sun Z, Lloyd DB, Bradley JA, Opsahl AC, Tengowski MW, Chen $X$, and Zhou J (2005) Pentamidine reduces hERG expression to prolong the QT interval. Br J Pharmacol 145:15-23.

Darden T, York D, and Pedersen L (1993) Particle mesh Ewald: An N.log (N) method for Ewald sums in large systems. J Chem Phys 98:1008910092. 


\section{Chapter 6}

De Git KC, de Boer TP, Vos MA, and van der Heyden MAG (2013) Cardiac ion channel trafficking defects and drugs. Pharmacol Ther 139:24-31.

Dennis AT, Wang L, Wan H, Nassal D, Deschenes I, and Ficker E (2012) Molecular determinants of pentamidine-induced hERG trafficking inhibition. Mol Pharmacol 81:198-209.

Ficker E, Obejero-Paz CA, Zhao S, and Brown AM (2002) The binding site for channel blockers that rescue misprocessed human long QT syndrome type 2 ether-a-gogo-related gene (HERG) mutations. $\mathrm{J}$ Biol Chem 277:4989-4998.

Gardner A, Wu W, Thomson S, Zangerl-Plessl EM, Stary-Weinzinger A, and Sanguinetti MC (2017) Molecular Basis of Altered hERG1 Channel Gating Induced by Ginsenoside Rg3. Mol Pharmacol 92:437-450.

Garg V, Stary-Weinzinger A, and Sanguinetti MC (2013) ICA-105574 interacts with a common binding site to elicit opposite effects on inactivation gating of EAG and ERG potassium channels. Mol Pharmacol 83:805-813.

Gerlach AC, Stoehr SJ, and Castle NA (2010) Pharmacological removal of human ether-à-go-go-related gene potassium channel inactivation by 3-nitro-N-(4-phenoxyphenyl) benzamide (ICA-105574). Mol Pharmacol 77:58-68.

Guo J, Cheng YM, Lees-Miller JP, Perissinotti LL, Claydon TW, Hull CM, Thouta S, Roach DE, Durdagi S, Noskov SY, and Duff HJ (2015) NS1643 interacts around L529 of hERG to alter voltage sensor movement on the path to activation. Biophys J 108:1400-1413.

Hess B, Bekker H, Berendsen HJC, and Fraaije JGEM (1997) LINCS: a linear constraint solver for molecular simulations. J Comput Chem 18:14631472.

Himmel HM (2013) Drug-induced functional cardiotoxicity screening in stem cell-derived human and mouse cardiomyocytes: effects of reference compounds. J Pharmacol Toxicol Methods 68:97-111. 
Imai YN, Ryu S, and Oiki S (2009) Docking model of drug binding to the human ether-a-go-go potassium channel guided by tandem dimer mutant patch-clamp data: a synergic approach. J Med Chem 52:16301638.

Jones G, Willett P, Glen RC, Leach AR, and Taylor R (1997) Development and validation of a genetic algorithm for flexible docking. $J \mathrm{Mol} B \mathrm{BiOl}$ 267:727-748.

Jo S, Kim T, Iyer VG, and Im W (2008) CHARMM-GUI: a web-based graphical user interface for CHARMM. J Comput Chem 29:1859-1865.

Kamiya K, Niwa R, Mitcheson JS, and Sanguinetti MC (2006) Molecular determinants of HERG channel block. Mol Pharmacol 69:1709-1716.

Kuryshev YA, Ficker E, Wang L, Hawryluk P, Dennis AT, Wible BA, Brown AM, Kang J, Chen XL, Sawamura K, Reynolds W, and Rampe D (2005) Pentamidine-induced long QT syndrome and block of hERG trafficking. J Pharmacol Exp Ther 312:316-323.

Nalos L, de Boer TP, Houtman MJ, Rook MB, Vos MA, and van der Heyden MAG (2011) Inhibition of lysosomal degradation rescues pentamidinemediated decreases of $\mathrm{K}_{\mathrm{IR}} 2.1$ ion channel expression but not that of $\mathrm{K}_{\mathrm{v}}$ 11.1. Eur J Pharmacol 652:96-103.

Obergrussberger A, Juhasz K, Thomas U, Stölzle-Feix S, Becker N, Dörr L, Beckler M, Bot C, George M, and Fertig N (2016) Safety pharmacology studies using EFP and impedance. $J$ Pharmacol Toxicol Methods 81:223-232.

Parrinello M, and Rahman A (1981) Polymorphic transitions in single crystals: A new molecular dynamics method. J Appl Phys 52:71827190.

Perissinotti L, Guo J, Kudaibergenova M, Miller JL, Khovich MO, Sharapova A, Perlovich G, Muruve D, Gerull B, Noskov SY, and Duff HJ (2019) The Pore-Lipid Interface: Role of Amino Acid Determinants of Lipophilic Access by Ivabradine to the hERG1 Pore Domain. Mol Pharmacol 


\section{Chapter 6}

$96: 259-271$.

Perry M, Sachse FB, and Sanguinetti MC (2007) Structural basis of action for a human ether-a-go-go-related gene 1 potassium channel activator. Proc Natl Acad Sci U S A 104:13827-13832.

Perry M, Sanguinetti M, and Mitcheson J (2010) Symposium review: Revealing the structural basis of action of hERG potassium channel activators and blockers. J Physiol 588:3157-3167.

Qile M, Beekman HD, Sprenkeler DJ, Houtman MJ, van Ham WB, StaryWeinzinger A, Beyl S, Hering S, van den Berg DJ, de Lange EC, Heitman LH, IJzerman AP, Vos MA, and van der Heyden MA (2019) LUF7244, an allosteric modulator/activator of $\mathrm{K}_{\mathrm{v}} 11.1$ channels, counteracts dofetilide-induced TdP arrhythmia in the chronic atrioventricular block dog model. Br J Pharmacol 176:3871-3885.

Rajamani S, Anderson CL, Anson BD, and January CT (2002) Pharmacological rescue of human $\mathrm{K}^{+}$channel long-QT2 mutations: human ether-a-go-go-related gene rescue without block. Circulation 105:2830-2835.

Sala L, Yu Z, Ward-van Oostwaard D, van Veldhoven JP, Moretti A, Laugwitz $\mathrm{KL}$, Mummery $\mathrm{CL}$, IJzerman AP, and Bellin M (2016) A new hERG allosteric modulator rescues genetic and drug-induced long-QT syndrome phenotypes in cardiomyocytes from isogenic pairs of patient induced pluripotent stem cells. EMBO Mol Med 8:1065-1081.

Sanguinetti MC (2014) HERG1 channel agonists and cardiac arrhythmia. Curr Opin Pharmacol 15:22-27.

Sanguinetti MC and Tristani-Firouzi M (2006) hERG potassium channels and cardiac arrhythmia. Nature 440:463-469.

Saxena P, Zangerl-Plessl EM, Linder T, Windisch A, Hohaus A, Timin E, Hering $S$, and Stary-Weinzinger A (2016) New potential binding determinant for hERG channel inhibitors. Sci Rep 6:24182. 
Schrodinger, LLC (2015) The PyMOL molecular graphics system, version 1.8. Schrodinger LLC, New York, NY.

Torp-Pedersen C, Møller M, Bloch-Thomsen PE, Køber L, Sandøe E, Egstrup K, Agner E, Carlsen J, Videbaek J, Marchant B, and Camm AJ (1999) Dofetilide in patients with congestive heart failure and left ventricular dysfunction. N Engl J Med 341:857-865.

Vandenberg JI, Perry MD, Perrin MJ, Mann SA, Ke Y, and Hill AP (2012) hERG K ${ }^{+}$channels: structure, function, and clinical significance. Physiol Rev 92:1393-1478.

Vanommeslaeghe K, Hatcher E, Acharya C, Kundu S, Zhong S, Shim J, Darian E, Guvench O, Lopes P, Vorobyov I, and MacKerell Jr AD (2010) CHARMM general force field: A force field for drug-like molecules compatible with the CHARMM all-atom additive biological force fields. $J$ Comput Chem 31:671-690.

Varkevisser R, Houtman MJ, Linder T, de Git KC, Beekman HD, Tidwell RR, IJzerman AP, Stary-Weinzinger A, Vos MA, and van der Heyden MAG (2013a) Structure-activity relationships of pentamidine-affected ion channel trafficking and dofetilide mediated rescue. $\mathrm{Br} \mathrm{J}$ Pharmacol 169:1322-1334.

Varkevisser R, Houtman MJ, Waasdorp M, Man JC, Heukers R, Takanari H, Tieland RG, van Bergen en Henegouwen PM, Vos MA, and van der Heyden MAG (2013b) Inhibiting the clathrin-mediated endocytosis pathway rescues $\mathrm{K}_{\mathrm{IR}} 2.1$ downregulation by pentamidine. Pflugers Arch 465:247-259.

Wang W and MacKinnon R (2017) Cryo-EM structure of the open human ether-à-go-go-related K+ channel hERG. Cell 169:422-430.

Wible BA, Hawryluk P, Ficker E, Kuryshev YA, Kirsch G, and Brown AM (2005) HERG-Lite: a novel comprehensive high-throughput screen for druginduced hERG risk. J Pharmacol Toxicol Methods 52:136-145. 


\section{Chapter 6}

Yan M, Zhang K, Shi Y, Feng L, Lv L, and Li B (2015) Mechanism and pharmacological rescue of berberine-induced hERG channel deficiency. Drug Des Devel Ther 9:5737-5747.

Yu Z, Klaasse E, Heitman LH, and IJzerman AP (2014) Allosteric modulators of the hERG $\mathrm{K}^{+}$channel: radioligand binding assays reveal allosteric characteristics of dofetilide analogs. Toxicol Appl Pharmacol 274:7886.

Yu Z, Liu J, van Veldhoven JP, IJzerman AP, Schalij MJ, Pijnappels DA, Heitman LH, and de Vries AA (2016) Allosteric Modulation of Kv11.1 (hERG) Channels Protects Against Drug-Induced Ventricular Arrhythmias. Circ Arrhythm Electrophysiol 9:e003439.

Yu Z, van Veldhoven JP, 't Hart IM, Kopf AH, Heitman LH, and IJzerman AP (2015) Synthesis and biological evaluation of negative allosteric modulators of the Kv11.1 (hERG) channel. Eur J Med Chem 106:50-59.

Zhou Z, Gong Q, and January CT (1999) Correction of defective protein trafficking of a mutant HERG potassium channel in human long QT syndrome. Pharmacological and temperature effects. J Biol Chem 274:31123-31126. 



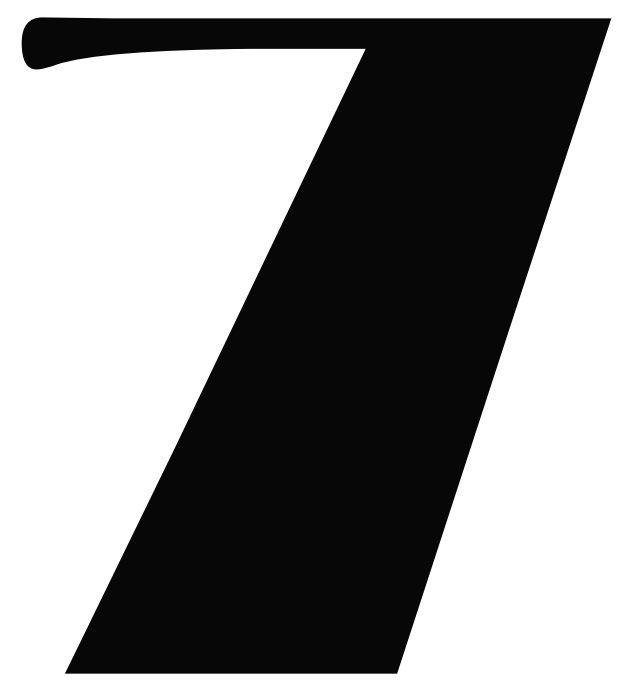




\section{CHAPTER 7}

\section{Drug-likeness of linear pentamidine analogues and their impact on the hERG $\mathrm{K}^{+}$ channel - correlation with structural features}

Teresa Żołek ${ }^{1}$, Muge Qile², Paweł Kaźmierczak ${ }^{1}$, Meye Bloothooft ${ }^{2}$, Marcel A. G. van der Heyden ${ }^{2}$ and Dorota Maciejewska ${ }^{1}$

${ }^{1}$ Department of Organic Chemistry, Faculty of Pharmacy, Medical University of Warsaw, Warsaw, Poland

2 Department of Medical Physiology, Division of Heart \& Lungs, University Medical Center Utrecht, Utrecht, The Netherlands 


\section{ABSTRACT}

This work presents drug-likeness and the cardiotoxicity profiles of six potent pentamidine analogs 1-6 and three new compounds 7-9 as chemotherapeutics for therapy of Pneumocystis jiroveci pneumonia. A combination of experimental and computational approaches was used in the cardiotoxicity examination. The hERG trafficking and functionality of the hERG currents were tested by western blot analyses, immunofluorescent staining procedures, and patch-clamp electrophysiological assays. Cardiotoxicity combined with blocking hERG $\mathrm{K}^{+}$channel was predicted, and then simulated by docking to the CSM-TM model 732 protein. Location of pentamidines in the proximity of Leu622, Thr623, Ser649, Tyr652, Ala653, and Phe656, and the high energies of interactions were in accordance with probable blocking of the hERG channel. However, in the biochemical experiments, no significant changes in $I_{\text {hERG }}$ densities and a minor effect on hERG maturation were observed. Predicted metabolic transformation of pentamidines with $\mathrm{S}$ atoms in the aliphatic linker leads to oxidation of one $\mathrm{S}$ atom, but those with phenyl sulfanilide moiety can be oxidized to chinones. The tested pentamidines characterized by the presence of sulfur atoms or sulfanilide groups, have favorable drug-likeness parameters and are promising lead structures in the development of new potent chemotherapeutics against PJP. 
Pentamidine analogues and their impact on the hERG channel

\section{INTRODUCTION}

A major problem after identifying lead compounds is to evaluate their drug-likeness parameters and cardiotoxicity. A lot of lead compounds and drugs developed for different treatments have been found to interfere with normal cardiac physiology, and have been retracted from early- and latestage stage trials as well as from the medical practice ${ }^{1,2}$. Cardiotoxicity associated with the hERG (human ether-á-go-go related gene) $\mathrm{K}^{+}$ion channel named $\mathrm{KCNH} 2$ or $\mathrm{KV} 11.1$ has received considerable attention. ${ }^{3}$ This gene is expressed in a variety of tissues (i.e. heart and brain), but expression and function of the hERG protein are best described in cardiac myocytes. The hERG $\mathrm{K}^{+}$ion channel shapes the rapidly activating component of the cardiac delayed rectifier potassium current $\left(I_{\mathrm{Kr}}\right)$, which is crucial for repolarization of the cardiac action potential. Dysfunction of the hERG channel could cause long QT syndrome (LQTS) characterized by delayed repolarization and prolonged QT interval. These facts increase the risk of ventricular arrhythmias in the form of torsades de pointes (TdP) and sudden cardiac death. ${ }^{4-6}$ Diverse substances can induce LQTS via inhibition of hERG using a wide range of mechanisms. The mechanism often proposed for drug-induced QT interval is a block of hERG channels or its native current $I_{\mathrm{Kr}}$. The drugs interact with a structurally unique receptor domain (pore aliphatic helix residues Thr-623, Ser-624, and Val-625 and aromatic residues Tyr-652 and Phe-656) in the pore-S6 region of the channel to suppress $\mathrm{K}^{+}$ion permeation. ${ }^{7}$ Another mechanism for drug-induced LQTS is the disorganization of hERG channel protein trafficking to the cell surface membrane. Fewer mature hERG channels reach the surface membrane, thus reducing hERG $\mathrm{K}^{+}$current ( $I_{\mathrm{hERG}}$ ) or $I_{\mathrm{Kr} .} .{ }^{8}$ Whereas some drugs induce adverse effects via only one of the mechanisms, other act via a combination of both. ${ }^{9,10}$ The importance of hERG-related toxicity is driven by the tendency of hERG channels to bind many compounds, including anti-biotics (e.g., erythromycine, clarithromycine), ${ }^{11}$ anti-viral (e.g., amantadine), ${ }^{12}$ anti-fungal (e.g., ketoconazole, itraconazole), ${ }^{13,14}$ anti-cancer (e.g., arsenic trioxide), ${ }^{15}$ anti-protozoal and anti-malarial (e.g., pentamidine, chloroquine), ${ }^{16,17}$ anti-psychotic (e.g., chlorpromazine), ${ }^{18}$ anti-histamine (e.g., astemizole), ${ }^{19}$ and anti-arrhythmic (e.g., quinidine, dofetilide) $)^{20}$ drugs, which strongly block or disorder the membrane trafficking of hERG channels. 
In recent years, Pneumocystis jiroveci pneumonia (PJP) has become one of the potentially fatal illness encountered in immunocompromised patients. ${ }^{21-23}$ Although the development of highly active anti-retroviral therapy, and the extensive use of Pneumocystis chemoprophylaxis, PJP remains an important cause of morbidity and mortality in patients with acquired immunodeficiency syndrome (AIDS). ${ }^{24}$ At present, interest in PJP infection goes beyond the people which suffer from AIDS due to the increasing number of patients receiving immunosuppressive therapies because of massive organ transplantations, malignancies and autoimmune diseases, for which PJP is increasingly diagnosed.23,25,26 The effective treatment for PJP is trimethoprim-sulfamethoxazole (TMP-SMX) drug combination, but also alternative drugs have been developed, ${ }^{27,28}$ including pentamidine, dapsone, and atovaquone. Among them, intravenous pentamidine is known as the most potent for the second-line treatment of PJP. ${ }^{29}$ Structurally, pentamidine belongs to the aromatic bis-amidine which are lead compounds in many drug discovery pathways, but no substance has passed over the phases of clinical trials because of toxicity and improper drug-likeness properties. ${ }^{30}$ Therefore, there is an urgent need for an evaluation of these properties for newly available compounds. Many efforts were made for pentamidine cardiotoxicity examinations. Therapy with pentamidine can cause the prolongation of the QT interval on the electrocardiogram and in some cases TdP tachycardia's which can be transformed into ventricular fibrillation and cause sudden cardiac death. ${ }^{31}$ Several studies have shown that pentamidine prolongs the cardiac action potential by the impact on hERG trafficking and decreasing of the number of functional hERG channels at the cell surface. ${ }^{32-34}$

In an effort to find a more efficient therapeutic agent for the treatment of PJP, our laboratory has developed a number of linear pentamidine analogs which showed excellent anti-Pneumocystis activity. ${ }^{35-}$ 37 Among them, we have designed, synthesized and evaluated six bisbenzamidines 1-6 characterized by the presence of a one or two sulfur atoms in the linker and introduction of alkyl substituents to the amidine groups (see Fig. 1). The tests for $\mathbf{1}-\mathbf{3}$ revealed the high activities (IC50 with range $0.01-1.18 \mu \mathrm{M}$ ) and less or no cytotoxicity in mammalian cell lines compared to the parent compound pentamidine. In continuing the search for new drug candidates, we have taken into account the promising activity and very low cytotoxicity received for 3-phenylsulfonyl-1,5-bis(4-amidino2,6-dimethylphenoxy)-3-azapentane dihydrochloride. ${ }^{37}$ We synthesized 
three new bis-benzamidines 7-9 in which two sulfanilide groups are in the ortho-, meta- and para-positions of the benzene ring. Moreover, these derivatives represent molecules with less mobile linker connecting bisbenzamidine moieties, what can have an impact on cardiotoxicity.

To get full insight on the drug-likeness of tested molecules, we calculated the theoretical values of the physio-chemical and biopharmaceutical parameters associated with adsorption, distribution, metabolism, elimination, and toxicity (ADMET) in the human body. Next, we elucidated the nature of the interaction between pentamidines and the hERG $\mathrm{K}^{+}$channel for all nine compounds 1-9 using a combination of experimental and computational approaches. The impact of tested compounds on hERG trafficking and functionality the hERG currents were examined by traditional western blot analyses, immunofluorescent staining procedures, and patch clamp electrophysiological assays. The specific interactions governing the predicted blockade of the cardiac $\mathrm{K}^{+}$channel was scrutinized by molecular docking and free enthalpy calculations.

\section{THEORETICAL CALCULATIONS}

\section{Ligands and hERG channel}

Nine compounds synthesized in our laboratory (Fig. 1) were evaluated: 1,5-bis(4-amidinophenoxy)-3-thiapentane dihydrochloride (1), 1,5-bis[4(amidino)phenylthio]-3-oxapentane dihydrochloride (2), 1,5-bis[4-(4,5dihydro-2-imidazolyl)phenylthio]-3-oxapentane dihydrochloride (3), 1,5bis[4-(4,5-dihydro-2-imidazolyl)phenoxy]-3-thiapentane dihydrochloride (4), 1,5-bis[4-( $N$-butylamidino)phenoxy)]-3-thiapentane dihydrochloride (5), 1,5-bis[4-( $N$-cyclohexylamidino)phenoxy)]-3-thiapentanedihydrochloride (6), 4,4'-[1,3-phenylenebis(aminosulfonyl)]dibenzamidinedihydrochlo ride (7), 4,4'-[1,2-phenylenebis(aminosulfonyl)]dibenzamidine dihydrochlo ride (8) and 4,4'-[1,4-phenylenebis(aminosulfonyl)]dibenzamidine dihydro chloride (9). Three-dimensional structures of ligand were prepared using Discovery Studio 2017R2 visual interface BIOVIA. ${ }^{38}$ Geometries of all compounds were optimized using the density functional theory (DFT) with the B3LYP/6-311G $(d, p)$ hybrid functional, as implemented in Gaussian 16. ${ }^{39}$ ESP-atomic partial charges on all atoms were computed using the Breneman model reproducing the molecular electrostatic potential. ${ }^{40}$ Out of 


\section{Chapter 7}

the generated structural models of the hERG $\mathrm{K}^{+}$channel ${ }^{41-44}$ we used the open state model named CSM-TM-model 732 originated from the studies of S. Y. Noskov group. ${ }^{41}$ The experimentally validated model selected by us is a valuable tool in the theoretical studies of blockade hERG current also for cationic compounds. ${ }^{45-47}$

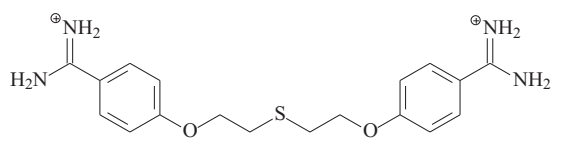

1

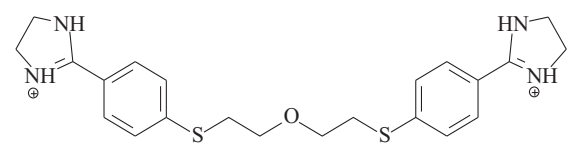

3

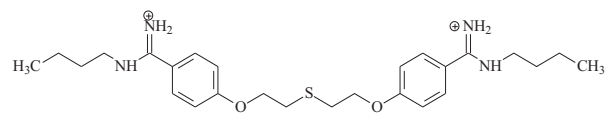

5

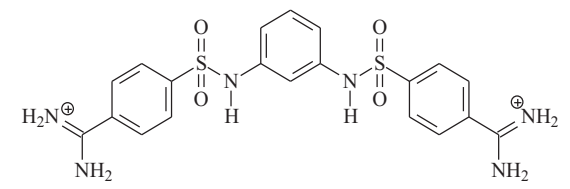

7<smiles>N=C(N)c1ccc(SCCOCCSc2ccc(C(=N)N)cc2)cc1</smiles>

2

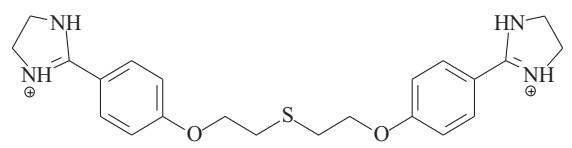

4<smiles>[Y9]C(NC1CCCCC1)c1ccc(OCCCNCCCOc2ccc(C(C)NC3CCCCC3)cc2)cc1</smiles>

6

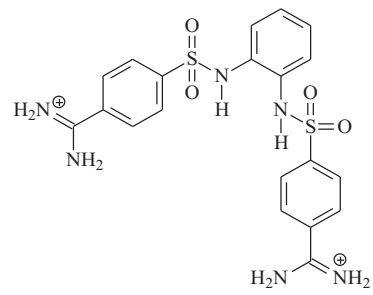




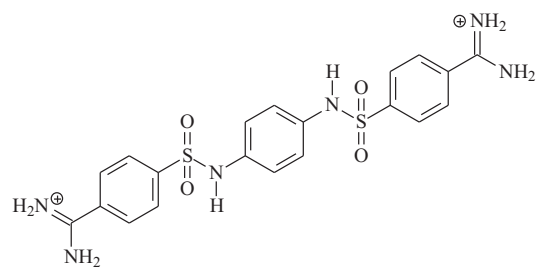

9

Figure 1. Chemical formulas of pentamidine analogs 1-9 used in this study.

\section{Prediction of drug-likeness descriptors and toxicity}

To find out the drug-likeness properties for the synthesized compounds, ADMET calculations were performed by the mathematical models $^{48}$ implemented into ADMET Predictor ${ }^{\mathrm{TM}}$ software version 8.5 Simulations Plus. ${ }^{49}$ We have predicted various drug-likeness parameters like molecular weight (MWt), distribution coefficient at $\mathrm{pH}=7.4(\log \mathrm{D})$, number of rotatable bonds $\left(N_{\mathrm{RB}}\right)$, number of aromatic rings $\left(N_{\mathrm{AR}}\right)$, the topological polar surface area (TPSA), the volume of distribution $\left(V_{\mathrm{d}}\right)$, the solubility $\left(S_{w}\right)$, the effective permeability $\left(P_{\text {eff }}\right)$, Madin-Darby Canine Kidney cells apparent permeability (MDCK), qualitative likelihood of penetrating the blood-brain barrier (BBB) filter express as high/low, the logarithm of the blood-brain barrier partition coefficient $\log C_{\text {brain }} / C_{\text {blood }}(\log B B)$, percentage of unbound drug to proteins within blood plasma (\% Unbnd) and blood-toplasma concentration ratio ( $\left.\mathrm{RBP}=C_{\text {whole-blood }} / C_{\text {plasma }}\right)$ were estimated for $\mathbf{1}$ 9 at $\mathrm{pH}$ 7.4. Prediction of metabolic indicators was based on phase I tests including cytochrome P450 (CYP 450) forms CYP 2C19, 1A2, 2D6 and 3A4, and the intrinsic hepatic clearance ( $\mathrm{Cl}$ int). All the CYP-metabolites generated for each compound were tested for risk potential whenever it was possible. Phase II metabolism of pentamidine derivatives was evaluated to determine the probability that human uridine $5^{\prime}$-diphosphate-glucuronosyltransferases (UGT) were involved. Whereas, virtual screenings were also performed to evaluate toxicological properties including Maximum Recommended Therapeutic Dose (MRTD), cardiac toxicity by affinity towards hERGencoded potassium channels (described by the qualitative estimation of likelihood of the hERG potassium channel inhibition (hERG_Filter) and the 
$\mathrm{pIC}_{50}$ as measure of affinity for hERG $\mathrm{K}^{+}$channel (hERG_pIC ( $_{50}$ )), and the hepatotoxicity (described by the level of alkaline phosphatase (AlkPhos), $\mathrm{Y}^{-}$ glutamyl transferase (GGT), serum glutamate oxaloacetate transaminase (SGOT), serum glutamate pyruvate transaminase (SGPT) and lactate dehydrogenase (LDH)).

\section{Molecular docking and dynamic simulations}

Molecular docking was performed using CDOCKER module of Discovery Studio 2017R2. The binding site sphere of hERG $\mathrm{K}^{+}$channel was defined as the regions that come within radius $15 \AA$ from the geometric centroid of the ligands. The poses with the lowest CDOCKER interaction energies were selected as the best conformations for the binding with active site of the hERG $\mathrm{K}^{+}$channel through hydrogen bonds and hydrophobic interactions. The best poses predicted by CDOCKER were used as the starting points in the molecular dynamics (MD) simulation.

All MD simulation were run using the CHARMm force field 50 implemented in the module of Discovery Studio 2017R2. The hERG channel complexes were surrounded by a cubic box of water molecules (TIP3P models $)^{51}$ extending up to a distance of $10 \AA$ from any solute atom. Additional $\mathrm{K}$ and $\mathrm{Cl}$ ions were added randomly to each complex at a concentration of $\sim 0.15 \mathrm{M}$, close to physiological conditions ${ }^{52}$ using the Solvation module of Discovery Studio 2017R2. All energy minimization and molecular dynamics simulations were performed using the Particle Mesh Ewald (PME) algorithm ${ }^{53}$ for the correct treatment of electrostatic interactions $\mathrm{s}^{54}$ and periodic boundary conditions. Before simulations, 2500 steps of steepest descent algorithm followed by 2500 conjugate gradient energy-minimization steps (until the RMS gradient of the structure was below $0.01 \mathrm{kcal} \mathrm{mol}^{-1} \AA^{-1}$ ) were performed. Subsequently, each simulation started with gradually heating from 50 to $300 \mathrm{~K}$ for $100 \mathrm{ps}$ followed by an equilibration of the systems for up to 500 ps, after which potential energies were sufficient. The equilibrated system was taken as the starting structure for $10 \mathrm{~ns}$ production runs in NPT ensemble, at a temperature of $300 \mathrm{~K}$ and 1 bar maintained using a Berendsen thermostat algorithm. ${ }^{53}$ During minimized, heating and equilibration, the protein and ligand were restrained with a force constant of started with $10 \mathrm{kcal} \mathrm{mol}^{-1} \AA^{-2}$ and gradually decreased to $2 \mathrm{kcal} \mathrm{mol}^{-1} \AA^{-2}$ and then subjected to a $5.5 \mathrm{~ns}$ production run 
with removing all constraint. The SHAKE method was used to constrain hydrogen atoms and the time step was set to $2 \mathrm{fs} .{ }^{56}$ The coordinates were saved every $10 \mathrm{ps}$ for subsequent analysis.

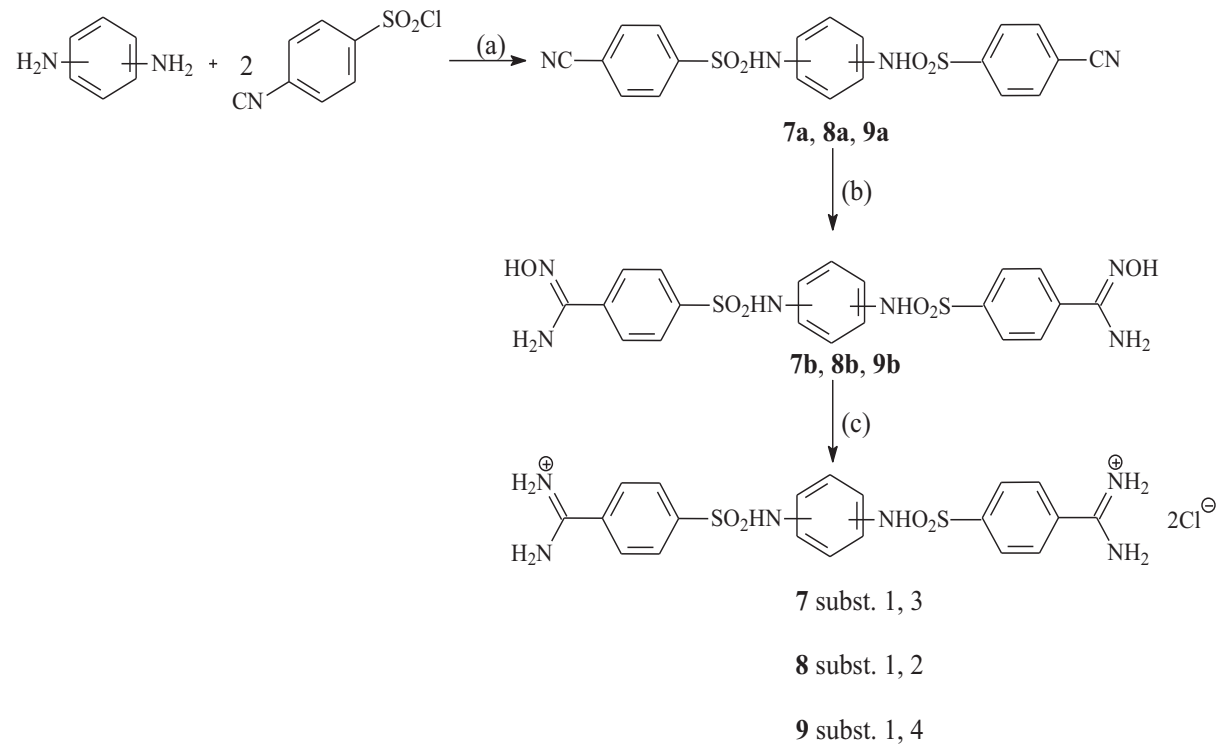

Figure 2. Synthetic route of new pentamidine analogs 7-9. Reagents and conditions: (a) NMP, $60{ }^{\circ} \mathrm{C}, 1 \mathrm{~h}$; (b) $50 \% \mathrm{NH}_{2} \mathrm{OH} / \mathrm{EtOH}$, r.t., 24 h; (c) $\mathrm{HCOOH} / 10 \% \mathrm{PdC} / \mathrm{AcOH}$, reflux, $3 \mathrm{~h}$, then aq. $\mathrm{HCl}$.

\section{Prediction the free enthalpy of binding}

Even though the docking combined with MD simulations can provide a clear image of the shape complementarity between the ligand and the receptor, it is required to have the additional and essential information of the free enthalpy of binding, which will assess to quantify the affinity of a ligand to its target. The obtained stable MD trajectory of each complex was used to calculated the binding free enthalpy by the MM-PBSA approach ${ }^{57}$ using explicit solvent molecules. The binding free enthalpy ( $\Delta G_{\text {bind }}$ ) of pentamidine derivatives to hERG channel was calculated by means of eqn (1):

$$
\Delta G_{\text {bind }}=G_{\text {hERG-ligand }}-G_{\text {hERG }}-G_{\text {ligand }}
$$




\section{Chapter 7}

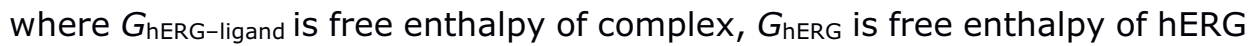
channel and $G_{\text {ligand }}$ is free enthalpy tested pentamidines. Binding free enthalpy was calculated based on the average structures obtained from the last $6 \mathrm{~ns}$ of MD trajectories. The components of each complex were minimized using the conjugate gradient method for 10000 steps after 100 steps of the steepest descent algorithm and a dielectric constant of 4 for the electrostatic interactions until the RMS gradient of the structure was $<0.001 \mathrm{kcal} \mathrm{mol}^{-1} \AA^{-1}$.
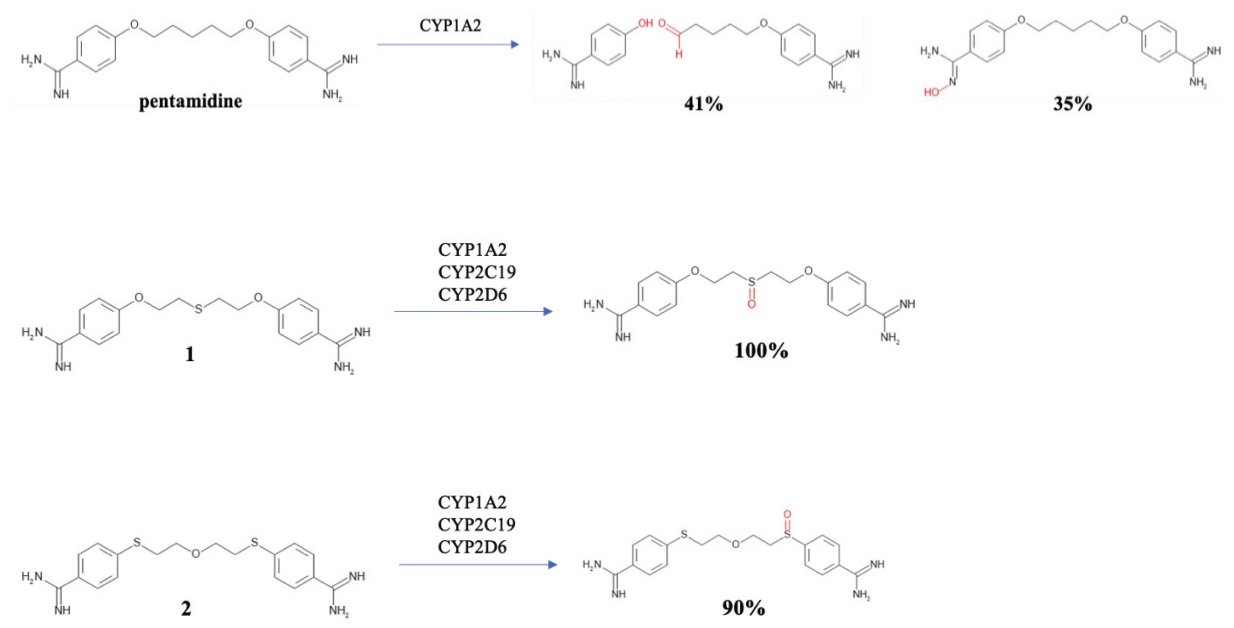

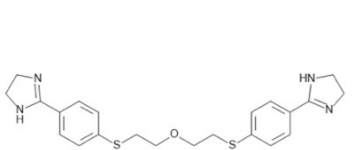

3

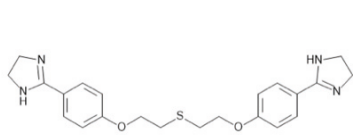

4

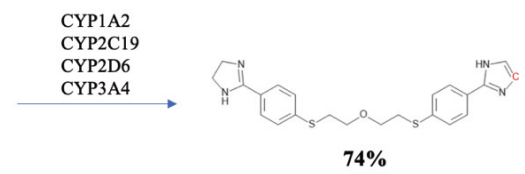

CYP1A2

CYP2C19 

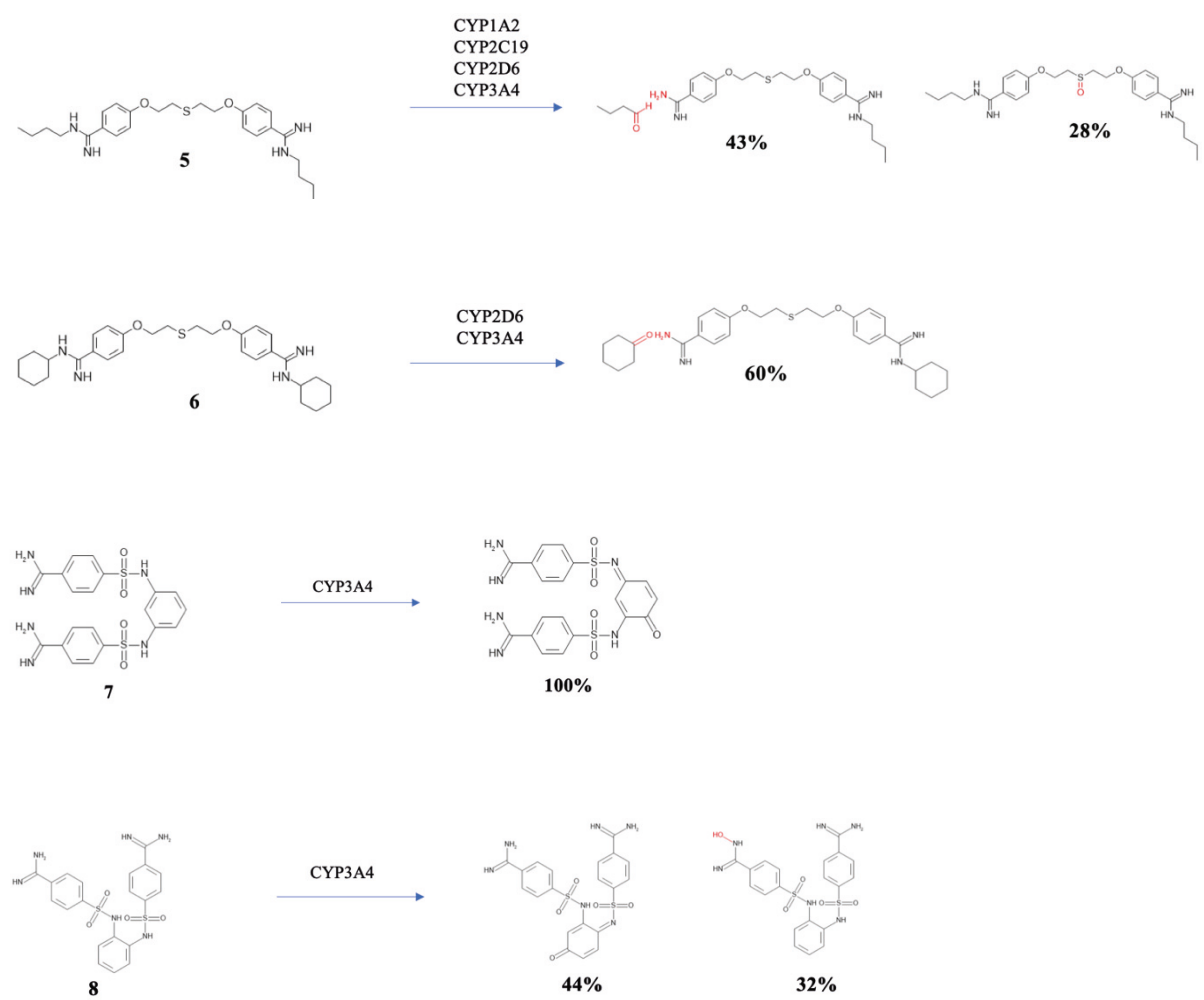

$44 \%$

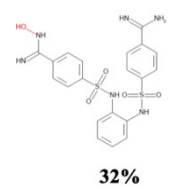

$32 \%$
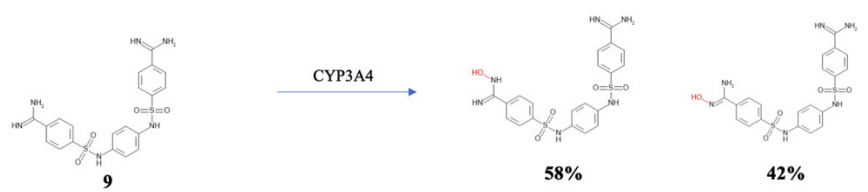

$\mathbf{4 2} \%$

Figure 3. Products of metabolism of pentamidine and 1-9 derivatives.

\section{EXPERIMENTAL METHODS}

\section{Chemical compounds}

Six pentamidine analogues 1-6 have been described previously, ${ }^{35-37}$ three 7-9 are newly synthesized. The synthesis of the three isomeric 
compounds 7-9 was carried out in three stages according to the general procedure shown in Fig. 2. In the first step, 4-cyanobenzenesulfonyl chloride reacted with an appropriate isomer of phenylenediamine in the presence of pyridine to give the initial dinitriles in a high yield. Only 1,3phenylenediamine was replaced with 1,3-phenylenediamine dihydrochloride, which is much more stable than a free amine and gives the expected product in a significantly higher yield. There was also used an appropriate excess of pyridine. In the second step, the previously obtained dinitriles were treated with an excess of $50 \%$ aqueous solution of hydroxylamine furnishing desired intermediate diamidoximes in high yields. In the last stage formerly received diamidoximes were catalytically $(\mathrm{Pd} / \mathrm{C})$ reduced with formic acid in boiling acetic acid to give finally expected diamidines. Treating with aqueous hydrochloric acid solution led to dihydrochlorides.

\section{General procedure for the synthesis of phenylenebis (aminosulfonyl) dibenzonitriles}

An appropriate phenylenediamine dihydrochloride $(1.08 \mathrm{~g}, 10 \mathrm{mmol})$ and pyridine $(1.92 \mathrm{~g}, 24 \mathrm{mmol}$ or $3.80 \mathrm{~g}, 48 \mathrm{mmol}$ ) were dissolved in $\mathrm{N}$ methyl-2-pyrrolidone $(20 \mathrm{~mL})$. To the stirred solution 4cyanobenzenesulfonyl chloride $(4.23 \mathrm{~g}, 21 \mathrm{mmol})$ was added portion-wise keeping the temperature below $40{ }^{\circ} \mathrm{C}$. Next, the mixture was heated at 60 ${ }^{\circ} \mathrm{C}$ for $1 \mathrm{~h}$ and finally poured into ice water $(80 \mathrm{~mL})$. The formed solid was filtered, washed with plenty of water and dried giving the almost pure product. They may be purified by refluxing with ethanol $(10-20 \mathrm{~mL})$ for several minutes.

3.2.1 4,4'-[1,3-phenylenebis(aminosulfonyl)]dibenzonitrile (7a). Yield 3,29 g (75\%), mp 245-246 ${ }^{\circ} \mathrm{C},{ }^{1} \mathrm{H}$ NMR (300 MHz, DMSO-d $\left.6, \delta \mathrm{ppm}\right)$ : $10.59(\mathrm{~s}, 2 \mathrm{H}), 8.05(\mathrm{~d}, \mathrm{~J}=9 \mathrm{~Hz}, 4 \mathrm{H}), 7.82(\mathrm{~d}, J=9 \mathrm{~Hz}, 4 \mathrm{H}), 7.10(\mathrm{t}, \mathrm{J}=$ $6 \mathrm{~Hz}, 1 \mathrm{H}), 7.00(\mathrm{~s}, 1 \mathrm{H}), 6.74(\mathrm{~d}, J=6 \mathrm{~Hz}, 2 \mathrm{H}) .{ }^{13} \mathrm{C} \mathrm{NMR}(75.4 \mathrm{MHz}, \delta \mathrm{ppm})$ : $143.2,137.8,133.4,130.2,127.3,117.4,116.2,115.4,111.6$.

3.2.2 4,4'-[1,2-phenylenebis(aminosulfonyl)]dibenzonitrile (8a). Yield 3,42 g (78\%), mp 238-239 ${ }^{\circ} \mathrm{C},{ }^{1} \mathrm{H}$ NMR (300 MHz, DMSO-d $\left.6, \delta \mathrm{ppm}\right)$ : $9.63(\mathrm{~s}, 2 \mathrm{H}), 8.05(\mathrm{~d}, J=8.1 \mathrm{~Hz}, 4 \mathrm{H}), 7.87(\mathrm{~d}, J=8.1 \mathrm{~Hz}, 4 \mathrm{H}), 7.09-7.06$ 
Pentamidine analogues and their impact on the hERG channel

$(\mathrm{m}, 2 \mathrm{H}), 6.95-6.92(\mathrm{~m}, 2 \mathrm{H}) .{ }^{13} \mathrm{C}$ NMR $(75.4 \mathrm{MHz}, \delta \mathrm{ppm}): 143.4,133.5$, $129.9,127.5,126.7,124.4,117.6,115.5$.

3.2.3 4,4'-[1,4-phenylenebis(aminosulfonyl)]dibenzonitrile (9a). Yield $3.94 \mathrm{~g}(90 \%), \mathrm{mp} 270-271{ }^{\circ} \mathrm{C},{ }^{1} \mathrm{H}$ NMR $\left(300 \mathrm{MHz}, \mathrm{DMSO}-\mathrm{d}_{6}, \delta \mathrm{ppm}\right)$ : $10.41(\mathrm{~s}, 2 \mathrm{H}), 8.02(\mathrm{~d}, J=9 \mathrm{~Hz}, 4 \mathrm{H}), 7.82(\mathrm{~d}, J=9 \mathrm{~Hz}, 4 \mathrm{H}), 6.95(\mathrm{~s}, 4 \mathrm{H})$. ${ }^{13} \mathrm{C}$ NMR $(75.4 \mathrm{MHz}, \delta \mathrm{ppm}): 143.2,133.7,133.4,127.4,122.1,117.5$, 115.1 .

\section{General procedure for the synthesis of phenylenebis(aminosulfonyl)dibenzamide dioximes}

An appropriate phenylenebis(aminosulfonyl)dibenzonitrile $(1.10 \mathrm{~g}, 2.5$ $\mathrm{mmol}$ ) was suspended in THF $(15 \mathrm{~mL})$. The $50 \%$ aqueous solution of hydroxylamine $(1,12 \mathrm{~g}, 16.8 \mathrm{mmol})$ was subsequently added and the whole was stirred for $24 \mathrm{~h}$ at room temperature. Next, the mixture was poured into water $(75 \mathrm{~mL})$. The solid was filtered, washed with water and dried giving pure products. They may be used in the next step without additional purification.

4,4'-[1,3-phenylenebis(aminosulfonyl)]dibenzamide dioxime (7b). Yield: $1.14 \mathrm{~g}(90 \%), \mathrm{mp} 130-140{ }^{\circ} \mathrm{C}$ (decomp.), ${ }^{1} \mathrm{H}$ NMR (300 MHz, DMSO$\left.\mathrm{d}_{6}, \delta \mathrm{ppm}\right): 10.34(\mathrm{~s}, 2 \mathrm{H}), 9.94(\mathrm{~s}, 2 \mathrm{H}), 7.80(\mathrm{~d}, J=8.4 \mathrm{~Hz}, 4 \mathrm{H}), 7.69(\mathrm{~d}$, $J=8.4 \mathrm{~Hz}, 4 \mathrm{H}), 7.11(\mathrm{~s}, 1 \mathrm{H}), 7.03(\mathrm{t}, J=8.1 \mathrm{~Hz}, 1 \mathrm{H}), 6.68(\mathrm{~d}, J=8.1 \mathrm{~Hz}$, $2 \mathrm{H}), 5.92(\mathrm{~s}, 4 \mathrm{H}) .{ }^{13} \mathrm{C}$ NMR $(75.4 \mathrm{MHz}, \delta \mathrm{ppm}): 149.6,139.3,138.4,137.4$, $129.8,126.6,125.9,115.1,110.8$.

4,4'-[1,2-phenylenebis(aminosulfonyl)]dibenzamide dioxime (8b). Yield: $1.06 \mathrm{~g}(86 \%), \mathrm{mp} 214-215{ }^{\circ} \mathrm{C},{ }^{1} \mathrm{H}$ NMR $\left(300 \mathrm{MHz}, \mathrm{DMSO}-\mathrm{d}_{6}, \delta \mathrm{ppm}\right)$ : $9.96(\mathrm{~s}, 2 \mathrm{H}), 9.38(\mathrm{~s}, 2 \mathrm{H}), 7.83(\mathrm{~d}, J=8.4 \mathrm{~Hz}, 4 \mathrm{H}), 7.71(\mathrm{~d}, J=8.4,4 \mathrm{H})$, 7.03-6.95 (m, 4H) $5.95(\mathrm{~s}, 4 \mathrm{H}) .{ }^{13} \mathrm{C}$ NMR $(75.4 \mathrm{MHz}, \delta \mathrm{ppm}): 149.5,138.9$, $137.6,129.9,126.8,126.1,126.0$.

4,4'-[1,4-phenylenebis(aminosulfonyl)]dibenzamide dioxime (9b). Yield: $1.16 \mathrm{~g}(92 \%), \mathrm{mp} 253-254^{\circ} \mathrm{C},{ }^{1} \mathrm{H}$ NMR $\left(300 \mathrm{MHz}, \mathrm{DMSO}-\mathrm{d}_{6}, \delta \mathrm{ppm}\right)$ : $10.17(\mathrm{~s}, 2 \mathrm{H}), 9.93(\mathrm{~s}, 2 \mathrm{H}), 7.78(\mathrm{~d}, J=9 \mathrm{~Hz}, 4 \mathrm{H}), 7.66(\mathrm{~d}, J=9 \mathrm{~Hz}, 4 \mathrm{H})$, $6.93(\mathrm{~s}, 4 \mathrm{H}), 5.92(\mathrm{~s}, 4 \mathrm{H}) .{ }^{13} \mathrm{C}$ NMR $(75.4 \mathrm{MHz}, \delta \mathrm{ppm}): 149.7,139.4$, $137.4,133.9,126.5,126.0,121.7$. 
General procedure for the synthesis of phenylenebis(aminosulfonyl)dibenzamidine dihydrochlorides

An appropriate phenylenebis(aminosulfonyl)dibenzamide oxime (1.00 $\mathrm{g}, 2 \mathrm{mmol})$ was suspended in glacial acetic acid $(8 \mathrm{~mL})$. Then palladium on carbon (Pd/C $10 \% \mathrm{w} / \mathrm{w})(80 \mathrm{mg})$ and subsequently formic acid $(0.8 \mathrm{~mL})$ were added. The mixture was refluxed for $3 \mathrm{~h}$, after which cooled to room temperature. The catalyst and other solid impurities were filtered off. To the filtrate, a $35 \%$ aqueous solution of $\mathrm{HCl}(0.5 \mathrm{~mL})$ was added dropwise and all the solvents evaporated to dryness. The solid residue was purified by refluxing with ethanol $(5-10 \mathrm{~mL})$.

\section{4,4'-[1,3-phenylenebis(aminosulfonyl)]dibenzamidine}

dihydrochloride (7). Yield: $1.00 \mathrm{~g}(92 \%), \mathrm{mp} 290^{\circ} \mathrm{C}$ (decomp.), ${ }^{1} \mathrm{H} \mathrm{NMR}$ (300 MHz, DMSO-d $6, \delta \mathrm{ppm}): 10.80(\mathrm{~s}, 2 \mathrm{H}), 9.60(\mathrm{~s}, 4 \mathrm{H}), 9.43(\mathrm{~s}, 4 \mathrm{H})$, $8.01-7.88(\mathrm{~m}, 8 \mathrm{H}), 7.20(\mathrm{~s}, 1 \mathrm{H}), 7.08(\mathrm{t}, J=7.8 \mathrm{~Hz}, 1 \mathrm{H}), 6.78(\mathrm{~d}, J=7.8$ $\mathrm{Hz}, 2 \mathrm{H}) .{ }^{13} \mathrm{C}$ NMR $(75.4 \mathrm{MHz}, \delta \mathrm{ppm}): 164.8,143.6,138.2,132.2,130.0$, $129.4,127.0,115.2,110.7$. TOF MS ES+ $[\mathrm{M}-2 \mathrm{Cl}-\mathrm{H}]^{+}$calcd for $\mathrm{C}_{28} \mathrm{H}_{21} \mathrm{~N}_{6} \mathrm{O}_{4} \mathrm{~S}_{2}$ (473.1066) found 473.1082 .

\section{4,4'-[1,2-phenylenebis(aminosulfonyl)]dibenzamidine}

dihydrochloride (8). Yield: $0.30 \mathrm{~g}(28 \%), \mathrm{mp} 290^{\circ} \mathrm{C}$ (decomp.), ${ }^{1} \mathrm{H} \mathrm{NMR}$ (300 MHz, DMSO-d $6, \delta \mathrm{ppm}): 10.30(\mathrm{~s}, 2 \mathrm{H}), 9.57(\mathrm{~s}, 4 \mathrm{H}), 9.37(\mathrm{~s}, 4 \mathrm{H})$, 8.03-7.96 (m, 8H), $7.01(\mathrm{~s}, 4 \mathrm{H}) .{ }^{13} \mathrm{C}$ NMR $(75.4 \mathrm{MHz}, \delta \mathrm{ppm}): 164.7,144.2$, $132.1,129.8,129.3,127.1,126.0,123.8$. TOF MS ES $+[\mathrm{M}-2 \mathrm{Cl}-\mathrm{H}]^{+}$calcd for $\mathrm{C}_{28} \mathrm{H}_{21} \mathrm{~N}_{6} \mathrm{O}_{4} \mathrm{~S}_{2}(473.1066)$ found 473.1053 .

\section{4,4'-[1,4-phenylenebis(aminosulfonyl)]dibenzamidine}

dihydrochloride (9). Yield: $0.86 \mathrm{~g}(79 \%), \mathrm{mp} 270{ }^{\circ} \mathrm{C}$ (decomp.), ${ }^{1} \mathrm{H} \mathrm{NMR}$ (300 MHz, DMSO-d,$\delta \mathrm{ppm}): 10.64(\mathrm{~s}, 2 \mathrm{H}), 9.95(\mathrm{~s}, 4 \mathrm{H}), 9.37(\mathrm{~s}, 4 \mathrm{H})$, 7.97-7.91 (m, 8H), $7.02(\mathrm{~s}, 4 \mathrm{H}) .{ }^{13} \mathrm{C}$ NMR $(75.4 \mathrm{MHz}, \delta \mathrm{ppm}): 164.8,143.7$, $133.7,132.2,129.4,126.9,121.5$. TOF MS ES $+[\mathrm{M}-2 \mathrm{Cl}-\mathrm{H}]^{+}$calcd for $\mathrm{C}_{28} \mathrm{H}_{21} \mathrm{~N}_{6} \mathrm{O}_{4} \mathrm{~S}_{2}$ (473.1066) found 473.1052 .

\section{Biological data}

All analogues were dissolved in DMSO as stock solution at $50 \mathrm{mM}$ and further diluted in $\mathrm{ddH}_{2} \mathrm{O}$. The final working solution for all compounds was 
3 mM. Pentamidine-isethionate (Pentacrit ${ }^{\circledR}$ 300, Sanofi Aventis, Gouda, The Netherlands) was dissolved in $\mathrm{ddH} 2 \mathrm{O}$ and final working solution was $10 \mathrm{mM}$. Dofetilide (Procter and Gamble, Cincinnati, USA) was dissolved in DMSO and further diluted in $\mathrm{ddH} 2 \mathrm{O}$, final working solution was $1 \mathrm{mM}$. Concentrations of these controls were used as in previous research. ${ }^{34}$ All compounds were sterilized by filtration $(0.2 \mu \mathrm{m})$, aliquoted and stored at $20^{\circ} \mathrm{C}$ until use.

\section{Cell culture}

HEK-293T cells stably expressing hERG (HEK-hERG) were obtained from C. January. ${ }^{58}$ The cells were maintained in DMEM (GibcoFisherScientific, Landsmeer, The Netherlands) with $10 \%$ fetal calf serum (Sigma-Aldrich, Zwijndrecht, the Netherlands), $2 \mathrm{mM}$ L-glutamine, $50 \mu \mathrm{g}$ $\mathrm{mL}^{-1}$ streptomycin and $1 \mathrm{U} \mathrm{mL}^{-1}$ penicillin (all three Lonza, Breda, the Netherlands). Cells were split twice a week and cultured at $37^{\circ} \mathrm{C}$ and $5 \%$ $\mathrm{CO}_{2}$. The amount of DMSO added to the cells was kept below $0.1 \%$.

\section{Western blotting}

Cells were cultured in $60 \mathrm{~mm}$ dishes for 20-24h till a confluency of 60$70 \%$. Cells were treated with pentamidine (hERG trafficking blocker, 10 $\mu \mathrm{M}$ ), dofetilide (hERG trafficking activator, $1 \mu \mathrm{M}$ ) or pentamidine analogues 1-9 $(1$ and $10 \mu \mathrm{M})$ for 24 hours. Full dose-response experiments were performed with 1, 2 and $5(0.5,1,3,5,10$ and $20 \mu \mathrm{M})$. Following incubations, cells were washed with PBS (Lonza, Basel, Switzerland) containing $1 \mathrm{mM} \mathrm{MgCl}$ and $\mathrm{CaCl}_{2}\left(\mathrm{PBS}^{++}\right)$twice, and lysed in 130-180 $\mu \mathrm{L}$ of lysis buffer (buffer D 20 mM HEPES, $125 \mathrm{mM} \mathrm{NaCl}, 10 \%$ (v/v) glycerol, $1 \mathrm{mM}$ EDTA, $1 \mathrm{mM}$ EGTA, $1 \mathrm{mM}$ dithiothreitol and 1\% (v/v) Triton X-100), $6.8 \mathrm{mg} \mathrm{mL}^{-1}$ aprotinin (Sigma-Aldrich, Zwijndrecht, The Netherlands and 1 mM PMSF) per dish was added depending on cell confluency. Lysates were centrifuged at $14000 \times g$ for $10 \mathrm{~min}$ and the supernatant was collected. Protein concentrations were determined by bicichroninic acid (Pierce ${ }^{\mathrm{TM}}$ BCA protein assay kit, Thermo Scientific, Waltham, USA) in combination with the Nanodrop 2000 (Thermo Scientific, Waltham, USA). Ten $\mu$ g samples were run by $7 \%$ SDS-PAGE and proteins were blotted on a nitrocellulose membrane (Bio-Rad Laboratories, Veenendaal, The Netherlands). Reversible Ponceau red staining was used to determine equal loading and 
subsequent quantification. Membranes were blocked with $5 \%(w / v)$ non-fat milk powder (in TBST) and subsequently incubated overnight at $4{ }^{\circ} \mathrm{C}$ with primary antibody, anti-Kv11.1 (1:2500; Alomone Labs, Jerusalem, Israel). Secondary antibody GaRb HRP (Bio-Rad Laboratories, Veenendaal, The Netherlands) was applied for 2 hours at room temperature at 1:10.000. Membranes were developed using Amersham ECL ${ }^{T M}$ prime western blotting detection reagent (GE Lifesciences, Chicago, USA) with Chemidoc XRS ${ }^{+}$ (Bio-Rad Laboratories, Veenendaal, The Netherlands). Quantification was done by Image Lab $^{T M}$ software version 5.2.1 (Bio-Rad Laboratories, Veenendaal, The Netherlands).

\section{Immunofluorescence microscopy}

HEK-hERG cells were cultured on $\varnothing 15 \mathrm{~mm}$ glass coverslips coated with $0.1 \%$ gelatin. After $24 \mathrm{~h}$ treatment with pentamidine $(10 \mu \mathrm{M})$, dofetilide ( 1 $\mu \mathrm{M})$ or $\mathbf{1}, \mathbf{2}$ or $\mathbf{5}(10 \mu \mathrm{M})$ coverslips were washed with $\mathrm{PBS}^{++}$, fixated with $3 \%$-paraformaldehyde and permeabilized with $0.5 \%$ triton $\mathrm{X}-100$ (in PBS). After permeabilization cells were quenched with PBS/glycine $(50 \mathrm{mM})$ and incubated twice with NET-gel $(0.25 \%$ gelatin, $50 \mathrm{mM}$ Tris-Cl, $150 \mathrm{mM} \mathrm{NaCl}$, $4 \mathrm{mM}$ EDTA, $0.05 \%$ Igepal, $\pm 0.01 \% \mathrm{NaN}_{3}, \mathrm{pH} 7.4$ ). Cells were incubated with the primary antibody in NET-gel overnight (anti-Kv11.1, Alomone Labs, Jerusalem, Israel). After washing the cells, samples were incubated with the secondary antibody (Jackson). Coverslips were mounted with Vectashield (Vector Laboratories Inc., Burlingame, USA) and imaged using a Nikon Eclipse 80i (Nikon, Amsterdam, The Netherlands) and NIS elements Basic Research (Nikon, Amsterdam, The Netherlands) software.

\section{Electrophysiological recordings}

HEK-hERG cells were cultured on $\varnothing 12 \mathrm{~mm}$ glass coverslips coated with poly-L-lysine (Sigma-Aldrich, Germany). IhERG was recorded in wholecell voltage mode. Pipettes (Harvard apparatus, Hollisto, USA) were pulled and polished (Model P-2000, Sutter instruments co., Novato, USA) and had a resistance of 2-4 $M \Omega$ once filled with solution. Potassium currents were measured with Axopatch 200B (Axon instruments, USA) and Clampex 10.0 software. ${ }^{59}$ The following protocol was used: holding potential was $-80 \mathrm{mV}$, a hyperpolarizing step was applied for $50 \mathrm{~ms}$ at $-120 \mathrm{mV}$ to correct for leak currents. Thereafter $4 \mathrm{~s}$ test pulses between $-80 \mathrm{mV}$ and $+60 \mathrm{mV}$ in $10 \mathrm{mV}$ 
increments were applied. And it was followed by $5 \mathrm{~s}$ deactivation pulse at $50 \mathrm{mV}$. After $3.5 \mathrm{~min}$ when the current had stabilized a control measurement was done. Subsequently, acute treatment with $\mathbf{4}, \mathbf{5}, \mathbf{6}, \mathbf{7}, \mathbf{8}$ or $9(1 \mu \mathrm{M})$ was applied with a flow of $\sim 1 \mathrm{~mL} \mathrm{~min}^{-1}$. Currents were measured at 3.5, 7 and $15 \mathrm{~min}$. All measurements were obtained at room temperature $\left(22^{\circ} \mathrm{C}\right)$. Bath solution consisted of $140 \mathrm{mM} \mathrm{NaCl}, 4 \mathrm{mM} \mathrm{KCl}, 10 \mathrm{mM}$ HEPES, $2 \mathrm{mM} \mathrm{CaCl} 2,1 \mathrm{mM} \mathrm{MgCl} 2$ and adjusted to $\mathrm{pH} 7.4(\mathrm{NaOH})$. Pipette solution consisted of $10 \mathrm{mM}$ EGTA, $110 \mathrm{mM} \mathrm{KCl}, 10 \mathrm{mM}$ HEPES, $4 \mathrm{mM} \mathrm{K}$-ATP, 5.17 $\mathrm{mM} \mathrm{CaCl}, 1.42 \mathrm{mM} \mathrm{MgCl} 2,15 \mathrm{mM}$ sucrose and adjusted to $\mathrm{pH} 7.2(\mathrm{KOH})$. The data were quantified by Clampfit software. ${ }^{60}$

\section{Data analysis}

All results are presented as mean \pm standard deviation. Differences were tested with a one-way ANOVA and a Bonferroni post hoc test. Only for difference between 1 and $10 \mu \mathrm{M}$ treated cells a two-way ANOVA has been performed. All western blot data were normalized for control before statistical analysis. For the patch clamp data values at $+10 \mathrm{mV}$ were used for statistical analysis. Differences were considered statistically significant with a $p$-value $<0.05$. All analyses were performed using GraphPad Prism version $7.04 .^{61}$

\section{RESULTS AND DISCUSSION}

\section{Assessing of drug-likeness parameters}

All studied pentamidines 1-9 are analyzed in dicationic form. The predicted drug-likeness parameters (the topological polar surface area (TPSA), volume of distribution $\left(V_{d}\right)$, water solubility $\left(S_{w}\right)$, effective permeability $\left(P_{\text {eff }}\right)$, apparent permeability $(M D C K)$, percentage of unbound drug to blood plasma proteins ( $\%$ Unbnd), blood-to-plasma concentration ratio (RBP), BBB_filter, blood-brain barrier partition coefficient (log BB)) for tested pentamidines are shown in Table 1. TPSA serves as an important parameter for the evaluation of molecular transport properties, especially in intestinal absorption and blood-brain barrier penetration. Its values for 1-6 were found within range 58.01-118.2 $\AA^{2}$ and these compounds are predicted to have a high capacity for penetrating cell membranes. ${ }^{62} \mathrm{New}$ 
compounds 7-9 with sulfanilide groups show values close to $192 \AA^{2}$ and it may accounts for their easy penetration in hydrophilic environments, such as the core of transporter proteins. ${ }^{63}$ The volume $V_{\mathrm{d}}$ is the pharmacokinetic parameter which can show the dose required to give a certain plasma concentration. The volume $V_{\mathrm{d}}$ of all compounds under study are in the range of $0.454-10.621 \mathrm{~L} \mathrm{~kg}^{-1}$ and probably they are not distributed to all tissues in the body. Compounds 7-9 which have $V_{\mathrm{d}}$ below $0.7 \mathrm{~L} \mathrm{~kg}^{-1}$ are confined to the blood plasma, but compounds 1-6 with one or two $S$ atoms in the linker have values higher than $4.5 \mathrm{~L} \mathrm{~kg}^{-1}$ and are predicted to be distributed in whole blood. The aqueous solubility $\left(S_{w}\right)$ of all tested pentamidine derivatives (we should remember that they are dihydrochlorides) are good and are within the range of $0.043-1.192 \mathrm{mg} \mathrm{mL}^{-1}$. The best solubility's have two dihydrochlorides: 1,5-bis(4-amidinophenoxy)-3-thiopentane (1) and 1,5-bis[4-(amidino)phenylthio]-3-oxapentane (2) (1.192 and $0.697 \mathrm{mg}$ $\mathrm{mL}^{-1}$, respectively). Human jejunal permeability $\left(P_{\text {eff }}\right)$ which reflects the passive transport velocity in $\mathrm{cm} \mathrm{s}^{-1}$ across the epithelial barrier in the human jejunum, was predicted high for 1-6 $\left(0.701-2.063 \times 10^{-4} \mathrm{~cm} \mathrm{~s}^{-1}\right)$. The values of Madin-Darby canine kidney (MDCK), a parameter for assessing the apparent membrane permeability properties, were also high (47.23$\left.804.27 \times 10^{-7} \mathrm{~cm} \mathrm{~s}^{-1}\right)$. New dihydrochlorides with phenylenebis (aminosulfonyl) linker $(\mathbf{7}, \mathbf{8}$ and $\mathbf{9})$ have these two parameters decreased

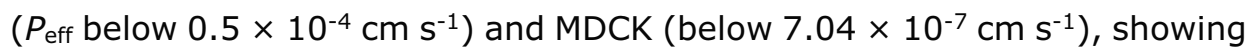
poor jejunal permeation and apparent membrane permeability. An ability to bind to plasma proteins, which is in most cases considered as undesirable, is characterized by two parameters: the percentage of drug unbound to protein within blood plasma (\% Unbnd) and the concentration of the drug in whole blood compared to plasma (RBP). For the majority of tested pentamidines the values of $\%$ Unbnd are in the region $10-41 \%$, and the values of RBP in the region 1.01-1.17, which indicates low or moderate binding to plasma protein. Only values of \% Unbnd and RBP for compounds 5 and $\mathbf{6}$ were below $10 \%$ and 1, respectively, which suggests that the alkyl substituents at amidine groups increase the plasma protein binding. The next molecular properties (BBB_filter and log BB) determine the likelihood of crossing the blood-brain barrier (BBB). Analysis of both parameters revealed that 3-6 derivatives remain in the qualitative likelihood of crossing the $\mathrm{BBB}$ and $\log \mathrm{BB}$ was more than 0.3 values, suggesting that alkyl substituent at amidine groups increases the potential for BBB penetration. Whilst, bis-benzamidines 1, 2 and new 7-9 have the lowest log BB values 
(below 0 and even below -1) suggesting the favourable impact of phenylenebis(aminosulfonyl) linker for toxicity joined with BBB penetration.

Table 1. Theoretical values of topological polar surface area (TPSA), distribution $\left(V_{\mathrm{d}}\right)$, water solubility $\left(S_{\mathrm{w}}\right)$, effective permeability $\left(P_{\text {eff }}\right)$, apparent permeability MDCK, percentage of unbound drug to blood plasma proteins (\% Unbnd), bloodto-plasma concentration ratio (RBP), BBB filter and blood-brain barrier partition coefficient $(\log B B)$ for 1-9

\begin{tabular}{|c|c|c|c|c|c|c|c|c|c|}
\hline \multirow[b]{3}{*}{ Compound } & TPSA & $V_{\mathrm{d}}$ & $S_{\mathrm{w}}$ & $P_{\text {eff }}$ & MDCK & $\%$ Unbnd & RBP & BBB filter & $\log B B$ \\
\hline & \multicolumn{9}{|c|}{ Expected values } \\
\hline & $\begin{array}{l}(\leq 140 \\
\left.\AA^{2}\right)\end{array}$ & $\begin{array}{l}(\leq 3.7 \mathrm{~L} \\
\left.\mathrm{kg}^{-1}\right)\end{array}$ & $\begin{array}{l}(\geq 0.010 \mathrm{mg} \\
\left.\mathrm{mL}^{-1}\right)\end{array}$ & $\begin{array}{l}(\geq 0.5 \mathrm{~cm} \\
\left.\mathrm{s}^{-1} \times 10^{4}\right)\end{array}$ & $\begin{array}{l}(\geq 30 \mathrm{~cm} \\
\left.\mathrm{s}^{-1} \times 10^{7}\right)\end{array}$ & $(>10 \%)$ & $(<1)$ & (High/low) & \\
\hline 1 & 118.20 & 4.606 & 1.192 & 0.701 & 59.926 & 16.085 & 1.122 & High & -0.058 \\
\hline 2 & 108.97 & 6.410 & 0.697 & 0.728 & 47.227 & 15.652 & 1.116 & High & -0.231 \\
\hline 3 & 58.01 & 7.178 & 0.183 & 2.063 & 638.620 & 10.100 & 1.163 & High & 0.592 \\
\hline 4 & 67.24 & 4.570 & 0.509 & 2.003 & 804.274 & 9.687 & 1.173 & High & 0.783 \\
\hline 5 & 90.22 & 10.621 & 0.096 & 0.810 & 407.340 & 2.841 & 0.912 & High & 0.576 \\
\hline 6 & 90.22 & 5.462 & 0.043 & 0.807 & 374.797 & 1.776 & 0.993 & High & 0.653 \\
\hline 7 & 192.08 & 0.454 & 0.160 & 0.141 & 4.343 & 34.676 & 1.076 & Low & -0.677 \\
\hline 8 & 192.08 & 0.462 & 0.102 & 0.180 & 7.039 & 22.170 & 1.104 & Low & -1.251 \\
\hline 9 & 192.08 & 0.617 & 0.287 & 0.131 & 3.953 & 41.859 & 1.012 & Low & -1.083 \\
\hline
\end{tabular}

Pentamidines were targeted for the evaluation of the metabolic biotransformation. The predictions were made for phase I (cytochrome P450s hepatic enzyme system) and phase II (the enzymatic conjugation of substrates with the UGT enzymes). ${ }^{64}$ Modes of action (substrate/nonsubstrate/inhibition) and intrinsic hepatic clearance ( $\left.\mathrm{Cl}_{\text {int }}\right)$ are predicted for four isoforms cytochrome P450 (1A2, 2C19, 2D6 and 3A4), ${ }^{65}$ which are considered as the most important in xenobiotic metabolism (Table 2). Compounds $\mathbf{1}$ and $\mathbf{2}$ cannot be metabolized by CYP3A4, while the other tested pentamidines can be its substrates. Pentamidine derivatives $\mathbf{3}$ and $\mathbf{4}$ with amidine groups closed in imidazoline rings can be substrates or inhibitors of all isoforms, but 6 cannot be metabolized by CYP2C19, 7 and 9 by CYP2D6, and 8 by three isoforms CYP1A2, CYP2C19, and CYP2D6. Since inhibition of cytochrome P450 is the main source of adverse drug interactions, we examined intrinsic hepatic clearance $\left(\mathrm{Cl}_{\text {int }}\right)$ which describes the intrinsic ability of the liver to remove the drug in absence of restrictions imposed on drug delivery to the liver cell by blood flow or protein binding. The recommended range for predicted $\mathrm{Cl}_{\text {int }}$ values is $>30\left(\mu \mathrm{L} \mathrm{min}{ }^{-1} \mathrm{mg}^{-1}\right)$. All studied pentamidines demonstrated microsomal metabolic labilities with wide range of Clint values ranging from 15.3 to $80.3\left(\mu \mathrm{L} \mathrm{min}{ }^{-1} \mathrm{mg}^{-1}\right)$ for CYP1A1, from 64.0 to $437.7\left(\mu \mathrm{L} \mathrm{min}{ }^{-1} \mathrm{mg}^{-1}\right)$ for CYP2C19, from 104.5 to $812.0\left(\mu \mathrm{L} \mathrm{min}{ }^{-1} \mathrm{mg}^{-1}\right)$ for CYP2D6, and from 5.0 to $1790.0\left(\mu \mathrm{L} \mathrm{min}^{-1} \mathrm{mg}^{-1}\right)$ 
for CYP3A4. The highest value (1790.0 $\left(\mu \mathrm{L} \mathrm{min}{ }^{-1} \mathrm{mg}^{-1}\right)$ for CYP3A4) was observed for compound $\mathbf{6}$ with cyclohexyl substituent at amidine groups, while the lowest value $\mathrm{Cl}_{\text {int }}<30\left(\mu \mathrm{L} \mathrm{min}{ }^{-1} \mathrm{mg}^{-1}\right)$ also for CYP3A4 was seen for new compounds 7, 8 and $\mathbf{9}$ with benzenesulfanilide linker (11.24, 7.95 and $5.03\left(\mu \mathrm{L} \mathrm{min}^{-1} \mathrm{mg}^{-1}\right)$, respectively). It can mean that hepatic flow will have minimal influence on its metabolism. Further, nine main microsomal hepatic UGTs were checked to identify which isoforms may be responsible for pentamidines glucuronidation reaction leading to their easier elimination. Compounds 1-6 are evaluated as a substrate for three isoenzymes $1 \mathrm{~A} 1,1 \mathrm{~A} 3$ and $1 \mathrm{~A} 4$, but new bis-benzamidines 7-9 are predicted rather not conjugate in phase II. Only isoforms $1 \mathrm{~A} 8$ or $1 \mathrm{~A} 9$ have some potential to metabolize these compounds (see Table S1 in electronic supplementary information (ESI)). Potential structures of metabolites for tested pentamidines are shown in Fig. 3. Experimental data are approachable for pentamidine itself in rats. ${ }^{66}$ Two major pentamidine metabolites have the hydroxyl groups at pentyl linker. Proposed metabolic transformations in humans lead to carboxylic acid derivative and 4hydroxybenzamidine. For pentamidines 1-6 in which $\mathrm{S}$ atoms are present in the aliphatic linker, oxidation of one $\mathbf{S}$ atom were predicted for compounds 1-3 and 5, while for compound $\mathbf{4}$ dehydrogenation of imidazoline ring was predicted. Moreover, in $\mathbf{5}$ and $\mathbf{6}$ the aliphatic substituents may also be removed. New pentamidines 7-9 with phenyl sulfanilide moiety can be oxidized to chinones or one amidine group can be substituted by the hydroxyl group.

In the evaluation of the toxicity profile of pentamidines 1-9 several predictors including human maximum tolerated dose and hepatotoxicity were used (see Table 3). A maximum recommended therapeutic dose (MRTD) in a unit of $\mathrm{mg}$ per $\mathrm{kg}$ of body weight per day should be greater than $3.16 \mathrm{mg}$ per $\mathrm{kg}$ bw per day, which can show that the tested compound has fewer side effects. All by one pentamidines have MRTD value $>3.16$, indicating that the appearance of side effects is less likely. Only 1,5-bis[4( $N$-cyclohexylamidino)phenoxy)]-3-thiapentane dihydrochloride (6) has MRTD value below 3.16. In the test of the hepatic injury, the majority of studied pentamidines are predicted as "non-toxic". Level of LDH, SGOT, and SGPT are elevated only for $\mathbf{1}$ and $\mathbf{4}$ indicating some hepatic problems. The cytotoxicity of 1-6 were tested experimentally in our former works ${ }^{35-37}$ with other groups of pentamidines, which can explain observed data. In these assays, the majority of compounds were not cytotoxic (also those with the 
sulfobenzene group), only compounds $\mathbf{1}$ and $\mathbf{4}$ exhibited less or moderate cytotoxicity. The predicted hepatic problems for $\mathbf{1}$ and $\mathbf{4}$ have thrown more light on the factors affecting experimental data.

Table 2. Mode of action (inhibition/induction) and intrinsic hepatic clearance ( $\left.\mathrm{Cl}_{\text {int }}\right)$ for selected cytochrome P450 enzymes of 1-9 ${ }^{\text {a }}$

\begin{tabular}{|c|c|c|c|c|c|c|c|c|}
\hline \multirow[b]{3}{*}{ Compound } & \multicolumn{8}{|l|}{ CYP } \\
\hline & \multicolumn{4}{|c|}{ Mode of action } & \multicolumn{4}{|c|}{$\mathrm{Cl}_{\text {int }}\left(\mu \mathrm{L} \min ^{-1} \mathrm{mg}^{-1}\right)$} \\
\hline & $1 \mathrm{~A} 2$ & 2C19 & 2D6 & $3 \mathrm{~A} 4$ & $1 \mathrm{~A} 2$ & 2C19 & 2D6 & $3 \mathrm{~A} 4$ \\
\hline 1 & $\mathrm{~S} / \mathrm{I}$ & $\mathrm{s}$ & $\mathrm{S} / \mathrm{I}$ & NS & 16.878 & 63.994 & 104.452 & - \\
\hline 2 & $\mathrm{~S} / \mathrm{I}$ & $\mathrm{s}$ & $\mathrm{S} / \mathrm{I}$ & NS & 15.311 & 85.408 & 229.701 & - \\
\hline 3 & S/I & $\mathrm{s}$ & $\mathrm{S} / \mathrm{I}$ & $\mathrm{s}$ & 28.593 & 157.004 & 811.987 & 43.544 \\
\hline 4 & S/I & $\mathrm{s}$ & I & $\mathrm{S}$ & 80.280 & 153.788 & - & 46.525 \\
\hline 5 & $\mathrm{~S}$ & $\mathrm{~s}$ & $\mathrm{~S} / \mathrm{I}$ & $\mathrm{S}$ & 70.659 & 437.686 & 367.709 & 377.690 \\
\hline 6 & I & NS & $\mathrm{S} / \mathrm{I}$ & $\mathrm{S}$ & - & - & 727.161 & 1789.969 \\
\hline 7 & I & I & NS & $\mathrm{S}$ & - & - & - & 11.238 \\
\hline 8 & NS & NS & NS & $\mathrm{S}$ & - & - & - & 7.949 \\
\hline 9 & I & I & NS & $\mathrm{s}$ & - & - & - & 5.025 \\
\hline
\end{tabular}

a I - denotes inhibition of CYP isoforms; $\mathrm{S}$ - denotes substrate of CYP isoform; NS - denotes non-substrate for isoform.

Table 3. Predicted hepatoxicity parameters for 1-9: maximum recommended therapeutic dose MRTD, level of alkaline phosphatase (AlkPhos), level of $\gamma$-glutamyl transferase (GGT), level of serum glutamate oxaloacetate transaminase (SGOT), level of serum glutamate pyruvate transaminate (SGPT), level of lactate dehydrogenase (LDH)

\begin{tabular}{|c|c|c|c|c|c|c|}
\hline Compound & \multicolumn{6}{|l|}{ Expected values } \\
\hline 1 & Above 3.16 & NT & NT & $\mathrm{T}$ & $\mathrm{T}$ & $\mathrm{T}$ \\
\hline 4 & Above 3.16 & NT & NT & $\mathrm{T}$ & $\mathrm{T}$ & $\mathrm{T}$ \\
\hline 5 & Above 3.16 & NT & NT & $\mathrm{T}$ & NT & $\mathrm{T}$ \\
\hline 6 & Below 3.16 & NT & NT & $\mathrm{T}$ & NT & $\mathrm{T}$ \\
\hline 7 & Above 3.16 & NT & $\mathrm{T}$ & $\mathrm{T}$ & NT & NT \\
\hline 8 & Above 3.16 & $\mathrm{~T}$ & $\mathrm{~T}$ & $\mathrm{~T}$ & $\mathrm{~T}$ & NT \\
\hline 9 & Above 3.16 & $\mathrm{~T}$ & $\mathrm{~T}$ & $\mathrm{~T}$ & NT & NT \\
\hline
\end{tabular}

\section{Impact of molecular descriptors on hERG binding}

Cardiotoxicity is a severe problem in pharmacology; therefore, the theoretical parameters can be very useful in the drug discovery pipeline. Selected theoretical physio-chemical properties are presented in Table 4. The molecular weights (MWt) are in the range defined for orally available compounds and only compound 6 has the MWt of $>500 \mathrm{~g} \mathrm{~mol}^{-1}$, since $N$, 
$N^{\prime}$-cyclohexyl substituent attached to the amidine group increase its MWt to $522.76 \mathrm{~g} \mathrm{~mol}^{-1}$. Many studies suggest that the relationship between hERG blockage and molecular size is complex - the probability of inhibition is very low for small molecules with MWt $<250 \mathrm{~g} \mathrm{~mol}^{-1}$, but larger molecules can be also non-blockers of the hERG channel. ${ }^{67-69}$ The $\log P$ values (for pentamidines acting as neutral molecules) were within the range 1.21-3.88 for the majority of compounds which is an agreement with a probability of lack inhibition of hERG channel ( $\log P \leq 4)$. For two pentamidine derivatives, 5 and 6 , the $\log P$ values were predicted to be above 4 indicating a higher risk for hERG $\mathrm{K}^{+}$channel inhibition. ${ }^{68}$ We also examined logarithm of the distribution coefficient values $(\log D)$ at $\mathrm{pH} 7.4$, which give an estimate of the lipophilicity of a drug at the $\mathrm{pH}$ of blood plasma. The average values of $\log D$ are within the range -0.03 to 2.75 and not exceeding the traditionally cutoff value of 3.5. Molecular flexibility is an important contributor to hERG affinity, as rigid molecules with little conformational freedom are less likely to occupy an optimal pose within the binding region. We have chosen to describe this property by the ratio of rotatable bonds to all bonds in the molecule $\left(F_{\mathrm{RB}}=N_{\mathrm{RB}} / N_{\text {total bonds }}\right.$ ) rather than the overall count of rotatable bonds. According to the suggestion of Didziapetris et al. ${ }^{69} F_{\mathrm{BR}}$ below 0.4 becomes a major indicator of poor hERG binding for compounds with highly constrained ring systems. The obtained results indicate that among the analyzed pentamidine derivatives, only compound 5 with 4-(N, $N^{\prime}-$ butylamidino)phenoxy substituent can show $F_{\mathrm{RB}}$ above 0.4 i.e. should show some binding affinity to the hERG $\mathrm{K}^{+}$channel. The impact of $\pi$-stacking interactions is another molecular property essential for hERG affinity, ${ }^{70}$ even though the currently accepted view is that aromaticity is not essential for efficient hERG binding, as long as the molecule is sufficiently lipophilic and has a suitable size and shape. ${ }^{71}$ The number of aromatic rings $\left(N_{\mathrm{AR}}\right)$ is 2 or 3 for all tested pentamidine analogs, which is consistent with several published pharmacophore models that predict the ability to induce the LQTS by blocking the hERG $\mathrm{K}^{+}$channel. The minimal structural requirements in these models are three phenyl rings suitably spaced and one proton at nitrogen. ${ }^{72,73}$

The calculated qualitative estimation of the likelihood of the hERG potassium channel inhibition as $\mathrm{hERG}$ _filter and the $\mathrm{pIC}_{50}$ as a measure of affinity for hERG $\mathrm{K}^{+}$channel (hERG_pIC 50 ) are promising for compounds 1$\mathbf{3}$ and new 7-9 i.e. they can be classified as non-cardiotoxic. For other three 
pentamidines (4, 5 and $\mathbf{6}$ with one $\mathrm{S}$ atom in the linker and the alkyl substituent in the amidine moiety) hERG_filter is marked as Yes and hERG_pIC 50 values are in the range 6.154-6.676, exceeding the cutoff value 5.5 . It means that only these compounds can potentially block hERG channels in the heart cells leading to cardiac problems. To explain the molecular mechanism of cardiotoxicity for those pentamidine analogues, compounds 4, 5 and $\mathbf{6}$ have been chosen to perform hERG receptor affinity examination by molecular modeling technique and experimental measurements.

Table 4. Physio-chemical and cardiotoxicity (hERG_filter and affinity for hERG $\mathrm{K}^{+}$ (hERG_pIC 50)) parameters for 1-9

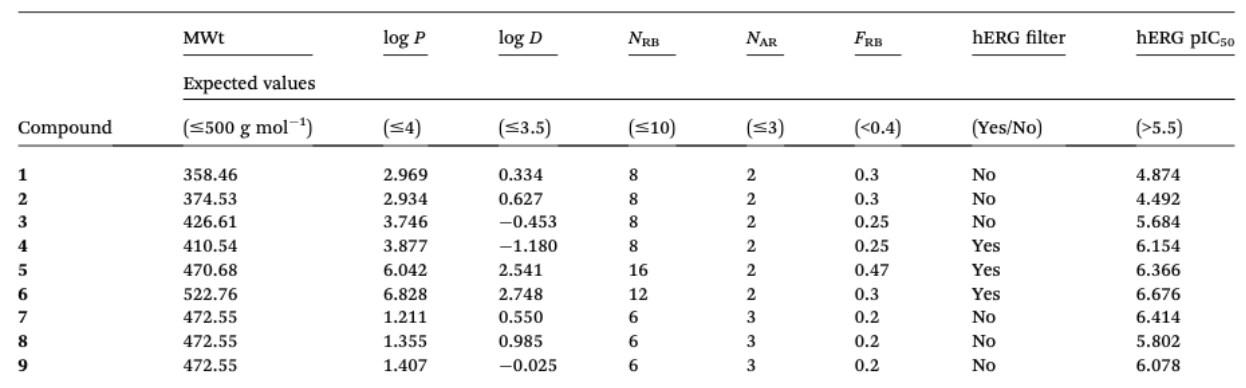

\section{Theoretical evaluation of interactions with hERG channel}

First, the molecular docking calculations have been employed in order to find the optimal position of compounds in the binding pocket of hERG $\mathrm{K}^{+}$ channel. CDOCKER program successfully docked compounds 4, 5 and $\mathbf{6}$ into the binding cavity of hERG $\mathrm{K}^{+}$channel producing ten poses for every compound with scores shown in Table S2 in ESI. The poses which demonstrated the strongest interaction energies were selected as the ligand starting structures to the extensive molecular dynamics' simulations and the binding free enthalpy calculations. The predicted binding mode by CDOCKER is presented in ESI, Fig. S1 for $\mathbf{4 ,} \mathbf{5}$ and $\mathbf{6}$. The results demonstrate that analyzed compounds could interact with hERG $\mathrm{K}^{+}$channel using hydrogen bonds, hydrophobic and van der Waals interactions. The amino acids Leu622, Thr623, Ser624 and Ser649 were consistently involved in the hydrogen bonds and the amino acids Tyr652, Ala653, and Phe656 in the hydrophobic and the $\pi-\Pi$ interactions. Compounds $\mathbf{5}$ and $\mathbf{6}$ interacted 
with the amino acid Phe656, while 4 with Tyr652 amino acid what is characteristic for the hERG $\mathrm{K}^{+}$channel blockers. ${ }^{74}$

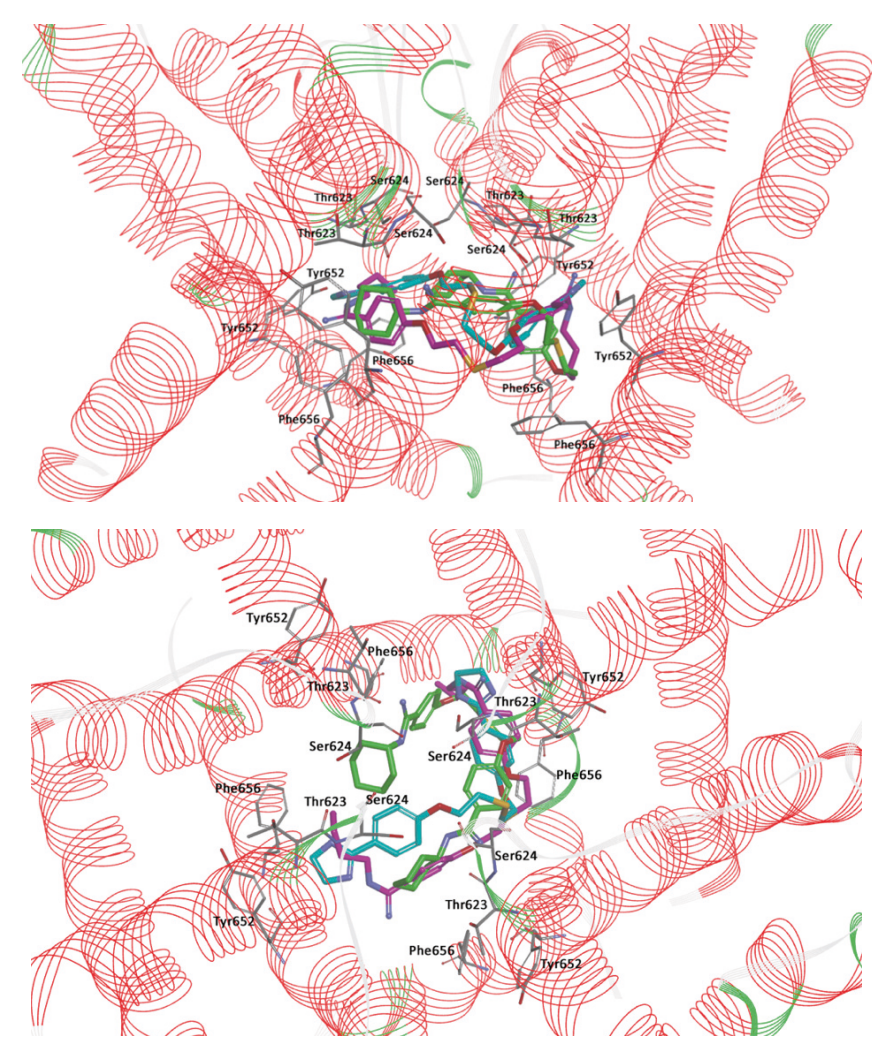

Figure 4. Two views of predicted docking pose in the cavity of hERG $\mathrm{K}^{+}$channel for compounds: 4 (cyan), 5 (fuchsia) and $\mathbf{6}$ (green). For clarity, subunits of the hERG K${ }^{+}$channel were removed and key residues (Thr623, Ser624, Tyr652 and Phe656) interacting with the ligands are visible. Upper part: projection of the compounds from the wall side seen perpendicular. Lower part: projection of the compounds from the upper side of the channel.

Next, the molecular dynamics simulation and binding free enthalpy calculations were performed for better understanding the various interactions between the ligand and the active site of hERG and to rationalize the obtained biological results. The structures of hERG complexes with 4-6 were optimized with water molecules and ions. The RMSD values between the average structures of replicate MD simulations as well as between the ligand starting and average structures were low in 
all cases. The binding free enthalpy values calculated using the MM-PBSA method were as follows $-23.34 \mathrm{kcal} \mathrm{mol}^{-1}(\mathbf{4}),-31.55 \mathrm{kcal} \mathrm{mol}^{-1}(\mathbf{5})$ and $13.70 \mathrm{kcal} \mathrm{mol}^{-1}(\mathbf{6})$, indicating the strongest interactions with compound $\mathbf{5}$ where butyl substituents at amidine groups are present. All compounds are

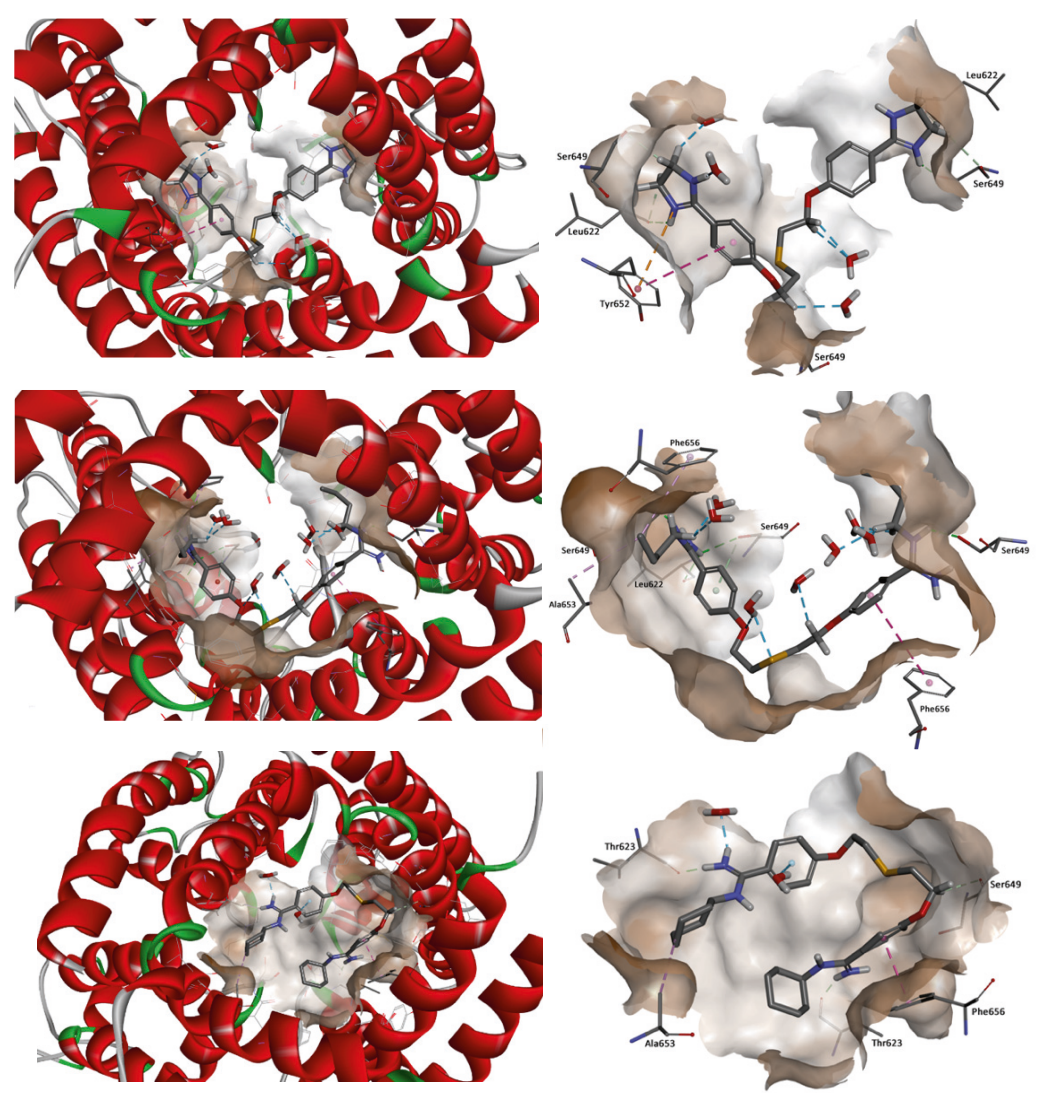

Figure 5. Binding modes of compounds $\mathbf{4 , 5}$ and $\mathbf{6}$ in the hERG $\mathrm{K}^{+}$channel optimized by MD.

in the same region of the hERG $\mathrm{K}^{+}$cavity and are located perpendicularly to the cavity walls (Fig. 4). Our modelling suggests that tested pentamidines are accommodated in the proximity of amino acids Leu622, Thr623, Ser649, Tyr652, Ala653, and Phe656. The binding cavity is highly hydrophobic, and this feature is following the biochemical function of the hERG fragment which is embedded in the membrane bilayer. 
The interactions inside complexes 4-6 are depicted in Fig. 5. These compounds are highly similar structurally and differ only by the kind of $N, N^{\prime}-$ substituent at amidine groups. Compound $\mathbf{4}$ with amidine groups closed in 4-(4,5-dihydro-2-imidazolyl) substituents is predicted to be accommodated in the hERG channel in a bent conformation. Such orientation in the binding cavity leads to the $\pi-\pi$ stacking (a distance of $5.61 \AA$ ) and electrostatic interaction (a distance of $4.72 \AA$ ) with the phenyl ring of amino acid Tyr652. Additionally, the position of $\mathbf{4}$ allows for creating strong hydrogen bonds with two copies of amino acids Leu622 (2.07 and $2.85 \AA$ ) and Ser649 (2.11 and $2.25 \AA$ ). Compound $\mathbf{5}$ with $N, N^{\prime}$-butylamidino substituents adopts a similar orientation like that of $\mathbf{4}$ and interacts with two copies of Phe656 involving T-shaped $\pi-\pi$ stacking (4.93 and $5.70 \AA$ ). Aliphatic substituent interacts with side chains of two Ser649 (2.26 and $2.45 \AA$ ), one Leu622 $(2.28 \AA)$ and forms the hydrophobic interaction with Ala653 (4.26 $\AA$ ). Compound $\mathbf{5}$ takes part in the hydrogen bond network, which can affect a higher affinity to the hERG channel than $\mathbf{4}$. Binding of compound $\mathbf{6}$ with $N, N^{\prime}$-cyclohexylamidino substituent is predicted in the hERG cavity in $\mathrm{U}$ shaped conformation. In this mode, the phenyl ring of $\mathbf{6}$ forms a strong $\pi$ $\pi$ stacking interaction (a distance of $3.73 \AA$ ) with the aromatic ring of Phe656, whereas the $N, N^{\prime}$-cyclohexyl substituents interacts with both Thr623 (1.71 and $2.34 \AA$ ) and Ala653 (4.83 $\AA$ ). However, we have to make clear that drug-channel interactions do not necessarily result in full inhibition of the hERG channel.

\section{Electrophysiological effects of pentamidine analogues on hERG channel activity}

To explore potential functional hERG channel blockade of 4-6 as indicated above, and the newly developed compounds 7-9, an electrophysiological patch-clamp assay on HEK-293T cells stably expressing hERG channels were used. hERG channel gating is complex and displays slow activation upon depolarization, followed by fast inactivation especially upon further depolarization, restricting outward $\mathrm{K}^{+}$flow during early phases of the cardiac action potential. Upon initial the repolarization, fast recovery from inactivation then drives repolarization of the action potential. In both 
A

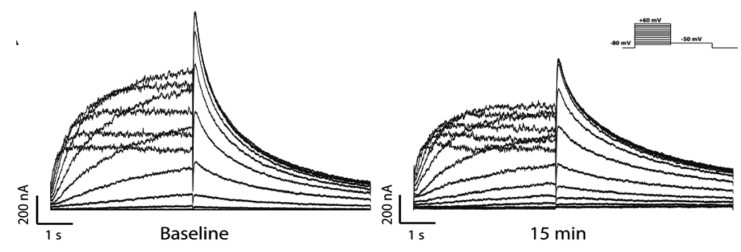

B
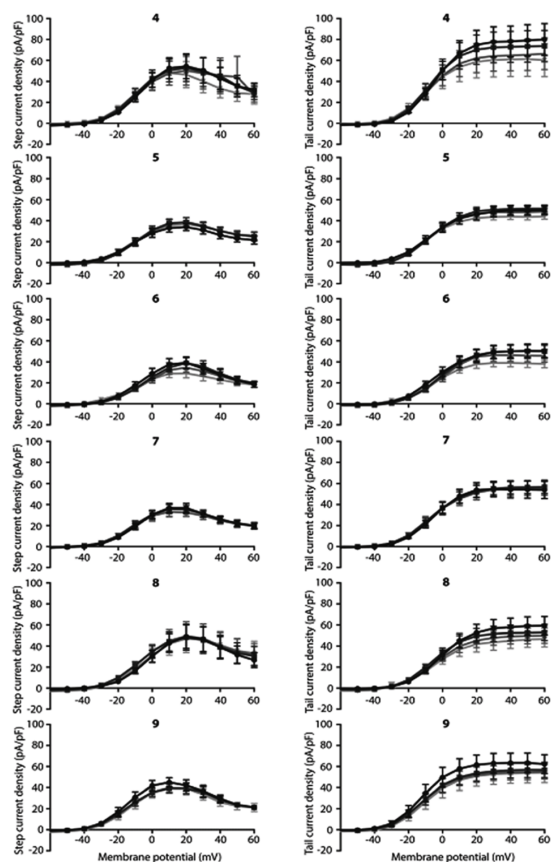

C

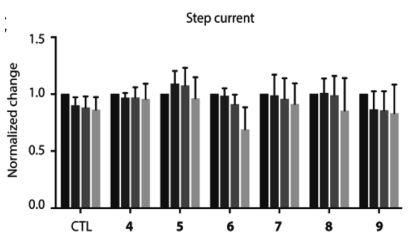

D

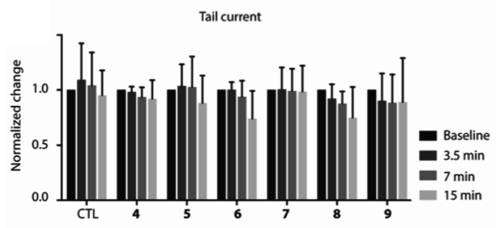

Figure 6. Absence of $I_{\text {hERG }}$ inhibition in response to treatment with 4-9 $(1 \mu \mathrm{M})$. (A) Representative traces of $I_{\text {hERG }}$ treated with $6(1 \mu \mathrm{M})$ under baseline and 15 min perfusion. Stimulation protocol is shown at right panel. (B) $I-V$ relationship curves of step (left panels) and tail (right panels) current densities following treatment with 4-9 at baseline, $3.5 \mathrm{~min}, 7 \mathrm{~min}$ and $15 \mathrm{~min}$. (C, D) Summary of step current (C) and tail current (D) densities, determined at $+10 \mathrm{mV}$, under control (untreated) condition and following treatment with 4-9. Summarized data are normalized by their baseline. All data are presented as the mean \pm SD. $N$-values for baseline,

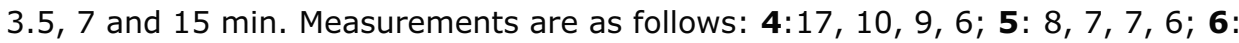
$17,8,8,6 ; 7: 10,10,9,8 ; 8: 10,9,8,8 ; 9: 9,9,9,5$. 
the step-current pulse, evaluating slow activation and rapid inactivation, and tail-current, evaluating fast recovery, measurements, no significant changes in $I_{\text {hERG }}$ densities were observed in the 15 min timeframe at a concentration of $1 \mu \mathrm{M}$ (Fig. 6). Furthermore, no apparent effects on the voltage dependence of the hERG channel were observed with any of the compounds. Finally, we did not observe any obvious changes in channel dynamics when performing or analyzing the patch-clamp experiments and data, respectively. Compared to pentamidine, which shows no acute block at $1 \mu \mathrm{M}$ using similar pulse protocols, ${ }^{32}$ modifications resulting in compounds 4-9 do not induce acute hERG channel blockade. It can mean that theoretically predicted interactions with hERG channel for 4-6 does not block the conduction path, however these findings do not exclude potential long-term effects on I $_{\text {hERG }}$ densities.

\section{Impact of pentamidine analogues on hERG trafficking}

Pentamidine affects forward the trafficking of the hERG channel resulting in decreased mature/immature protein ratios. ${ }^{32}$ Pentamidine likely interferes with the process of proper hERG protein folding, in which the compound interacts with one or more intermediate folding states and thus inhibits subsequent folding steps required for endoplasmic reticulum export. ${ }^{33}$ One could imagine that pentamidine-bound folding intermediates affect proper chaperone function resulting in improper folding, ER retention and/or degradation of the channel protein. ${ }^{75}$ The high-affinity drug binding site Phe656 of the hERG channel is essential for intracellular pentamidine interaction, which may also explain the capacity of high-affinity hERG blockers to correct pentamidine-induced hERG trafficking defects. ${ }^{34}$ Decreased levels of mature hERG expression are one of the life-threatening side effects of pentamidine and the major trigger of Torsade de Pointes arrhythmias. To identify potentially trafficking inhibition structures, pentamidine and 1-9 were tested for effects on hERG mature/immature ratios.

HEK-hERG cells were treated with 1 and $10 \mu \mathrm{M}$ pentamidine and its analogues for $24 \mathrm{~h}$ (Fig. 7). We did not observe induction of cell toxicity by routine visual inspection using phase-contrast microscopy and lysate protein concentration. As also observed in earlier studies, ${ }^{33,34}$ pentamidine treatment significantly decreased maturation (mature/immature ratio) of 
hERG. Dofetilide, which promotes forward trafficking, increases mature/immature ratios. In contrast to pentamidine, its analogues displayed minor effect on hERG maturation resulting in slightly lower mature/immature ratios, especially at $10 \mu \mathrm{M}$ (pentamidine vs. $11 \mu \mathrm{M} p$ $<0.0001,21 \mu \mathrm{M} p<0.0001 ; 31 \mu \mathrm{M} p<0.05 ; 41 \mu \mathrm{M} p<0.01 ; 51 \mu \mathrm{M} p$ $<0.0001 ; 61 \mu \mathrm{M} p<0.05 ; 81 \mu \mathrm{M} p<0.05$ ) (Fig. 7B). No significant changes between 1 and $10 \mu \mathrm{M}$ of each compound except for 1, 2 and $\mathbf{5}$ (Fig. 7C) were seen.
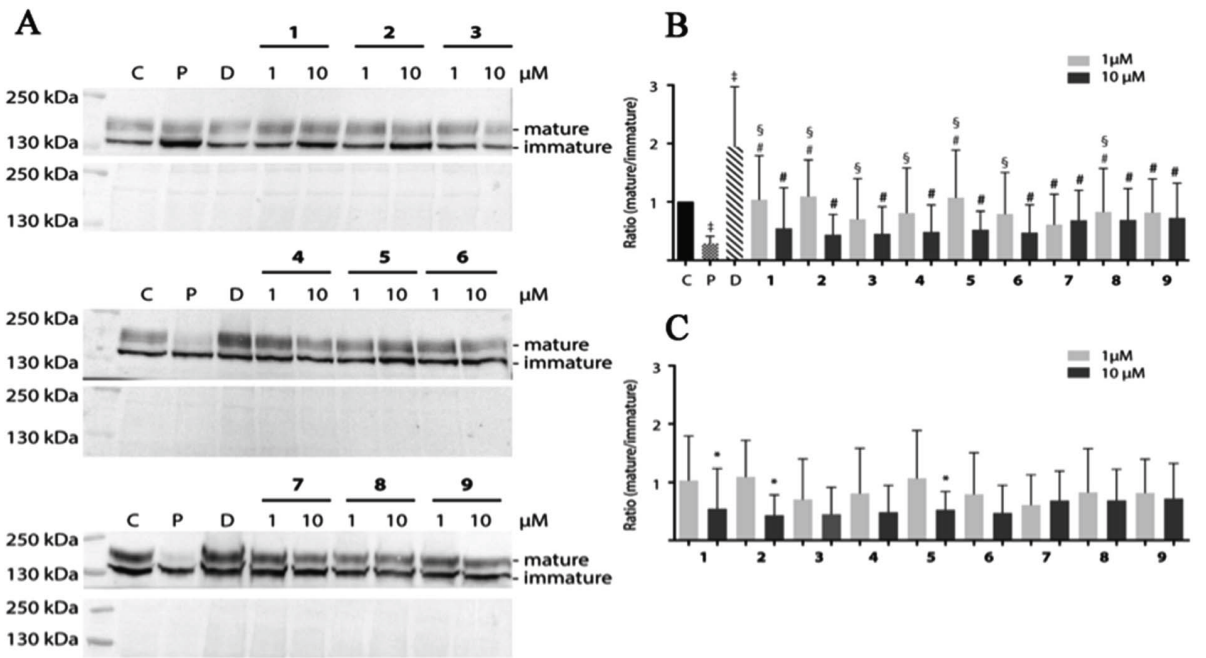

Figure 7. The maturation of hERG is affected differently by pentamidine and its analogues 1-9 in HEK-hERG cells. (A) Western blot results of HEK-hERG cells exposed to pentamidine $(10 \mu \mathrm{M})$, dofetilide $(1 \mu \mathrm{M})$ and $\mathbf{1 - 9}(1$ and $10 \mu \mathrm{M})$ for 24 h. Total protein ponceau staining was used as loading control. (B) Summarized data of the ratios of mature and immature hERG expression in HEK-hERG cells after $24 \mathrm{~h}$ treatment with pentamidine $(10 \mu \mathrm{M})$, dofetilide $(1 \mu \mathrm{M})$ or analogues. $\neq$ indicated $P<0.05$ vs. control, $\S P<0.05$ vs. pentamidine, \# $P<0.05$ vs. dofetilide. Control protein ratios were designated as 1 . (C) Two concentration comparison in maturation ratio of hERG. * $P<0.05$ between 1 and $10 \mu \mathrm{M}$ treatment. Data are presented in mean \pm SD. $N$-values for are as follows: control: 26; pentamidine: 27 ; dofetilide: $24 ; \mathbf{1}(1,10 \mu \mathrm{M}): 10,10 ; \mathbf{2}: 13,10 ; \mathbf{3}: 4,4 ; \mathbf{4}$ : 4,$4 ; 5: 7,10 ; 6: 4,3 ; 7: 4,4 ; 8: 4,4 ; 9: 4,3$.

Since the compounds $\mathbf{1}, \mathbf{2}$ and $\mathbf{5}$ indicated dose-dependent effects in hERG maturation (Fig. 7C) we performed a full dose-response analysis. The three analogues were applied to HEK-hERG cells in different concentrations 
ranging from 0.5 till $20 \mu \mathrm{M}$ (Fig. 8). A $20-25 \%$ decrease in total lysate protein concentration was observed with the highest concentration.

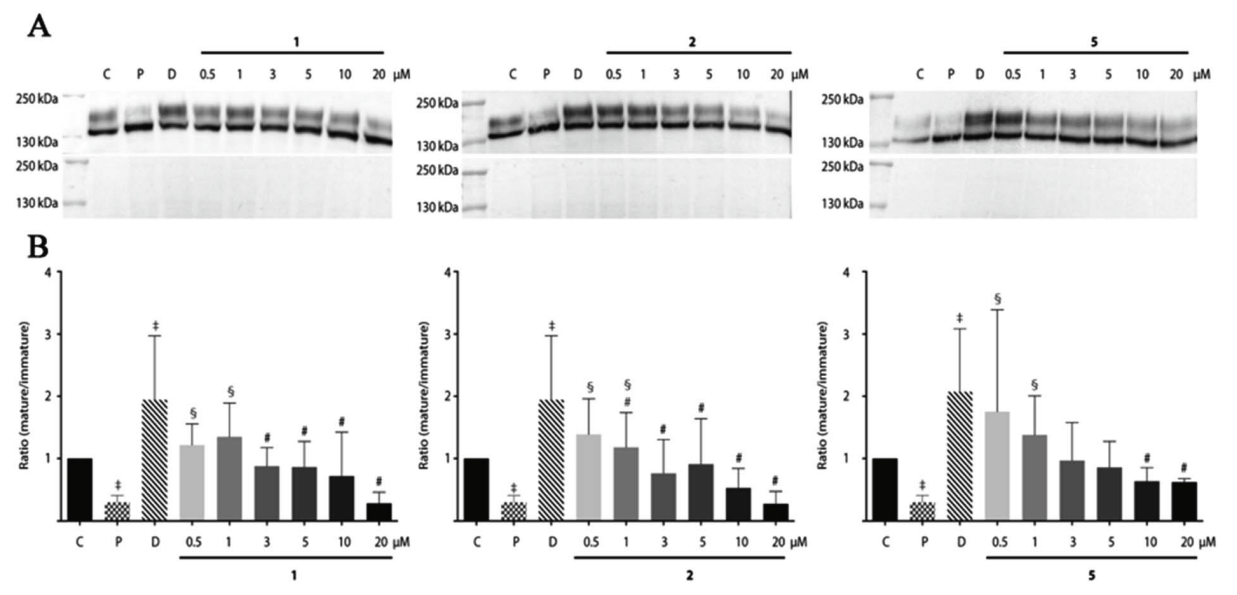

Figure 8. Dose-response effects of $\mathbf{1}, \mathbf{2}$ and $\mathbf{5}$ on hERG maturation. (A) Dosedependent effect on hERG expression after $24 \mathrm{~h}$ treatment with $\mathbf{1}, \mathbf{2}$ and $\mathbf{5}$ (0.5$20 \mu \mathrm{M})$, pentamidine $(10 \mu \mathrm{M})$ or dofetilide $(1 \mu \mathrm{M})$. In the lower panels, ponceau staining reveals equal loading. (B) Summarized results of $(\mathbf{A})$. Data are presented as the ratios of mature and immature hERG. $¥$ indicates $P<0.05 \mathrm{vs}$. control, § $P$ $<0.05$ vs. pentamidine, $\# P<0.05$ vs. dofetilide. $N$-values for are as follows: control: 29; pentamidine: 27; dofetilide: 27; 1 (all concentrations): 6; 2 (all concentrations): $6 ; \mathbf{5}$ : (all concentrations) 3.

However, this will not affect the experimental outcomes since identical amounts of protein were loaded and mature/immature hERG ratios were determined to assess forward trafficking. As expected, hERG maturation was dose-dependently decreased following $\mathbf{1}, \mathbf{2}$ and $\mathbf{5}$ application (pentamidine $n=27$ v.s $10.5 \mu \mathrm{M} p<0.01 ; 11 \mu \mathrm{M} p<0.001$; $20.5 \mu \mathrm{M} p<0.05 ; 21 \mu \mathrm{M} p<0.0001 ; 50.5 \mu \mathrm{M} p<0.05 ; 51 \mu \mathrm{M} p<0.05)$. Interestingly, the lowest concentration $(0.5 \mu \mathrm{M})$ showed a trend for increasing maturation. The subcellular localization of the hERG protein after exposure to pentamidine and its analogues 1, 2 and $\mathbf{5}(10 \mu \mathrm{M})$ was studied by immunofluorescence microscopy on HEK-hERG cells (Fig. 9). In untreated control cells, hERG was distributed throughout the cell with clear membrane staining. The membrane hERG protein expression was remarkably decreased after pentamidine treatment and the intracellular expression level was relatively lower than untreated cell, in contrast to dofetilide $(1 \mu \mathrm{M})$. The intracellular localization of hERG after 1, 2 and $\mathbf{5}$ 
treatment revealed a pattern comparable with control cells and clear membrane staining was detected. These results are in accordance with observations displayed in Fig. 7 and 8. These qualitative results indicate that the modifications resulting in $\mathbf{1}, \mathbf{2}$ and $\mathbf{5}$ reduce, but not completely abolish, the effects seen on hERG trafficking by pentamidine, whereas the newly developed compounds 7-9 show the least effects on hERG trafficking.

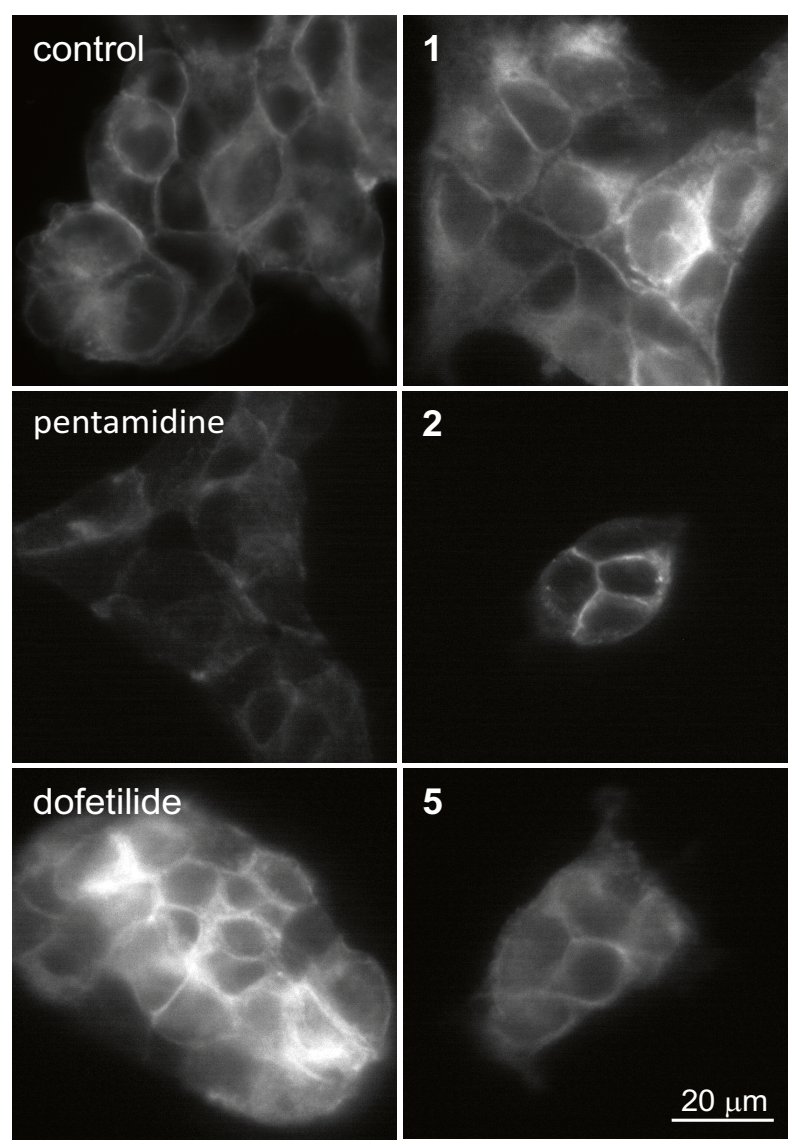

Figure 9. Expression of hERG at the membrane in control (untreated) and HEKhERG cells treated for $24 \mathrm{~h}$ with pentamidine $(10 \mu \mathrm{M})$, dofetilide $(1 \mu \mathrm{M}), \mathbf{1}, \mathbf{2}$ or $\mathbf{5}$ $(10 \mu \mathrm{M})$. The scale bar represents $20 \mu \mathrm{m}$. 


\section{CONCLUSIONS}

The tested linear pentamidine analogues 1-9 have favourable druglikeness parameters (the topological polar surface area (TPSA), volume of distribution $\left(V_{\mathrm{d}}\right)$, water solubility $\left(S_{\mathrm{w}}\right)$, effective permeability $\left(P_{\text {eff }}\right)$, apparent permeability (MDCK), percentage of unbound drug to blood plasma proteins (\% Unbnd), blood-to-plasma concentration ratio (RBP), BBB_filter, bloodbrain barrier partition coefficient $(\log B B)$ ) as the potential oral drugs. Nevertheless, some cardiotoxicity joined with hERG channel was suggested for tested analogs with one $\mathrm{S}$ atom in the linker and alkyl part in the amidine groups. The theoretical analysis of complexes between the hERG $\mathrm{K}^{+}$channel and the selected compounds showed the binding free enthalpy values as follows $-23.34 \mathrm{kcal} \mathrm{mol}^{-1}$ (4 with amidine groups closed in imidazolyl ring), $-31.55 \mathrm{kcal} \mathrm{mol}^{-1}$ (5 with butyl substituent) and $-13.70 \mathrm{kcal} \mathrm{mol}^{-1}$ (6 with cyclohexyl substituent), predicting the moderate strength of interactions. All compounds are located in the same region of the hERG $\mathrm{K}^{+}$cavity in the proximity of amino acids Leu622, Thr623, Ser649, Tyr652, Ala653 and Phe656, what is in accordance with the possibility blocking hERG $\mathrm{K}^{+}$ channel. However, in the electrophysiological patch clamp experiments for 1-9 on HEK-293T cells, no significant changes in $I_{\text {hERG }}$ densities were observed in the 15 min timeframe at a concentration of $1 \mu \mathrm{M}$. In the next biochemical experiments, in contrast to pentamidine, its analogues displayed minor effect on hERG maturation resulting in slightly lower mature/immature ratios, especially at $10 \mu \mathrm{M}$. The intracellular localization of hERG after $\mathbf{1}, \mathbf{2}$ and $\mathbf{5}$ treatment revealed a pattern comparable with control cells and clear membrane staining was detected. After a combined theoretical and experimental approach, we can suggest that the pentamidines characterized by the presence of sulfur atoms or sulfanilide groups are promising, not-toxic lead structures in the developments of new potent chemotherapeutics against PJP. 
Pentamidine analogues and their impact on the hERG channel

\section{REFERENCES}

1. S. Kongsamut, J. Kang, X. L. Chen, J. Roehr and D. Rampe, Eur J Pharmacol, 2002, 450, 37-41.

2. R. Netzer, A. Ebneth, U. Bischoff and O. Pongs, Drug Discov Today, 2001, 6, 78-84.

3. M. C. Sanguinetti and M. Tristani-Firouzi, Nature, 2006, 440, 463469.

4. J. C. Hancox, M. J. McPate, A. El Harchi and Y. H. Zhang, Pharmacol Ther, 2008, 119, 118-132.

5. D. M. Roden, Circulation, 2008, 118, 981-982.

6. H. Morita, J. Wu and D. P. Zipes, Lancet, 2008, 372, 750-763.

7. M. C. Sanguinetti and J. S. Mitcheson, Trends Pharmacol Sci, 2005, $26,119-124$

8. L. L. Eckhardt, S. Rajamani and C. T. January, Br J Pharmacol, 2005, $145,3-4$.

9. M. A. van der Heyden, M. E. Smits and M. A. Vos, Br J Pharmacol, 2008, 153, 406-409.

10. K. C. de Git, T. P. de Boer, M. A. Vos and M. A. van der Heyden, Pharmacol Ther, 2013, 139, 24-31.

11. D. Justo and D. Zeltser, Mycoses, 2006, 49, 463-470.

12. M. Schwartz, M. Patel, Z. Kazzi and B. Morgan, J Med Toxicol, 2008, 4, 173-179.

13. P. K. Honig, D. C. Wortham, K. Zamani, D. P. Conner, J. C. Mullin and L. R. Cantilena, JAMA, 1993, 269, 1513-1518.

14. P. K. Honig, D. C. Wortham, R. Hull, K. Zamani, J. E. Smith and L. R. Cantilena, J Clin Pharmacol, 1993, 33, 1201-1206. 


\section{Chapter 7}

15. E. Ficker, Y. A. Kuryshev, A. T. Dennis, C. Obejero-Paz, L. Wang, P. Hawryluk, B. A. Wible and A. M. Brown, Mol Pharmacol, 2004, 66, 3344.

16. A. J. Taylor, R. W. Hull, P. E. Coyne, R. L. Woosley and A. H. Eliasson, Clin Pharmacol Ther, 1991, 49, 698-700.

17. J. E. Touze, P. Heno, L. Fourcade, J. C. Deharo, G. Thomas, S. Bohan, P. Paule, P. Riviere, E. Kouassi and A. Buguet, Am J Trop Med Hyg, 2002, 67, 54-60.

18. K. S. Kim and E. J. Kim, Drug Chem Toxicol, 2005, 28, 303-313.

19. Z. Zhou, V. R. Vorperian, Q. Gong, S. Zhang and C. T. January, J Cardiovasc Electrophysiol, 1999, 10, 836-843.

20. L. C. Macdonald, R. Y. Kim, H. T. Kurata and D. Fedida, Sci Rep, 2018, $8,289$.

21. N. G. Mansharamani, R. Garland, D. Delaney and H. Koziel, Chest, 2000, 118, 704-711.

22. C. F. Kelley, W. Checkley, D. M. Mannino, C. Franco-Paredes, C. Del Rio and F. Holguin, Chest, 2009, 136, 190-197.

23. H. Chang, M. C. Kuo, T. L. Lin, J. H. Wu and P. N. Wang, Intern Med J, 2018, 48, 81-83.

24. E. J. Calderón, S. Gutiérrez-Rivero, I. Durand-Joly and E. Dei-Cas, Expert Rev Anti Infect Ther. , 2010, 8, 683 - 701.

25. E. M. Carmona and A. H. Limper, Ther Adv Respir Dis, 2011, 5, 4159.

26. Y. Liu, L. Su, S. J. Jiang and H. Qu, Oncotarget, 2017, 8, 5972959739.

27. F. R. Sattler, R. Cowan, D. M. Nielsen and J. Ruskin, Ann Intern Med, $1988,109,280-287$.

28. S. Safrin, D. M. Finkelstein, J. Feinberg, P. Frame, G. Simpson, A. Wu, T. Cheung, R. Soeiro, P. Hojczyk and J. R. Black, Ann Intern Med, $1996,124,792-802$. 
Pentamidine analogues and their impact on the hERG channel

29. B. Wispelwey and R. Pearson, Drug Saf, 1990, 5, 212-219.

30. A. Porollo, J. Meller, Y. Joshi, V. Jaiswal, A. G. Smulian and M. T. Cushion, Curr Drug Targets, 2012, 13, 1575-1585.

31. C. R. Kroll and L. S. Gettes, J Cardiovasc Electrophysiol, 2002, 13, 936-938.

32. Y. A. Kuryshev, E. Ficker, L. Wang, P. Hawryluk, A. T. Dennis, B. A. Wible, A. M. Brown, J. Kang, X. L. Chen, K. Sawamura, W. Reynolds and D. Rampe, J Pharmacol Exp Ther, 2005, 312, 316-323.

33. A. T. Dennis, L. Wang, H. Wan, D. Nassal, I. Deschenes and E. Ficker, Mol Pharmacol, 2012, 81, 198-209.

34. R. Varkevisser, M. J. Houtman, T. Linder, K. C. de Git, H. D. Beekman, R. R. Tidwell, A. P. Ijzerman, A. Stary-Weinzinger, M. A. Vos and M. A. van der Heyden, Br J Pharmacol, 2013, 169, 1322-1334.

35. D. Maciejewska, J. Zabinski, P. Kazmierczak, M. Rezler, B. Krassowska-Swiebocka, M. S. Collins and M. T. Cushion, Eur J Med Chem, 2012, 48, 164-173.

36. D. Maciejewska, J. Zabinski, P. Kazmierczak, K. Wojciuk, M. Kruszewski and H. Kruszewska, Bioorg Med Chem Lett, 2014, 24, 2918-2923.

37. D. Maciejewska, J. Zabinski, M. Rezler, P. Kazmierczak, M. S. Collins, L. Ficker and M. T. Cushion, Medchemcomm, 2017, 8, 2164-2164.

38. Dassault Systèmes BIOVIA, San Diego: Dassault Systèmes, 2016.

39. M. J. Frisch, G. W. Trucks, H. B. Schlegel, G. E. Scuseria, M. A. Robb, J. R. Cheeseman, G. Scalmani, V. Barone, G. A. Petersson, H. Nakatsuji, X. Li, M. Caricato, A. Marenich, J. Bloino, B. G. Janesko, R. Gomperts, B. Mennucci, H. P. Hratchian, J. V. Ortiz, A. F. Izmaylov, J. L. Sonnenberg, D. Williams-Young, F. Ding, F. Lipparini, F. Egidi, J. Goings, B. Peng, A. Petrone, T. Henderson, D. Ranasinghe, V. G. Zakrzewski, J. Gao, N. Rega, G. Zheng, W. Liang, M. Hada, M. Ehara, K. Toyota, R. Fukuda, J. Hasegawa, M. Ishida, T. Nakajima, Y. Honda, O. Kitao, H. Nakai, T. Vreven, K. Throssell, J. Montgomery, J. A., J. E. Peralta, F. Ogliaro, M. Bearpark, J. J. Heyd, E. Brothers, K. N. Kudin, V. N. Staroverov, T. Keith, R. Kobayashi, J. Normand, K. Raghavachari, A. Rendell, J. C. Burant, S. S. Iyengar, J. Tomasi, M. 
Cossi, J. M. Millam, M. Klene, C. Adamo, R. Cammi, J. W. Ochterski, R. L. Martin, K. Morokuma, O. Farkas, J. B. Foresman and D. J. Fox, 2016.

40. C. M. Breneman and K. B. Wiberg, J Comp Chem, 1990, 11, 361-373.

41. S. Durdagi, S. Deshpande, H. J. Duff and S. Y. Noskov, J Chem Inf Model, 2012, 52, 2760-2774.

42. J. Louvel, J. F. Carvalho, Z. Yu, M. Soethoudt, E. B. Lenselink, E. Klaasse, J. Brussee and A. P. Ijzerman, J. Med. Chem., 2013, 56, 9427-9440.

43. P. Schmidtke, M. Ciantar, I. Theret and P. Ducrot, J. Chem. Inf. Model., 2014, 54, 2320-2333.

44. W. Wang and R. MacKinnon, Cell, 2017, 169, 422-430.

45. S. Durdagi, H. J. Duff and S. Y. Noskov, J Chem Inf Model, 2011, 51, 463-474.

46. J. P. Lees-Miller, J. O. Subbotina, J. Guo, V. Yarov-Yarovoy, S. Y. Noskov and H. J. Duff, Biophys J, 2009, 96, 3600-3610.

47. Y. Wang, J. Guo, L. L. Perissinotti, J. Lees-Miller, G. Teng, S. Durdagi, H. J. Duff and S. Y. Noskov, Sci. Rep., 2016, 6, 32536.

48. J. Ghosh, M. S. Lawless, M. Waldman, V. Gombar and R. Fraczkiewicz, Methods Mol. Biol., 2016, 1425, 63-83.

49. ADMET Predictor ${ }^{T M}$ software provided by Simulation Plus, Inc., Lancaster, California, USA.

50. B. R. Brooks, R. E. Bruccoleri, B. D. Olafson, D. J. States, S. Swaminathan and M. Karplus, J Comp Chem, 1983, 4, 187-217.

51. W. L. Jorgensen, J. Chandrasekhar, J. D. Madura, R. W. Impey and M. L. Klein, J Chem Phys, 1983, 79, 926-935.

52. J. Aqvist, J Phys Chem-Us, 1990, 94, 8021-8024.

53. U. Essmann, L. Perera, M. L. Berkowitz, T. Darden, H. Lee and L. G. Pedersen, J Chem Phys, 1995, 103, 8577-8593. 
Pentamidine analogues and their impact on the hERG channel

54. C. Sagui and T. A. Darden, Annu Rev Biophys Biomol Struct, 1999, 28, 155-179.

55. H. J. C. Berendsen, J. P. M. Postma, W. F. Vangunsteren, A. Dinola and J. R. Haak, J Chem Phys, 1984, 81, 3684-3690.

56. J. P. Ryckaert, G. Ciccotti and H. J. C. Berendsen, J Comp Phys., 1977, 23, 327-341.

57. P. A. Kollman, I. Massova, C. Reyes, B. Kuhn, S. Huo, L. Chong, M. Lee, T. Lee, Y. Duan, W. Wang, O. Donini, P. Cieplak, J. Srinivasan, D. A. Case and T. E. Cheatham, 3rd, Acc Chem Res, 2000, 33, 889897.

58. Z. Zhou, Q. Gong, B. Ye, Z. Fan, J. C. Makielski, G. A. Robertson and C. T. January, Biophys J, 1998, 74, 230-241.

59. Clampex software version 10.7.0.3, 2016, Molecular Devices, San Jose, USA.

60. Clampfit software version 10.7.0.3, 2016, Molecular Devices, San Jose, USA.

61. One-way ANOVA followed by Bonferroni multiple comparisons test was performed using GraphPad Prism version 7.04 for Windows, GraphPad Software, La Jolla California, USA, www.graphpad.com.

62. K. Palm, P. Stenberg, K. Luthman and P. Artursson, Pharmaceut Res, $1997,14,568-571$.

63. J. Fernandes and C. R. Gattass, J Med Chem, 2009, 52, 1214-1218.

64. P. J. van Bladeren, Chem Biol Interact, 2000, 129, 61-76.

65. S. Rendic and F. P. Guengerich, Chem Res Toxicol, 2015, 28, 38-42.

66. B. J. Berger, N. A. Naiman, J. E. Hall, J. Peggins, T. G. Brewer and R.

R. Tidwell, Antimicrob Agents Chemother, 1992, 36, 1825-1831.

67. M. J. Twiner, G. J. Doucette, A. Rasky, X. P. Huang, B. L. Roth and M.

C. Sanguinetti, Chem Res Toxicol, 2012, 25, 1975-1984. 


\section{Chapter 7}

68. C. Buyck, An in silico model for detecting potential hERG blocking., Blackwell Publishing, 2003.

69. R. Didziapetris and K. Lanevskij, J Comput Aided Mol Des, 2016, 30, $1175-1188$.

70. A. M. Aronov, Drug Discov Today, 2005, 10, 149-155.

71. D. Fernandez, A. Ghanta, G. W. Kauffman and M. C. Sanguinetti, J Biol Chem, 2004, 279, 10120-10127.

72. A. Cavalli, R. Buonfiglio, C. Ianni, M. Masetti, L. Ceccarini, R. Caves, M. W. Chang, J. S. Mitcheson, M. Roberti and M. Recanatini, J Med Chem, 2012, 55, 4010-4014.

73. A. Cavalli, E. Poluzzi, F. De Ponti and M. Recanatini, J Med Chem, 2002, 45, 3844-3853.

74. B. O. Villoutreix and O. Taboureau, Adv Drug Deliv Rev, 2015, 86, 72-82.

75. J. L. Smith, C. L. Anderson, D. E. Burgess, C. S. Elayi, C. T. January and B. P. Delisle, Journal of Arrhythmia, 2016, 32, 373-380. 


\section{SUPPLEMENTARY MATERIAL}

Table S1 Probability of metabolism by human uridine 5'-diphosphateglucuronosyltransferases (UGT) for 1-9.

\section{UGT}

Compound

$1 \mathrm{~A} 1 \quad 1 \mathrm{~A} 3 \quad 1 \mathrm{~A} 4 \quad 1 \mathrm{~A} 6 \quad 1 \mathrm{~A} 8 \quad 1 \mathrm{~A} 9 \quad 1 \mathrm{~A} 10 \quad 2 \mathrm{~B} 7 \quad 2 \mathrm{~B} 15$

1 Yes no Yes no no Yes No Yes No

2 Yes Yes Yes no no Yes no Yes No

3 Yes Yes Yes No No No No Yes No

4 Yes Yes Yes No No Yes No Yes No

5 Yes Yes Yes no no no no Yes No

6 Yes Yes Yes No No No no No No

7 No No No No No Yes No Yes No

8 No No No No Yes No No No No

9 No No No No No Yes No No No 
Chapter 7

Table S2. Values of CDOCKER interaction energy $\left(\mathrm{kcal} \cdot \mathrm{mol}^{-1}\right)$ for pentamidine derivatives (4, 5 and $\mathbf{6})$.

\begin{tabular}{|c|c|c|c|}
\hline \multirow{2}{*}{$\begin{array}{c}\text { Pose } \\
\text { number }\end{array}$} & \multicolumn{3}{|c|}{ CDOCKER interaction energy } \\
\hline & 4 & 5 & 6 \\
\hline 1 & $-48,9474$ & $-59,0164$ & $-55,1398$ \\
\hline 2 & $-49,6748$ & $-52,6177$ & $-56,6219$ \\
\hline 3 & $-43,7155$ & $-55,7457$ & $-53,9279$ \\
\hline 4 & $-46,4077$ & $-57,0773$ & $-54,1317$ \\
\hline 5 & $-41,6959$ & $-52,8375$ & $-49,0274$ \\
\hline 6 & $-44,5029$ & $-52,7724$ & $-55,2444$ \\
\hline 7 & $-42,2372$ & $-47,7179$ & $-49,6112$ \\
\hline 8 & $-42,2035$ & $-52,9497$ & $-48,2851$ \\
\hline 9 & $-41,7638$ & $-48,8009$ & $-50,2068$ \\
\hline 10 & $-42,6056$ & $-52,007$ & $-45,8554$ \\
\hline
\end{tabular}


Pentamidine analogues and their impact on the hERG channel

4

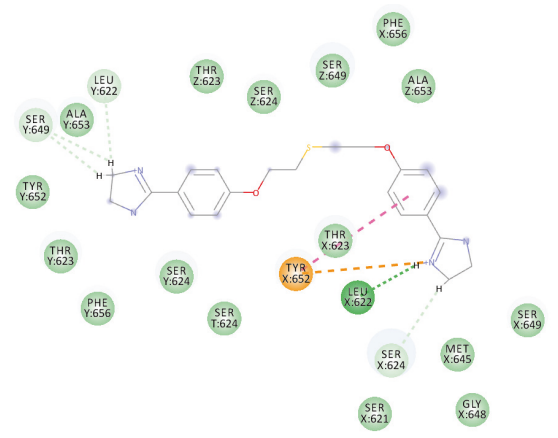

5

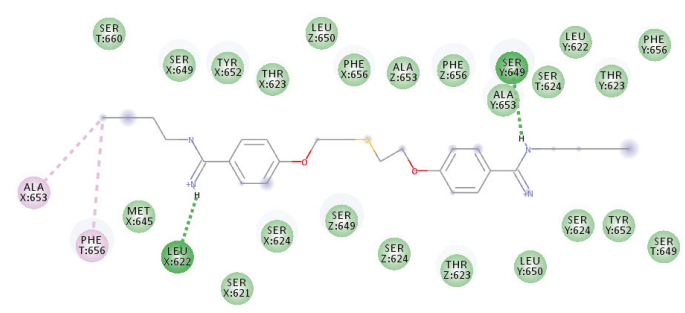

6

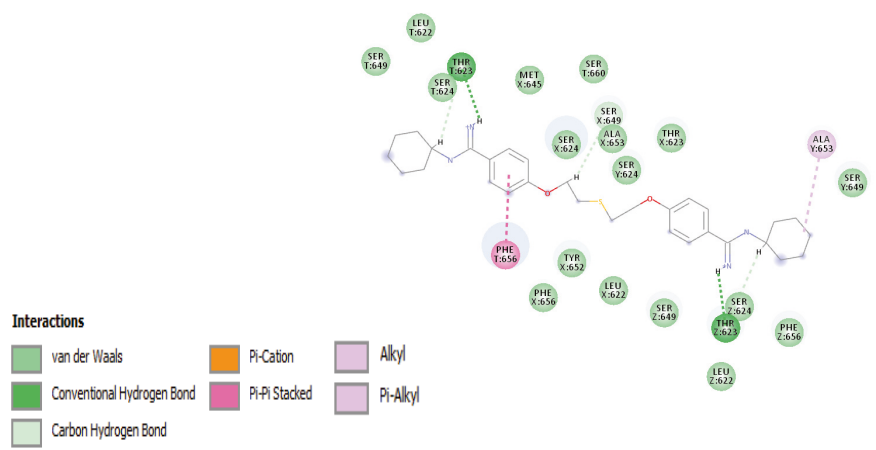

Figure S1. Predicted intermolecular interactions by CDOCKER for compounds $\mathbf{4}, \mathbf{5}$ and $\mathbf{6}$. 


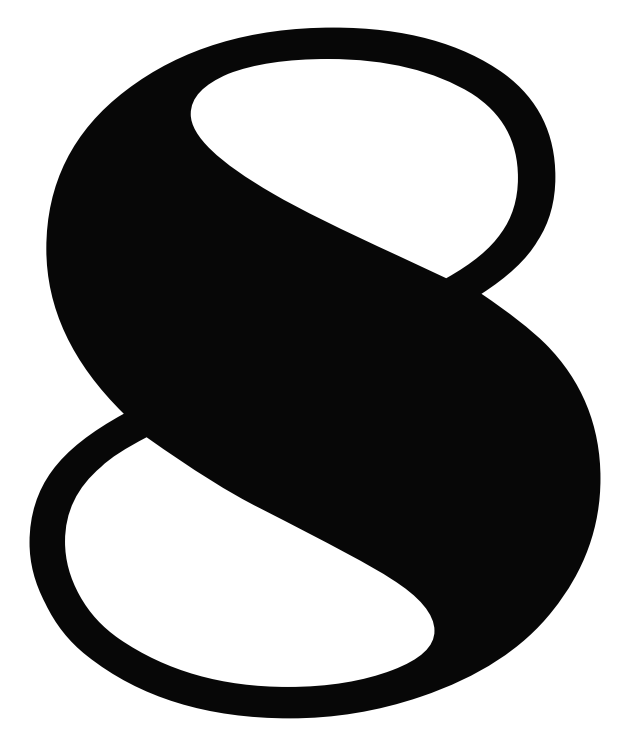


CHAPTER 8

General discussion 


\section{GENERAL DISCUSSION}

Cardiac arrhythmias, either inherited or acquired, are closely related to cardiac ion channels' functionality. Amongst those ion channels involved in generating the action potential, potassium channels carry diverse roles in subsequent phases. The trafficking pathways are believed to play a substantial role in ion channel function, but research on the underlying processes is limited when compared to our knowledge on channel gating and kinetics, possibly due to the different time scales at which they operate; hours to days vs. milliseconds or even faster. For the heart, clinical applications with respect to ion channel trafficking modification are in an early stage at their best. The field now requires thorough insights in trafficking for each and every ion channel at the molecular and cellular level, its impacts on in vivo arrhythmogenicity and the development of pharmacological interventions to steer optimal ion channel trafficking. Therefore, we are aiming to discuss the current development in this field and the potential value in drug discovery endeavors and our contributions in these investigations as depicted in the current thesis.

\section{Potassium channel trafficking defects and its clinical implication}

Congenital driven aberrations in ion channel function, although relatively rare, are very illustrative in our understanding of sequencefunction relations with respect to trafficking. Mutations in $\mathrm{K}_{\mathrm{v}} 11.1$ channels, either leading to gain- or loss-of-function have been associated with clinical phenotypes. For example, gain-of-function N588K mutation in $\mathrm{KCNH} 2$ gene encoding for $\mathrm{I}_{\mathrm{Kr}}$ channel carried by $\mathrm{K}_{\mathrm{v}} 11.1$, is clinically characterized by short QT syndrome and sudden cardiac death (Brugada et al., 2004), while other $\mathrm{KCNH} 2$ mutations as well as M54T, I57T mutations in MiRP1, a regulatory subunit of the $I_{K r}$ channel encoded by KCNE2 gene, are associated with inherited LQT (Curran et al., 1995; Abbott et al., 1999). In two comprehensive studies, it was shown that the majority of mutations in the $\mathrm{KCNH} 2$ gene result in trafficking defects, with or without concomitant effects on channel kinetics (Anderson et al., 2014; Anderson et al., 2006). 
Also, mutations in the KCNQ1 gene encoding the IKs channel, carried by the KCNQ1 $\alpha$-subunit, usually associate with LQT (type 1) (Wang et al., 1996), while a patient with a gain-of-function mutation, KCNQ1V307L has been found with enhanced repolarization and short QT interval (Bellocq et al., 2004). S74L, D76N mutations in KCNE1 gene encoding $\beta$-subunits of $I_{\mathrm{Ks}}$ channel, MinK and an inherited S1570L mutation in AKAP9 gene encoding Yotiao which is required to be assembled with $\mathrm{K}_{\mathrm{v}}$, can suppress $\mathrm{I}_{\mathrm{Ks}}$ channel function, diminish $\mathrm{I}_{\mathrm{Ks}}$ current and cause inherited LQT (Splawski et al., 1997; Chen et al., 2007). To which extent these mutations affect trafficking of the channels' subunits is largely unknown and requires comprehensive analysis as performed for the $\mathrm{I}_{\mathrm{kr}}$ channel.

For the $\mathrm{KCNJ} 2$ gene encoding the a-subunit of $\mathrm{K}_{\mathrm{IR}} 2.1$ channel that carries the cardiac inward rectifier current $\mathrm{I}_{\mathrm{K} 1}$, several mutations have been identified that associate with Andersen-Tawil syndrome (Zhang et al., 2005). An inherited mutation D71V causes a dominant negative effect on channel function and QT prolongation (Plaster et al., 2001). Whereas, carriers of heterozygous/homozygous $\mathrm{D} 172 \mathrm{~N}$ mutations in $\mathrm{K}_{\mathrm{IR}} 2.1$ channel are vulnerable to short QT syndrome (Priori et al., 2005). In an effort to determine sequence-function relationships for $\mathrm{K}_{\mathrm{IR}}$ channels with respect to trafficking, we aligned disease associated $K_{\text {IR }}$ protein mutations with known trafficking defects. As illustrated in Chapter 2, these mutations form clusters in aligned sequences. These findings will potentially benefit future drug discovery to targeting channel trafficking. However, sequence-function relationships have to be confirmed experimentally before attempting to target channel (domains) by pharmacological approaches. Therefore, we focused on one intracellular domain in Chapter 4. There we identified a new domain in $\mathrm{K}_{\mathrm{IR}} 2.1$ channel, a so-called PEST domain thought to be involved in rapid protein degradation from literature. However, we found that protein stability and trafficking was not (strongly) affected and that this domain has a role in coregulation of inward rectification.

A significant percentage of drug-induced LQT2 is associated with $\mathrm{K}_{\mathrm{v}} 11.1$ forward trafficking defects (Wible et al., 2005). To which extent this phenomenon is also responsible for drug-induced arrhythmias mediated by other channels is largely unknown and deserves further clarification. In our work, we used pentamidine as a $\mathrm{K}_{\mathrm{v}} 11.1$ trafficking inhibitor (Chapter 6). The binding affinity of pentamidine to the $\mathrm{K}_{\mathrm{v}} 11.1$ channel is known to be 
highly regulated by its amidine and aromatic rings (Varkevisser et al., 2013). Any alteration in these regions will significantly impair pentamidines capacity of $\mathrm{K}_{\mathrm{v}} 11.1$ trafficking inhibition. Along this reasoning, we synthesized new pentamidine analogues (Chapter 7) having modified sulfur atoms or sulfanilide groups, and determined their long term effects on $\mathrm{K}_{\mathrm{v}} 11.1$ trafficking and short term effects on channel kinetics. Some pentamidine analogs modified at several positions demonstrated that sulfur atoms or sulfanilide groups have minor effect on $I_{\text {Kv11.1 }}$ densities and $\mathrm{K}_{\mathrm{v}} 11.1$ maturation (Żołek et al., 2019). These insights may contribute to the development of improved specificity for drugs addressing Pneumocystis jiroveci pneumonia.

Finally, to which extent disease conditions affect ion channel trafficking is largely unknown. It is known that in the process of cardiac electrical remodeling some channels display decreased expression at the plasma membrane, as for example seen for the $\mathrm{I}_{\mathrm{Kr}}$ channel in the dog with chronic AV block (Oros et al., 2008) used in Chapter 5. Other disease states affect ion channel expression too, for example observations of decreased $I_{K 1}$ densities in heart failure (Beuckelmann et al., 1993). To further explore the significance and underlying mechanisms of noncongenital disease linked trafficking defects associated with cardiac arrhythmia, in vivo models are an important requirement. In Chapter $\mathbf{3}$ we reviewed a number of animal models, and contemplated on their usefulness for ion channel trafficking research.

\section{Drug discovery of trafficking correctors and their applications}

Potassium channels in general have attracted increasing interest as drug binding targets in various fields and applications. Besides, simply blocking channel pore via binding to extracellular binding site, it is also possible to change channel kinetics, regulating upstream mRNA expressing level or interference in the channel trafficking pathway. Comparing to others, targeting channel trafficking may facilitate the channel's normal function and regulation at the plasma membrane. 
As indicated above, pentamidine has been a useful tool to establish an experimentally acquired $\mathrm{K}_{\mathrm{v}} 11.1$ trafficking defect by impairing $\mathrm{K}_{\mathrm{v}} 11.1$ maturation (Dennis et al., 2012). This trafficking defect can be rescued by dofetilide, and dofetilide analogues in dependence of their binding affinity for $K_{\mathrm{v}} 11.1$ channel (Varkevisser et al., 2013). Astemizole can also rescue pentamidine-induced $\mathrm{K}_{\mathrm{v}} 11.1$ trafficking inhibition by directly binding and blocking $\mathrm{K}_{\mathrm{v}} 11.1$ channels, and correcting misfolded $\mathrm{K}_{\mathrm{v}} 11.1$ as a pharmacological chaperone (Ficker et al., 2002; Dennis et al., 2012). The N470D mutation generates defective folding of immature $\mathrm{K}_{\mathrm{v}} 11.1$ protein resulting in prolonged association with calnexin and retention in the endoplasmic reticulum. $\mathrm{K}_{\mathrm{v}} 11.1$ channel blocker $\mathrm{E}-4031$ can shorten the association duration and improve proper protein folding leading to hERG maturation (Gong et al., 2006).

Importantly, structure-activity relationship studies will give us more information about pharmacological correction of ion channel trafficking defects and facilitate designing drugs with limited side effects (Chapter 7). This trafficking rescue should be certain domain/site-restricted. The binding affinity of pentamidine to $\mathrm{K}_{\mathrm{v}} 11.1$ channel is highly dependent by its amidine and aromatic rings. Any alteration in these areas will significantly impair its capacity of $\mathrm{K}_{\mathrm{v}} 11.1$ trafficking inhibition. On the other hand, within the pharmacological corrector dofetilide, methanesulphonamide substitution with a polar $\mathrm{NH}_{2}$ group completely inhibits its interaction with $\mathrm{K}_{\mathrm{v}} 11.1$ and abolishes channel defect correction (Varkevisser et al., 2013). Besides, the protonated tertiary nitrogen, phenyl rings and the structure formed by the central nitrogen and the aromatic residues in dofetilide are also essential for binding (Guo et al., 2009; Pearlstein et al., 2003). Phenylalanine 656 in $\mathrm{K}_{\mathrm{v}} 11.1$ has been reported as a crucial binding site for pentamidine (Dennis et al., 2012). $\mathrm{K}_{\mathrm{v}} 11.1$ (HERG) G601S mutant is characterized by trafficking defects and can be rescued by many $\mathrm{K}_{\mathrm{v}} 11.1$ channel blockers (also shown in Chapter 6), while both F805C and R823W mutations cannot (Ficker et al., 2002). The disadvantage of current compounds with $\mathrm{K}_{\mathrm{v}} 11.1$ trafficking rescue is the fact that they are also potent channel inhibitors by their ability to interact within the conductive pore region. These observations indicate that it would be worthwhile to develop new broad spectrum $\mathrm{K}_{\mathrm{v}} 11.1$ correctors that will normalize $\mathrm{I}_{\mathrm{Kr}}$ in many forms of congenital LQT2. Furthermore, we may anticipate that such broad spectrum correctors are also favorable in targeting acquired, e.g. disease- or drug-induced, LQT2. 
However, as correctors may become important pharmacological options, they are most likely not sufficient for a complete normalization of channel function. Channel activators, drugs that increase currents by altering the channels gating kinetics, have proven to be effective in several conditions. For example, minoxidil is an I IATP channel opener used as a vasodilator in treatment of resistant hypertension (Mundt et al., 2016), and to promote hair growth in Androgenetic alopecia patients (Varothai et al., 2014). Furthermore, activators are being used, in combinations with correctors, in treatment of cystic fibrosis (Ratjen et al., 2015). In our studies we investigated some of the potential applications of the $\mathrm{K}_{\mathrm{v}} 11.1$ negative allosteric modulator/activator LUF7244 (Chapter 5, Chapter 6). First, it became apparent that LUF7244 by itself has no potential for rescue of acquired or congenital $\mathrm{K}_{\mathrm{v}} 11.1$ trafficking defects. However, in combination with a pharmacological corrector (dofetilide, E-4031) normal trafficking and improved current densities were observed. Furthermore, in the acute setting, LUF7244 was able to increase $I_{\mathrm{kv} 11.1} / \mathrm{I}_{\mathrm{kr}}$ to ameliorate dofetilide-induced TdP arrhythmias in vivo. Whether LUF7244 counteracts congenital and/or acquired LQT2 in general needs to be established.

Finally, the field of $\mathrm{K}_{\mathrm{IR}} 2$ channel trafficking corrections and activation by pharmacological means lags behinds that of the $\mathrm{K}_{v} 11.1$ channel. But given the capacity of some drugs, for example flecainide, to increase $\mathrm{I}_{\mathrm{K} 1}$ as a non-primary effect may indicate that generating $\mathrm{K}_{\mathrm{IR}} 2.1$ activating compounds is feasible (Caballero et al., 2010).

\section{Concluding remarks}

Compared to direct channel pore blocking mechanisms, regulating channel trafficking mechanisms have not received sufficient attention thus far. Considering the disadvantage of pore blocking, like narrow treatment windows, or affecting channel gating properties, targeting channel trafficking could benefit more to patients baring mutant potassium channels, especially those with a loss-of-function mutation. Our findings demonstrate the feasibility and validity of this approach. Therefore, gaining more knowledge on potassium ion channel trafficking, pharmacological interventions and building appropriate animal models will be important and necessary future directions. 


\section{REFERENCES}

Abbott GW, Sesti F, Splawski I, Buck ME, Lehmann MH, Timothy KW, Keating MT, Goldstein SA. MiRP1 forms IKr potassium channels with HERG and is associated with cardiac arrhythmia. Cell. $1999 \mathrm{Apr}$ $16 ; 97(2): 175-87$.

Anderson CL, Delisle BP, Anson BD, Kilby JA, Will ML, Tester DJ, Gong Q, Zhou Z, Ackerman MJ, January CT. Most LQT2 mutations reduce Kv11. 1 (hERG) current by a class 2 (trafficking-deficient) mechanism. Circulation. 2006 Jan 24;113(3):365-73.

Anderson CL, Kuzmicki CE, Childs RR, Hintz CJ, Delisle BP, January CT. Large-scale mutational analysis of Kv11. 1 reveals molecular insights into type 2 long QT syndrome. Nature communications. 2014 Nov $24 ; 5(1): 1-3$.

Bellocq C, van Ginneken AC, Bezzina CR, Alders M, Escande D, Mannens MM, Baró I, Wilde AA. Mutation in the KCNQ1 gene leading to the short QT-interval syndrome. Circulation. 2004 May 25;109(20):2394-7.

Beuckelmann DJ, Näbauer M, Erdmann E. Alterations of $K+$ currents in isolated human ventricular myocytes from patients with terminal heart failure. Circulation research. 1993 Aug;73(2):379-85.

Brugada R, Hong K, Dumaine R, Cordeiro J, Gaita F, Borggrefe M, Menendez TM, Brugada J, Pollevick GD, Wolpert C, Burashnikov E. Sudden death associated with short-QT syndrome linked to mutations in HERG. Circulation. 2004 Jan 6;109(1):30-5.

Caballero R, Dolz-Gaitón P, Gómez R, Amorós I, Barana A, de la Fuente MG, Osuna L, Duarte J, López-Izquierdo A, Moraleda I, Gálvez E. Flecainide increases Kir2. 1 currents by interacting with cysteine 311, decreasing the polyamine-induced rectification. Proceedings of the National Academy of Sciences. 2010 Aug 31;107(35):15631-6.

Chen L, Marquardt ML, Tester DJ, Sampson KJ, Ackerman MJ, Kass RS. Mutation of an A-kinase-anchoring protein causes long-QT syndrome. 


\section{Chapter 8}

Proceedings of the National Academy of Sciences. 2007 Dec $26 ; 104(52): 20990-5$.

Curran ME, Splawski I, Timothy KW, Vincen GM, Green ED, Keating MT. A molecular basis for cardiac arrhythmia: HERG mutations cause long QT syndrome. Cell. 1995 Mar 10;80(5):795-803.

Dennis AT, Wang L, Wan H, Nassal D, Deschenes I, Ficker E. Molecular determinants of pentamidine-induced hERG trafficking inhibition. Molecular pharmacology. 2012 Feb 1;81(2):198-209.

Ficker E, Obejero-Paz CA, Zhao S, Brown AM. The binding site for channel blockers that rescue misprocessed human long QT syndrome type 2 ether-a-gogo-related gene (HERG) mutations. Journal of Biological Chemistry. 2002 Feb 15;277(7):4989-98.

Gong Q, Jones MA, Zhou Z. Mechanisms of pharmacological rescue of trafficking-defective hERG mutant channels in human long QT syndrome. Journal of Biological Chemistry. 2006 Feb 17;281(7):406974.

Guo D, Klaasse E, de Vries H, Brussee J, Nalos L, Rook MB, Vos MA, van der Heyden MA, IJzerman AP. Exploring chemical substructures essential for hERG $\mathrm{K}+$ channel blockade by synthesis and biological evaluation of dofetilide analogues. ChemMedChem: Chemistry Enabling Drug Discovery. 2009 Oct 5;4(10):1722-32.

Mundt HM, Matenaer M, Lammert A, Goettmann U, Kraemer BK, Birck R, Benck U. Minoxidil for Treatment of Resistant Hypertension in Chronic Kidney Disease--A Retrospective Cohort Analysis. The Journal of Clinical Hypertension. 2016 Nov;18(11):1162-7.

Oros A, Beekman JD, Vos MA. The canine model with chronic, complete atrio-ventricular block. Pharmacology \& therapeutics. 2008 Aug $1 ; 119(2): 168-78$.

Pearlstein R, Vaz R, Rampe D. Understanding the structure- activity relationship of the human ether-a-go-go-related gene cardiac $\mathrm{K}+$ 
channel. A model for bad behavior. Journal of medicinal chemistry. 2003 May 22;46(11):2017-22.

Plaster NM, Tawil R, Tristani-Firouzi M, Canún S, Bendahhou S, Tsunoda A, Donaldson MR, Iannaccone ST, Brunt E, Barohn R, Clark J. Mutations in Kir2. 1 cause the developmental and episodic electrical phenotypes of Andersen's syndrome. Cell. 2001 May 18;105(4):511-9.

Priori SG, Pandit SV, Rivolta I, Berenfeld O, Ronchetti E, Dhamoon A, Napolitano C, Anumonwo J, Di Barletta MR, Gudapakkam S, Bosi G. A novel form of short QT syndrome (SQT3) is caused by a mutation in the KCNJ2 gene. Circulation research. 2005 Apr 15;96(7):800-7.

Ratjen F, Bell SC, Rowe SM, Goss CH, Quittner AL, Bush A. Cystic fibrosis. Nature Reviews Disease Primers. 2015 May 14;1(1):1-9.

Splawski I, Tristani-Firouzi M, Lehmann MH, Sanguinetti MC, Keating MT. Mutations in the hminK gene cause long QT syndrome and suppress I Ks function. Nature genetics. $1997 \mathrm{Nov} ; 17(3): 338-40$.

Varkevisser R, Houtman MJ, Linder T, de Git KC, Beekman HD, Tidwell RR, IJzerman AP, Stary-Weinzinger A, Vos MA, van der Heyden MA. Structure-activity relationships of pentamidine-affected ion channel trafficking and dofetilide mediated rescue. British journal of pharmacology. 2013 Jul;169(6):1322-34.

Varothai S, Bergfeld WF. Androgenetic alopecia: an evidence-based treatment update. American journal of clinical dermatology. 2014 Jul $1 ; 15(3): 217-30$.

Wang Q, Curran M, Splawski I, Burn TC, Millholland JM, VanRaay TJ, Shen J, Timothy KW, Vincent GM, De Jager T, Schwartz PJ. Positional cloning of a novel potassium channel gene: KVLQT1 mutations cause cardiac arrhythmias. Nature genetics. 1996 Jan;12(1):17-23.

Wible BA, Hawryluk P, Ficker E, Kuryshev YA, Kirsch G, Brown AM. HERG-

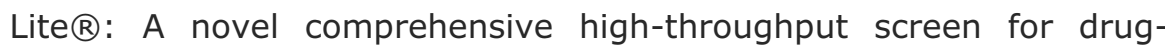




\section{Chapter 8}

induced hERG risk. Journal of pharmacological and toxicological methods. 2005 Jul 1;52(1):136-45.

Zhang L, Benson DW, Tristani-Firouzi M, Ptacek LJ, Tawil R, Schwartz PJ, George AL, Horie $M$, Andelfinger $G$, Snow $G L$, Fu $Y H$. Electrocardiographic features in Andersen-Tawil syndrome patients with KCNJ2 mutations: characteristic TU-wave patterns predict the KCNJ2 genotype. Circulation. 2005 May 31;111(21):2720-6.

Żołek T, Qile M, Kaźmierczak P, Bloothooft M, van der Heyden MA, Maciejewska D. Drug-likeness of linear pentamidine analogues and their impact on the hERG $\mathrm{K}+$ channel-correlation with structural features. RSC Advances. 2019;9(66):38355-71. 



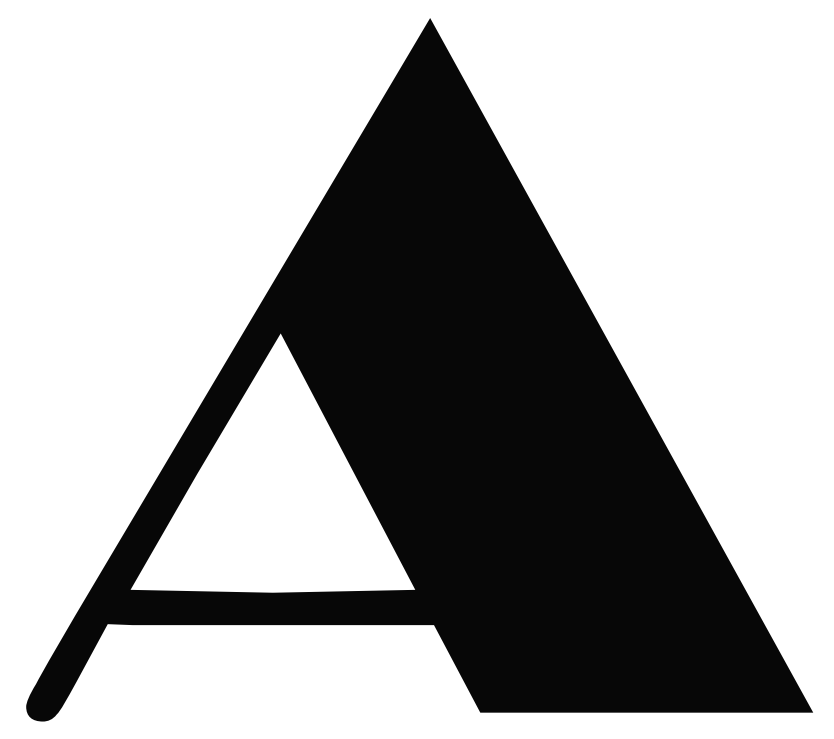




\title{
APPENDIX
}

\author{
English summary \\ Nederlandse samenvatting \\ Acknowledgements \\ List of publications \\ Curriculum Vitae
}




\section{SUMMARY}

There is no doubt that normal heart function plays a vital role on life maintenance, which means beating in a healthy and regular rhythm. This spontaneous beating results from the electrical impulse of pacemaker cells located in the sinus node and its propagation to the rest of cardiomyocytes. The electrical activity associated with every heartbeat can be recorded by a surface electrocardiogram (ECG, see below). It starts with a P wave, which results from right and left atrial electrical activity. Then this impulse goes through AV node to reach the ventricle. The subsequent conduction and activation goes rapidly through ventricle and shows in the ECG as a QRS complex. Then repolarization begins in the last depolarized cells. The T wave represents ventricular repolarization. Under certain circumstances, the heart beat may become irregular which may deteriorate into arrhythmia, or even Torsades de Pointes (TdP). These are life-threatening symptoms that could lead to ventricular fibrillation and sudden cardiac death.

The conditions resulting in arrhythmia can be divided into inherited or acquired. Before we focus on the treatment, it will be helpful to understand the underlying molecular mechanism of each arrhythmia type. Therefore, instead of looking at the ECG as the resultant of activity of all cardiomyocytes, action potential duration can be used as the representation of individual cardiomyocytes instead. As mentioned in Chapter 1, the action potential contains five different phases that each involves the function of several ion channels. In this thesis we mainly discuss potassium channel, especially $K_{I R}$ and $K_{v} 11.1$. The generation of sufficient amounts of channel protein expressed in the plasma membrane and its functional gating properties are playing essential roles in keeping normal cardiac function. Thence, it brings our attention to the potassium channel trafficking.

There is a number of diseases associated with $\mathrm{K}_{\mathrm{IR}}$ channel mutations. In Chapter 2, we listed several inherited diseases that relate to altered ion channel function and linked it to channel mistrafficking. The alignment analysis of these mutations indicated some "hotspots" in the protein sequence, which are mutation clusters that may correlate to channel trafficking. 


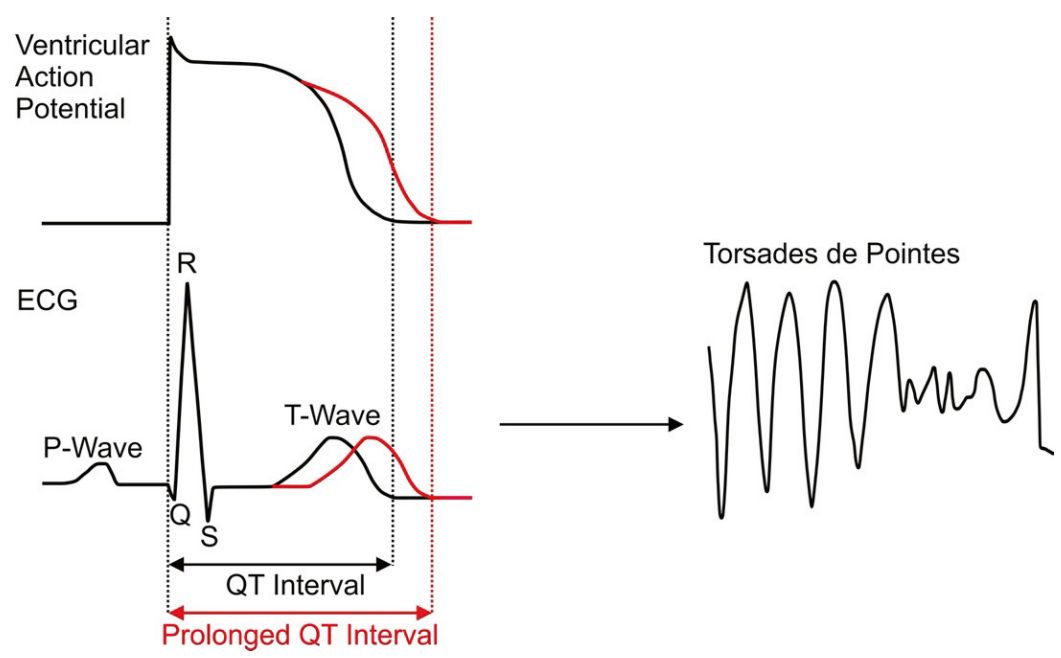

Figure. The correlation between action potential and ECG, and representations of Torsades de Pointes.

The difficulties in clinical case tracing makes animal research still being important. Unfortunately, we do not have one successful animal model to study potassium channel trafficking yet. In Chapter 3, we discussed several animal models and its applicability in channel trafficking research, which would benefit drug screening and narrow down the gap between molecular studies and clinical trials.

When we focus on the heart beat and keep zooming in, as smaller the unit becomes more accurate the target will be. This is essential when we develop new drugs. The knowledge of $\mathrm{K}_{\mathrm{IR}}$ channel structure and trafficking is still limited and received less attention than the $\mathrm{K}_{\mathrm{v}} 11.1$ channel. Therefore, in Chapter 4, we identified a new sequence located in the $\mathrm{K}_{\mathrm{IR}}$ channel protein C-terminus, which is related to rectification of $\mathrm{I}_{\mathrm{k} 1}$.

Besides gaining better understanding of the molecular mechanism of arrhythmia and finding new drug binding targets, we are also interested in reducing adverse effects of existing drugs. In Chapter 5, we found that LUF7244 as an allosteric modulator and channel activator, could counteract dofetilide-induced TdP. It provides us new strategies to treat patients. In Chapter 6, we further investigated the chronic effects of LUF7244 and its influence on channel trafficking. 
Appendix

The interaction between a drug and potassium channel could be changed due to molecular modification. Therefore, compound analogues studies are often used to improve target binding affinity and reducing adverse effects. In Chapter 7, we further identified the functional properties of several Pentamidine analogues, a typical $\mathrm{K}_{\mathrm{v}} 11.1$ trafficking inhibitor.

Finally, in Chapter 8, we summarized and discussed the results and conclusions from previous chapters. To conclude, potassium channel trafficking is a valid and important target for treating cardiac arrhythmia, using a pharmacological approach. 


\section{NEDERLANDSE SAMENVATTING}

Het lijdt geen twijfel dat een normale hartfunctie een vitale rol speelt in het leven, wat betekent dat het hart in een gezond en regelmatig ritme moet kloppen. Dit spontane slaan is het gevolg van de elektrische impuls van pacemakercellen in de sinusknoop en de voortgeleiding hiervan naar de rest van de hartspiercellen. De elektrische activiteit van elke hartslag kan worden geregistreerd door een oppervlakte-elektrocardiogram (ECG, zie hieronder). Het begint met een P-golf, die het gevolg is van elektrische activiteit in het rechter en linker atrium. Vervolgens gaat deze impuls door de AV-knoop om het ventrikel te bereiken. De verdere geleiding en activering van het ventrikel gaat snel en wordt in het ECG weergegeven als het QRS-complex. Vervolgens begint de repolarisatie, als eerste in de laatst gedepolariseerde cellen. De T-golf representeert de repolarisatie van het ventrikel. Onder bepaalde omstandigheden kan de hartslag onregelmatig worden en treedt er aritmie op, of zelfs Torsades de Pointes (TdP). Dit zijn levensbedreigende symptomen die kunnen leiden tot ventriculaire fibrillatie en plotselinge hartdood.

De oorzaak van aritmiën kan worden onderverdeeld in overerfbare en verworven factoren. Voordat we ons concentreren op de behandelingstherapie, moeten we het onderliggende moleculaire mechanisme van elke aritmie begrijpen. Daarom kan, in plaats van naar het overkoepelde ECG als geheel te kijken, de duur van actiepotentialen worden gebruikt als representatie van de elektrische activiteit van individuele hartspiercellen. Zoals vermeld in hoofdstuk 1 , bevat de actiepotentiaal vijf verschillende fasen, elk gevormd door verschillende ionenkanalen. In dit proefschrift bespreken we voornamelijk kaliumkanalen, in dit geval $\mathrm{K}_{\mathrm{IR}}$ en $\mathrm{K}_{\mathrm{v}} 11.1$. Het aanwezig zijn voldoende hoeveelheden kanaaleiwit op het plasmamembraan, samen met de functionele poorteigenschappen, is een essentiële moleculaire factor voor een normale hartfunctie. Vandaar dat het onze aandacht vestigt op het transport van kaliumkanaal eiwitten in de hartcel.

Een aantal ziekten is geassocieerd met $\mathrm{K}_{\mathrm{IR}}$-kanaalmutaties. In hoofdstuk 2 benoemen we verschillende erfelijke ziekten die verband houden met een veranderde hoeveelheid ionkanalen op het membraan, te 
wijten aan verstoringen in het intracellulaire eiwit transport. De sequentievergelijking van deze mutaties biedt ons zicht op 'hotspots' in de eiwitsequentie, dit zijn mutatieclusters die een mogelijke correlatie met een verstoord transport aanwijzen.

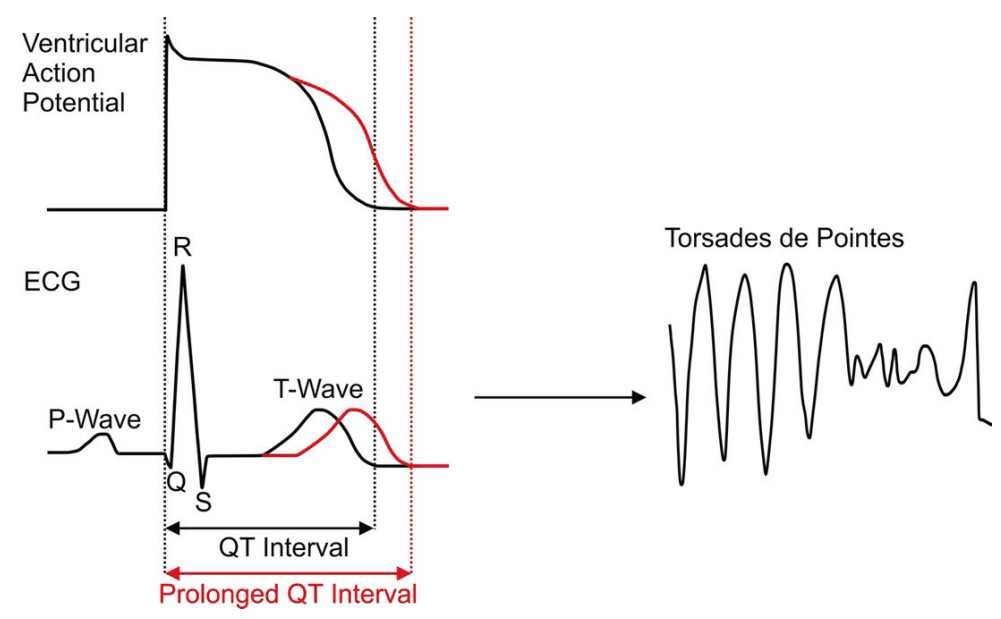

Figuur. De correlatie tussen actiepotentiaal en ECG, en representaties van Torsades de Pointes.

Omdat het lastig is om direct uit een klinische casus een onderliggend mechanisme te bepalen, is dierexperimenteel onderzoek belangrijk. Helaas hebben we nog geen succesvol diermodel om het intracellulair transport van kaliumkanalen te bestuderen. In hoofdstuk $\mathbf{3}$ hebben we verschillende diermodellen besproken en de toepasbaarheid ervan in onderzoek naar zulk transport samengevat, wat de screening van geneesmiddelen ten goede kan komen en de kloof tussen moleculair onderzoek en klinische proeven zal verkleinen.

Wanneer we ons concentreren op de hartslag en blijven inzoomen, is duidelijk dat naarmate de eenheid kleiner wordt het doel nauwkeuriger is. Gedetailleerde moleculaire kennis is dan ook essentieel bij het ontwikkelen van nieuwe medicijnen. De kennis van de $\mathrm{K}_{\mathrm{IR}}$-kanaalstructuur en intracellulair transport is nog steeds beperkt, en dit eiwit heeft veel minder aandacht gekregen dan het $\mathrm{K}_{\mathrm{v}} 11.1-\mathrm{kanaal}$. Daarom identificeerden we in hoofdstuk 4 een nieuwe sequentie in de C-terminus van het $\mathrm{K}_{\mathrm{IR}^{-}}$ kanaaleiwit, dat verband houdt met de rectificatie van $\mathrm{I}_{\mathrm{K} 1}$. 
Naast het beter begrijpen van de moleculaire mechanismes van hartritmestoornissen en het vinden van nieuwe en betere medicatie, zijn we ook geïnteresseerd in het verminderen van de bijwerkingen van bestaande medicijnen. In Hoofdstuk 5 ontdekten we dat LUF7244 als allostere modulator en kanaalactivator de door dofetilide geïnduceerde TdP kon tegengaan. Deze kennis biedt ons nieuwe perspectieven om patiënten te behandelen. In hoofdstuk 6 onderzoeken we de chronische effecten van LUF7244 en de invloed ervan op intracellulair ionkanaal transport verder.

De interactie tussen een geneesmiddel en het kaliumkanaal kan veranderen als gevolg van moleculaire modificaties. Daarom worden studies naar zogenoemde "druganalogen" vaak gebruikt om de bindingsaffiniteit te verbeteren en bijwerkingen te verminderen. In Hoofdstuk 7 identificeerden we de functionele eigenschappen van verschillende Pentamidine-analogen, een typische $\mathrm{K}_{\mathrm{v}} 11.1$ kanaaltransport remmer.

Ten slotte hebben we in hoofdstuk 8 de resultaten en conclusies van alle eerdere hoofdstukken samengevat en besproken. We kunnen concluderen dat het intracellulaire transport van kaliumkanaal-eiwitten een waardevol aangrijpingspunt is om hartritmestoornissen middels een farmacologische weg te behandelen. 


\section{ACKNOWLEDGEMENTS}

The Department of Medical Physiology is an amazing place. All the support and help from my supervisors and colleagues make this thesis complete. And friends I met in Utrecht, thank you for making these four years such a wonderful experience.

First of all, thank you Marcel. I feel so lucky to have you as my copromotor. Thank you for accepting me and offering me a PhD position in your team. I was amazed by the atmosphere in your group at the beginning. The group meeting is relaxing and professional. Whenever I need help, you are always happy to guide me. My improvement is recognized. Again, I deeply appreciate your support.

Marc, my promotor, thank you so much for letting me join this department. You are eager to share your experience, which I valued the most. Also your passion about beer. I wish you all the best. And good luck with traveling around the world. Maybe one day you can visit China again. I would be happy to see you.

Toon, thanks for every suggestion you provided after the working discussions. Although we haven't worked together before, your greeting in the department hallway always brought me your kindness. Teun, I appreciate your efforts to organize a Patch clamp theory session once in a while. Also the technical support during cell meetings.

Tonny, thanks for everything you did for me. Also the beautiful blanket you made for me, which was totally a big surprise. Every time you share your photos or amazing food you cooked with me, I feel like you are my family. I will miss having a tea break with you. Marien, thank you so much for helping me in these four years. I am impressed by your stable and professional skills. You are always eager to help. Besides, thank you for sharing some really awesome bands.

Jet, thanks for all the support regarding animal experiments and your guidance in the operation room. Also I really enjoyed organizing LabStapDag together with you. We had a great time. Leonie, Linda, your management make the lab and department really organized and efficient. 
Thank you for answering my question when I need help. Marti, thanks for all the help regarding to PhD courses. Sanne, thank you for encouraging me to participate in assignment supervision. All your friendly guidance helped me to go through it. Martin and Maria, I will keep all your kindness in my mind. Enjoy your retirement.

Agnieszka, thank you for being my paranimf! I enjoyed all parties at your place. Hope you also like those dumplings we made. Most of Friday afternoon, we share our favorite songs in our PhD corner. I will always remember those relaxing moments. Good luck with rest of your PhD. You will be a great cardiologist. Love your enthusiasm! Joanne, your accompany during these four years helped me get through some tough time. Thank you so much for being there when I need someone to talk to. I wish you all the best for your project. Let's keep in touch.

Birgit, congratulations on your defense and thesis. You did a great job. Thank you for letting me meet the cutest Bob, and all the fan conversations with you. Good luck with your postdoc in Amsterdam. Alan, it's great to have you joined the patch clamp team. I will miss our conversations about SciFi books. I wish you all the best with your postdoc project. Meye, thanks for all the efforts for the PNs project. I really enjoyed the time doing patch clamp together. You will be great whatever you do. Stephanie, you are so sweet. I wish you all the best for the coming years and PhD track. To other candidates Willem and Vera, good luck with your projects. Then I would like to thank all the previous PhDs, Alex, Helen, David, Chantal, Elise and Lotte, thank you for the support during these years. Your warm welcome made me feel integrated in the department.

Personally, I was so excited when I started to work in Hubrecht. Jeroen Bakkers, thank you for letting me have the opportunities to work with zebrafish. Yeszamin and Sonja, thanks a lot for your guidance when I learned to do microinjection. Also, thanks to my two students Doreth and Fee for your efforts in my projects. I wish you all the best in your future career.

Yuan, 十分感激你在我初到荷兰时的帮助，使我消除了陌生感并快速的融入 了部门的工作环境中。一路看着你有了安然, 站在你身侧见证了你的毕业典礼, 随后 你回国安定, 感慨之余也为你高兴。过往种种都令我期待回国后早点相见, 继续我们 


\section{Appendix}

在荷兰时的拰吃逛吃。Valerie, 很感激你邀请我去你家做客, 能在部门里偶尔和你讲 中文真的很开心, 你一定会成为一名优秀的医生, 祝你博士学业顺利!

赵玉筀, 好想念你的招牌大盘鸡! 第一次到乌特的时候来接我的人是你, 转眼 现在我已经博士毕业。感谢你这些年的关照, 让我在异国他乡也能热热闹闹的过年。 祝愿你和 Vincent 好好享受在北京的时间，工作顺利！何宇洁，陈娜，常晓，江凌蕾， 高栅, 霍银赫, 感激 UMC 的各位, 怀念和你们一起过年, 一起蹭大㕌的晚饭的日子。 作为比你们晚来荷兰几年的人, 很多时候都是你们在照顾我, 十分感谢大家的包容和 接纳。祝你们一切顺利!

桂天书, 余博, 很感激在读博期间遇见你们, 我会一直怀念和你们一起谈天说 地的时光, 咱们的火锅局是支撑我度过荷兰慢慢冬日的支柱。希望你们顺利毕业, 无 论身在何方都能保持联系, 继续我们的探讨。郑书轩, 你的到来给我在荷兰的最后两 年时间增添了很多不一样的体验, 和你一起经历了很多难忘的时刻, 相信多年以后回 想起来, 都会记得有你相伴的旅程。Mack, hope you will enjoy your new adventure in Japan. Let's continue our discussion there in near future. 李爽, 爽妹子加油, 希望你顺利毕业, 找到满意的工作! 杨森, 特别高兴能在荷兰认识你, 和你交流总是带给我新鲜的观点和知识, 喜欢你的态度和生活方式。咱们的每次聊天 都能看到彼此的成长, 愿你一切顺利! 段文, 徐阳, 作为我在荷兰最早认识的一批人, 感谢你们在我初来乍到时的帮助。这四年我们一起看过球赛, 逛过博物馆, 对荷兰最 初的探索都有你们陪伴。祝愿你们都能顺利毕业并找到愿意为之奋斗的事业。张小刚, 石涛, 陶卫阳, 李伯会, 丁云, 祝你们毕业顺利, 找到称心的工作!

马媛, 新婚快乐! 相识十几年, 一路见证了彼此的各个重要时刻, 看得到你的 成长, 也感受得到在我面前一直不变的那个你。感谢你支持着我的每个决定, 愿意倾 听我的烦恼, 祝你一切顺利, 继续探索更多更美的风景。包文婷, 感谢你愿意成为我 的 Paranimfen。即使我们不在同一个国家, 但是有你在法国, 就足够令初到荷兰的 我心里有所依靠。在欧洲的这四年, 我们一起自驾南法, 瑞士徒步, 时时相见分享近 况, 感谢这种无形的支持。愿你一切顺利, 我们时时相聚。 
感谢初文峰老师, 使我在哈尔滨医科大学的三年时间里能有幸跟着老师和一群 优秀的同学学习。同时非常感谢老师当初给了我机会学习膜片钳技术, 这也成了我日 后继续深造的一个契机。这篇论文也带着我想令老师感到骄傲的心愿，即使您已经无 法收到, 我也会继续砥砺前行。

感谢爸妈, 感谢你们一直以来无条件的支持, 有你们作为我坚实的后盾才有今 时今日的我。最后, 想特别感谢邱放, 感谢多年来的相互守望, 是你的鼓励和支持令 我能够有勇气去追求自己的目标, 去成为更加优秀的人。期待未来与你相伴的许许多 多的日子。

\section{Thank you all!}

\section{Muge Qile/其乐木格}




\section{LIST OF PUBLICATIONS}

\section{Published articles:}

Qile M*, Ji Y*, Golden TD, Houtman MJC, Romunde F, Fransen D, Van Ham WB, IJzerman AP, January CT, Heitman LH, Stary-Weinzinger A, Delisle BP, Van der Heyden MAG. LUF7244 plus dofetilide rescues aberrant $\mathrm{K}_{\mathrm{v}} 11.1$ trafficking and produces functional I I $\mathrm{K}_{11.1}$. Mol Pharmacol. 2020 Jun $1 ; 97(6): 355-64$.

Qile M, Beekman HD, Sprenkeler DJ, Houtman MJC, Van Ham WB, StaryWeinzinger A, Beyl S, Hering S, Van den Berg DJ, De Lange EC, Heitman LH, IJzerman AP, Vos MA, Van der Heyden MAG. LUF7244, an allosteric modulator/activator of $\mathrm{K}_{\mathrm{v}} 11.1$ channels, counteracts dofetilide-induced torsades de pointes arrhythmia in the chronic atrioventricular block dog model. Br J Pharmacol. 2019 Oct;176(19):3871-85.

Qile M, Ji Y, Houtman MJC, Veldhuis M, Romunde F, Kok B, Van der Heyden MAG. Identification of a PEST sequence in vertebrate $K_{\text {IR }} 2.1$ that modifies rectification. Front Physiol. 2019;10:863.

Zangerl-Plessl EM*, Qile M*, Bloothooft M, Stary-Weinzinger A, Van der Heyden MAG. Disease associated mutations in $\mathrm{K}_{\mathrm{IR}}$ proteins linked to aberrant inward rectifier channel trafficking. Biomolecules. 2019 Nov;9(11):650.

Żołek T, Qile M, Kaźmierczak P, Bloothooft M, Van der Heyden MAG, Maciejewska D. Drug-likeness of linear pentamidine analogues and their impact on the hERG $\mathrm{K}^{+}$channel-correlation with structural features. $R S C$ Adv. 2019;9(66):38355-71.

Houtman MJC, Chen X, Qile M, Duran K, Van Haaften G, Stary-Weinzinger A, Van der Heyden MAG. Glibenclamide and HMR1098 normalize Cantú syndrome-associated gain-of-function currents. J Cell Mol Med. 2019 Aug;23(8):4962-9.

Ji Y, Takanari H, Qile M, Nalos L, Houtman MJC, Romunde FL, Heukers R, Van Bergen en Henegouwen PM, Vos MA, Van der Heyden MAG. Class III 
antiarrhythmic drugs amiodarone and dronedarone impair $\mathrm{K}_{\mathrm{IR}} 2.1$ backward trafficking. J Cell Mol Med. 2017 Oct;21(10):2514-23.

Sun F, Duan W, Zhang Y, Zhang L, Qile M, Liu Z, Qiu F, Zhao D, Lu Y, Chu $W$. Simvastatin alleviates cardiac fibrosis induced by infarction via upregulation of TGF- $\beta$ receptor III expression. $\mathrm{Br} J$ Pharmacol. 2015 Aug;172(15):3779-92.

Dong X, Liu S, Zhang L, Yu S, Huo L, Qile M, Liu L, Yang B, Yu J. Downregulation of miR-21 is involved in direct actions of ursolic acid on the heart: implications for cardiac fibrosis and hypertrophy. Cardiovasc Ther. 2015 Aug;33(4):161-7.

* contributed equally

\section{Conference presentations:}

Qile M, Houtman MJC, Sarkar L, Li J, Zangerl-Plessl EM, Van der Heyden MAG. Determination of new regulatory sequences for $\mathrm{K}_{\mathrm{IR}} 2.1$ channel trafficking by an evolutionary approach and synthetic biology. ePoster presentation at Heart Rhythm Society Scientific Sessions 2020.

Qile M, Beekman HD, Sprenkeler DJ, Houtman MJC, Van Ham WB, StaryWeinzinger A, Beyl S, Hering S, Van den Berg DJ, De Lange EC, Heitman LH, IJzerman AP, Vos MA, Van der Heyden MAG. Pharmacological activation of hERG channels prevent drug-induced Torsades de Pointes. Oral presentation at Dutch Physiology Days 2020 - Utrecht, The Netherlands.

Qile M, Beekman HD, Sprenkeler DJ, Heitman LH, IJzerman AP, Van der Heyden MAG, Vos MA. LUF7244, a negative allosteric modulator of $\mathrm{K}_{\mathrm{v}} 11.1$ channels, counteracts dofetilide-induced TdP arrhythmia in the chronic atrioventricular block dog model. Poster presentation at European Heart Rhythm Association Scientific Sessions 2018 - Barcelona, Spain.

Qile M, Ji Y, Houtman MJC, Veldhuis M, Romunde F, Kok B, Van der Heyden MAG. Identification of a PEST sequence in vertebrate $\mathrm{K}_{\mathrm{IR}} 2.1$ that modifies rectification. Poster presentation at European Heart Rhythm Association Scientific Sessions 2017 - Vienna, Austria. 



\section{CURRICULUM VITAE}

Muge Qile was born on February $16^{\text {th }}$, 1991 in Hulunbuir, China. From 2009 to 2013, she studied pharmaceutical engineering at the Inner Mongolia Medical University in China. In June 2013, she graduated as Bachelor of Science. Driven by a strong interest in pharmacology, she started the Master's program of Pharmacology at Harbin Medical University in Heilongjiang, China. During this period, Muge became very focused on

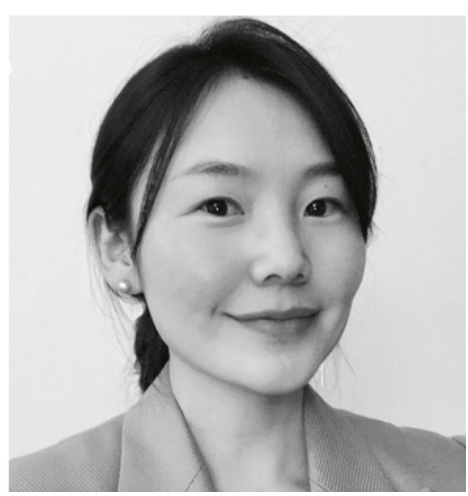
Cardiovascular research, with special interested in electrophysiology. Also for the first time, she started to do patch clamp experiments to study potassium channel currents. Right after she obtained her Master's degree in June 2016, she moved to the Netherlands and started her PhD at the department of Medical Physiology (University Medical Center Utrecht) under supervision of Professor Dr. M.A. Vos and Dr. M.A.G. van der Heyden. The results are described in this thesis entitled "Targeting potassium channel trafficking in cardiac arrhythmia", which she will defend on the $3^{\text {rd }}$ of September 2020. 
